ELÍ WILFREDO ZAVALETA AGUILAR

\title{
MODELAGEM TÉRMICA DA COLUNA DE DESTILAÇÃO DE UM CICLO DE REFRIGERAÇÃO POR ABSORÇÃO DE AMÔNIAIÁGUA
}

Dissertação apresentada à Escola

Politécnica da Universidade de São Paulo para obtenção do Titulo de Mestre em Engenharia 


\section{MODELAGEM TÉRMICA DA COLUNA DE DESTILAÇÃO DE UM CICLO DE REFRIGERAÇÃO POR ABSORÇÃO DE AMÔNIAIÁGUA}

Dissertação apresentada à Escola Politécnica da Universidade de São Paulo para obtenção do titulo de Mestre em Engenharia

Área de Concentração:

Engenharia Mecânica de Energia de Fluidos

Orientador: Prof. Livre-Docente José Roberto Simões Moreira 
Este exemplar foi revisado e alterado em relação à versão original, sob responsabilidade única do autor e com a anuência de seu orientador.

São Paulo, 09 de março de 2010.

Assinatura do autor

Assinatura do orientador

FICHA CATALOGRÁFICA

Zavaleta Aguilar, Elí Wilfredo

Modelagem térmica da coluna de destilação de um ciclo de refrigeração por absorção de amônia/água I E.W. Zavaleta Aguilar. -- ed.rev. -- São Paulo, 2010.

$146 \mathrm{p}$.

Dissertação (Mestrado) - Escola Politécnica da Universidade de São Paulo. Departamento de Engenharia Mecânica.

1. Destilação 2. Amônia 3. Refrigeração 4. Transferência de calor I. Universidade de São Paulo. Escola Politécnica. Departamento de Engenharia Mecânica II. t. 


\section{DEDICATÓRIA}

Aos meus pais Américo e Rita. 


\section{AGRADECIMENTOS}

Ao Prof. Livre-Docente José Roberto Simões Moreira, pela orientação e ensinamentos durante o desenvolvimento de projetos.

Agradeço também ao Conselho Nacional de Desenvolvimento Cientifico e Tecnológico (CNPq) pelo apoio financeiro.

A Ricardo, Marcelo e demais colegas do Laboratório de Sistemas Energéticos Alternativos (SISEA) e professores, sempre prontos para prestar assistência para o desenvolvimento deste trabalho.

A Iracema, Juan e René por seu constante apóio. 


\section{RESUMO}

O objetivo deste trabalho é apresentar a análise de uma coluna de destilação de pratos perfurados com vertedor segmentado em condições de regime permanente para um ciclo de refrigeração por absorção com capacidade de 5 toneladas de refrigeração que trabalha com amônia/água. Para garantir que o ciclo de refrigeração trabalhe em condições de projeto, a coluna de destilação deve proporcionar vapor com elevado grau de pureza de amônia.

Os balanços de massa e de energia da coluna foram realizados com o método de Ponchon-Savarit o qual considera escoamentos do líquido e do vapor na saída de cada prato em equilíbrio termodinâmico. Para estas condições foi calculado como 4 o número de pratos ideais e a alimentação à coluna seria acima do segundo prato. A análise de sensibilidade do fator de refluxo indica que é um parâmetro importante na análise econômica do projeto, já que dele depende o alto custo inicial de construção da coluna, ou as maiores despesas de gasto em combustível no funcionamento do ciclo.

As considerações hidráulicas, as quedas pressão e as razões de fluxos mássicos deram como resultado a geometria interna da coluna, a qual resultou satisfatória para os parâmetros de projeto recomendados, embora tenham sido usadas correlações da área de petróleo, petroquímica e de destilação de bebidas alcoólicas. A distância entre pratos é uma medida da compactabilidade da coluna e ficou muito dependente, assim como outras medidas do prato, da altura do vertedor a qual foi encontrada como ótima para valores entre $4 \mathrm{~mm}$ e $8 \mathrm{~mm}$. A geometria do prato resulta ser sensível à carga de vapor e, em menor grau, à carga do líquido, mostrando-se insensível ao diâmetro do furo.

A eficiência da coluna leva em conta fenômenos de transporte no prato que o afasta da condição de idealidade. Calculou-se uma eficiência da coluna de 50 \%. Este valor baixo se deve principalmente ao baixo valor da inclinação da curva de equilíbrio amônia/água no início da seção de esgotamento e à baixa razão da vazão molar do vapor dividido pela vazão molar do líquido, nessa seção.

Palavras-chave: Destilação. Amônia. Refrigeração. Transferência de calor. 


\section{ABSTRACT}

The objective of this work is to present the analysis of a segmented weir sieve tray distillation column in steady-state conditions for a 5 Tons of Refrigeration ammonia/water absorption refrigeration cycle. For a proper and correct cycle operation, the distillation column should provide ammonia at high degree of purity.

Column, mass and energy balances were made using the Ponchon-Savarit method, which considers that the liquid and the vapor leaves the tray at thermodynamic equilibrium. For these conditions it was calculated as being 4 the ideal number of trays and the feeding to the column would be above the second tray. A sensibility analysis of the reflux factor indicates that it is an important project from an economical study, as from that parameter depends the initial cost of the column manufacture, or the expenses whit fuel for the cycle operation.

Hydraulic considerations, pressure loss and of mass flow ratios provides the internal geometry of the column, which resulted satisfactory for the project parameters recommended, although, correlations used are more applied in petroleum, petrochemical and alcoholic industries. Tray spacing, which is a measure of the compactness of the column, and other geometric tray values, depend on the weir height. It was found optimal values between $4 \mathrm{~mm}$ and $8 \mathrm{~mm}$. The tray geometry is also sensitive, to the vapor load and to the liquid load, at smaller degree, and it is insensible with the hole diameter.

The column efficiency depends on the transport phenomena on the tray. This value fixes the tray number at the actual condition. It was calculated an efficiency of the column of $50 \%$. This low value depends mainly on the low value of the slope of the ammonia/water equilibrium curve below the stripping section and the low value of the molar flow vapor-liquid ratio at this section.

Keywords: Distillation. Ammonia. Refrigeration. Heat transfer. 


\section{LISTA DE ILUSTRAÇÕES}

Figura 1.1 - Oferta e consumo da energia elétrica no Brasil (adaptado do EPE, 2008)................... 19

Figura 2.1 - Ciclo de refrigeração por absorção de amônia/água de simples efeito. ........................... 27

Figura 2.2 - Ciclo de refrigeração por absorção de simples efeito com pré-resfriador. ........................ 27

Figura 2.3 - Ciclo de refrigeração por absorção de simples efeito com aproveitamento de fluxo de

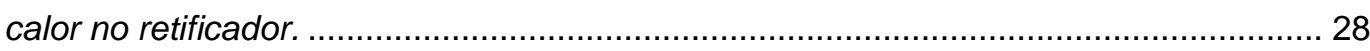

Figura 2.4 - Ciclo de refrigeração por absorção de duplo efeito, (Herold, 1996). ................................ 29

Figura 2.5 - Ciclo de refrigeração por absorção com sistema GAX ................................................ 31

Figura 2.6 - Refrigerador de Von Platen e Carl Munters, patenteado em 1926............................... 33

Figura 2.7 - Refrigerador de Albert Einstein, patenteado em 1930.................................................. 34

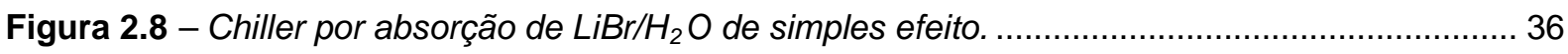

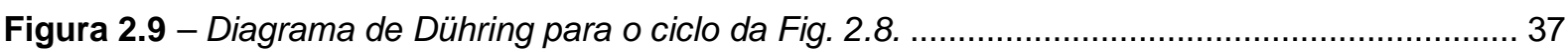

Figura 2.10 - (a) chiller por absorção de $\mathrm{LiBr} / \mathrm{H}_{2} \mathrm{O}$ de 4,6 TR (Tuma, 2009), (b) chiller por absorção de amônia/água de 5 TR (Robur, 2009)..................................................................... 41

Figura 2.11 - Componentes básicos de um ciclo de refrigeração por compressão. ........................... 42

Figura 2.12 - Fonte de energia para o acionamento dos ciclos de refrigeração (Adaptado da ASHRAE, 1994).

Figura 2.13 - Gráfico de break-even na substituição de um ciclo de refrigeração por compressão por um de absorção (Felamingo, 2007)..................................................................... 45

Figura 2.14 - Alambique. 46

Figura 2.15 - Estágios ideais. (a) estágio geral, (b) com adição de fluxo de calor, (c) com retirada de fluxo de calor

Figura 2.16 - Coluna de destilação. 48

Figura 2.17 - Coluna de destilação (em cor preta) no ciclo de refrigeração por absorção. 49

Figura 2.18 - (a) Prato com borbulhador, (b) borbulhador. 50

Figura 2.19 - Prato perfurado. (a) com fluxo cruzado (b) vertedor circular. 51

Figura 2.20 - Prato ou bandeja valvulada. 51

Figura 2.21 - Recheios aleatórios (a) anéis raching, (b) selas "berl", (c) aneis "pall", (d) IMTP, (e) recheio estruturado. 53

Figura 2.22 - Distribuidor de Líquido. 54

Figura 2.23 - "Temperatura glide" para uma solução amônia/água com 1 \% em massa de água (Herold et al. 1996).

Figura 2.24 - COP em função da concentração de refrigerante, Fernández-Seará e Sieres (2006a) 59 Figura 2.25 - Sensibilidade do COP em função da concentração do refrigerante no sistema GAX... 60

Figura 3.1 - Características de evaporação e condensação em misturas binárias. ............................. 62

Figura 3.2 - Equilíbrio líquido-vapor misturas binárias. 63 
Figura 3.3 - Curvas de equilíbrio líquido-vapor nos eixos: (a) frações mássicas líquido-vapor (b) entalpia - fração mássica.

Figura 3.4 - Variação das curvas de equilíbrio de frações molares com a volatilidade relativa. ........ 66

Figura 4.1 - Variáveis externas no balanço de massa e de energia na coluna de destilação. ........... 69

Figura 4.2 - Esquema para os balanços de massa e de energia: (a) na seção enriquecedora, retificador e acumulador, (b) no prato " $n$ ".

Figura 4.3 - Diagrama $h-x$ e $x_{L}-x_{V}$, para o balanço de massa e de energia na seção enriquecedora, retificador e acumulador.

Figura 4.4 - Seção esgotamento e gerador (a) esquema para os balanços de massa e de energia, (b)

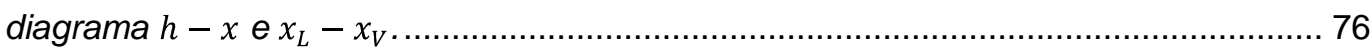

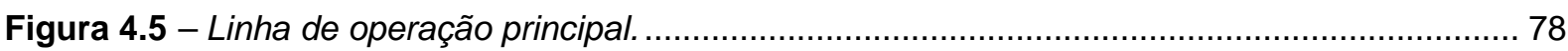

Figura 4.6 - Prato de alimentação à coluna destilação (a) ótima (b) muito abaixo (c) muito acima. .. 79 Figura 4.7 - Refluxo total - número de pratos mínimo. .................................................. 80

Figura 4.8 - Refluxo mínimo - número de pratos infinito. ................................................. 81

Figura 4.9 - Passagem de vapor pelos furos do prato, em fluxo cruzado com o escoamento líquido (adaptado de Kister, 1992). ........................................................................... 83

Figura 4.10 - Regimes de operação da coluna de destilação (adaptado de Caldas, 2007). .............. 83

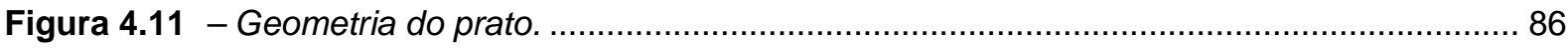

Figura 4.12 - Distribuição dos furos em forma de triangulo equilátero....................................... 86

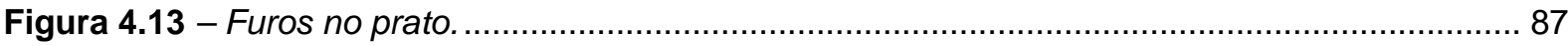

Figura 4.14 - Configuração dos escoamentos líquido e vapor e algumas dimensões no prato

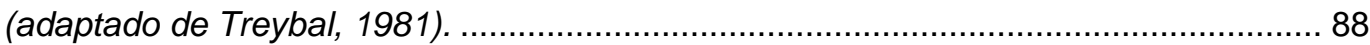

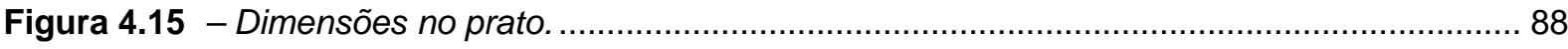

Figura 4.16 - (a) transferência de massa num elemento, (b) representação das frações molares na interface (c) representação das frações molares na curva de equilíbrio........................ 95

Figura 4.17 - Esquema para o cálculo da eficiência de ponto, e do prato. ....................................... 99

Figura 4.18 - (a) variáveis de entrada (b) variáveis de entrada e saída para a o balanço da coluna de destilação segundo o método de Ponchon-Savarit. ............................................. 103

Figura 4.19 - Variáveis de entrada e saída para o cálculo da geometria da coluna, perdas de carga

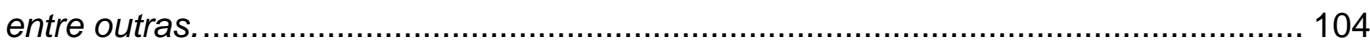

Figura 5.1 - Esquema das variáveis de entrada na coluna de destilação.................................. 108

Figura 5.2 - Esquema mostrando alguns resultados da simulação. ......................................... 109

Figura 5.3 - Linhas de operação e equilíbrio e número de pratos teóricos nos eixos $h-x$ e $x_{L}-x_{V}$.

Figura 5.4 - Variação da fração mássica do vapor na coluna. ............................................. 112

Figura 5.5 - Variação da fração mássica do líquido na coluna. ............................................... 113

Figura 5.6 - Variação da vazão mássica do vapor na coluna. ................................................... 113

Figura 5.7 - Variação da vazão mássica do líquido na coluna. .............................................. 114

Figura 5.8 - Variação da temperatura dos escoamentos na coluna......................................... 114

Figura 5.9 - Variação do número de pratos com o fator de refluxo. .......................................... 115 
Figura 5.10 - Variação do fluxo de calor no gerador e no retificador com o fator de refluxo. 116

Figura 5.11 - Variação do COP com o fator de refluxo. .................................................... 117

Figura 5.12 - Geometria dos pratos da coluna de destilação.............................................. 119

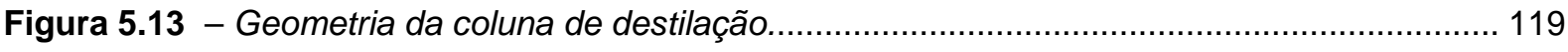

Figura 5.14 - Variação do diâmetro da coluna e o comprimento do vertedor com a altura do vertedor.

Figura 5.15 - Variação da distância entre pratos com a altura do vertedor. ................................... 121

Figura 5.16 - Variação da altura da coluna com a altura do vertedor. ........................................ 121

Figura 5.17 - Variação das eficiências com a altura do vertedor. ......................................... 122

Figura 5.18 - Quedas de pressão no prato............................................................... 123

Figura 5.19 - Variação da geometria da coluna com o diâmetro do furo. .................................. 124

Figura 5.20 - Variação das quedas de pressão com o diâmetro do furo. ................................... 124

Figura 5.21 - Variação da geometria da coluna com a vazão de vapor. ..................................... 125

Figura 5.22 - Variação das quedas de pressão com a vazão mássica do vapor........................... 125

Figura 5.23 - Variação da eficiência da coluna com a vazão mássica do vapor. ........................... 126

Figura 5.24 - Variação da geometria da coluna com a vazão mássica do líquido.......................... 127

Figura 5.25 - Variação das quedas de pressão com a vazão mássica do líquido. ........................ 127

Figura 5.26 - Variação da eficiência da coluna com a vazão mássica do líquido............................ 128 


\section{LISTA DE TABELAS}

Tabela 1.1 - Refrigerantes comuns e sua influência na redução da camada de ozônio e aquecimento global (Wang, 2001). 21

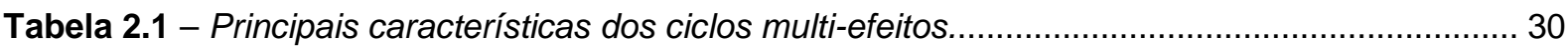

Tabela 2.2 - Fontes de calor aplicáveis a sistemas de absorção. .................................................. 30

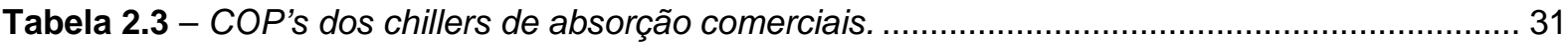

Tabela 2.4 - Tabela comparativa para os ciclos por absorção de amônia/água e de Brometo de

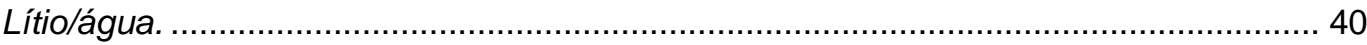

Tabela 2.5 - Parâmetros para a comparação: chillers por absorção e compressão ........................... 45

Tabela 4.1 - Variáveis no líquido e no vapor envolvidas nos balanços de massa e de energia. ........ 70

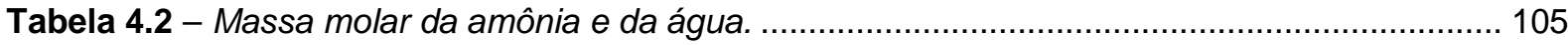

Tabela 5.1 - Variáveis de entrada para o balanço de massa e de energia na coluna de destilação. 107 Tabela 5.2 - Vazão mássica e principais propriedades termodinâmicas dos escoamentos da coluna.

Tabela 5.3 - Variáveis de entrada para o cálculo da geometria da coluna. ...................................... 118

Tabela 5.4 - Resultados da simulação para a geometria da coluna.............................................. 118 


\section{LISTA DE ABREVIATURAS E SIGLAS}

ARS

BEN

CFC

CN

COP

EES

EIA

EPE

EUA

GAX

GN

HCFC

HFC

HGWP

ODP

PEM

PFC

RHX

SHX

SCA

TC
Absorvedor Resfriado por Solução

Balanço Energético Nacional

Clorofluorcarboneto

Câmara de Nivelamento

Coeficiente de Eficácia

Solucionador de Equações de Engenharia

Departamento de Energia dos Estados Unidos

Empresa de Pesquisa Energética

Estados Unidos de America

Trocador de Calor Gerador - Absorvedor

Gás Natural

Hidroclorofluorcarboneto

Hidrofluorcarboneto

Potencial de Aquecimento Global de Halocarbonos

Potencial de Destruição de Ozônio

Membrana de Troca Protônica

Perfluorcarboneto

Pré-resfriador de refrigerante

Trocador de Calor de Solução

Absorvedor Resfriado por Solução

Trocador de Calor 
TCS

tep

TR

UNPD

VE

VC
Trocador de Calor por Solução

Tonelada Equivalente de Petróleo

Tonelada de refrigeração

Unidade de População das Nações Unidas

Válvula de Expansão

Volume de Controle 


\section{LISTA DE SÍMBOLOS}

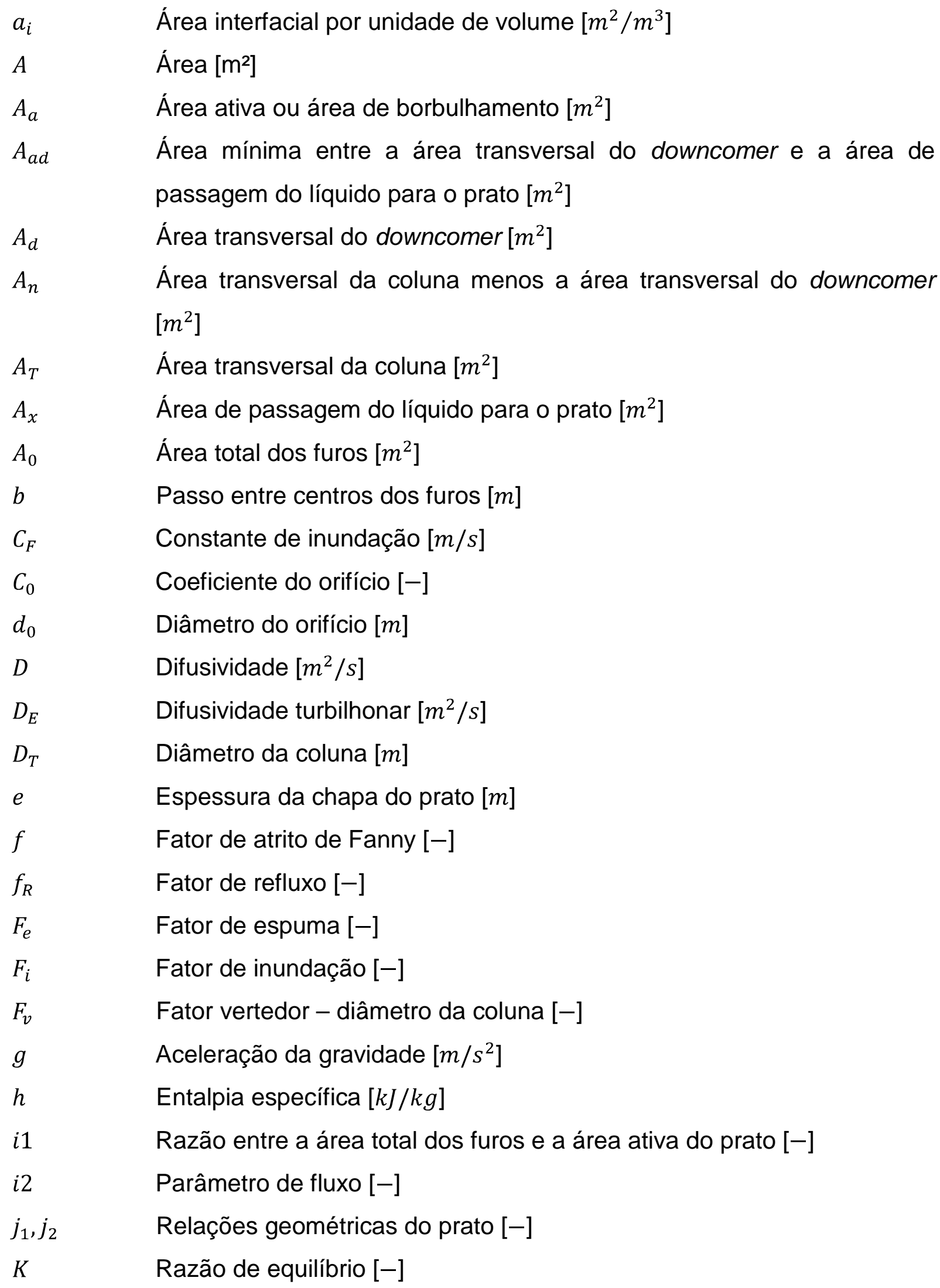


$k_{x} \quad$ Coeficiente de transferência de massa na fase líquida baseado nas frações molares $\left[\mathrm{kmol} / \mathrm{m}^{2} \mathrm{~s}\right]$

$k_{y} \quad$ Coeficiente de transferência de massa na fase vapor baseado nas frações molares $\left[\mathrm{kmol} / \mathrm{m}^{2} \mathrm{~s}\right]$

$K_{Y} \quad$ Coeficiente global de transferência de massa na fase vapor $\left[\mathrm{kmol} / \mathrm{m}^{2} \mathrm{~s}\right]$

$L_{c v} \quad$ Comprimento de corda do vertedor $[m]$

$L_{L} \quad$ Altura do líquido sem espuma, sobre o prato $[\mathrm{m}]$

$L_{\text {cve }} \quad$ Comprimento de corda efetivo do vertedor $[\mathrm{m}]$

$L_{T} \quad$ Altura da coluna $[m]$

$L_{v} \quad$ Altura do vertedor $[m]$

$L_{0 v} \quad$ Altura de líquido sobre o vertedor $[\mathrm{m}]$

$L_{1} \quad$ Distancia entre pratos $[\mathrm{m}]$

$L_{2} \quad$ Altura do líquido no downcomer sobre a altura do líquido no prato $[\mathrm{m}]$

$m \quad$ Inclinação da curva de equilíbrio [-]

$m^{\prime} \quad$ Razão entre número de unidades de transferência e vazões molares

$[-]$

$\dot{m} \quad$ Vazão mássica $[\mathrm{kg} / \mathrm{s}]$

$\dot{m}^{\prime \prime} \quad$ Fluxo mássico com referencia à área transversal $\left[\mathrm{kg} / \mathrm{m}^{2} \mathrm{~s}\right]$

$\bar{m} \quad$ Vazão molar $[\mathrm{kmol} / \mathrm{s}]$

$\bar{m}^{\prime \prime} \quad$ Fluxo molar com referencia à área transversal $\left[\mathrm{kmol} / \mathrm{m}^{2} \mathrm{~s}\right]$

$M \quad$ Massa molar $[\mathrm{kg} / \mathrm{kmol}]$

$N_{i} \quad$ Número de pratos ideais [-]

$N_{i} \quad$ Número de furos do pratos [-]

$N_{r} \quad$ Número de pratos reais [-]

$N_{t L} \quad$ Número de unidades de transferência da fase liquida [-]

$N_{t V} \quad$ Número de unidades de transferência da fase vapor [-]

$N_{\text {tov }} \quad$ Número de unidades de transferência global [-]

$N^{\prime \prime} \quad$ Fluxo molar com referencia à área interfacial líquido-vapor $\left[\mathrm{kmol} / \mathrm{m}^{2} \mathrm{~s}\right]$

$P \quad$ Pressão do sistema [bar]

Pe Número de Péclet [-]

$\dot{Q} \quad$ Vazão volumétrica $\left[\mathrm{m}^{3} / \mathrm{s}\right]$

$\dot{Q}_{A} \quad$ Fluxo de calor retirado do absorvedor $[k W]$

$\dot{Q}_{C} \quad$ Fluxo de calor retirado do condensador $[k W]$ 


$\begin{array}{ll}\dot{Q}_{E} & \text { Fluxo de calor retirado do evaporador }[\mathrm{kW}] \\ \dot{Q}_{G} & \text { Fluxo de calor fornecido ao gerador }[\mathrm{kW}] \\ \dot{Q}_{R} & \text { Fluxo de calor retirado so retificador }[\mathrm{kW}] \\ R & \text { Razão de refluxo [-] } \\ R e & \text { Número de Reynolds [-] } \\ S & \text { Superfície }\left[\mathrm{m}^{2}\right] \\ S c & \text { Número de Schmidt [-] } \\ T & \left.\text { Temperatura [ }{ }^{\circ} \mathrm{C}\right] \\ V & \left.\text { Volume [ } \mathrm{m}^{3}\right] \\ V_{a} & \text { Velocidade do vapor referido à área ativa }[\mathrm{m} / \mathrm{s}] \\ V_{F} & \text { Velocidade do vapor de afogamento }[\mathrm{m} / \mathrm{s}] \\ V_{V} & \text { Velocidade do vapor }[\mathrm{m} / \mathrm{s}] \\ V_{0} & \text { Velocidade do vapor no orifício }[\mathrm{m} / \mathrm{s}] \\ V_{0 w} & \text { Velocidade do vapor de gotejamento pelo orifício }[\mathrm{m} / \mathrm{s}] \\ \dot{W}_{C} & \text { Potencia do compressor }[\mathrm{kW}] \\ \dot{W}_{B} & \text { Potencia da bomba }[\mathrm{kW}] \\ x_{q} & \text { Título [-] } \\ x & \text { Fração mássica [-] } \\ \bar{x} & \text { Fração molar [-] } \\ Z & \text { Largura media de percurso do líquido no prato }[\mathrm{m}] \\ Z_{1} & \text { Comprimento do trajeto do líquido no prato }[\mathrm{m}] \\ & \end{array}$

Letras Gregas

$\alpha \quad$ Volatilidade relativa [-]

$\Delta P_{V} \quad$ Queda de pressão total do vapor ao passar pelo líquido e pelo prato $[\mathrm{Pa}]$

$\Delta P_{p} \quad$ Queda de pressão do vapor ao passar pelo prato seco $[\mathrm{Pa}]$

$\Delta P_{L} \quad$ Queda de pressão do vapor ao passar pelo líquido $[\mathrm{Pa}]$

$\Delta P_{R} \quad$ Queda de pressão residual do vapor [Pa]

$\Delta P_{e} \quad$ Queda de pressão do líquido ao entrar no prato $[\mathrm{Pa}]$

$\varepsilon \quad$ Rugosidade relativa [-]

$\eta_{c} \quad$ Eficiência da coluna [-]

$\eta_{M V} \quad$ Eficiência de Murphree [-] 


$\begin{array}{ll}\eta_{M V E} & \text { Eficiência de Murphree corrigida pelo arraste [-] } \\ \eta_{P V} & \text { Eficiência de ponto [-] } \\ \theta & \text { Tempo de residência }[\mathrm{s}] \\ \mu & \text { Viscosidade dinâmica }[\mathrm{kg} / \mathrm{ms}] \\ \rho & \text { Massa especifica }\left[\mathrm{kg} / \mathrm{m}^{3}\right] \\ \sigma & \text { Tensão superficial }[\mathrm{N} / \mathrm{m}] \\ \psi & \text { Arraste fracionário }[-] \\ & \\ \text { Índices Subscritos } \\ a & \text { Amônia } \\ d & \text { Vapor destilado } \\ e & \text { Entrada da alimentação à coluna } \\ i & \text { Interface } \\ L & \text { Líquido } \\ r & \text { Refluxo } \\ s & \text { Saída da solução } \\ V & \text { Vapor } \\ w & \text { Équilíbrio } \\ & \end{array}$




\section{SUMÁRIO}

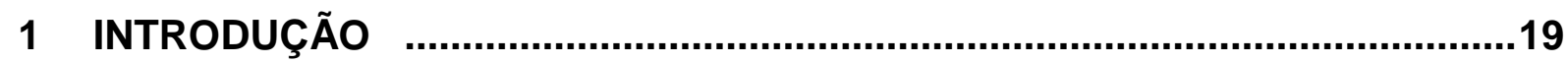

1.1 OBJETIVO

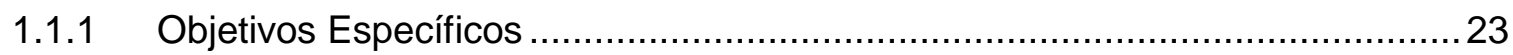

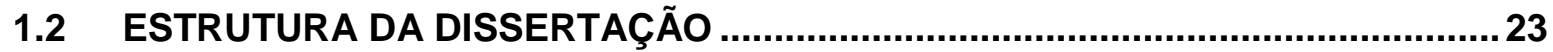

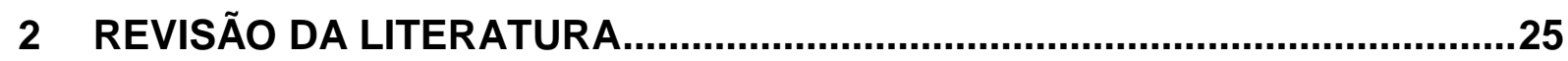

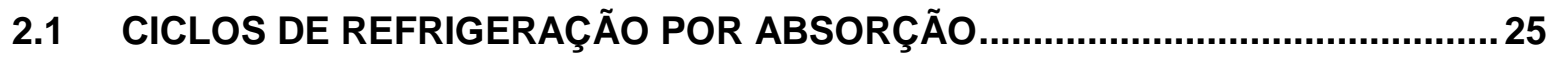

2.1.1 Ciclo de refrigeração por absorção de amônia/água .......................................25

2.1.2 Ciclo de refrigeração por absorção amônia/água/hidrogênio ............................ 32

2.1.3 Comparação dos chillers de amônia/água e brometo de lítio/água.....................35

2.1.4 Comparação no uso dos chillers por absorção com chillers por compressão de

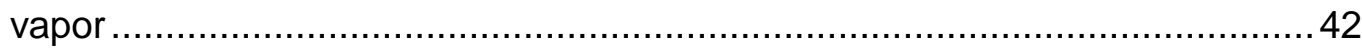

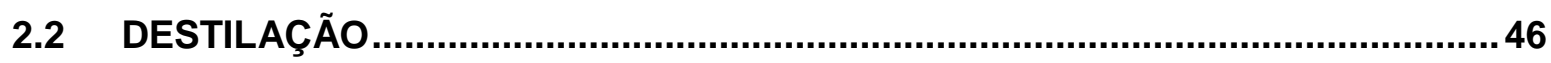

2.2.1 Enchimentos usados em colunas de destilação …………………….............50

2.3 ESTADO DA ARTE DOS SISTEMAS DE PURIFICAÇÃO AMÔNIAIÁGUA...........55

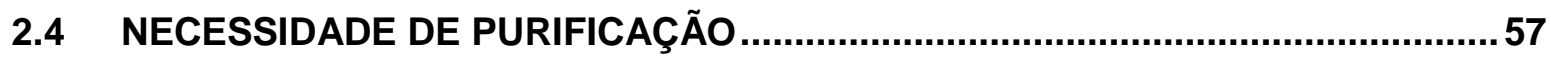

3 EQUILÍBRIO LÍQUIDO - VAPOR EM MISTURAS BINÁRIAS ..........................61

3.1 RAZÃO DE EQUILÍBRIO E VOLATILIDADE RELATIVA A.....................................64

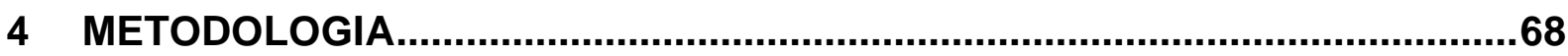

4.1 BALANÇOS DE MASSA E DE ENERGIA NA COLUNA DE DESTILAÇÃO, MÉTODO DE PONCHON-SAVARIT................................................................68

4.1.1 Análise dos parâmetros de operação da coluna de destilação .........................78

4.2 PROJETO HIDRÁULICO E GEOMETRIA INTERNA DA COLUNA DE DESTILAÇÃO

4.3 EFICIÊNCIA DA COLUNA DE DESTILAÇÃO E NÚMERO DE PRATOS REAIS .94

4.4 VARIÁVEIS DE ENTRADA E SAÍDA E PARÂMETROS DE SIMULAÇÃO..........102

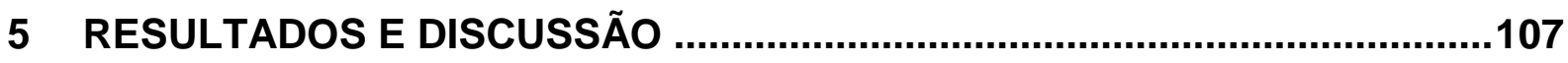

6 CONCLUSÕES E SUGESTÕES DE FUTUROS TRABALHOS ......................129

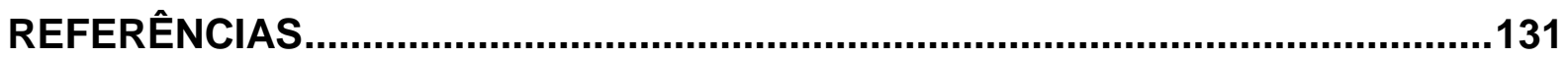


APÊNDICE A - ROTINA DO PROGRAMA DE SIMULAÇÃO REALIZADO NO EES... 


\section{INTRODUÇÃO}

O consumo de energia numa região tem relação direta com o número de pessoas, as novas tecnologias, o grau de industrialização, entre outras. O aumento da população no mundo teve um crescimento muito grande desde a revolução industrial em meados dos anos 1700, desde essa época até o ano 2009 a população aumentou aproximadamente 7,6 vezes (UNPD, 1999; UNPD, 2008). Com isso, o consumo de eletricidade no mundo está também aumentando, sendo que em 1990 consumiu-se $10.406 \mathrm{TWh}$ e no ano de 2006, 16.378 TWh, isto representa um aumento no consumo de eletricidade de $57 \%$ em 16 anos. Segundo a EIA (2008), no mundo as tendências de oferta de energia elétrica serão maiores que o consumo, assegurando assim energia elétrica para as próximas gerações. No Brasil, o consumo de energia elétrica tem aumentado de forma comparável a oferta, como se pode ver na Fig. 1.1. Cada ano a autoprodução de energia elétrica originada principalmente da cogeração no setor industrial, esta aumentando (EPE, 2008). Já com referência ao gás natural, o Brasil conta com muito mais oferta que o consumo e seu uso é de grande potencial.

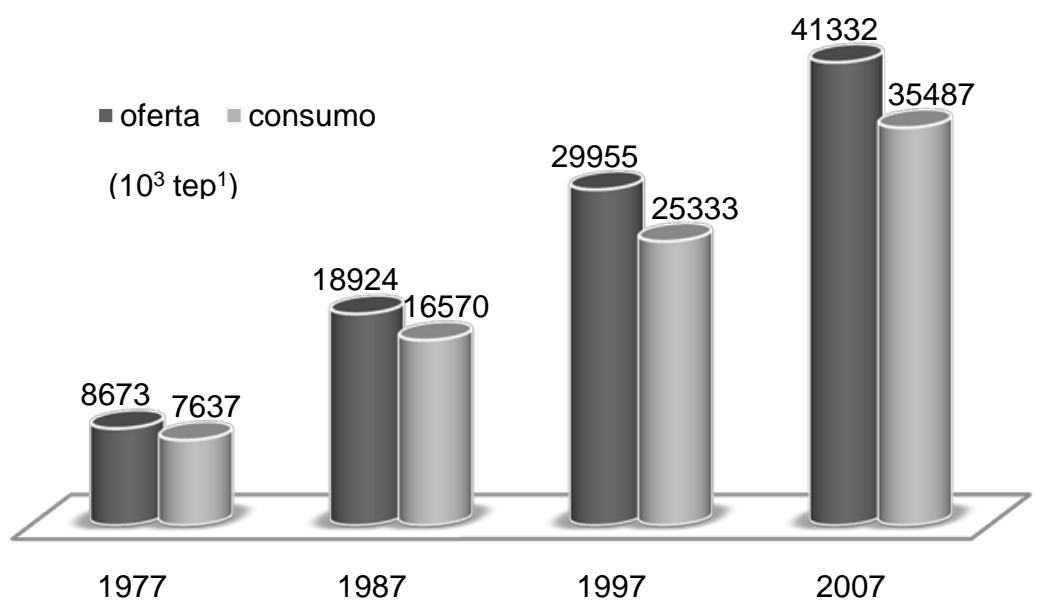

Figura 1.1 - Oferta e consumo da energia elétrica no Brasil (adaptado do EPE, 2008).

No Brasil $85 \%$ da oferta de energia elétrica é de origem hidráulico (EPE, 2008), a qual depende das chuvas para aumentar os níveis dos reservatórios. A

\footnotetext{
${ }^{1}$ Tonelada equivalente de petróleo (tep) é a quantidade de energia contida em uma tonelada de petróleo de referência, adotada no Balanço Energético Nacional (BEN) e em outras publicações internacionais como 10.000 Mcal (EPE-2008).
} 
ausência de chuvas como aconteceu em 2001 e 2002 foi uma das maiores nas últimas décadas, assim, registrou-se nesses anos racionamento de energia elétrica, influenciando direta e indiretamente em todos os setores da economia e da política brasileira (Bardelin, 2004). O consumo de energia elétrica em aparelhos de ar condicionado e refrigeração é elevado nos dias de verão, intensificando-se em horários de pico. Neste cenário, o uso racional e eficiente de energia elétrica deve ser posto em uso.

Ligado ao maior consumo de energia, a queima de combustíveis e a diminuição das áreas verdes, por causa do aumento da população, trazem um fenômeno conhecido como aquecimento global, o qual está causando, na atualidade, mudanças climáticas preocupantes. Outro fato que está trazendo problemas no planeta é a redução da camada de ozônio, cuja causa é, entre outros fatores, alguns refrigerantes halogenados. Sistemas de refrigeração por compressão usam esses tipos de refrigerantes, entre eles, podemos mencionar: PFCs, HFCs, HCFCs e CFCs. A Tabela 1.1 mostra o impacto no ambiente no uso destes refrigerantes, o refrigerante tipo HFC não destrói a camada de ozônio, mas tem impacto no aquecimento global. Em 1987 foi assinado o protocolo de Montreal, e desde então, tem-se tomado medidas em muitos países do mundo para reduzir e até eliminar o uso de refrigerantes de elevado índice de ODP (Ozone Depleting Potential). A Honeywell em conjunto com a Dupont vem testando um novo refrigerante chamado HFO-1234yf o qual pode ser o que vai substituir ao HFC-134a já que tem desempenho semelhante. Nielsen et al. (2007) concluiu que este novo refrigerante tem uma vida na atmosfera de 11 dias e que seu índice de HGWP (20 anos) é de $7,6 \times 10^{-4}$.

A preocupação com a redução da camada de ozônio e o aquecimento global traz novamente interesse em utilizar ciclos de refrigeração por absorção. Sendo que os fluidos de trabalho mais comuns nestes equipamentos são amônia/água e brometo de lítio/água, os quais não contribuem na intensificação desses fenômenos. Os ciclos de refrigeração por absorção de amônia/água conseguem temperaturas de refrigeração abaixo de $0{ }^{\circ} \mathrm{C}$, sendo que o ponto de congelamento da amônia à pressão ambiente é $-33,6{ }^{\circ} \mathrm{C}$. Esse ciclo também pode trabalhar em condicionamento de ar, para temperaturas de amônia no evaporador maiores que 0 ${ }^{\circ} \mathrm{C}$. Já o ciclo de refrigeração por absorção de brometo de lítio/água, trabalha 
somente em aplicações de ar condicionado. A comparação desses ciclos será descrita mais detalhadamente na Seção 2.1.3. Por sua maior abrangência em refrigeração, este trabalho considera estudar o ciclo com o par amônia/água.

Tabela 1.1 - Refrigerantes comuns e sua influência na redução da camada de ozônio e aquecimento global (Wang, 2001).

\begin{tabular}{lcc}
\hline \multicolumn{1}{c}{ Refrigerante } & ODP & HGWP \\
\hline CFC & 1,0 (base) & 1,0 (base) $^{\star}$ \\
R-11 & 1,0 & 3,1 \\
R-12 & & \\
HCFC & 0,05 & 0,34 \\
$\quad$ R-22 & 0,0 & \\
HFC & 0,0 & 0,28 \\
$\quad$ R-134a & 0,95 \\
R-404a & 0,48 \\
R-410a & & 0,0 \\
Composto inorgânico & 0,0 & 0,0 \\
R-717 (Amônia) &
\end{tabular}

* Em 20 anos, $1 \mathrm{~kg} \mathrm{R}-22$ causa o mesmo efeito que $4100 \mathrm{~kg}$ de $\mathrm{CO}_{2}$.

O uso dos ciclos de refrigeração por absorção se torna economicamente viável quando existe uma fonte de calor barata, como por exemplo, em sistemas de cogeração, em que nesses sistemas os produtos de combustão são reaproveitados para gerar vapor ou água quente. Já o ciclo de refrigeração por absorção aproveita essa energia térmica para produzir frio, formando um sistema de trigeração, constituindo assim em um uso racional e eficiente da energia. Atualmente esses ciclos de refrigeração não são construídos no Brasil, o que faz com que sejam importados. Um conhecimento mais profundo sobre estes tipos de ciclos de refrigeração abrirá as portas para que em um futuro possa-se construir estes ciclos de absorção no Brasil, o que é parte motivadora deste trabalho.

No ciclo de refrigeração por absorção amônia/água, a coluna de destilação e o absorvedor são componentes de em que ocorre transferência simultânea de calor e de massa em escoamentos bifásicos de uma mistura de amônia/água, este fato faz com que sua complexidade de modo de trabalho seja maior em comparação com os outros componentes, os quais somente trabalham com amônia praticamente 
pura. A coluna de destilação recebe o fluxo de calor do meio externo para produzir vapor de amônia que constitui o refrigerante do ciclo, sendo que para uma capacidade de resfriamento fixa do ciclo de refrigeração, quanto mais fluxo de calor é fornecido ao gerador, a eficiência do ciclo será menor. Além disso, o correto funcionamento da coluna de destilação garante que no evaporador não chegue vapor de água, porque se isso acontece o ciclo terá sua capacidade reduzida. Nesse sentido, a coluna de destilação é um dos componentes críticos do ciclo de refrigeração por absorção e, portanto, seu estudo é de grande importância para o entendimento e operação do ciclo como um todo.

O presente trabalho estuda o processo de purificação de vapor amônia úmido na coluna de destilação, assim como também proporciona a geometria necessária para atingir os valores de pureza desejados. A pureza de vapor de amônia neste trabalho é entendida como vapor com alta concentração de amônia e baixíssima de água. Dentro da coluna de destilação (também chamada coluna fracionadora ou fracionador) tem-se um reservatório de solução líquida de amônia/água, denominado gerador. Quando o fluxo de calor é fornecido a essa solução líquida, parte dela torna-se vapor de amônia úmida, a qual sobe pela coluna em contracorrente com o líquido. O vapor e o líquido se encontram nas unidades de transferência da coluna de destilação chamadas pratos (ou estágios), as duas correntes entram em contato e acontece uma transferência simultânea de calor e de massa. À medida que o vapor sobe pela coluna, vai aumentando sua pureza e enquanto o líquido desce sua concentração de amônia diminui.

São investigadas as relações entre os estágios da coluna de destilação, fazendo os respectivos balanços de massa e de energia em cada um deles, com isso consegue-se conhecer os parâmetros de trabalho da coluna, tais como: razão de refluxo, número de pratos e posicionamento da entrada de solução na coluna, entre outros. Esse balanço será feito pelo método de Ponchon-Savarit, que será detalhado na Seção 4.1. Esse método leva em consideração estágios ideais, supondo que os escoamentos de líquido e vapor saiam em equilíbrio de cada prato. Esta suposição será corrigida pela eficiência da coluna, que considera conceitos de transferência de massa no prato. Também serão abordados aspectos hidráulicos e a geometria interna da coluna. A implementação do equacionamento obtido pelo balanço de massa e de energia, eficiência e geometria da coluna será realizado no 
software EES - Engineering Equation Solver, o qual tem inserido como sub-rotina condições de equilíbrio da mistura amônia/água.

\subsection{OBJETIVO}

Estudar e projetar uma coluna de destilação de pratos perfurados para um ciclo de refrigeração de absorção de amônia/água com capacidade de 5 toneladas de refrigeração $(T R)$.

\subsubsection{Objetivos Específicos}

Utilizar o método de Ponchon-Savarit para fazer o balanço de massa e de energia na coluna de destilação de amônia/água e analisar os parâmetros de operação como razão de refluxo e entrada da alimentação na coluna; assim como, calcular o número de pratos ideais para alcançar níveis adequados de purificação do vapor refrigerante.

Usar o conhecimento de transferência de massa para calcular o a eficiência da coluna e com isso corrigir o número de pratos necessários.

Aplicar o conhecimento geral de colunas de destilação para projetar a geometria interna da coluna de destilação amônia/água.

Empregar o software EES (Engineering Equation Solver) para resolver os sistemas não lineares de equações e usar sua rotina de cálculo de propriedades termodinâmicas e equilíbrio para a solução amônia/água.

\subsection{ESTRUTURA DA DISSERTAÇÃO}

O presente trabalho está dividido em seis capítulos. No Capítulo 1 apresentase a introdução aos ciclos de refrigeração por absorção, dando ênfase à sua importância em sistemas de cogeração e trigeração no sentido do uso racional da energia. Explica-se também a motivação e os objetivos deste trabalho. 
O Capítulo 2 trata da revisão da literatura. Inicia com uma breve descrição de sistemas de refrigeração por absorção, aborda também as modificações que tiveram o objetivo de diminuir o fluxo de calor fornecido ao gerador para uma determinada capacidade de refrigeração, faz comparações de ciclos de refrigeração por absorção de amônia/água e brometo de lítio/água, assim como com ciclos de refrigeração por compressão. Descreve também o modo de funcionamento de uma coluna de destilação e os principais enchimentos usados para a troca de massa e de energia no seu interior, revisa os principais avanços no estudo da purificação de vapor amônia úmido e finaliza com a análise da necessidade de purificar esse vapor.

No Capítulo 3 é abordado o estudo sobre o equilíbrio líquido-vapor em sistemas binários, com ênfase na mistura amônia/água.

O Capítulo 4 apresenta a metodologia, onde são analisados os balanços de massa e energia na coluna de destilação pelo método de Ponchon-Savarit com a finalidade de obter o fluxo de calor necessário para ser fornecido ao gerador e ser retirado do retificador, a posição da entrada da solução na coluna de destilação e o número de pratos ideais. Na sequência, calcula-se a eficiência da coluna a partir da teoria de transferência de massa, sendo possível conhecer o número de pratos reais da coluna. Além disso, o capítulo abordará as considerações hidráulicas para o correto funcionamento da coluna e será também projetada a geometria interna da coluna, para isso serão aproveitadas correlações usadas em torres de destilação de petróleo e bebidas alcoólicas.

O Capítulo 5 apresenta os resultados obtidos das simulações executadas, a análise das vazões, temperaturas e concentrações em cada um dos pratos da coluna, análise da sensibilidade da coluna com o fator de refluxo e com a altura do vertedor.

E, finalmente, o Capítulo 6 apresenta as conclusões do trabalho, assim como os limites da simulação e algumas recomendações de continuidade do estudo da coluna de destilação e do ciclo de refrigeração por absorção de amônia/água. 


\section{REVISÃO DA LITERATURA}

\subsection{CICLOS DE REFRIGERAÇÃO POR ABSORÇÃO}

Nos anos 1600 e 1700 numerosos estudos referentes a mudanças de fase, temperatura e pressão foram feitos e levados para o estudo de refrigeração. Em 1777, Nairne reportou um dos primeiros experimentos feitos com absorção, usando ácido sulfúrico para absorver água (Stephan, 1983). Já em 1805, Oliver Evans, EUA, propôs, mas não construiu, um ciclo de compressão que trabalha com o fluido volátil éter para fazer gelo. Perkins, em 1834, usou as idéias de Evans e fez a primeira patente de uma máquina de refrigeração por compressão de vapor (Calm, 2008). 0 primeiro chiller por absorção foi desenvolvido pelo francês Edmond Carré em 1850, e usava água e ácido sulfúrico para produzir gelo. Seu irmão, Ferdinand Carré, em 1859, patentearia na França o sistema de refrigeração por absorção que trabalhava com amônia/água, depois, em 1860, patentearia sua primeira unidade comercial nos EUA (Stephan, 1983).

Hoje, as máquinas por absorção mais usadas comercialmente são: chillers de brometo de lítio/água, chillers de amônia/água e refrigeradores de amônia/água hidrogênio. Destes três sistemas, o primeiro a ser usado foi o chiller por absorção amônia/água. Na sequência, serão descritos com mais detalhes os ciclos por absorção de amônia/água, amônia/água hidrogênio e será comparado o uso dos chillers de amônia/água e brometo de lítio/água e também o uso de chillers por absorção com chillers por compressão.

\subsubsection{Ciclo de refrigeração por absorção de amônialágua}

Em meados do século XIX o ciclo de refrigeração por absorção amônia/água era usado para produção de gelo e armazenamento de alimentos. A amônia era usada porque permite temperaturas de resfriamento muito baixas, congelando somente a $-77,7^{\circ} \mathrm{C}$.

O sistema mais simples de refrigeração por absorção de amônia/água é o de simples efeito mostrado na Fig. 2.1. Nestes ciclos de refrigeração por absorção, quando o fluxo de calor é fornecido ao gerador, a amônia evapora juntamente com 
certa quantidade de água, formando um vapor de amônia "úmido". Isto acontece pelas propriedades de volatilidade da solução amônia/água, como será explicado no Capítulo 3. Se essa água vai até o evaporador, será continuamente acumulada e o comportamento do sistema mudará, inutilizando-o (Herold et al., 1996); esse comportamento será explicado com mais detalhe na Seção 2.4.

Depois do gerador a amônia úmida continua até o retificador, onde a pouca quantidade de água é condensada, produto da remoção de fluxo calor. O vapor de amônia praticamente puro (linha pontilhada) passa do retificador para o condensador onde ocorre outro fluxo de calor para a água ou ar (fluidos mais usados), passando assim ao estado líquido. A amônia condensada passa pela válvula de expansão $A$ (VE-A), reduzindo sua pressão e sua temperatura num processo idealmente isoentálpico, tornando-se bifásica e passando ao evaporador, virando vapor novamente, como consequência de receber o fluxo de calor do ambiente de interesse. Logo, segue para o absorvedor onde é absorvido pela solução que praticamente só tem água (chamada "solução fraca"). O processo de absorção é exotérmico, por isso essa solução é aquecida e é necessário que o retirar fluxo de calor do absorvedor para que o processo de absorção continue. A solução líquida que sai do absorvedor terá uma importante porcentagem de amônia ( 30 \%) assim será chamada de "solução forte". Essa solução aumenta sua pressão mediante a bomba $B$ e depois é enviada até o gerador.

Na Fig. 2.1 pode-se ver o trocador de calor que está entre o gerador e o absorvedor que é conhecido na literatura como TCS - Trocador de Calor de Solução (SHX - Solution Heat Exchanger). Esse componente aproveita a energia térmica da solução que sai do gerador (que tem alta temperatura) para aquecer a solução que vai da bomba $B$ até o gerador. Assim, o fluxo de calor necessário para aquecer a solução no gerador será menor do que se não houvesse esse trocador de calor. Também a solução que vai do gerador até o absorvedor diminuirá sua temperatura e com isto o fluxo de calor, que é necessário ser retirado do absorvedor para resfriar a mistura bifásica e provocar a absorção de vapor de amônia no absorvedor, será menor. E assim, o ciclo se reinicia. 


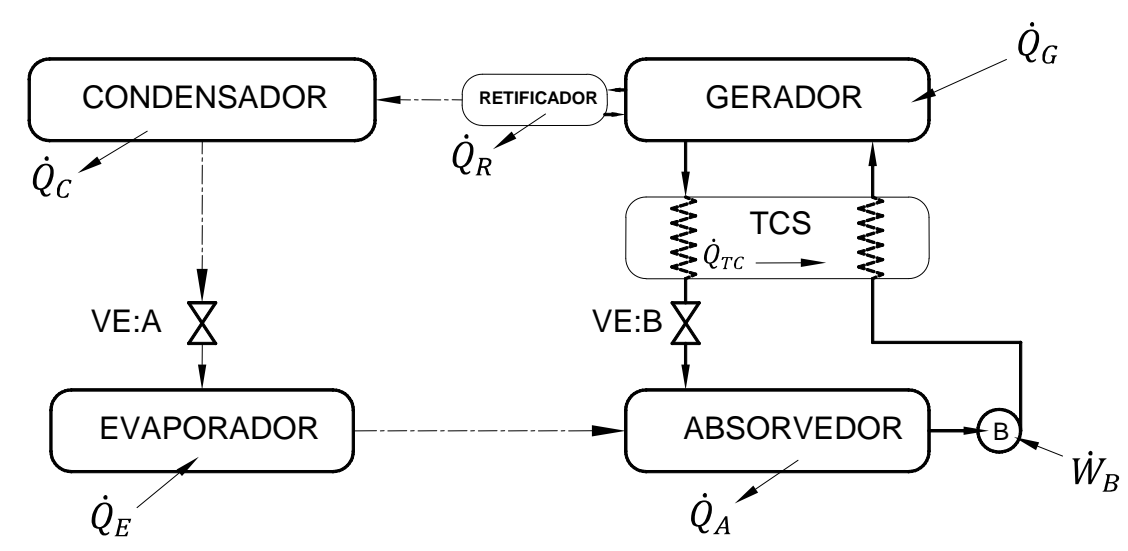

Figura 2.1 - Ciclo de refrigeração por absorção de amônia/água de simples efeito.

O trocador de calor TCS é um componente importante no reaproveitamento de fluxos de calor, sendo que para uma mesma demanda de refrigeração o Coeficiente de Eficácia (COP), definido na Eq. (2.1), é incrementado em 60\% (Srikhirin et al., 2001), se comparado com o mesmo ciclo de refrigeração sem TCS, já que o fluxo de calor fornecido ao gerador será menor.

$$
C O P=\frac{\text { Efeito útil de Refrigeração }}{\text { Fluxo de Calor fornecido ao Gerador }}=\frac{\dot{Q}_{E}}{\dot{Q}_{G}}
$$

Uma modificação no ciclo de refrigeração de simples efeito mostrado na Fig. 2.1 é apresentada na Fig. 2.2.
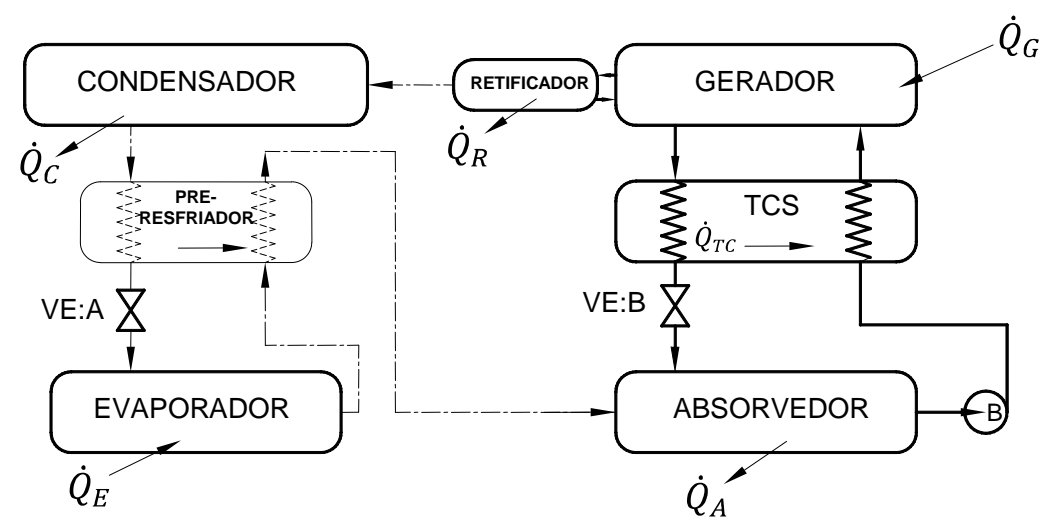

Figura 2.2 - Ciclo de refrigeração por absorção de simples efeito com pré-resfriador. 
Quando a amônia passa pela válvula de expansão A (VE-A), reduz sua pressão e sua temperatura e no evaporador ela geralmente muda somente de estado (de líquido a vapor) conservando sua temperatura baixa. Esta baixa temperatura é aproveitada para sub-resfriar a amônia líquida que sai do condensador, aumentando assim a capacidade de resfriamento do evaporador. Este trocador de calor é chamado na literatura como pré-resfriador (precooler ou RHX Refrigerant Heat Exchange).

Com o objetivo de aumentar o COP várias modificações foram introduzidas no lado da amônia/água, para diminuir o fluxo de calor fornecido ao gerador, reaproveitando algumas fontes de calor internas no ciclo. Como explicado por Herold et al. (1996), o absorvedor geralmente é resfriado com ar ou água à temperatura ambiente e, consequentemente, a temperatura da solução que sai do absorvedor fica em torno de $40{ }^{\circ} \mathrm{C}$. Essa solução é aproveitada para retirar o fluxo de calor do retificador, que tem vapor de amônia a uma temperatura mais alta, para depois passar pelo TCS, como mostrado na Fig. 2.3. O fluxo de calor transferido à solução no retificador e no TCS faz com que o fluxo de calor necessário para aquecer a solução no gerador seja menor, aumentando o COP. Ortigosa (2007) analisou a melhoria do COP para diversos ciclos de absorção amônia/água, começando com o mais elementar até configurações mais elaboradas.

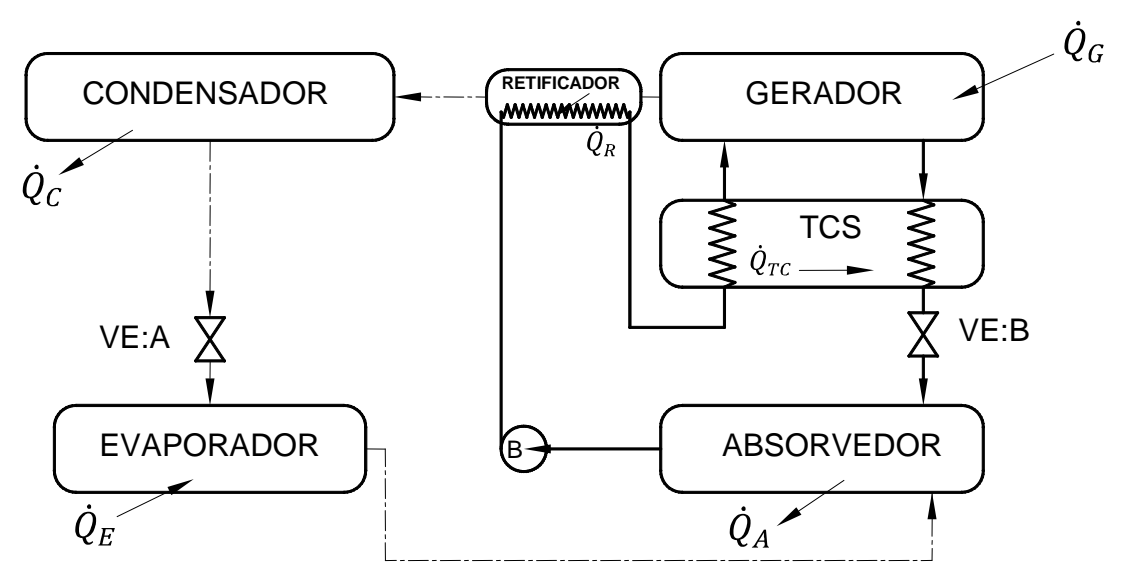

Figura 2.3 - Ciclo de refrigeração por absorção de simples efeito com aproveitamento de fluxo de calor no retificador. 
Para reaproveitar fontes de calor a alta temperatura, outra modificação pode ser feita, como por exemplo, chillers de duplo e triplo efeito. Esses ciclos de refrigeração foram introduzidos nos anos 1950 (Srikhirin et al., 2001) e podem ter diferentes configurações com dois ou mais componentes básicos (condensador, evaporador, pré-resfriador, absorvedor, gerador retificador e trocador de calor de solução). Na Fig. 2.4 é mostrado um chiller por absorção de duplo efeito com dois níveis de pressão. Os componentes do lado amônia/água estão duplicados, portanto o condensador trabalhará o dobro, assim como o evaporador. O vapor refrigerante produzido no gerador 1, depois de passar por vários elementos do ciclo, será absorvido no absorvedor 1 ; como consequência dessa absorção, fluxo de calor é produzido. Este fluxo de calor depois aquecerá o gerador 2 .

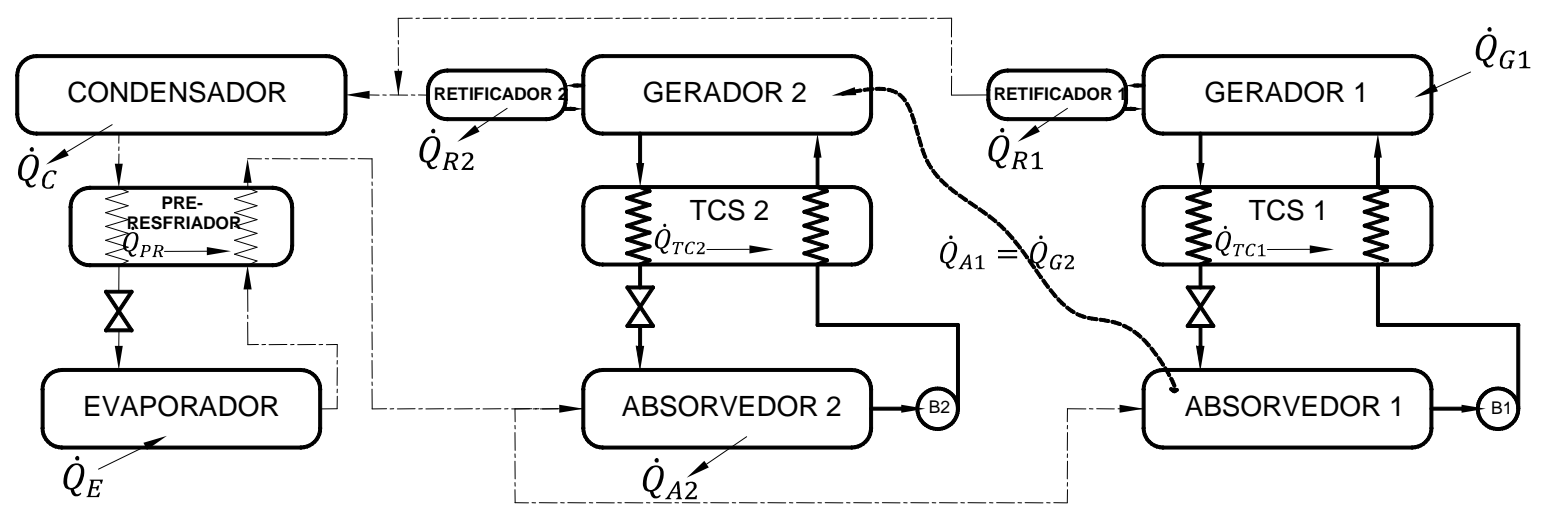

Figura 2.4 - Ciclo de refrigeração por absorção de duplo efeito, (Herold, 1996).

Ciclos de refrigeração por absorção de amônia/água de simples, duplo e triplo efeito foram estudados por Devault e Marsala (1990), nesse trabalho é enfatizado que nem todas as configurações de triplo efeito podem ser aplicadas a sistemas amônia/água, ressaltando como fator limitante a alta temperatura no absorvedor, que pode ultrapassar os limites de solubilidade da solução. Comparou as características de trabalho desses ciclos por absorção, os quais são mostrados na Tabela 2.1. Para o ciclo de duplo efeito ele alterou a sequência dos componentes diferentemente ao mostrado na Fig. 2.4, usando três níveis de pressão. Na Tabela 2.1 pode-se perceber o alto nível de pressão alcançado pelo condensador. 
Tabela 2.1 - Principais características dos ciclos multi-efeitos.

\begin{tabular}{lccc} 
& Simples Efeito & Duplo Efeito & Triplo Efeito \\
\hline COP & 0,77 & 1,20 & 1,41 \\
Capac. Refrigeração $(T R)$ & 20,8 & 32,5 & 21,7 \\
Pressão alta (bar) & 12,7 & 69 & 48,3 \\
Temperatura no gerador $\left({ }^{\circ} \mathrm{C}\right)$ & 115,7 & 199,6 & 218,7 \\
\hline
\end{tabular}

Adaptado de Devault e Marsala (1990)

Sistemas multi-efeitos em várias configurações foram estudados por Cheung et al. (1996), o COP aumenta segundo o número de estágios, mas a complexidade e o custo também aumentam. Num ciclo de quádruplo efeito, ele obteve um COP de 1,71 com uma temperatura no gerador de $240{ }^{\circ} \mathrm{C}$ e uma pressão no condensador de 34,3 bar.

Já a Tabela 2.2, mostra as fontes de calor aplicáveis a sistemas de absorção multi-efeitos, segundo Foley et al. (2000). Do mesmo trabalho são obtidos os COP's obtidos de chillers de absorção comerciais, os quais são mostrados na Tabela 2.3.

Tabela 2.2 - Fontes de calor aplicáveis a sistemas de absorção.

\begin{tabular}{lcl}
\hline Fonte de calor & Temp. $\left({ }^{\circ} \mathrm{C}\right)$ & Ciclo de refrigeração aplicável \\
\hline Turbina de gás & $>540$ & Triplo, duplo e simples efeito \\
Células de combustível de óxido sólido & $\sim 490$ & Triplo, duplo e simples efeito \\
Micro Turbina & $\sim 315$ & Triplo, duplo e simples efeito \\
Células a combustível de ácido fosfórico & $\sim 120$ & Duplo e simples efeito \\
Motor de combustão interna & $\sim 82$ & Simples efeito \\
Células de combustível PEM & $\sim 60$ & Simples efeito \\
\hline
\end{tabular}


Tabela 2.3 - COP's dos chillers de absorção comerciais.

\begin{tabular}{cc}
\hline Tipo de Chiller & COP \\
\hline Simples efeito & $0,6-0,7$ \\
Duplo efeito & $0,9-1,2$ \\
Triplo efeito & $1,45-1,8$ \\
\hline
\end{tabular}

Outro ciclo de refrigeração muito usado atualmente é o ciclo tipo GAX (Generator/Absorber Heat Exchange). Os primeiros que reportaram esse tipo de ciclo de refrigeração por absorção foram Altenkirch e Tenckhoff que patentearam esse sistema em 1914 (Srikhirin et al., 2001; Herold et al., 1996). A Fig. 2.5 mostra um diagrama simplificado do ciclo de refrigeração por absorção feito pelo fabricante Robur (Robur, 2009), o qual usa o conceito GAX e trabalha com amônia/água.

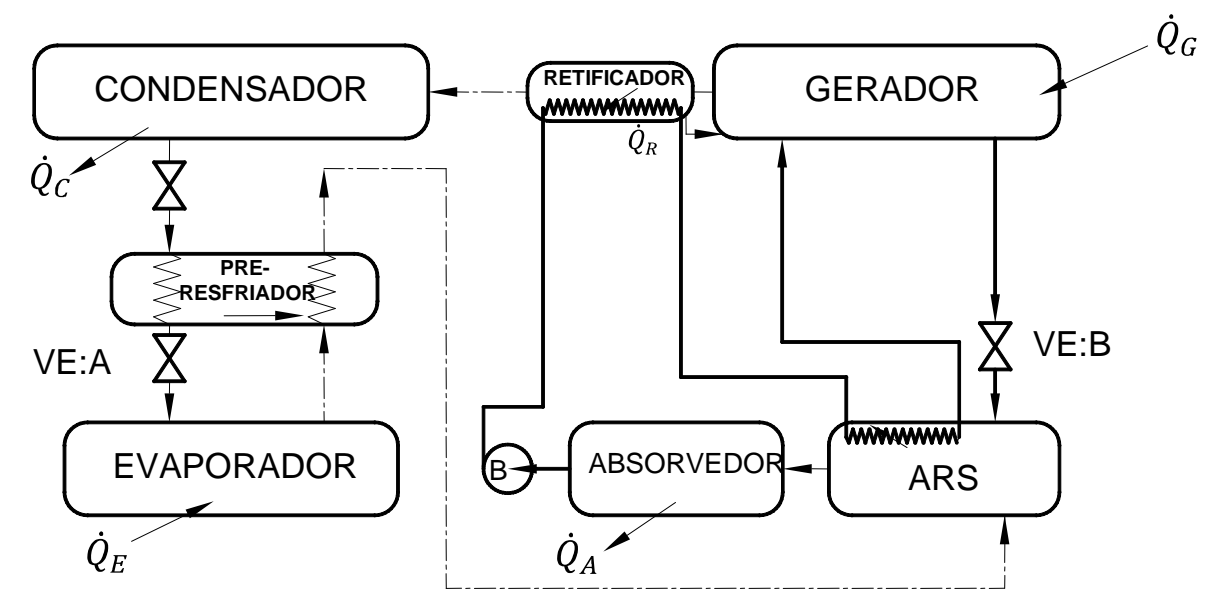

Figura 2.5 - Ciclo de refrigeração por absorção com sistema GAX.

O ciclo GAX aproveita o fluxo de calor disponível da mistura fraca que vem do gerador, a qual tem temperatura alta, e também parte do fluxo de calor liberado pela absorção de amônia para aquecer a mistura forte que sai do retificador. Portanto, a mistura forte que chega ao gerador terá alta temperatura, reduzindo assim o fluxo de calor fornecido por uma fonte externa. Além disso, a temperatura da mistura fraca que chega até o pré-absorvedor será menor. O pré-absorvedor é chamado (Herold et al. 1996; Robur, 2009) como ARS - Absorvedor Resfriado por Solução (SCA Solution Cooled Absorver). Este ciclo GAX é parecido com o ciclo por absorção de duplo efeito apresentado na Fig. 2.4, porque o fluxo de calor liberado no absorvedor 
serve para aquecer o gerador e também é parecido com o ciclo de simples efeito apresentado na Fig. 2.2 já que têm os mesmos componentes básicos, porém com maior $\operatorname{COP}(0,6-1,0)$.

Santos et al. (2008) analisaram as irreversibilidades que acontecem nos componentes de um ciclo de refrigeração por absorção de amônia/água. Os autores concluíram que o gerador e o retificador apresentaram maiores irreversibilidades. Neste trabalho também foi apresentado a análise termo-econômica de um motor a GN trabalhando em cogeração e a unidade de refrigeração. Marquez et al. (2006) apresentaram uma análise termo-economica, de um ciclo de refrigeração por absorção de amônia/água, mas esta vez, acoplado a um motor automotivo.

\subsubsection{Ciclo de refrigeração por absorção amônialágua/hidrogênio}

Em 1922, os suecos Von Platen e Carl Munters, ambos estudantes do Royal Institute of Technologia - Suíça, (Eletrolux, 2009) baseados no princípio de refrigeração do cientista Ferdinand Carré, inventaram um novo ciclo de refrigeração com uma configuração de três fluidos ao invés de dois. Esses três fluidos eram amônia/água e hidrogênio. O hidrogênio, gás inerte aos outros dois fluidos, estava presente no evaporador (e no absorvedor) para estabelecer uma baixa pressão parcial do refrigerante. A pressão total interna no ciclo é a mesma em cada ponto dele, mudando somente as pressões parciais. Vapor de amônia irá se difundir no hidrogênio e vice-versa, por isso esses refrigeradores são chamados de Diffution Absorption Refrigerator (DAR), os quais não tinham partes móveis e precisavam somente de uma fonte de calor para operar. A fonte de calor poderia ser uma resistência elétrica, queima de gás ou queima de querosene. A manutenção, o ruído e a vibração nesse ciclo eram mínimos. É apresentado na Fig. 2.6 o refrigerador de Von Platen e Carl Munters, que foi patenteado em 1926 (Platen e Munters, 1926).

Na sequência, descreve-se o modo de funcionamento deste refrigerador. O gerador tem mistura de água e amônia. O fluxo de calor liberador pela combustão do queimador 14 serve para aquecer a solução no gerador $K$, e consequentemente vapor de amônia úmido é produzido, indo para o condensador onde o vapor se transforma em líquido para depois ser distribuído em $I$. O fluido resfriador no condensador geralmente é água à temperatura ambiente. No evaporador tem-se 
também hidrogênio, o qual vai fazer com que a pressão parcial de vapor de amônia diminua, e como consequência sua temperatura de evaporação seja muito baixa. A amônia evapora, recebendo fluxo de calor do meio, resfriando-o; e ela segue para o absorvedor. Sendo $M$ um tubo comunicante, o absorvedor também terá hidrogênio. Pela tubulação $L$ a solução fraca vai do gerador até o absorvedor, sendo descarregado em $O$. Um líquido, geralmente água, resfria o absorvedor e a solução fraca absorve amônia, tornando-se solução forte. Esta retorna ao gerador pela tubulação $P$, onde o ciclo inicia novamente.

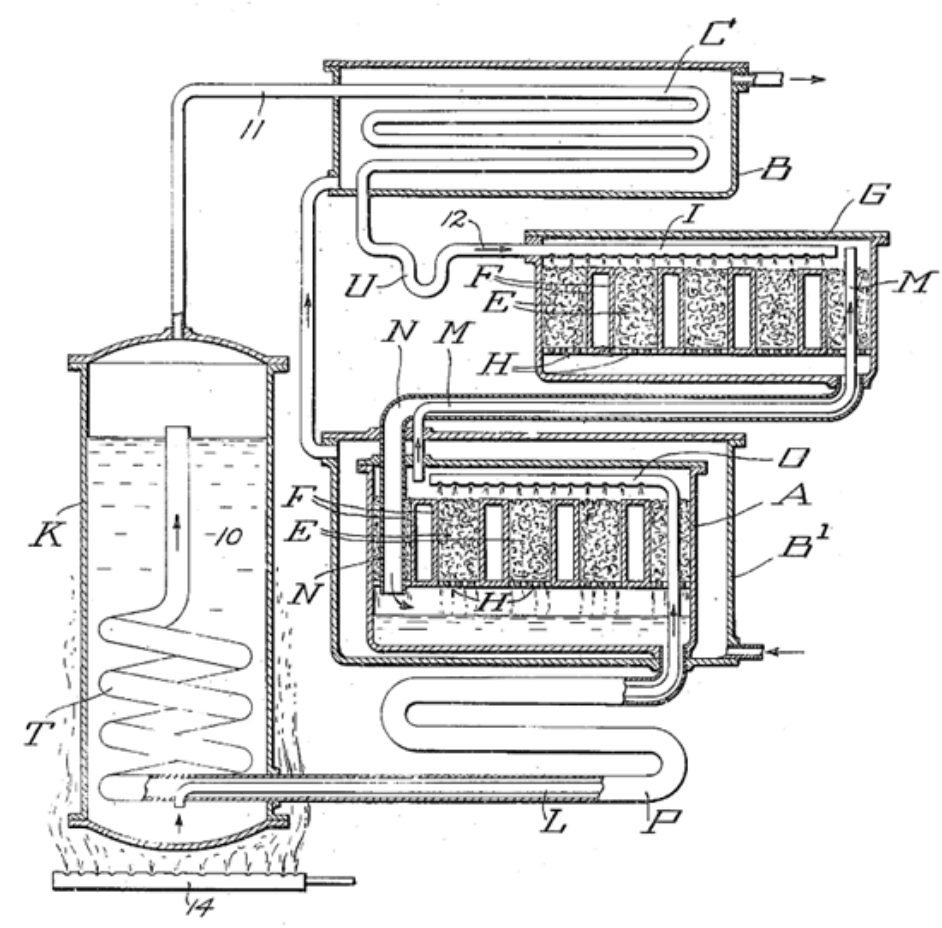

$$
\begin{aligned}
& \text { K-Gerador } \\
& \text { C-Condensador } \\
& \text { G-Evaporador } \\
& \text { A-Absorvedor } \\
& \text { U-Sifão } \\
& \text { M-Tubo comunicante } \\
& \quad \text { de hidrogênio }
\end{aligned}
$$

Figura 2.6 - Refrigerador de Von Platen e Carl Munters, patenteado em 1926.

Em 1923, a companhia AB Arctic fabricou os refrigeradores Platen - Munters. A Electolux compraria a AB Arctic em 1925 e no mesmo ano lançam no mercado os refrigeradores "D-fridge". Esta "caixa maravilhosa" resolveria o problema de armazenamento de alimentos frescos em casa (Platen e Munters, 1926).

Uma alternativa à idéia original de Von Platen e Carl Munters foi o refrigerador de Albert Einstein e seu estudante Leó Szilárd concebida em 1926. Albert Einstein e seu estudante patentearam esse refrigerador nos EUA em 11 de Novembro de 1930 (Einstein e Szilard, 1930) o qual é mostrado na Fig. 2.7. 


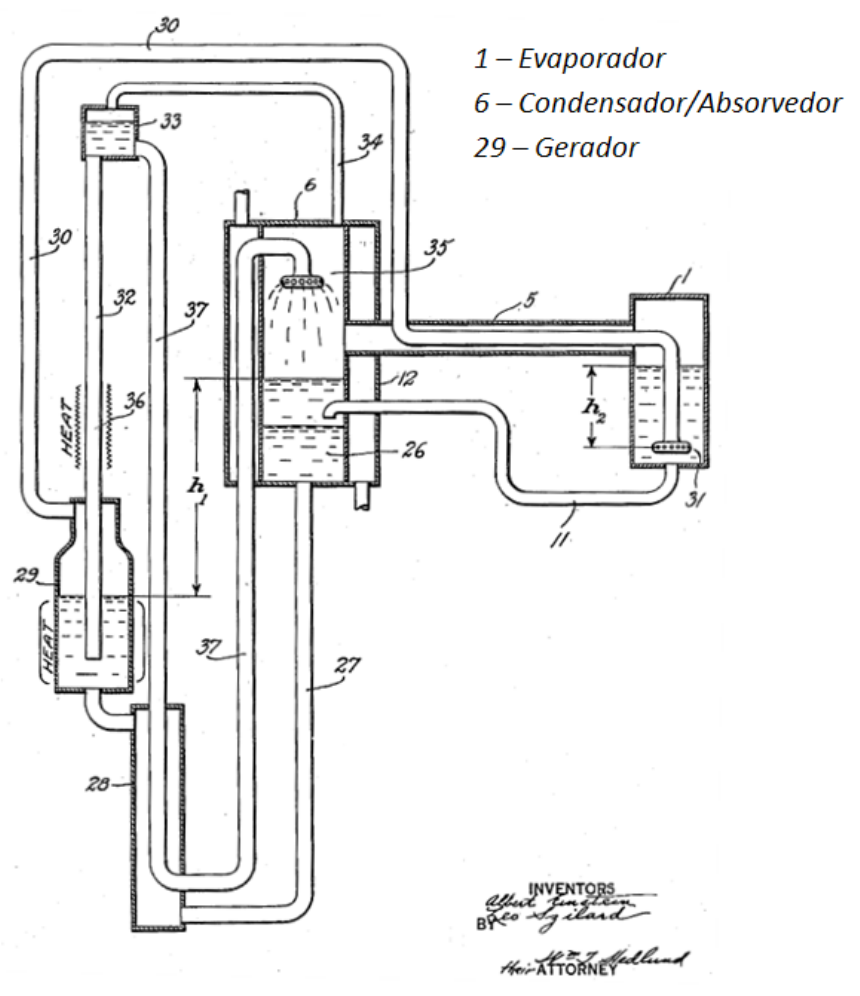

Figura 2.7 - Refrigerador de Albert Einstein, patenteado em 1930.

Os fluidos de trabalho desse refrigerador foram água como absorvente, butano como refrigerante e amônia como gás inerte. A solução forte é aquecida no gerador onde a amônia úmida evapora e é descarregada em 31 no evaporador, que tem butano líquido. O vapor de amônia faz com que a pressão parcial de butano diminua, causando sua evaporação e resfriamento do ambiente. Os vapores de amônia e butano percorrem pela tubulação 5 até o condensador, onde a solução fraca (que vem do gerador e é descarregada em 35) absorve a amônia. Então a pressão total do vapor (que será igual à pressão do sistema) será somente do butano fazendo com que esse vapor transforme-se em líquido. Como a solução forte de amônia/água é mais densa do que o butano líquido, ela ficará abaixo, e o butano volta para o evaporador através da tubulação 11 e a solução forte vai até o gerador através de tubulação 27 .

Os COP's atingidos por refrigeradores tipo DAR são muito baixos. Mejbri (2006) estudou um sistema parecido com o refrigerador de Einstein, achou COP's da ordem de 0,19, da mesma forma, Srikhirin e Aphornratana (2002) também obtiveram 
COP's de 0,09 - 0,15 num sistema DAR com amônia/água e hélio como fluidos de trabalho.

\subsubsection{Comparação dos chillers de amônia/água e brometo de lítiolágua}

Nos anos 1950 o sistema brometo de lítio/água $\left(\mathrm{LiBr} / \mathrm{H}_{2} \mathrm{O}\right)$ foi usado amplamente (Herold et al. 1996). Neste equipamento, água é o fluido refrigerante, e a solução brometo de lítio - água é o fluido absorvente. Sendo a água o fluido refrigerante, a temperatura disponível para resfriar no evaporador tem que ser superior a $0{ }^{\circ} \mathrm{C}$ para que não congele. Desta maneira, o uso de chillers por absorção de $\mathrm{LiBr} / \mathrm{H}_{2} \mathrm{O}$ é restringido a aplicações de ar condicionado.

À continuação serão mencionadas certas características dos chillers por absorção de $\mathrm{LiBr} / \mathrm{H}_{2} \mathrm{O}$, e na sequência será comparado com os chillers de amônia/água.

$\mathrm{Na}$ solução $\mathrm{LiBr} / \mathrm{H}_{2} \mathrm{O}$ o sal $\mathrm{LiBr}$ é essencialmente não volátil. Sendo que quando essa solução é aquecida no gerador somente o fluido refrigerante (água) evapora, fazendo com que o uso de purificadores de vapor de água seja desnecessário. Na Fig. 2.8 mostra-se o esquema de um chiller por absorção de $\mathrm{LiBr} / \mathrm{H}_{2} \mathrm{O}$ de simples efeito. O funcionamento do ciclo é basicamente similar ao de amônia/água, já explicado. Depois da solução de $\mathrm{LiBr} / \mathrm{H}_{2} \mathrm{O}$ ser aquecia no gerador, o vapor de água produzido está na condição de superaquecido. Em seguida, passa ao condensador onde é resfriado geralmente por água, tornando-se líquido na condição de saturação. Uma temperatura típica da água na saída do condensador é $40,2^{\circ} \mathrm{C}$ e a pressão de saturação nessa temperatura é de 7,44 kPa (0,0744 bar), e ao passar pela válvula de expansão a temperatura da água diminui drasticamente até uma temperatura típica de $1,3{ }^{\circ} \mathrm{C}$ (dependendo da aplicação) onde sua pressão de saturação é 0,673 kPa (0,00673 bar). Essa água entra no evaporador e ao sair, geralmente na condição de vapor saturado, vai até o absorvedor onde a solução de $\mathrm{LiBr} / \mathrm{H}_{2} \mathrm{O}$ absorve a água. Assim, a solução chega ao gerador mediante uma bomba de solução. O trocador de calor TC aproveita a alta temperatura da solução que sai do gerador para aquecer o ramo que sai do absorvedor, com isso será necessário uma menor quantidade de fluxo de calor para produzir vapor de água no gerador. 
Também a solução que vai até o absorvedor terá uma menor temperatura, sendo necessário retirar menor quantidade de fluxo de calor no processo de absorção no absorvedor.

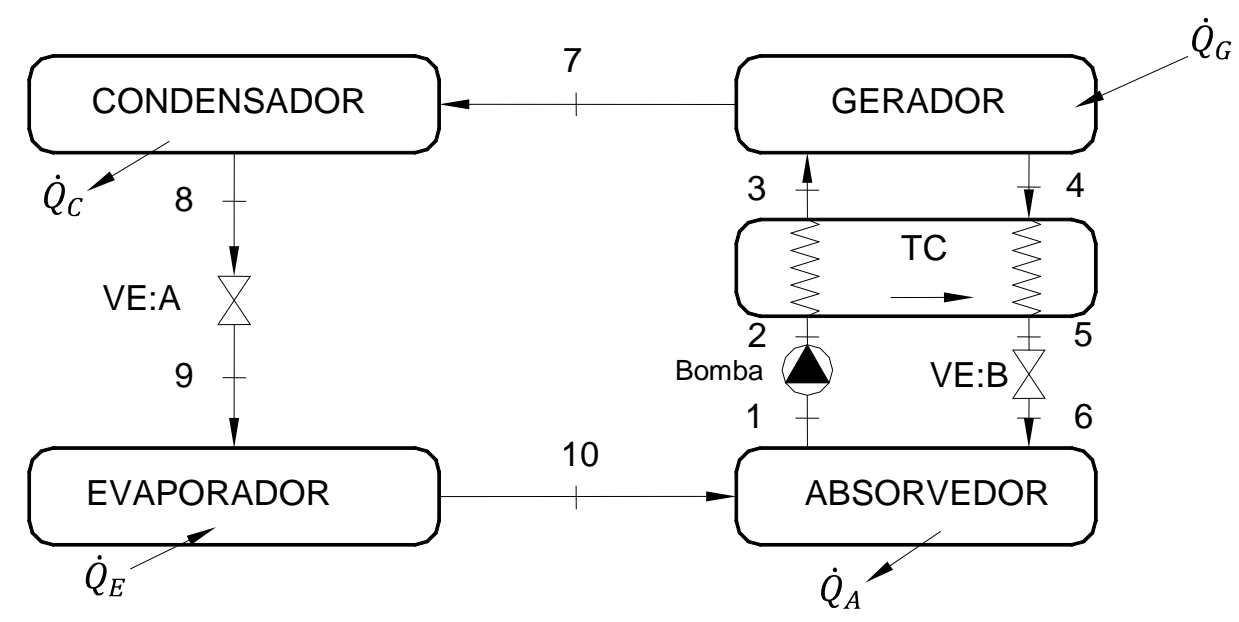

Figura 2.8 - Chiller por absorção de $\mathrm{LiBr} / \mathrm{H}_{2} \mathrm{O}$ de simples efeito.

Nas soluções aquosas com sais, o sal precipita (cristaliza) quando o limite de solubilidade é ultrapassado. A solubilidade é definida como a quantidade máxima que o soluto, neste caso $\mathrm{LiBr}$, pode dissolver-se em um solvente, neste caso água. Ela depende fortemente da temperatura e da concentração da solução e varia pouco com a pressão. O ciclo de refrigeração por absorção da Fig. 2.8 é representada mediante um diagrama de Düring mostrada da Fig. 2.9. Vê-se nessa figura as partes que num chiller por absorção de $\mathrm{LiBr} / \mathrm{H}_{2} \mathrm{O}$ pode haver formação de cristais de sal e elas correspondem à linha de solução que sai do $T C$ até o absorvedor, incluindo a válvula de expansão e o absorvedor. Liao e Radermacher (2007) enfatizam que a parte mais provável do ciclo em ter formação de cristais é depois da válvula VE-B. A formação de cristais de sal pode bloquear o escoamento na tubulação e interromper o funcionamento do sistema (Almeida, 2006). Uma vez que uma pequena porção de cristais é produzida a formação de cristais ao redor dela é mais provável. 


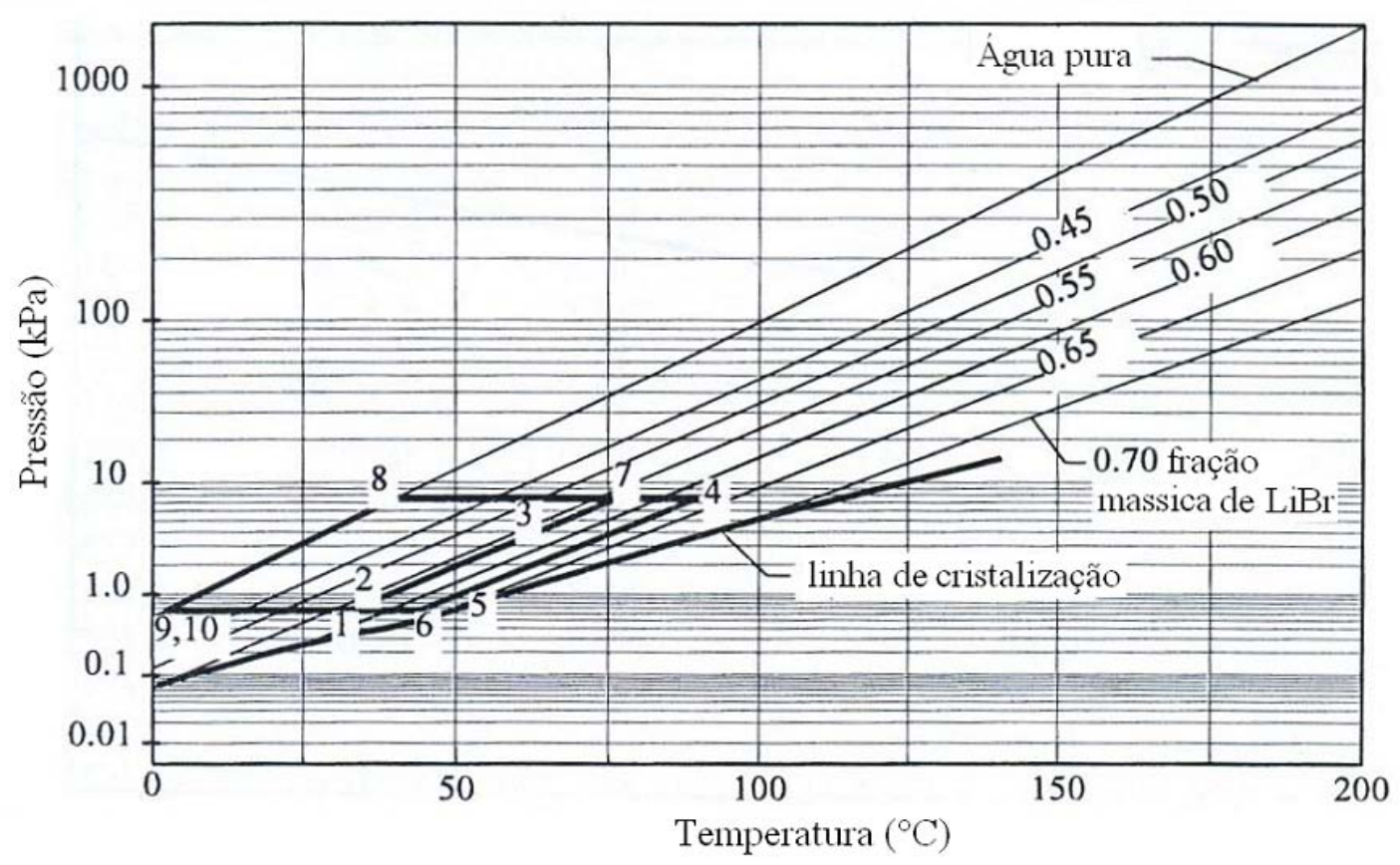

Figura 2.9 - Diagrama de Dühring para o ciclo da Fig. 2.8.

Como é mostrado na Fig. 2.9, temperaturas maiores que $40^{\circ} \mathrm{C}$ no absorvedor (6) prevêem a formação de cristais, por isso nos sistemas de $\mathrm{LiBr} / \mathrm{H}_{2} \mathrm{O}$, os absorvedores resfriados por ar não são apropriados para climas quentes ou estações de verão. Também a formação de cristais faz com que a solução seja mais viscosa e quando ela se movimenta na tubulação fica aquecida e sua pressão diminui. É necessário então que nos projetos desses equipamentos de absorção se intensifique medidas para reduzir ou eliminar a formação de cristais; uma medida para que isso aconteça seria conduzir líquido do evaporador para o absorvedor.

Como pode ser visto na Fig. 2.9, as pressões aplicadas a chillers de absorção de $\mathrm{LiBr} / \mathrm{H}_{2} \mathrm{O}$ de simples efeito são inferiores à pressão atmosférica. Já nos chillers de triplo efeito o gerador e o condensador (de alta pressão) atingem pressões superiores à pressão atmosférica. No chiller de simples efeito para uma temperatura de evaporação de $5^{\circ} \mathrm{C}$ a pressão de vapor da água é de 0,872 kPa (0,0087 bar), então o sistema tem que ser extremamente lacrado já que um pequeno furo pode fazer com que o ar entre no ciclo provocando corrosão.

As soluções aquosas de $\mathrm{LiBr}$ são altamente corrosivas no cobre e no aço na presença de oxigênio. Mas assegurando boa hermeticidade no circuito, esses 
materiais são os mais usados em chillers de simples efeito. Também se pode colocar agentes inibidores de corrosão os quais geralmente são adicionados em porcentagens da ordem de $1 \%$ em peso. Para altas temperaturas no chiller, como por exemplo no gerador de um sistema duplo ou triplo efeito, o uso de ligas de metais de Co - Ni podem ser usadas. Aço inoxidável apresenta rachaduras na presença de soluções aquosas de LiBr a alta temperatura (Herold et al., 1996).

Os volumes específicos da água com baixa pressão são elevados, por exemplo, para uma pressão no evaporador de $1 \mathrm{kPa}$ o vapor saturado terá um volume específico de $129,2 \mathrm{~m}^{3} / \mathrm{kg}$. Com esse volume específico alto, as velocidades atingidas pelo vapor são altas, assim como também a perda de carga. Esse problema de perda de carga é mais perigoso na linha que vai do evaporador ao absorvedor e se se mantém à mesma temperatura no absorvedor (6) pode acontecer cristalização. Na prática, o evaporador e o absorvedor ocupam a mesma carcaça para reduzir o comprimento entre esses componentes e diminuir a perda de carga. Também é possível aumentar o diâmetro do tubo, diminuindo a velocidade do vapor para o mesmo efeito, porém o absorvedor terá um maior volume.

A manutenção nos chillers de absorção de $\mathrm{LiBr} / \mathrm{H}_{2} \mathrm{O}$ implica:

- Periodicidade para expulsar o ar do circuito (por exemplo, por uma bomba de vácuo).

- Periodicidade na adição de octan-1-ol (álcool octílico, $\mathrm{CH}_{3}\left(\mathrm{CH}_{2}\right)_{7} \mathrm{OH}$ ) para aumentar a taxa de transferência de massa no absorvedor.

- Periodicidade na adição de inibidores de corrosão.

Os procedimentos de manutenção são relativamente simples e as misturas químicas relativamente baratas.

Comparando o chiller por absorção de $\mathrm{LiBr} / \mathrm{H}_{2} \mathrm{O}$ com o de amônia/água, no evaporador o vapor de amônia tem um volume especifico baixo, com isso as tubulações para transferência de calor serão pequenas em comparação a água do chiller de $\mathrm{LiBr} / \mathrm{H}_{2} \mathrm{O}$. A amônia reage com o cobre, então os materiais comumente usados nos chillers de amônia/água são aço carbono e aço inoxidável, quando utilizado aço carbono inibidores de corrosão devem ser adicionados. Esses 
inibidores de corrosão reagem com as paredes internas do ciclo formando uma camada de óxido que protege o metal.

As pressões internas do chiller de absorção de amônia/água superam a pressão atmosférica, então o ar não pode ingressar no ciclo.

Pode-se ver na Tabela 2.4 algumas outras comparações dos chillers de amônia/água e de brometo de lítio/água. A maior vantagem do chiller por absorção de amônia/água é sua possibilidade de ser usado tanto na refrigeração como no condicionamento de ar e a maior desvantagem é sua complexidade de purificação do vapor de amônia úmido que sai do gerador. Outro fator negativo é seu baixo COP se comparado ao chiller de $\mathrm{LiBr} / \mathrm{H}_{2} \mathrm{O}$. Para atingir valores de $\mathrm{COP}$ semelhantes aos chillers de $\mathrm{LiBr} / \mathrm{H}_{2} \mathrm{O}$, tem que se reaproveitar fluxos de calor internos do ciclo e aumentar o número de trocadores de calor e trocadores de calor e de massa. Chillers por absorção de amônia/água tem aplicação residencial, mas devem ser posicionados em áreas ventiladas como prevenção de qualquer vazamento. A maior vantagem dos chillers de $\mathrm{LiBr} / \mathrm{H}_{2} \mathrm{O}$ é a não volatilidade do sal $\mathrm{LiBr}$ da solução aquosa de $\mathrm{LiBr}$, pois evita o uso de purificador de vapor refrigerante. Outra vantagem dos chillers de absorção de $\mathrm{LiBr} / \mathrm{H}_{2} \mathrm{O}$ é que a solução aquosa de $\mathrm{LiBr}$ precisa de menos fluxo de calor para evaporar água, assim o COP será maior, se comparado com o chiller de amônia/água. Entre as desvantagens no uso de chillers de $\mathrm{LiBr} / \mathrm{H}_{2} \mathrm{O}$ estão o limite de resfriamento no evaporador que deve ser superior a 0 ${ }^{\circ} \mathrm{C}$, o limite de solubilidade da solução aquosa de $\mathrm{LiBr}$ que provoca cristalização, os problemas de corrosão e sua periodicidade de manutenção. 
Tabela 2.4 - Tabela comparativa para os ciclos por absorção de amônia/água e de Brometo de Lítio/água.

\begin{tabular}{|c|c|c|}
\hline Característica & Ciclo $\mathrm{NH}_{3} / \mathrm{H}_{2} \mathrm{O}$ & Ciclo $\mathrm{LiBr} / \mathrm{H}_{2} \mathrm{O}$ \\
\hline Fluido refrigerante & Amônia & Água \\
\hline Temperatura de congelamento a 1 bar $\left({ }^{\circ} \mathrm{C}\right)$ & $-33,6$ & 0 \\
\hline \multicolumn{3}{|l|}{ Ponto triplo } \\
\hline Temperatura $\left({ }^{\circ} \mathrm{C}\right)$ & $-77,7$ & 0,01 \\
\hline Pressão (bar) & 0,06 & 0,006 \\
\hline Toxicidade & $\begin{array}{c}\text { Tóxica em } \\
\text { concentrações acima de } \\
70 \text { ppm }\end{array}$ & Não tóxica \\
\hline Fluido absorvente & Água & Brometo de Lítio aquoso \\
\hline Volatilidade & Volátil & Não volátil (LiBr) \\
\hline Toxicidade & Não tóxica & Não tóxica \\
\hline Cristalização & Não & Sim \\
\hline Pressão no condensador (bar) & $12-18$ & 0,075 \\
\hline Pressão no evaporador (bar) & $1,5-4$ & 0,0067 \\
\hline Aplicação & $\begin{array}{l}\text { Refrigeração e ar } \\
\text { condicionado }\end{array}$ & Ar condicionado \\
\hline COP (simples efeito) ${ }^{\star}$ & $\sim 0,5$ & $0,7-0,8$ \\
\hline Materiais de construção & Aço carbono, aço inox. & Aço carbono, cobre \\
\hline
\end{tabular}

Nos chillers por absorção amônialágua o número de dispositivos de transferência de calor e transferência de calor e de massa é maior que os de $\mathrm{LiBr} / \mathrm{H}_{2} \mathrm{O}$, porém nestes ciclos, os componentes são maiores devido a baixos coeficientes de troca de massa e também devido ao alto volume especifico do vapor de água a baixas pressões. Pode-se ver na Fig. 2.10 as das dimensões de chillers por absorção de $\mathrm{LiBr} / \mathrm{H}_{2} \mathrm{O}$ de 4,6 TR e de amônia/água 5 TR (as medidas estão em milímetros). Nota-se que o chiller de amônia/água é menor. 


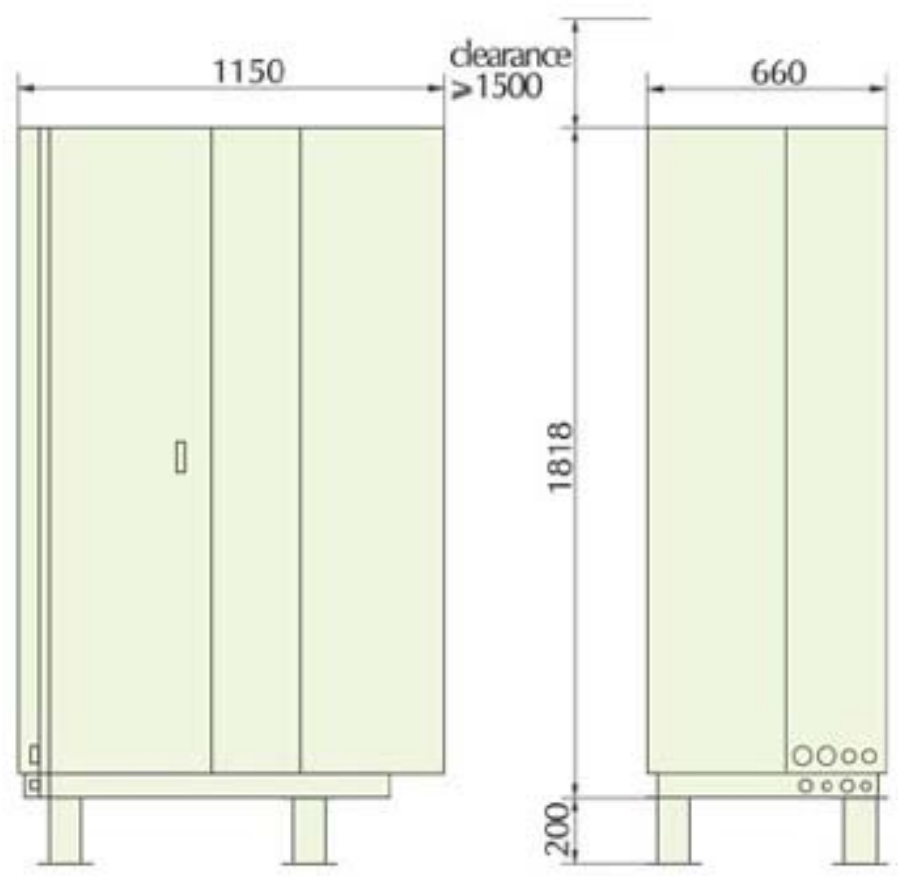

(a)
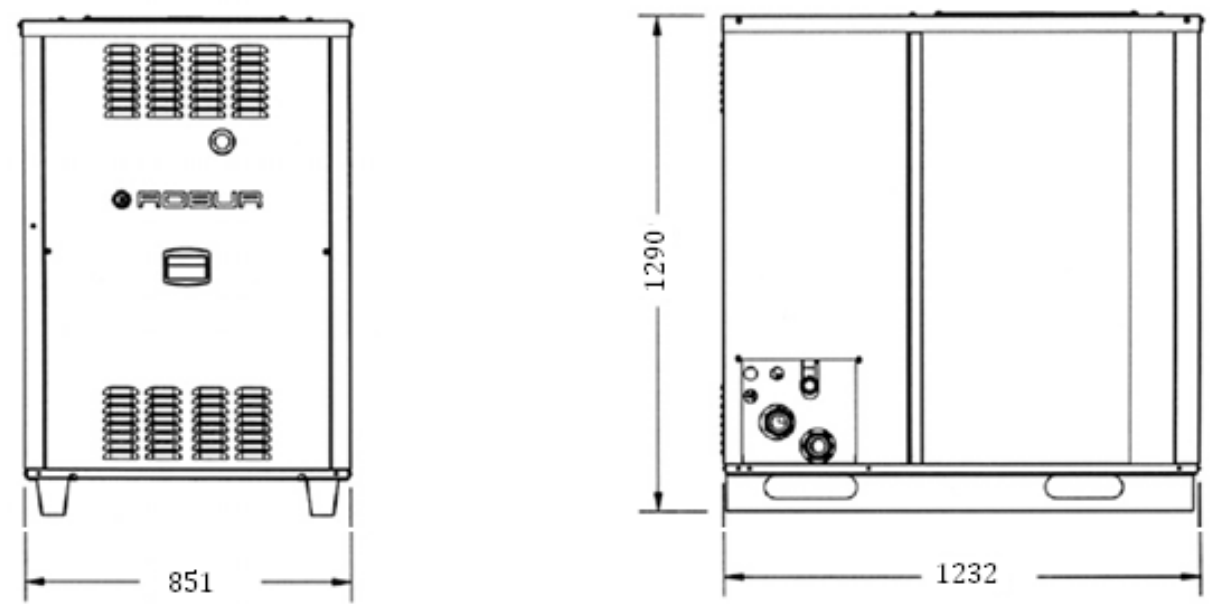

(b)

Figura 2.10 - (a) chiller por absorção de $\mathrm{LiBr} / \mathrm{H}_{2} \mathrm{O}$ de 4,6 TR (Tuma, 2009),

(b) chiller por absorção de amônia/água de 5 TR (Robur, 2009).

Considerando que a amônia pode ser usada tanto para ar condicionado quanto para refrigeração, se estuda neste trabalho este sistema por absorção de amônia/água. 


\subsubsection{Comparação no uso dos chillers por absorção com chillers por compressão de vapor}

Entre os métodos para refrigeração e condicionamento de ar, os ciclos de refrigeração por compressão de vapor são os mais usados, já que seu custo inicial é menor e seu coeficiente de eficácia é maior quando comparado aos chillers por absorção. Na Fig. 2.11 são mostrados os componentes básicos de um ciclo por compressão a vapor.

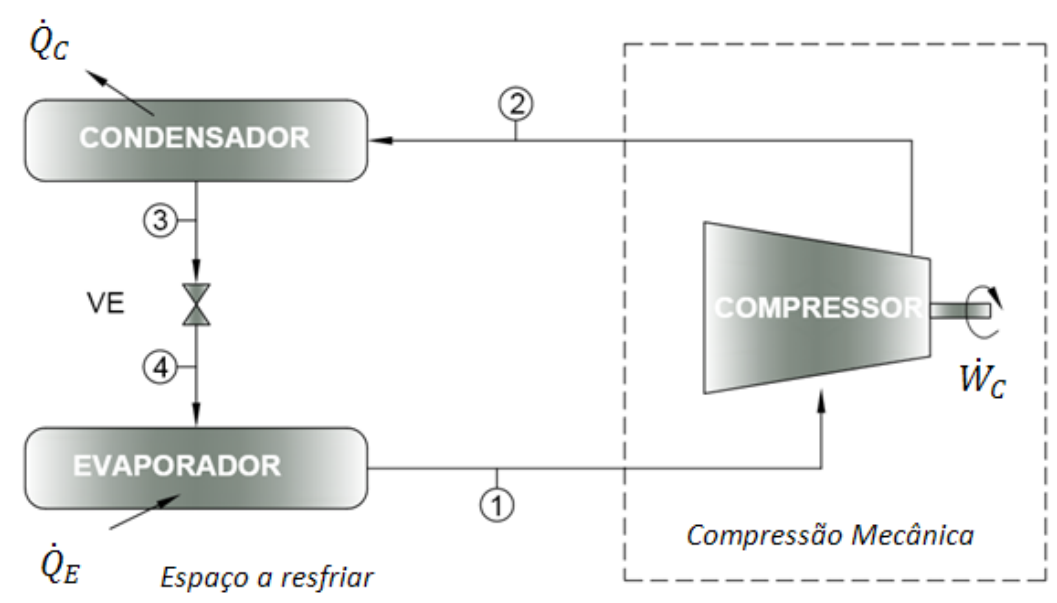

Figura 2.11 - Componentes básicos de um ciclo de refrigeração por compressão.

O vapor sai do evaporador a baixa pressão e temperatura, depois passa pelo compressor aumentando sua pressão. O condensador resfria esse vapor até torná-lo líquido, em seguida esse líquido passa pela válvula reduzindo drasticamente sua pressão e temperatura até a condição de mistura bifásica. No evaporador, o ambiente resfriado é acompanhado da evaporação do líquido refrigerante com baixa temperatura e pressão. A temperatura e pressão do vapor aumentam por compressão mecânica, e o ciclo reinicia-se.

A refrigeração por compressão a vapor pode ser um método eficiente, mas o trabalho de eixo de compressão é alto, precisando então de muita energia elétrica para produzí-lo. Além disso, as energias comparativas para o cálculo do coeficiente de eficácia referem-se a qualidades diferentes como pode ser visto na Fig. 2.12. Nesta figura, vê-se que a energia "motriz" do ciclo de compressão é a energia elétrica, que é produto de um processo de transformações de energias e perdas das 
mesmas até chegar ao compressor. Também é grande o número de equipamentos de transformação e transporte de energia. Já a energia motriz do chiller por absorção, é mais direta se comparada à energia elétrica.

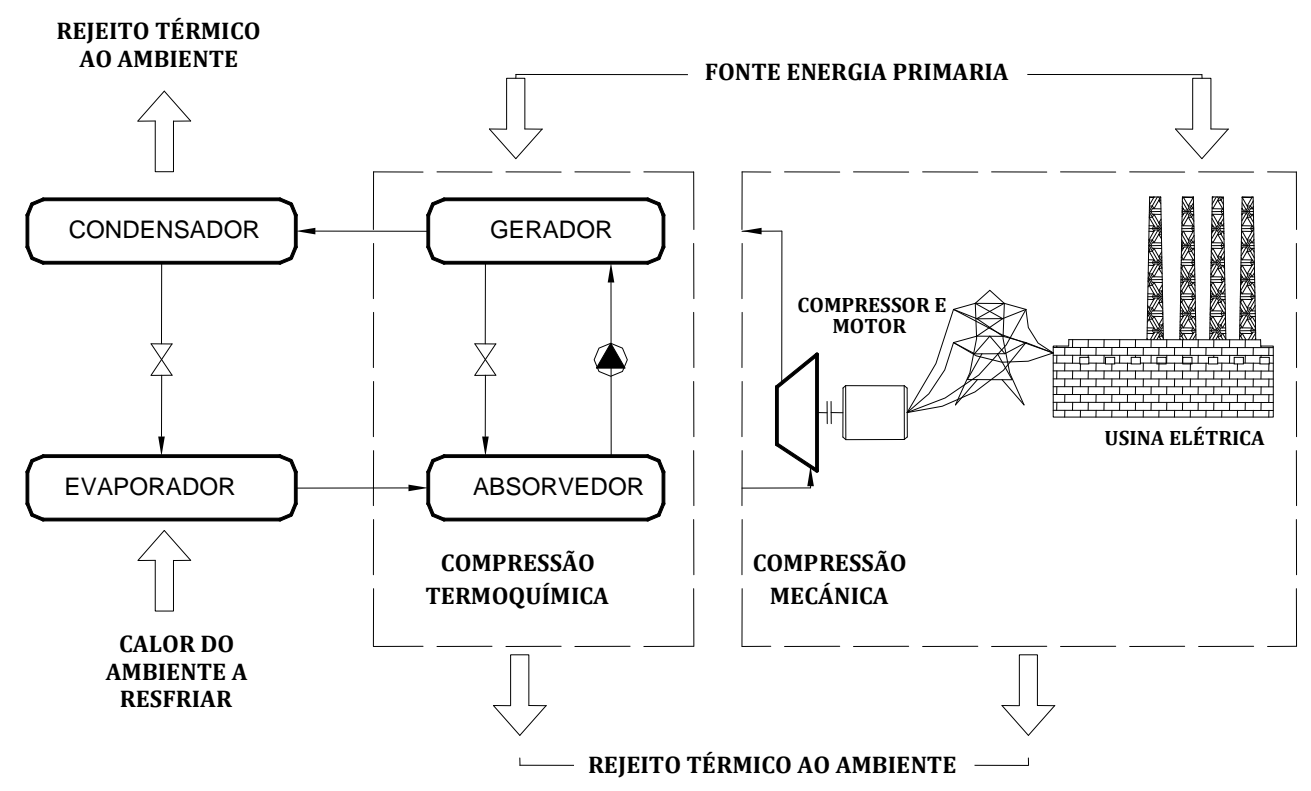

Figura 2.12 - Fonte de energia para o acionamento dos ciclos de refrigeração (Adaptado da ASHRAE, 1994).

Um chiller por compressão de vapor possui muitas peças móveis gerando assim um aumento significativo na sua manutenção no decorrer dos anos. A vida útil esperada desses chillers é de 10 a 15 anos (Tuma, 2009).

$\mathrm{Na}$ medida do uso apropriado de energia, grande importância tem sido dada aos sistemas de refrigeração por absorção como alternativa aos ciclos de compressão mecânica a vapor. A bomba de solução, o gerador e o absorvedor constituem um "compressor termoquímico" como mostrado na Fig. 2.12. Os ciclos de refrigeração por absorção não geram outro ruído além da bomba de solução, consomem pouca energia elétrica e podem operar por meio de rejeitos térmicos, por queima direta de gás natural ou outro tipo de combustível, por uso de energia solar, entre outras. Estes ciclos de refrigeração podem também atender as demandas de frio em localidades ou residências isoladas com uso de energia solar para aquecer o gerador, serem utilizados em embarcação pesqueira para resfriar peixes 
(Fernández-Seara et al., 1998), aplicados em plataformas offshore, entre outros. Estes ciclos de refrigeração tem somente a bomba de solução como componente móvel e por isso a vida útil gira em torno de 20 anos (Herold et al.,1996; ASHRAE, 1994).

Os baixos coeficientes de eficácia nos chillers por absorção são o resultado da grande quantidade de energia térmica que deve ser abastecida ao gerador para produzir vapor refrigerante. Assim, são necessárias inovações em projetos de chillers de absorção para viabilizar um baixo consumo energético. Embora o fluxo de calor que ingressa no gerador possa ser mais alto do que a energia requerida para compressão mecânica, se a fonte de calor é suficientemente barata, o ciclo de absorção pode ser atrativamente econômico. A energia elétrica consumida num chiller por absorção é muito pequena, num ciclo de refrigeração por absorção que trabalha com pressão alta de 12,5 bar e baixa de 2 bar, a bomba de solução pode consumir até 90 vezes menos energia do que se usada a compressão mecânica por cada quilograma de amônia comprimida (Kuehn et al., 1998).

Felamingo (2007) comparou chillers por absorção e compressão, estudando a viabilidade econômica de substituir um chiller por compressão em uso, pela compra de um chiller por absorção. Na Tabela 2.5 mostram-se os principais parâmetros nessa comparação. Na Fig. 2.13 mostra-se o gráfico do break-even levando em consideração o investimento inicial, energia consumida, operação, manutenção, gastos com água de reposição na torre de resfriamento. O ponto de equilíbrio acontece nos quatro anos e meio, o que torna viável o sistema proposto, embora o chiller apresente um COP baixo (por ser um sistema de simples efeito). Assim, tornase economicamente viável. Na experiência desenvolvida pelo autor, ele indica que a substituição do chiller por compressão por um de absorção torna-se economicamente viável nas capacidades de refrigeração acima de 150 TR. O estudo deste caso tem objetivo comercial. 
Tabela 2.5 - Parâmetros para a comparação: chillers por absorção e compressão.

\begin{tabular}{cccccc}
\hline Tipo de Chiller & COP & $\begin{array}{c}\text { Investimento } \\
\text { inicial* } \\
\left(\mathbf{R} \$ \times 10^{3}\right)\end{array}$ & $\begin{array}{c}\text { Capacidade } \\
\text { (TR) }\end{array}$ & & \multicolumn{2}{c}{$\begin{array}{c}\text { Água Cond. (Compressão) } \\
\text { Água Cond/Abs (Absorção) }\end{array}$} \\
\cline { 5 - 6 } & & 714 & 122 & 7,0 & 128 \\
\hline Absorção & 0,7 & 0 & 122 & 5,5 & 88 \\
\hline Compressão & 3,5 & 0 & & \\
\hline
\end{tabular}

* Chiller, bomba, tubulação, entre outros.

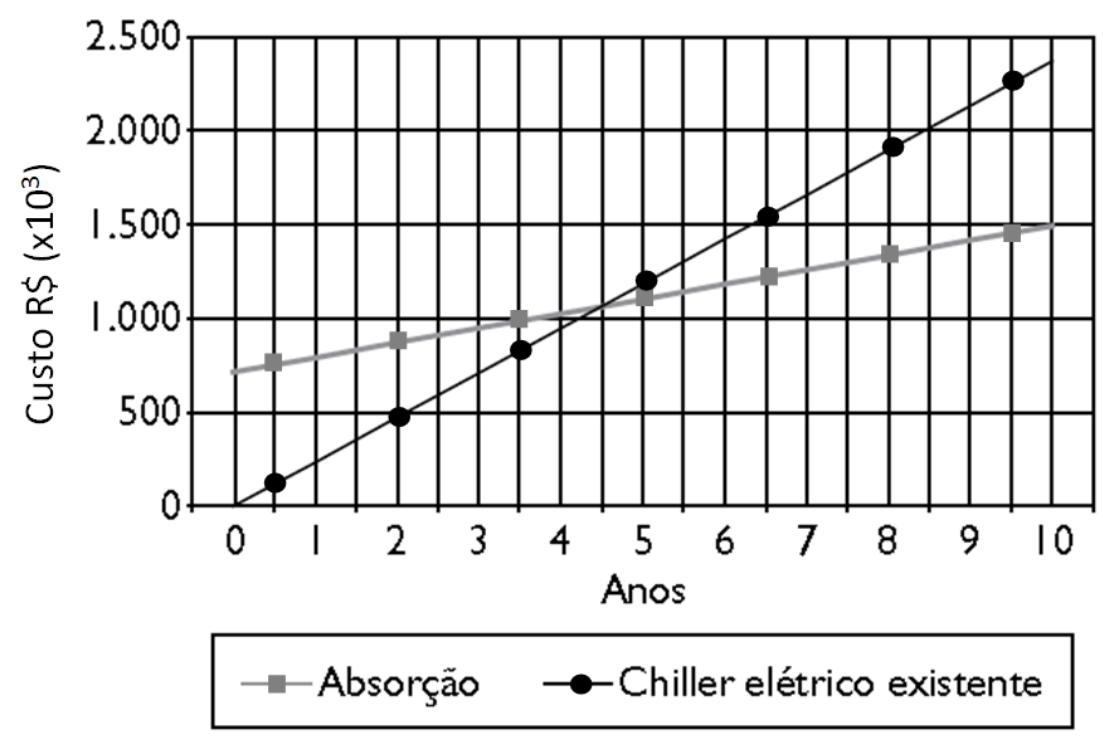

Figura 2.13 - Gráfico de break-even na substituição de um ciclo de refrigeração por compressão por um de absorção (Felamingo, 2007).

Como indicado na seção de Introdução, os refrigerantes dos chillers por compressão sempre trazem algum dano, seja no aquecimento global seja na redução da camada de ozônio, os refrigerantes dos chillers por absorção não trazem contaminação ao ambiente. Pode se concluir, então, que embora os chillers por compressão tenham melhor COP e menor custo inicial, os chillers por absorção são técnica e economicamente viáveis quando existem fontes de calor baratas. Torna-se necessário então conhecer ao máximo o modo de funcionamento desses chillers visando seu projeto mais barato e um consumo menor de energia. Atualmente no Brasil não se constrem chillers de absorção de amônia/água, que têm um grande potencial de aplicação na área de cogeração, o que motiva este trabalho. 


\subsection{DESTILAÇÃO}

Destilação é um processo de separação física de uma mistura em dois ou mais produtos que possuem diferentes pontos de vaporização por meio de fornecimento de fluxo de calor. Quando uma solução líquida de dois componentes é aquecida, o vapor produzido terá maior concentração do componente mais volátil (baixo ponto de vaporização), também terá maior concentração que a solução líquida da qual foi produzida. E se o vapor for resfriado, o componente menos volátil tem a tendência a se condensar em maior quantidade que o componente mais volátil. Esse processo é o mais amplamente usado na indústria química (Foust, 1982; Kister, 1992).

Os primeiros trabalhos em destilação foram feitos na China, no terceiro milênio a.C., depois na Índia, Egito, Grécia e outros. Mais tarde, essa arte foi adquirida pelos alquimistas, que procuravam "a pureza das coisas". Uma das primeiras substâncias produzidas foi o "líquido dos deuses", que depois foi chamado de al-kohul (álcool) pelos árabes. Um esquema básico do processo da destilação antiga é mostrado na Fig. 2.14, a qual mostra um alambique.

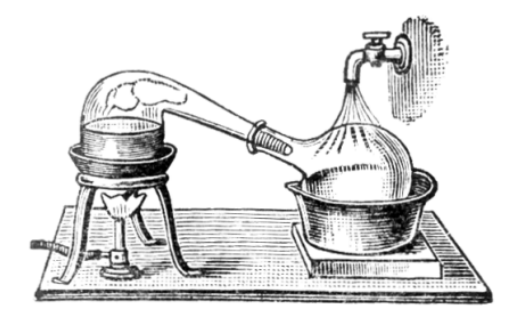

Figura 2.14 - Alambique.

As primeiras aplicações de destilação usavam equipamentos primários de condensação e evaporação para destilar bebidas alcoólicas. O processo de destilação foi aplicado depois a outras áreas importantes, como a indústria do petróleo e a indústria química (Locket, 1986). A primeira coluna de destilação contínua foi desenvolvida em 1813, por Cellier-Blumenthal, na França. Em 1822, a primeira versão de pratos com bubble-cap foi introduzida por Perrier na Inglaterra. A tecnologia de recheio já era usada pelo tecnólogo Clement, antes de 1820. Clement usou bolas de vidro na destilação de bebidas alcoólicas. Coffey, em 1830, 
desenvolveu a primeira coluna com pratos perfurados. O primeiro livro que relata os fundamentos de destilação foi ainda publicado em 1893 por Ernest Sorel, chamado "La Rectification de'l alcohol" (Kister, 1992).

Será explicado na sequência o processo de destilação e para isso abordar-seá primeiramente o conceito de estágio ideal.

Um estágio ideal é um dispositivo de transferência de calor e de massa que opera em regime permanente e que tem como produtos vapor e líquido. No estagio ideal, as fases líquida e vapor conseguem contato íntimo por um período de tempo suficiente para que seus efluentes líquido e vapor atinjam equilíbrio termodinâmico (igual pressão, temperatura e concentrações de equilíbrio). São apresentados na Fig. 2.15 os dispositivos que podem ser considerados como estágios ideais.

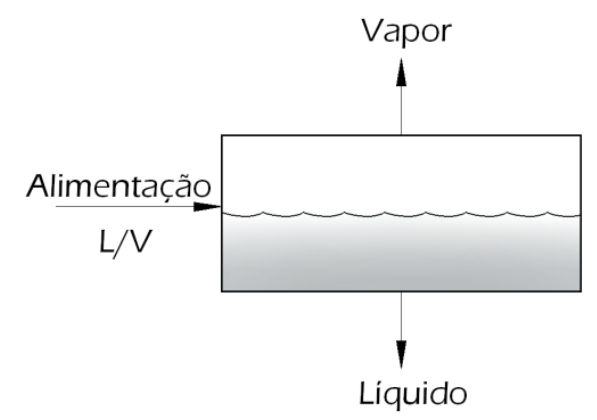

(a)

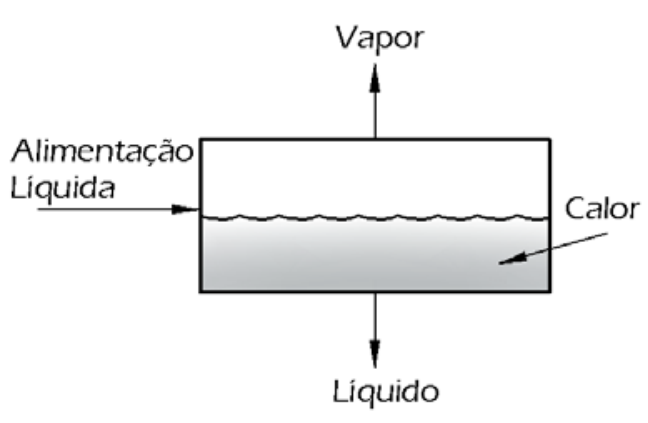

(b)

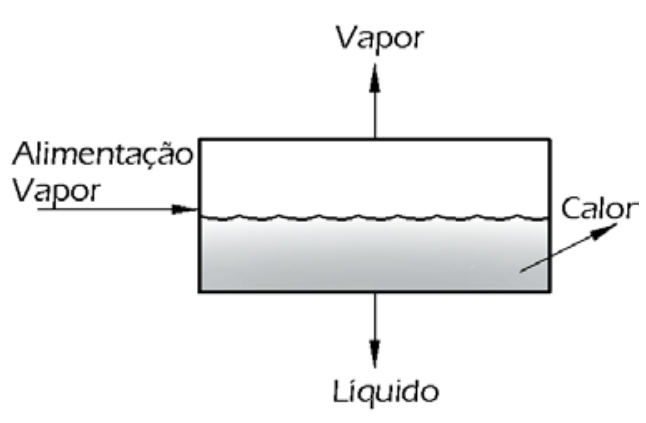

(c)

Figura 2.15 - Estágios ideais. (a) estágio geral, (b) com adição de fluxo de calor, (c) com retirada de fluxo de calor.

No caso de uma mistura amônia/água, o vapor que sai do estágio é mais concentrado em amônia que a solução de alimentação e o líquido que sai dele terá maior concentração em água que a solução de alimentação. Então, podem ser 
usados múltiplos estágios para atingir concentrações de amônia no vapor cada vez maiores. O processo de geração de vapor de amônia com alto grau de pureza (ou refinação) pode ser realizado numa coluna de destilação (ou fracionador), a qual é um sistema de vários componentes, como mostrado na Fig. 2.16, entre eles podemos mencionar:

- Gerador de vapor (ou refervedor)

- Seção de esgotamento (abaixo do ponto de alimentação)

- Seção de enriquecimento (acima do ponto de alimentação)

- Retificador (ou condensador parcial)

- Acumulador (ou tanque de refluxo ou câmara de nivelamento)

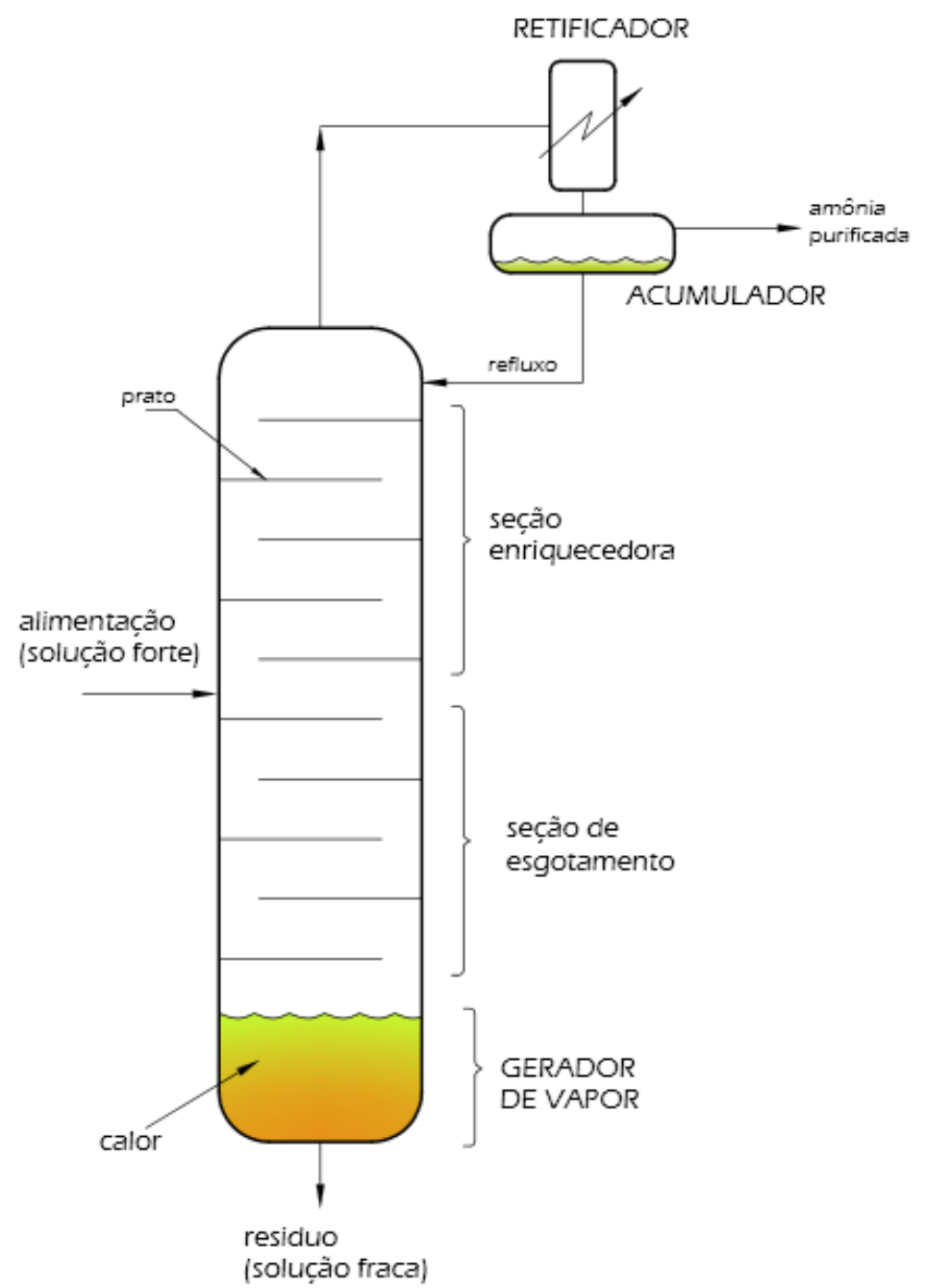

Figura 2.16 - Coluna de destilação. 
Tanto o gerador quanto os estágios da seção de esgotamento são chamados estágios de esgotamento, os quais concentram no líquido o fluido menos volátil. O vapor é produzido no gerador como resultado do fornecimento de fluxo de calor e, ao sair dele, sobe, vaporizando no líquido dos estágios seguintes o componente mais volátil.

Aos estágios da seção de enriquecimento e ao retificador/acumulador são chamados estágios de enriquecimento, os quais concentram no vapor o componente mais volátil. O refluxo líquido é produzido no retificador como resultado do rejeito de fluxo de calor ao ambiente, retornando à coluna, onde condensa o fluido menos volátil do fluxo de vapor.

A coluna de destilação trabalha de forma contínua e as seções de esgotamento e de enriquecimento são um sistema multiestágio em contracorrente líquido-vapor. Kuehn et al. (1998) entre outros autores chamam às seções de enriquecimento e esgotamento como analisador.

No ciclo de refrigeração por absorção tipo GAX mostrado na Fig. 2.17 (ver também Fig. 2.5), a alimentação da coluna de destilação é realizada com a solução forte que vem de um processo de absorção e bombeamento para aumentar sua pressão.

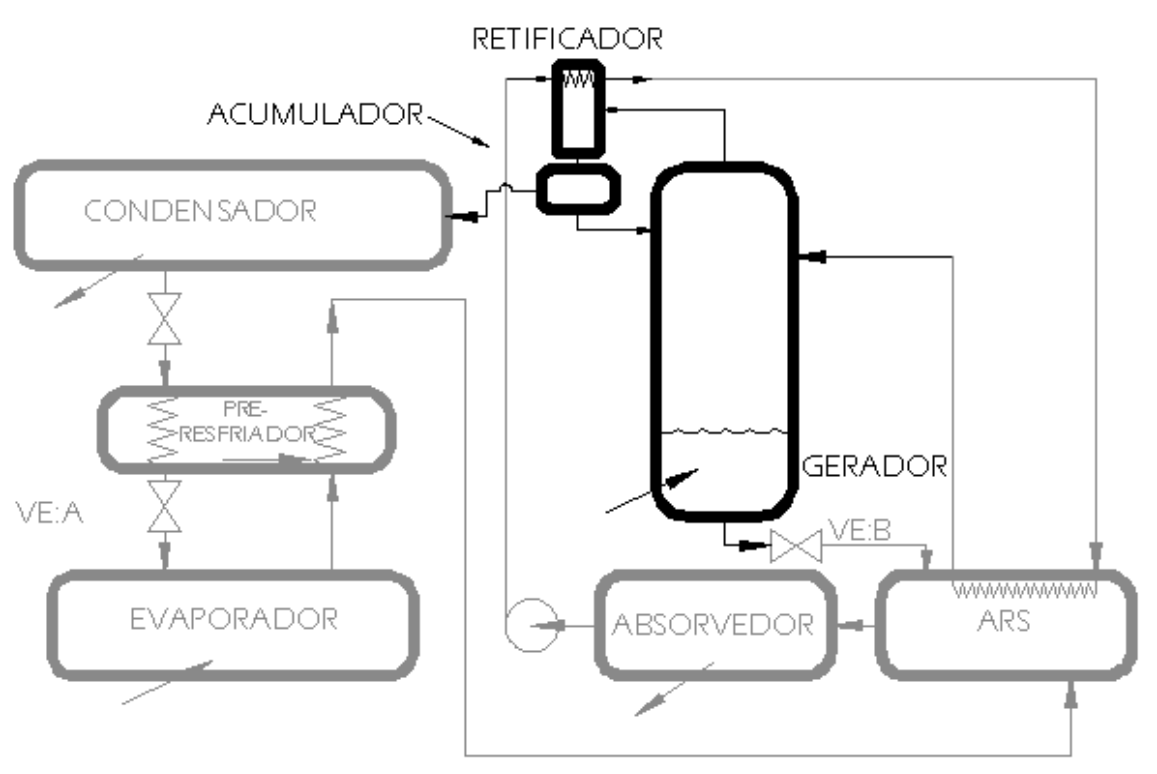

Figura 2.17 - Coluna de destilação (em cor preta) no ciclo de refrigeração por absorção. 
Esta solução forte, ao descer pela coluna, transfere calor e massa com o vapor que foi produzido no gerador, desta forma a solução líquida sai da coluna com pouca quantidade de amônia. Ao chegar ao topo da seção de enriquecimento o vapor ainda terá um pouco de água, então um processo de retificação num condensador parcial deve ser feito. No retificador, a água é condensada. No acumulador, as fases líquida e vapor são separadas. Como resultado do processo de destilação o produto obtido é chamado destilado que, neste caso, é vapor saturado de amônia purificada. A solução líquida que sai do acumulador retorna à coluna em forma de refluxo.

\subsubsection{Enchimentos usados em colunas de destilação}

Os enchimentos usados em colunas de destilação são pratos (ou bandejas) e recheios. No mercado existem muitos tipos de pratos entre os quais se pode mencionar: pratos com borbulhador, prato perfurado e prato com válvula. O prato com borbulhador é mostrado na Fig. 2.18(a) e o borbulhador na Fig. 2.18(b).

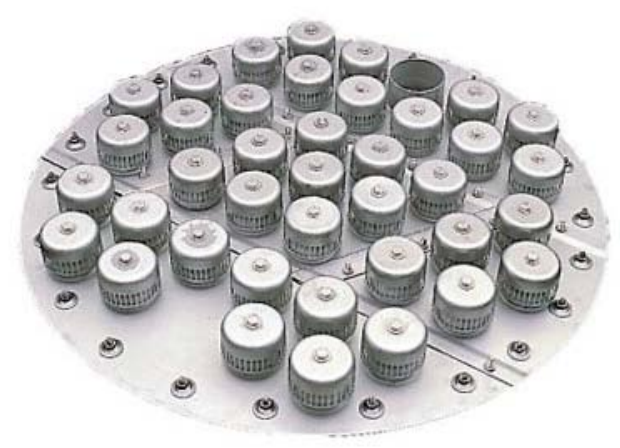

(a)

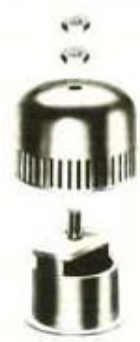

(b)

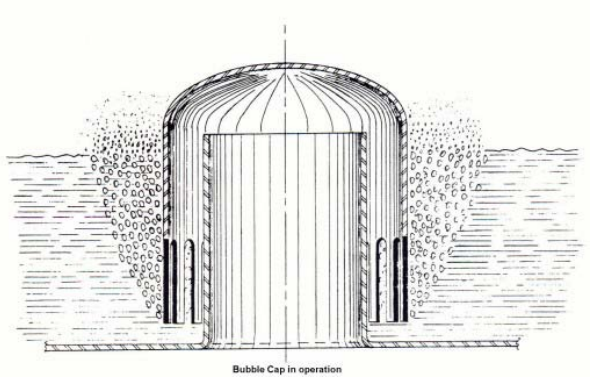

Figura 2.18 - (a) Prato com borbulhador, (b) borbulhador.

Quando o vapor tem baixa velocidade, os borbulhadores impedem que o líquido desça pelos espaços onde o vapor sobe.

O prato perfurado, mostrado na Fig. 2.19, é o mais popular por sua simplicidade e baixo custo, porém menos eficiente do que os pratos com borbulhador. 


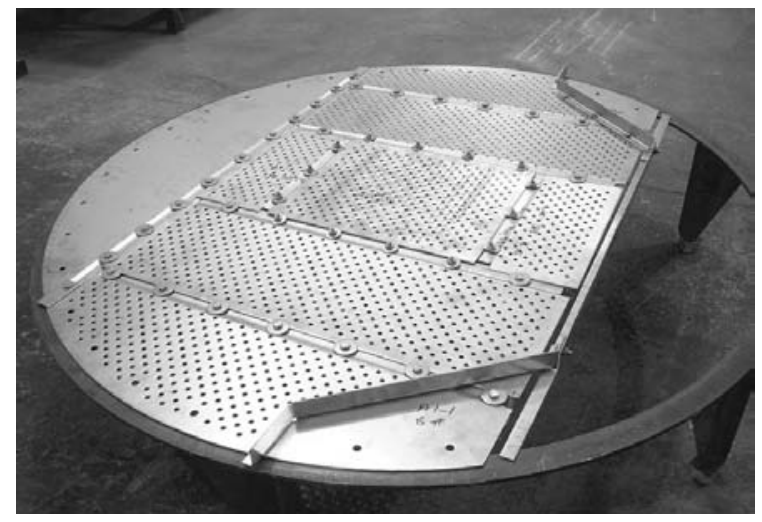

(a)

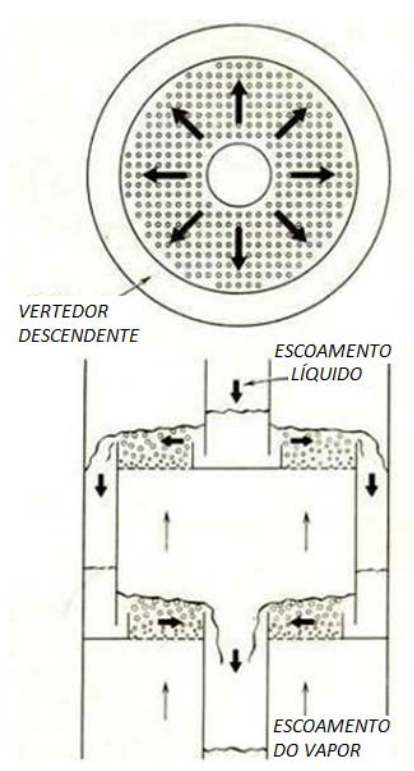

(b)

Figura 2.19 - Prato perfurado. (a) com fluxo cruzado (b) vertedor circular.

O diâmetro de cada orifício dos pratos perfurados é usualmente $1 / 8$ " a $1 / 2$ " (3,2- 12,7 mm), Foust, et al. (1982).

A bandeja valvulada apresenta uma modificação moderna dos pratos perfurados. Na Fig. 2.20 é mostrada uma bandeja valvulada fixa, embora existam também bandejas valvuladas com opérculos móveis, as quais são mais caras, porém com melhor desempenho.

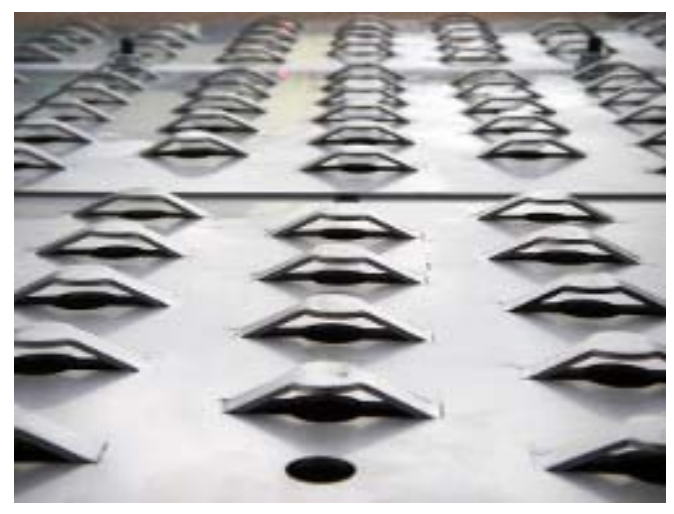

Figura 2.20 - Prato ou bandeja valvulada. 
O diâmetro no orifício da bandeja valvulada é maior do que o prato perfurado e atingem até 1 1/2" (38 mm). As velocidades dos escoamentos de líquido e vapor usados nestes pratos podem ser maiores que nos perfurados. O custo dos pratos valvulados fica entre os pratos com borbulhador e os pratos perfurados.

Outro tipo de enchimento usado em colunas de destilação são os recheios, os quais podem ser aleatórios ou estruturados. Os recheios aleatórios são jogados na coluna sem ter uma ordem de colocação. Já os recheios estruturados têm uma configuração fixa na coluna. Existe uma grande variedade em materiais, dimensões e formas de recheio os quais suprem uma ampla extensão de condições de trabalho. O uso do tipo de material no recheio depende das condições e dos fluidos de trabalho no processo de destilação já que esses elementos de transferência de calor e de massa devem ser quimicamente inertes ao processo. Alguns materiais e características dos recheios são citados a continuação:

- Cerâmica. É frágil, tem grande espessura, portanto alta perda de carga.

- Grês (rocha formada por grãos de quartzo). Tem menor espessura que os materiais cerâmicos, mas ainda apresenta perda de carga considerável.

- Metal. Tem menor perda de carga, pode acontecer oxidação, entretanto o uso de aço inoxidável pode eliminar esse problema.

- Polipropileno. Materiais não muito caros, leves, resistente à oxidação, não tem resistência à alta temperatura, sua característica de molhabilidade é baixa.

São mostrados na Fig. 2.21 alguns tipos de recheios. Os anéis "raching" (Fig. 2.21(a)) são os mais simples e baratos, porém os menos eficientes. Estes anéis quando maiores que $75 \mathrm{~mm}$ podem ser colocados vertical e ordenadamente para aumentar a eficiência de separação e menor perda de carga. Junto aos anéis "raching", as selas "berl" (Fig. 2.21(b)) são os recheios mais antigos. As selas "berl" têm o formato simétrico e se assemelham a uma sela, são mais fáceis de agrupar que os anéis "raching", o que proporciona uma maior superfície de contato por unidade de volume. Esses dois primeiros tipos de recheios têm sido substituídos gradualmente por recheios mais eficientes. Os anéis "Pall", mostrados na Fig. 2.21(c), são os recheios mais usados na destilação, por sua grande eficiência, flexibilidade e capacidade. 


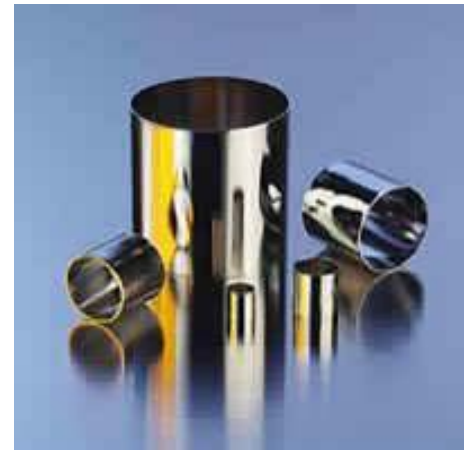

(a)

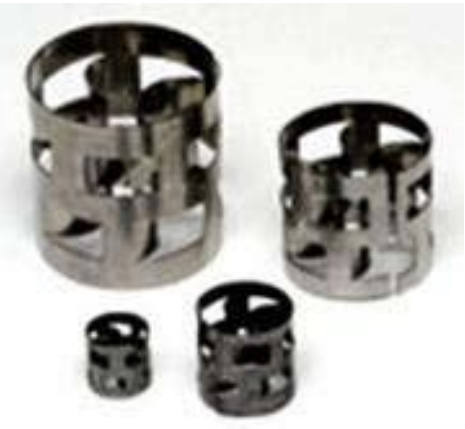

(c)

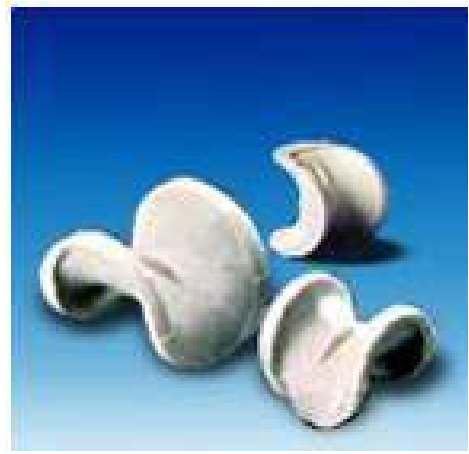

(b)

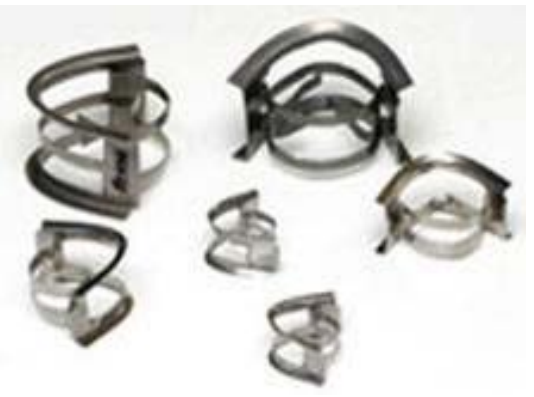

(d)

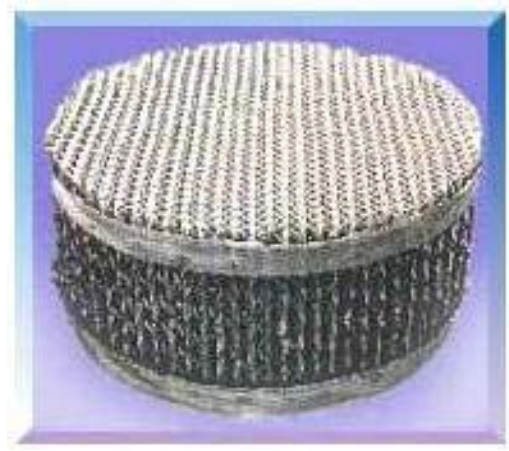

(e)

Figura 2.21 - Recheios aleatórios (a) anéis raching, (b) selas "berl", (c) aneis "pall", (d) IMTP, (e) recheio estruturado.

O recheio tipo IMTP (Intalox Metal Tower Packing), Fig. 2.21(d), que foi patenteada pela empresa Norton, é considerado mais eficiente que o anel "Pall" e são feitos em até seis tamanhos (15 a 70), sendo que o menor proporciona uma maior eficiência e o maior obterá uma menor perda de carga. O IMTP pode ser usado apresentando vantagens em processos como destilação a vácuo de petróleo, sistemas espumantes, fracionamentos criogênicos e outros. Em verdade, nenhum dos recheios possui todas as qualidades desejáveis. Os recheios estruturados (Fig. 
2.21(e)) têm melhores eficiências de separação e em geral menor perda de carga que os aleatórios, são recheios muito caros.

A seguir compara-se o desempenho dos pratos e dos recheios:

- Geralmente recheios trabalham melhor com fluxos baixos. As colunas de pratos podem trabalhar com escoamento maior de líquidos, com menos risco de ser inundada.

- A baixa queda de pressão em recheios estruturados faz com que seu uso seja eficiente em colunas de vácuo.

- Na parte superior da coluna de recheio é usado distribuidor de líquido (Fig. 2.22) para proporcionar uma distribuição uniforme do líquido de alimentação e diminuir o problema de caminhos preferenciais no recheio.

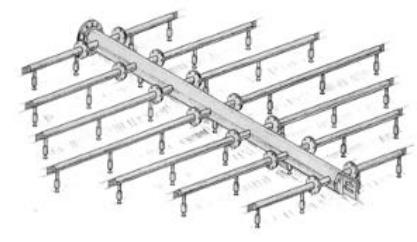

Figura 2.22 - Distribuidor de Líquido.

- Com altos fluxos e alta pressão os pratos trabalham melhor.

- A mistura e a separação das fases líquida e vapor no prato propiciam uma melhor troca de massa. Nas colunas recheadas corre-se o risco de formação de canais preferenciais ou misturar-se novamente.

- A limpeza das colunas de pratos é mais fácil se comparada à do recheio.

- Múltiplas entradas e saídas são mais flexíveis nas colunas de pratos.

- Os recheios são dispositivos eficientes e a queda de pressão do vapor através deles é baixa, porém, os pratos são mais baratos.

Nesse trabalho, optou-se por pratos perfurados já que apresentam um projeto simples, além de serem mais baratos, sua limpeza interna é mais efetiva, sua queda de pressão do vapor é a menor se comparada aos outros pratos e satisfazem a maioria das aplicações. Essa limpeza é importante, porque o ciclo de refrigeração por absorção uma vez cheio de solução amônia/água deverá ser lacrado por 
completo e a coluna de destilação pode ser um componente de acumulação de restos de metal.

\subsection{ESTADO DA ARTE DOS SISTEMAS DE PURIFICAÇÃO AMÔNIAIÁGUA}

Ahachad et al. (1992) estudaram um ciclo de refrigeração por absorção de amônia/água de simples efeito (ver Fig. 2.1) porém, sem coluna de purificação e sem retificador com o objetivo de fazer um chiller de fabricação mais simples. Este chiller de absorção foi fabricado e adicionaram um borbulhador depois do gerador para purificar a amônia. Compararam os resultados desse estudo com um ciclo de refrigeração por absorção sem borbulhador, usando para os dois casos coletores solares para o aquecimento do gerador. Os resultados da comparação mostraram que o COP foi melhorado de $15 \%$ a 35 \% no chiller de absorção com borbulhador e que a área necessária dos coletores solares foi menor (10 \%) para o mesmo requerimento de refrigeração. Entretanto, mesmo com borbulhador os COP's obtidos foram baixos, o maior foi de 0,4.

O projeto de torres de destilação é crítico no desempenho do sistema de refrigeração. Uma coluna de destilação pode ser projetada com enchimento de recheio (aleatório ou estruturado) ou de pratos. A coluna de destilação com pratos perfurados é uma das menos complexas em projeto e também menos custosa do que as de recheio estruturado (Anand e Erickson, 1999). Trabalhos como Bogart (1982), Herold et al. (1996) e Kuehn et al. (1998) mostram apenas conceitos para projetos em colunas de purificação para sistemas de refrigeração por absorção, mas não fazem análise de desempenho nem metodologia do projeto. A análise de desempenho de parâmetros como refluxo, entrada de solução forte e fluxos de calor envolvidos no gerador não são abordadas no trabalho de Anand e Erickson (1999), que estudaram uma coluna de destilação de pratos perfurados de um ciclo de refrigeração por absorção de amônia/água de 8 TR. Os autores deram ênfase a parâmetros de projeto como prevenção de inundação, vazamentos pelos furos do prato e geométrica da coluna.

Sieres et al. (2008) fizeram uma análise experimental de uma coluna de destilação que tinha como enchimento anéis do tipo "Pall" de aço inoxidável de 10 
$\mathrm{mm}$ que trabalhava com amônia/água. Eles mediram a temperatura, a concentração e a vazão em várias partes do sistema e analisaram o desempenho do coeficiente da transferência de massa, assim como, a altura necessária para purificação usando várias condições de trabalho como o fluxo de calor no gerador, pressão do sistema e refluxo. Seus resultados foram comparados com o estudo experimental de Sieres e Fernández-Seara (2007) a fim de encontrar a altura necessária para a mesma condição de pureza de vapor de amônia na saída da coluna com recheio tipo:

- selas "Berl" 1/2" de cerâmica,

- anéis "Raching" $15 \mathrm{~mm}$ de vidro e

- selas "Novalox" $1 / 2$ " de cerâmica.

Achou-se que a utilização de recheio tipo "Pall" reduzia a altura da coluna de 2,5 a 3 vezes comparado com os outros recheios. O experimento de Sieres e Fernández-Seara (2007) foi realizado, visando à necessidade de equipamentos de refrigeração que trabalhassem com pequenas cargas e que tivessem como fonte de calor energia solar ou sistemas de cogeração. Com o fluxo de calor fornecido ao gerador e com um COP de sistemas de simples efeito típico de 0,5, nesta experiência, a carga de refrigeração foi sempre menor que $1 T R$.

No mercado, recheios estruturados são encontrados em várias geometrias, materiais e tamanhos. Sieres et al. (2009), estudaram o desempenho do recheio estruturado corrugado de aço inoxidável "Mellapak Plus" 752.Y. As condições do protótipo de teste e condições de operação experimentais foram muito similares com o trabalho feito em Sieres et al. (2008). Em estudos anteriores Fernández-Seara et al. (2002) mostraram que no processo de purificação de amônia na coluna de destilação a fase vapor controla a transferência de massa, isso quer dizer que a maior resistência à transferência de massa será na fase vapor e que na fase líquida a amônia será difundida com facilidade. Logo, o coeficiente de transferência de massa na fase vapor toma importância nos seus trabalhos posteriores. No trabalho de Sieres et al. (2009) vê-se comparações com outros resultados experimentais do coeficiente volumétrico de transferência de massa, nas quais mostram grandes diferenças. $O$ autor justifica essa discrepância pelas condições de trabalho diferentes, como por exemplo, a pressão de operação ser de vácuo ou atmosférica e nos sistemas de refrigeração por absorção com amônia/água essa pressão ser em 
torno de 20 bar. Dado um requerimento de purificação, foram comparadas as alturas necessárias tanto para "Mellapak Plus" 752.Y quanto para os recheios utilizados no trabalho de Sieres et al. (2008) e concluiu que os anéis "Pall" forneciam uma menor altura, inclusive com relação aos recheios estruturados "Sulzer" BX, outro recheio analisado neste trabalho.

Mendes (2008) comparou experimentalmente dois modelos de purificação de amônia para um ciclo de refrigeração por absorção de amônia/água. O primeiro modelo consistiu em uma coluna de pulverização por bicos com ângulo de dispersão de $45^{\circ}$ e o segundo, por sua vez, possuía enchimento de selas "Novalox" de 1/2"; as eficiências de purificação foram de $90 \%$ e $97 \%$ e as frações em massa conseguidas chegaram a [0,9754 - 0,9903] e [0,9825 - 0,9912] respectivamente. A autora concluiu que as dimensões para as mesmas condições de purificação foram menores para a coluna de enchimento do que para a coluna de pulverização.

Existe uma importante quantidade de literatura que trata de sistemas de destilação, mas a maioria delas aborda o fracionamento de petróleo nas refinarias, produção de álcool e bebidas alcoólicas, entre outras. Treybal (1981), Bennett e Myers (1978), entre outros, apresentam um estudo geral de sistemas de contato líquido-gás, líquido-líquido e sólido-líquido. Para o caso de torres de destilação, esses autores citam dois métodos para sua análise: Ponchon-Savarit e McCabeThiele e apontam o primeiro método como mais rigoroso, já que o outro faz muitas simplificações, como considerar constantes as vazões de líquido e vapor. Bogart (1982) indica o método de McCabe-Thiele como impreciso.

Neste trabalho os balanços de massa e energia na coluna de destilação serão analisados usando o método de Ponchon-Savarit.

\subsection{NECESSIDADE DE PURIFICAÇÃO}

Nas substâncias puras o processo de evaporação de um líquido saturado se dá à temperatura constante. Essa propriedade é vantajosa porque no evaporador é necessário que o refrigerante esteja sempre a uma baixa temperatura para poder resfriar o meio de interesse. Já em substâncias binárias o processo de evaporação inicia com líquido saturado a uma dada temperatura e irá aumentando no decorrer 
deste processo. À diferença de temperatura entre o líquido saturado e o vapor saturado é chamada de "temperature glide" e será maior para menores concentrações de amônia (ou maiores concentrações de água). Se, por exemplo, a fração mássica ou concentração mássica (Eq. 2.2) do refrigerante na entrada do evaporador é fixada em $99 \%$ em massa ( $1 \%$ em massa de água), o aumento da temperatura ligada à evaporação é marcante, como pode ser visto na Fig. 2.23. Esse comportamento da temperatura faz com que o uso de amônia refrigerante seja inviável para concentrações de água consideráveis (Herold et al. 1996; FernándezSeara e Sieres, 2006a).

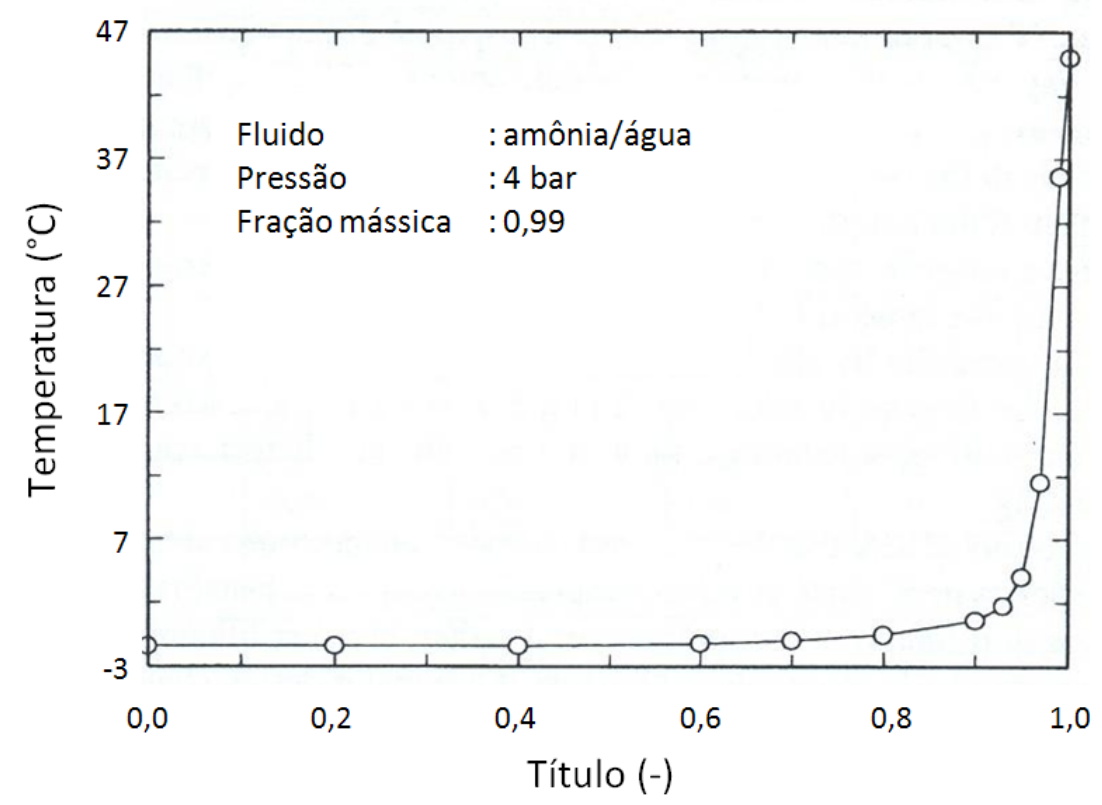

Figura 2.23 - "Temperatura glide" para uma solução amônia/água com 1 \% em massa de água (Herold et al. 1996).

$$
x=\frac{\text { massa de amônia }}{\text { massa total da solução }} \equiv \frac{k g \mathrm{NH}_{3}}{k g \mathrm{NH}_{3}+k g \mathrm{H}_{2} \mathrm{O}}
$$

Analisando o processo de evaporação no evaporador, para uma concentração de amônia de $1 \%$ em massa, por exemplo, o meio de interesse abaixará sua temperatura e o refrigerante evaporará aumentando sua temperatura, até que eles entrem em equilíbrio térmico, não sendo mais possível resfriar o meio de interesse. 
Como será analisado no Capítulo 3, em condições de equilíbrio, o vapor saturado que sai do evaporador terá uma concentração de amônia maior do que a do líquido que ingressou nele. Mesmo assim, sempre ficará água no evaporador. Esta água fará com que a "temperature glide" seja maior, e o evaporador não poderá mais resfriar o meio de interesse. Assim, as condições de trabalho do chiller por absorção de amônia/água entrarão em colapso, não atendendo às necessidades do projeto.

Uma maneira de prevenir o excesso de acúmulo de água no evaporador é drená-la periodicamente ao absorvedor (que depois será bombeada ao gerador), mas isso é prejudicial já que se precisaria de maior quantidade de fluxo de calor para evaporar a solução no gerador; somado a isso, a amônia tirada diminuiria a capacidade de refrigeração.

Fernández-Seará e Sieres (2006a) fizeram estudos para avaliar as consequências de existir elevadas porcentagens de água no vapor refrigerante num chiller por absorção de amônia/água, eles concluíram que a água é a responsável pelo baixo COP em sistemas reais da maioria de máquinas industriais e experimentais. Verifica-se na Fig. 2.24 os resultados obtidos pelos autores, mostrando a alta sensibilidade do COP com a pureza do vapor refrigerante.

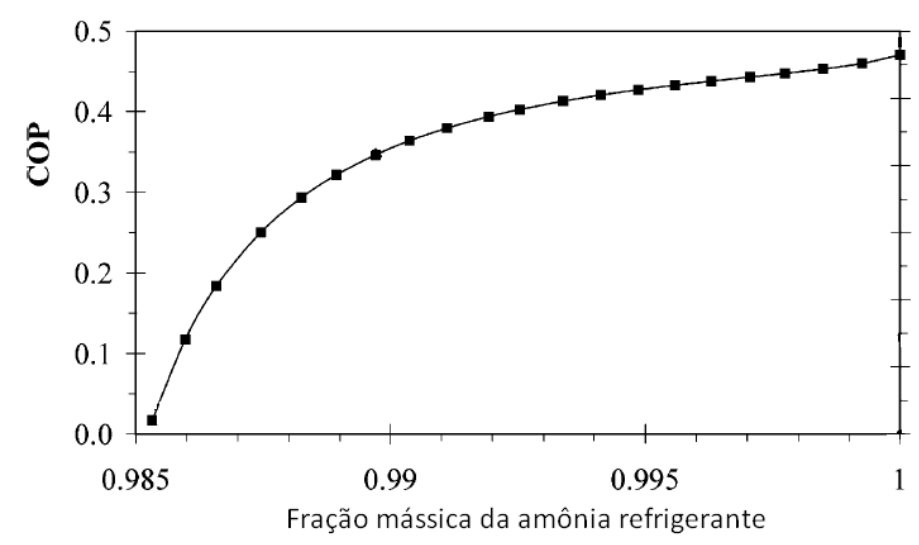

Figura 2.24 - COP em função da concentração de refrigerante, Fernández-Seará e Sieres (2006a)

Resultados parecidos aos de Fernández-Seará e Sieres (2006b) foram obtidos por Schiavon (2008), que modelou um ciclo comercial de refrigeração por absorção de amônia/água tipo $G A X$ de 5 TR e avaliou a sensibilidade do COP com a 
concentração de vapor de amônia na saída do retificador. Como mostrado na Fig. 2.25, o COP aumenta com a concentração do refrigerante.
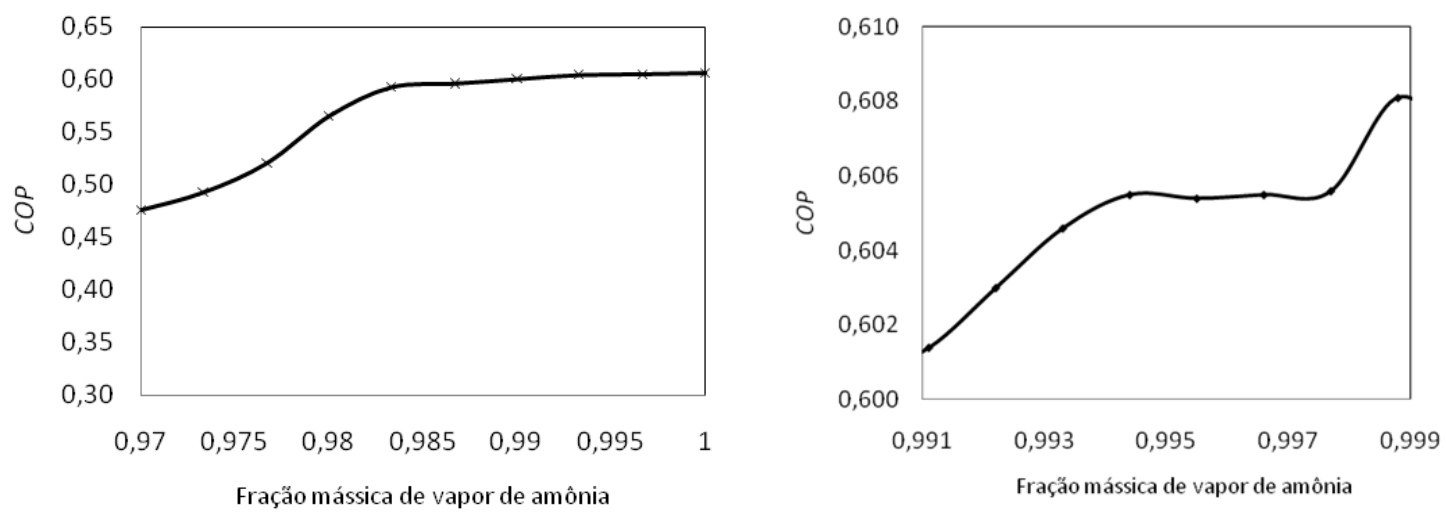

Figura 2.25 - Sensibilidade do COP em função da concentração do refrigerante no sistema GAX.

Bogart (1982) fez estudos teóricos para avaliar as consequências de vapor de água em evaporadores de sistemas de refrigeração por absorção de amônia/água. Concluiu que remover água na saída do gerador é assunto crucial para garantir a confiabilidade e eficiência nesses sistemas e indicou uma concentração de amônia refrigerante de 99,9\% em massa como ótimo para estes sistemas.

Neste trabalho adotar-se-á a recomendação de Bogart (1982), adotando uma concentração de vapor de amônia 99,9\% em massa na saída do retificador. 


\section{EQUILÍBRIO LÍQUIDO - VAPOR EM MISTURAS BINÁRIAS}

As relações entre pressão, temperatura e concentração são muito importantes em sistemas binários. Estas serão explicadas ao analisar o comportamento de aquecer uma solução líquida binária (neste caso, amônia e água). Imagina-se que o fluxo de calor é fornecido lentamente à solução líquida, como mostrado na Fig. 3.1(a). No diagrama $T-x$ da Fig. 3.1(c), o ponto 1 representa a solução líquida subresfriada. Como resultado do aquecimento da solução, aparece a primeira bolha de vapor no ponto 2, fazendo com que o êmbolo suba rapidamente; este ponto faz parte da linha de saturação líquida (ou curva do ponto de bolha). As paredes do cilindro não têm atrito, e por isso o êmbolo se movimentará livremente para equilibrar as pressões interna e externa. Se o fluxo de calor continuar sendo fornecido, mais vapor se desprenderá da solução líquida, como é indicado na Fig. 3.1(b), mas, se o experimento é parado certo tempo, as fases líquida e vapor conseguem o equilíbrio. Nesse momento, pode-se conhecer as frações mássicas tanto no líquido quanto no vapor, como simbolizados nos pontos 3 e 4 da Fig. 3.1(c). As frações mássicas nessa condição $(E)$ são para a solução líquida, $x_{L, 3}$, e para o vapor, $x_{V, 4}^{*}$. Pode-se perceber que para um sistema amônia/água qualquer condição de mistura bifásica como " $E$ ", dentro das linhas de saturação, a fração de amônia no vapor sempre será maior que a fração de amônia na solução líquida, assim $x_{V, 4}^{*}>x_{1}>x_{L, 3}$. As fases líquida e vapor (3 e 4) terão a mesma temperatura por estar em equilíbrio. Se o fluxo de calor continuar sendo fornecido ao sistema, toda a solução líquida vira vapor (ponto 5) com fração mássica $x_{V, 5}^{*}\left(x_{1}=x_{V, 5}^{*}\right)$, este será um ponto da linha de condensação (ou curva do ponto de orvalho). Quando mais fluxo de calor é adicionado ao sistema, o vapor saturado torna-se superaquecido (ponto 6). Fazendo a mesma experiência de aquecimento com todas as frações mássicas $x_{1} \in[0,1]$ obtém-se a curva de ponto de bolha e a curva de ponto de orvalho, como mostrado na Fig. 3.1(c). Um processo similar, retirando fluxo de calor do vapor superaquecido, pode ser feito para chegar da condição 6 à condição 1. 


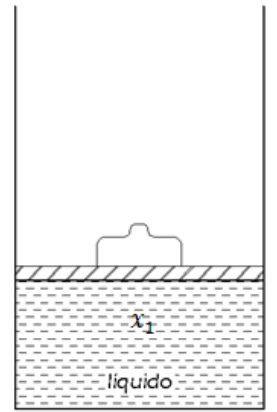

(a)

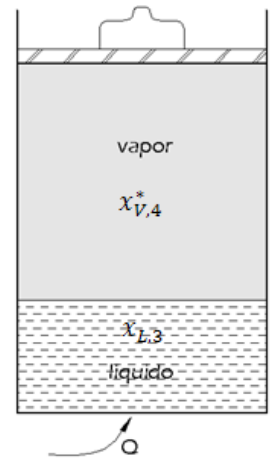

(b)

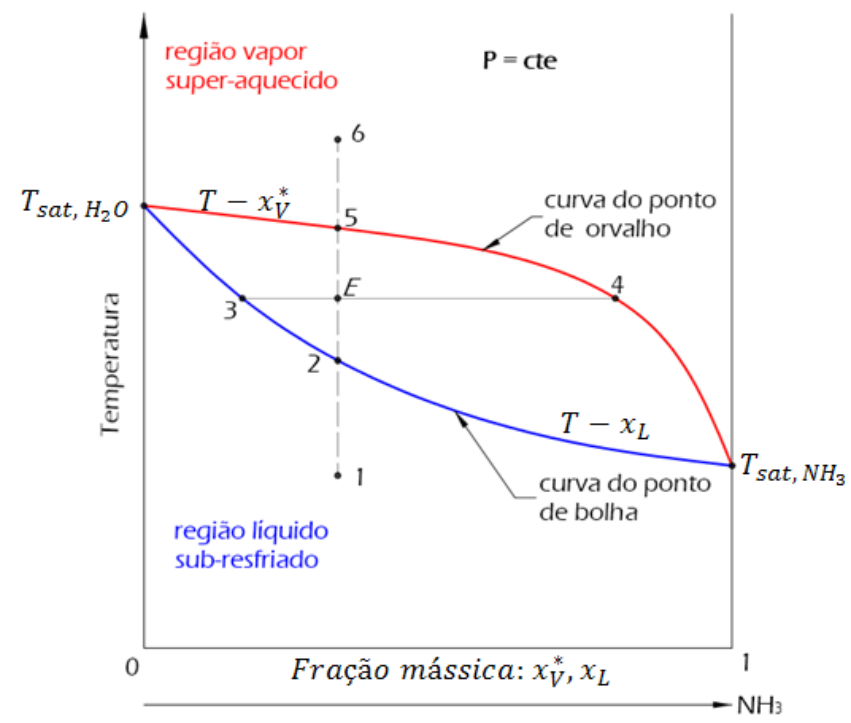

(c)

Figura 3.1 - Características de evaporação e condensação em misturas binárias.

Pode-se ver que a evaporação de uma solução binária não acontece à temperatura constante, como nas sustâncias puras. A quantidade de vapor numa mistura bifásica pode ser determinada mediante o título, que é definida como a quantidade em massa de vapor dividida pela massa total de mistura bifásica, Eq. (3.1).

$$
x_{q}=\frac{\text { massa do vapor }}{\text { massa total na mistura bifásica }}=\frac{\overline{3 E}}{\overline{34}}
$$

Quando a pressão do sistema aumenta, as curvas de ponto de orvalho e ponto de bolha sobem. Como pode ser verificado no diagrama tridimensional pressão-temperatura-concentração (Fig. 3.2) 


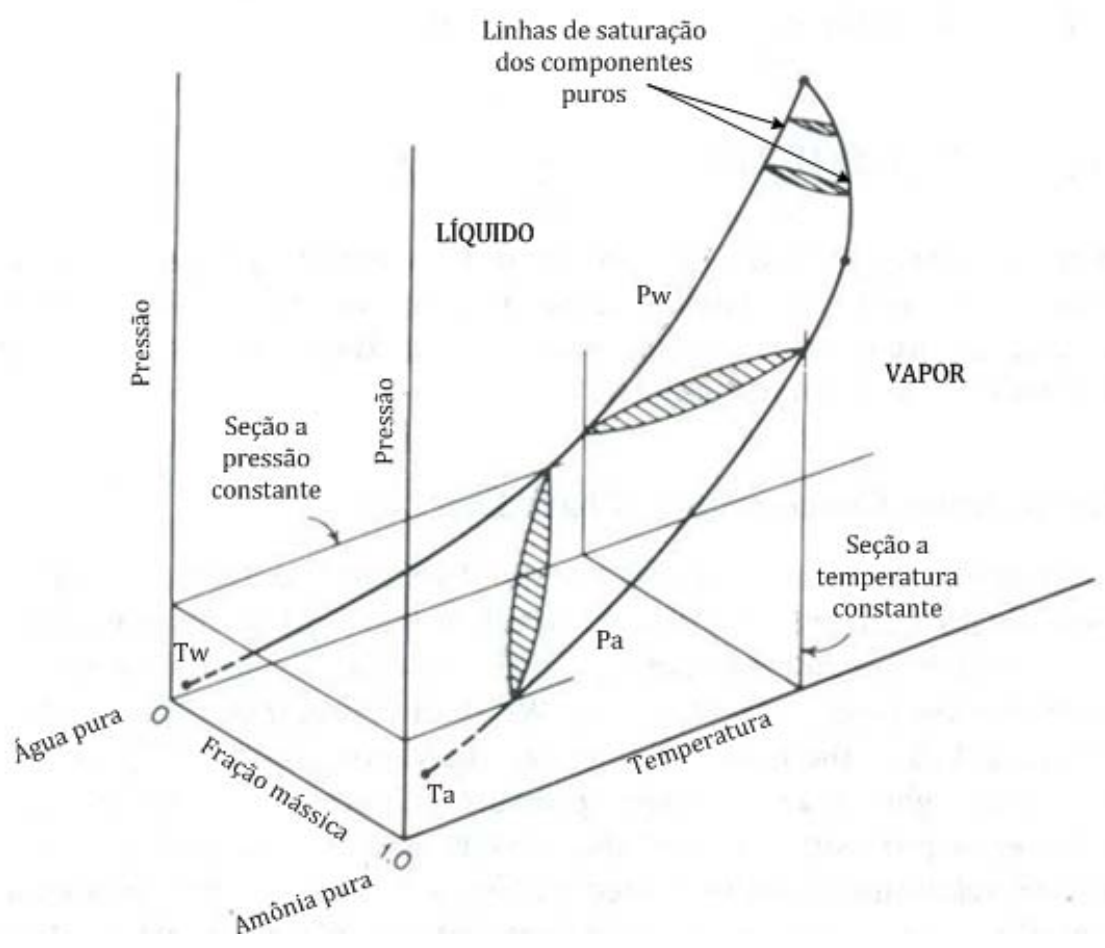

Figura 3.2 - Equilíbrio líquido-vapor misturas binárias.

O equilíbrio líquido-vapor também pode ser representada em termos de frações mássicas das fases, como mostrada na Fig. 3.3(a). O ponto $R$ representa a linha $\overline{34}$ da Fig. 3.1(c). A Fig. 3.3(b) representa esquematicamente as linhas de saturação líquida e vapor nos eixos fração mássica e entalpia a pressão constante. Os dados de equilíbrio líquido-vapor devem ser sempre determinados experimentalmente para maiores confiabilidades. 


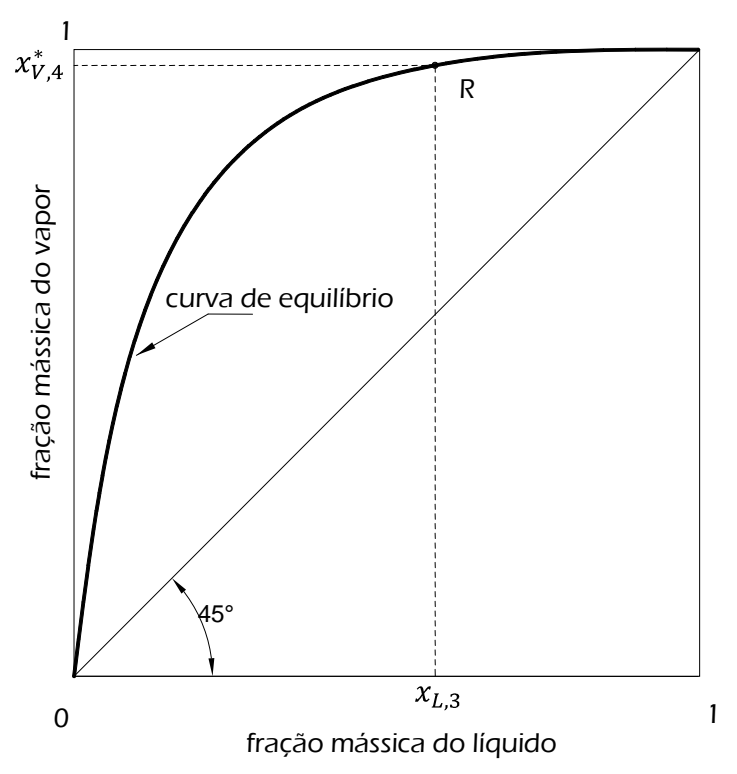

(a)

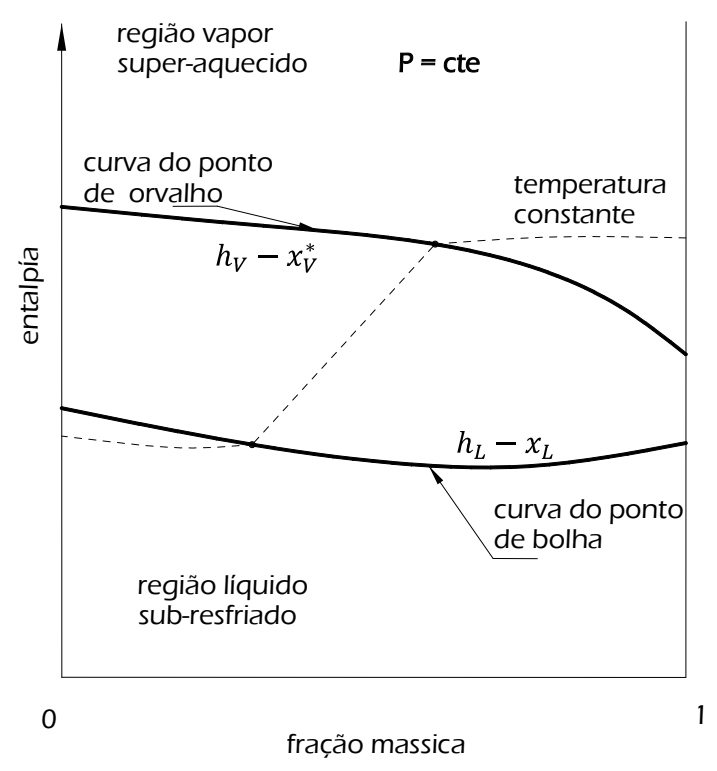

(b)

Figura 3.3 - Curvas de equilíbrio líquido-vapor nos eixos: (a) frações mássicas líquido-vapor (b) entalpia - fração mássica.

\subsection{RAZÃO DE EQUILÍBRIO E VOLATILIDADE RELATIVA}

Define-se fração molar de amônia (Eq. (3.2)) como a razão entre o número de moles de amônia dividido pelo número de moles da solução.

$$
\bar{x}=\frac{\text { número de moles de amônia }}{\text { número de moles da solução }}
$$

A razão de equilíbrio $(K)$ é uma medida do componente "a" (amônia) de se vaporizar e é definida segundo a Eq. (3.3).

$$
K_{a}=\frac{\bar{x}_{V}^{*}}{\bar{x}_{L}}
$$

Onde $\bar{x}_{V}^{*}$ é a fração molar de amônia na fase vapor em equilíbrio com a fração molar da amônia na fase líquida $\bar{x}_{L}$. 
Se a razão de equilíbrio é alta, o componente "a" tende-se a concentrar na fase vapor, mas se ela for baixa, na fase líquida. A razão de equilíbrio depende da temperatura, pressão e concentração do sistema.

Define-se volatilidade relativa como o quociente das razões de equilíbrio dos componentes de uma mistura, no caso da mistura binária amônia/água, é o quociente entre a razão de equilíbrio da amônia dividido pela razão de equilíbrio da água. A volatilidade relativa para a mistura amônia/água é mostrada na Eq. (3.4).

$$
\alpha_{a w}=\frac{K_{a}}{K_{w}}=\frac{\bar{x}_{V}^{*} / \bar{x}_{L}}{\left(1-\bar{x}_{V}^{*}\right) /\left(1-\bar{x}_{L}\right)}
$$

A volatilidade relativa representa a medida da facilidade de separação por destilação, ou seja, mede a tendência de vaporização dos componentes. Representa também a medida de afastamento da curva de equilíbrio e a linha de $45^{\circ}$ na Fig. 3.3(a). Por convenção a volatilidade relativa refere-se ao componente mais volátil (neste caso, amônia -"a") em relação ao outro componente menos volátil (neste caso, água -"w"), deste modo, o valor da volatilidade relativa será sempre maior que 1. Valores de $\alpha_{a w}$ muito maiores que 1 significam um grande grau de separação do componente "a". Valores de volatilidade relativa perto de 1 significam grande dificuldade do componente "a" em se separar. Como a razão de equilíbrio depende fortemente da temperatura, o mesmo ocorrerá com a volatilidade relativa. Conhecendo a concentração de amônia na fase líquida e a volatilidade relativa é possível calcular a concentração da amônia na fase vapor em equilíbrio com a fase líquida, como mostrada na Eq. (3.5).

$$
\bar{x}_{V}^{*}=\frac{\alpha_{a w} \bar{x}_{L}}{1+\left(\alpha_{a w}-1\right) \bar{x}_{L}}
$$

Assumindo a volatilidade relativa constante para as diferentes temperaturas a Eq. (3.5) pode ser representada num diagrama de frações molares na Fig. 3.4. 


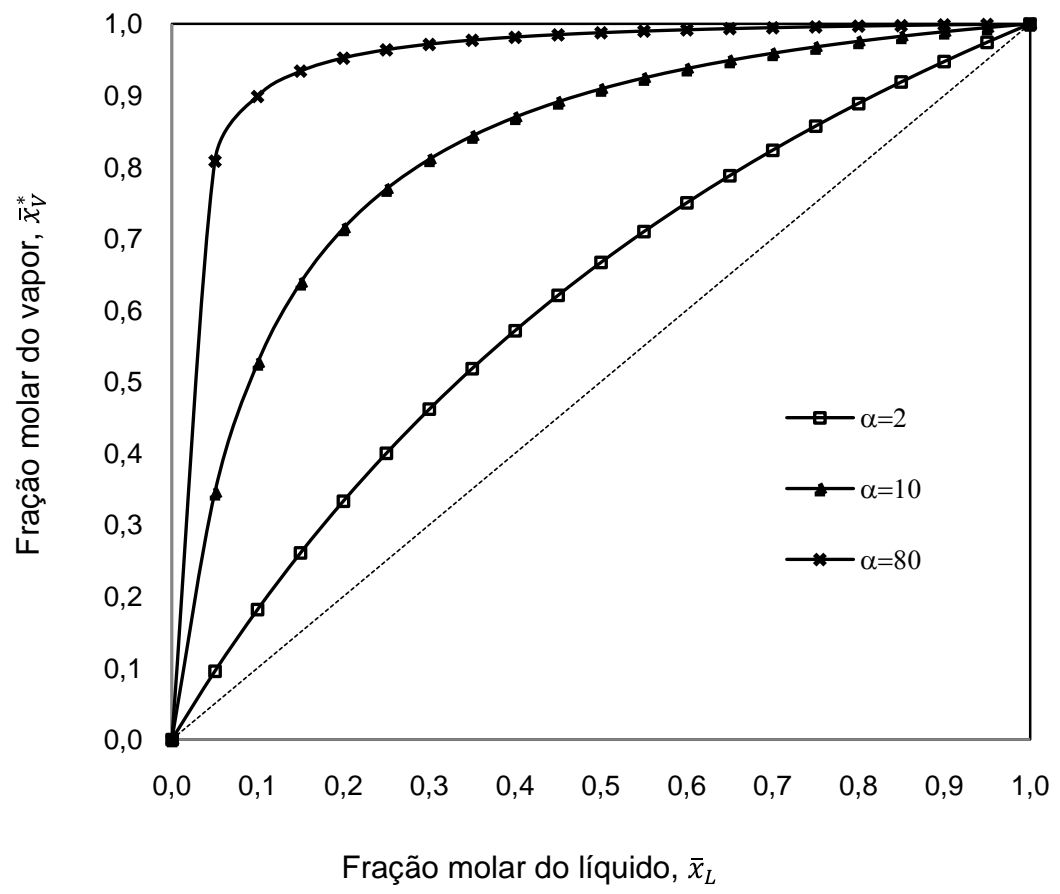

Figura 3.4 - Variação das curvas de equilíbrio de frações molares com a volatilidade relativa.

A volatilidade relativa pode ser expressa teoricamente assumindo algumas condições ideais como lei de Raoult e a lei de gás perfeito. As soluções ideais, segundo a lei de Raoult, mostradas nas Eqs. (3.6) e (3.7), são aquelas nas quais a pressão de equilíbrio parcial no vapor de uma substância $\left(p_{a}^{*}\right)$ a certa temperatura é igual à pressão de vapor da substância pura $\left(p_{a}\right)$ à mesma temperatura vezes sua fração molar em solução líquida $\left(\bar{x}_{L}\right)$.

$$
\begin{aligned}
& p_{a}^{*}=p_{a} \bar{x}_{L} \\
& p_{w}^{*}=p_{w}\left(1-\bar{x}_{L}\right)
\end{aligned}
$$

A lei de Dalton, neste caso, pode ser expressa como:

$$
\begin{aligned}
& p_{a}^{*}=\bar{x}_{V}^{*} P \\
& p_{w}^{*}=\left(1-\bar{x}_{V}^{*}\right) P
\end{aligned}
$$


Sendo $P$ a pressão total do sistema, a Eq. 3.4 para condições ideais de líquido e vapor pode ser expressa como:

$$
\alpha_{a w}=\frac{p_{a}}{p_{w}}
$$

A pressão de vapor de amônia numa dada temperatura é sempre maior que a pressão de vapor da água, então a amônia é mais volátil do que a água. 


\section{METODOLOGIA}

No capítulo anterior, foram revisados conceitos de equilíbrio líquido-vapor em misturas bifásicas, os quais servirão, na primeira seção deste capítulo, para analisar o balanço de massa e de energia de uma maneira ideal (em equilíbrio) de cada estágio assim como na coluna. Como já informado, o método empregado para resolver o balanço de massa e de energia na coluna será o de Ponchon-Savarit, permitindo obter, entre outros resultados, o número de pratos teóricos necessários para atingir a pureza desejada de vapor de amônia.

No item seguinte discutem-se as considerações hidráulicas de regimes de trabalho da coluna assim como as perdas de pressão dos escoamentos. Analisa-se também a geometria interna da coluna. Depois será quantificada a eficiência global da coluna com a qual é corrigido o número de pratos necessários para alcançar uma determinada pureza de vapor de amônia, já que os pratos na coluna trabalham em condições que não são de equilíbrio.

Finalizando este capítulo, são analisadas as variáveis de entrada e saída e parâmetros de simulação.

\subsection{BALANÇOS DE MASSA E DE ENERGIA NA COLUNA DE DESTILAÇÃO, MÉTODO DE PONCHON-SAVARIT}

Na Fig. 4.1 aparecem algumas das variáveis envolvidas no balanço de massa e de energia na coluna de destilação. O volume de controle VC-1 permite a troca de massa e de energia com seu entorno, sendo que no gerador o fluxo de calor trocado com o entorno é $\dot{Q}_{G}$ e no retificador é $\dot{Q}_{R}$, da mesma forma o VC-1 troca massa com o entorno permitindo neste caso uma entrada "e" que é a solução forte e duas saídas " $s$ " e " $d$ ", onde "s" é a solução fraca e " $d$ " é o vapor de amônia quase puro (ou o destilado da coluna), $L$ e $V$ são escoamentos de solução líquida e de vapor respectivamente, " $r$ " é o refluxo. Na coluna existem $N_{i}$ pratos (ideais), dos quais $n$ são da seção de enriquecimento e $N_{i}-m+1$ são da seção de esgotamento. Será assumido neste trabalho, que as seções de enriquecimento e de esgotamento da coluna de destilação são adiabáticas. 


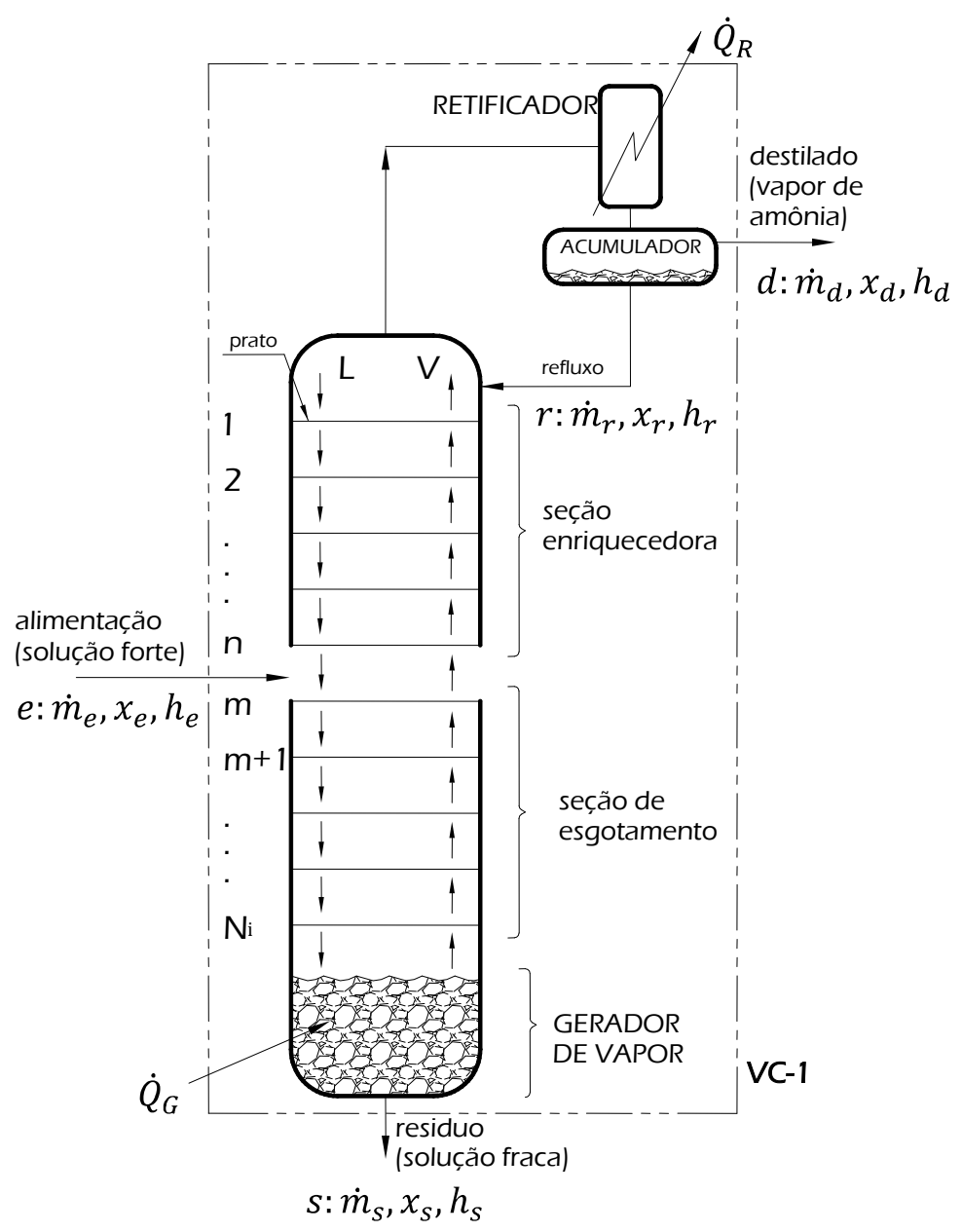

Figura 4.1 - Variáveis externas no balanço de massa e de energia na coluna de destilação.

Internamente à coluna existem muitas variáveis de vazão mássica, entalpia e fração mássica (tanto por prato quanto dos lados líquido e vapor de cada prato), que estão ligadas às variáveis correspondentes a " $e$ ", " $s$ " e " $d$ ".

O balanço de massa e de energia da coluna de destilação será dividido em três partes, em primeiro lugar será feito o balanço na seção enriquecedora, retificador e acumulador; depois, o balanço na seção de esgotamento e o gerador, e por último o balanço na coluna inteira.

A Fig. 4.2(a) mostra os componentes para a análise da primeira parte, assim como, as variáveis que intervêm neste balanço. A Fig. 4.2(b) indica as variáveis necessárias no balanço de massa e de energia no prato teórico " $n$ ". As leis de conservação de massa e de energia em todos os casos analisados serão consideradas para regimes permanentes. 
À exceção da solução de alimentação, todos os estados nos pontos de balanços da coluna estão nas condições de saturação. As variáveis correspondentes ao líquido saturado e ao vapor saturado são resumidas na Tabela 4.1.

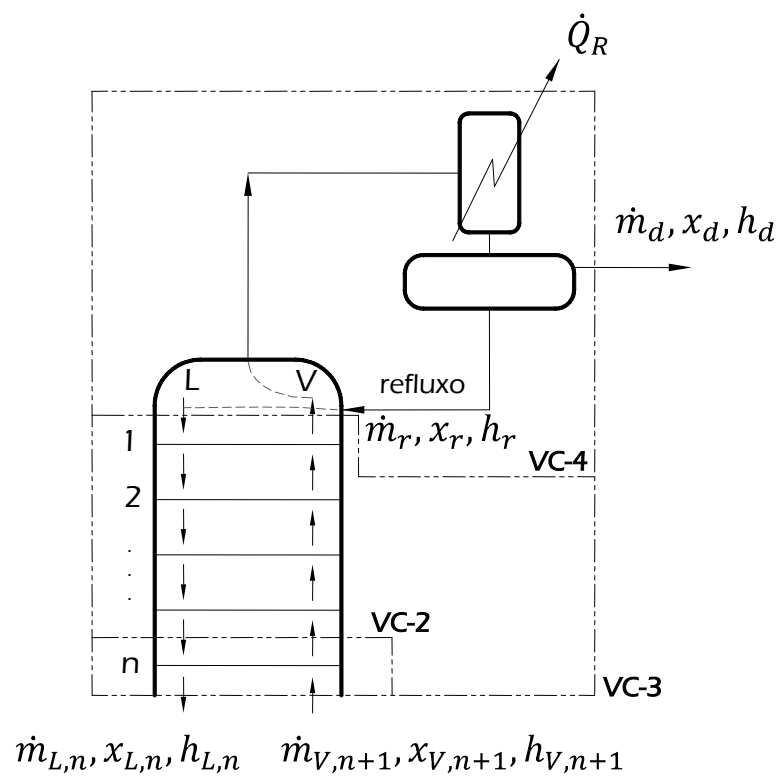

(a)
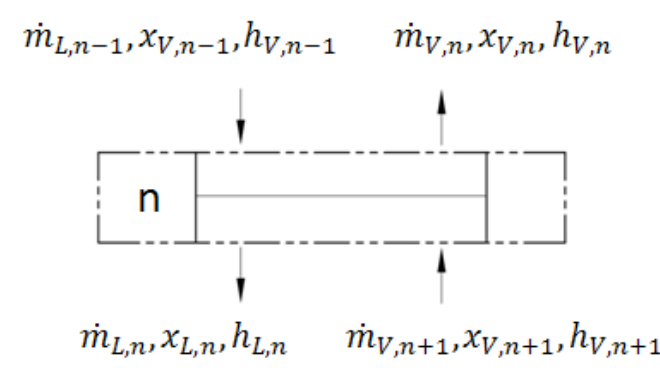

$\dot{m}_{L, n}, x_{L, n}, h_{L, n} \quad \dot{m}_{V, n+1}, x_{V, n+1}, h_{V, n+1}$

Figura 4.2 - Esquema para os balanços de massa e de energia: (a) na seção enriquecedora, retificador e acumulador, (b) no prato " $n$ ".

Tabela 4.1 - Variáveis no líquido e no vapor envolvidas nos balanços de massa e de energia.

\begin{tabular}{cccc}
\hline & Unidade & Líquido & Vapor \\
\hline Vazão mássica & $\mathrm{kg} / \mathrm{s}$ & $\dot{m}_{L}$ & $\dot{m}_{V}$ \\
Fração mássica & - & $x_{L}$ & $x_{V}$ \\
Entalpia especifica & $\mathrm{kJ} / \mathrm{kg}$ & $h_{L}$ & $h_{V}$ \\
\hline
\end{tabular}

Define-se razão de refluxo (ou razão de refluxo externo) à razão entre a vazão mássica do líquido saturado que retorna à parte superior da seção enriquecedora e a vazão mássica do vapor saturado que sai da coluna, como mostrada na Eq. (4.1).

$$
R=\frac{\dot{m}_{r}}{\dot{m}_{d}}
$$


Na sequência, são apresentadas para o prato " $n$ " (VC-2, Fig. 4.2(a)) as equações de conservação da massa total, da massa de amônia e da energia, respectivamente, segundo a Fig. 4.2(b):

$$
\begin{gathered}
\dot{m}_{V, n+1}+\dot{m}_{L, n-1}=\dot{m}_{V, n}+\dot{m}_{L, n} \\
\dot{m}_{V, n+1} x_{V, n+1}+\dot{m}_{L, n-1} x_{L, n-1}=\dot{m}_{V, n} x_{V, n}+\dot{m}_{L, n} x_{L, n} \\
\dot{m}_{V, n+1} h_{V, n+1}+\dot{m}_{L, n-1} h_{L, n-1}=\dot{m}_{V, n} h_{V, n}+\dot{m}_{L, n} h_{L, n}
\end{gathered}
$$

A conservação da massa total, da massa de amônia e da energia, respectivamente, na seção enriquecedora, retificador e acumulador, segundo o volume de controle VC-3 mostrado na Fig. 4.2(a), é representada como:

$$
\begin{gathered}
\dot{m}_{V, n+1}-\dot{m}_{L, n}=\dot{m}_{d} \\
\dot{m}_{V, n+1} x_{V, n+1}-\dot{m}_{L, n} x_{L, n}=\dot{m}_{d} x_{d} \\
\dot{m}_{V, n+1} h_{V, n+1}=\dot{m}_{L, n} h_{L, n}+\dot{m}_{d} h_{d}+\dot{Q}_{R}
\end{gathered}
$$

Da Eq. (4.7), chega-se a:

$$
\dot{m}_{V, n+1} h_{V, n+1}-\dot{m}_{L, n} h_{L, n}=\dot{m}_{d} h_{d}^{\prime}
$$

Com

$$
h_{d}^{\prime}=h_{d}+\frac{\dot{Q}_{R}}{\dot{m}_{d}}
$$


Substituindo $\dot{m}_{d}$ da Eq. (4.5) na Eq. (4.6) obtém-se:

$$
\dot{m}_{V, n+1}\left(x_{V, n+1}-x_{d}\right)=\dot{m}_{L, n}\left(x_{L, n}-x_{d}\right)
$$

Da mesma forma, substituindo $\dot{m}_{d}$ da Eq. (4.5) na Eq. (4.8) consegue-se:

$$
\dot{m}_{V, n+1}\left(h_{V, n+1}-h_{d}^{\prime}\right)=\dot{m}_{L, n}\left(h_{L, n}-h_{d}^{\prime}\right)
$$

Relacionando as Eqs. (4.10) e (4.11):

$$
\frac{\dot{m}_{L, n}}{\dot{m}_{V, n+1}}=\frac{x_{d}-x_{V, n+1}}{x_{d}-x_{L, n}}=\frac{h_{d}^{\prime}-h_{V, n+1}}{h_{d}^{\prime}-h_{L, n}}
$$

A relação entre fração mássica e entalpia específica da Eq. (4.12) pode ser representada com uma linha nas coordenadas entalpia - fração mássica como mostrado na linha $\overline{h_{L, n}-h_{d}^{\prime}}$ da Fig. 4.3, a qual é denominada linha de operação. Todos os balanços de massa e de energia do prato 1 até o prato $\mathrm{n}$ fornecem linhas de operação nos eixos $x-h$, as quais se intersectam no ponto $\left(x_{d}, h_{d}^{\prime}\right)$. Os escoamentos de líquido e de vapor que saem do prato estão em equilíbrio e são representados na figura com linhas de cor verde.

Na Fig. 4.3, quando se faz a projeção das frações mássicas $\left(x_{L, n}, x_{V, n+1}\right)$ correspondentes à linha de operação dos eixos $x-h$ nos eixos $x_{L}-x_{V}$ fornece-se um ponto que pertence à chamada curva de operação. Note-se que a fração mássica do vapor saturado primeiro vai até a linha de $45^{\circ}$ e depois ao eixo $x_{V}$. Fazendo as projeções de todas as frações mássicas das linhas de operação do eixo $x-h$ no eixo $x_{L}-x_{V}$ obtém-se a curva de operação completa. O primeiro ponto da curva de operação correspondente à entalpia do vapor destilado " $d$ " está na linha de $45^{\circ}$ uma vez que segue a tendência das projeções de linhas de operação (imaginarias) relacionadas com $\left(x_{d}, h_{d}^{\prime}\right)$ pertos de $x_{d}$. 


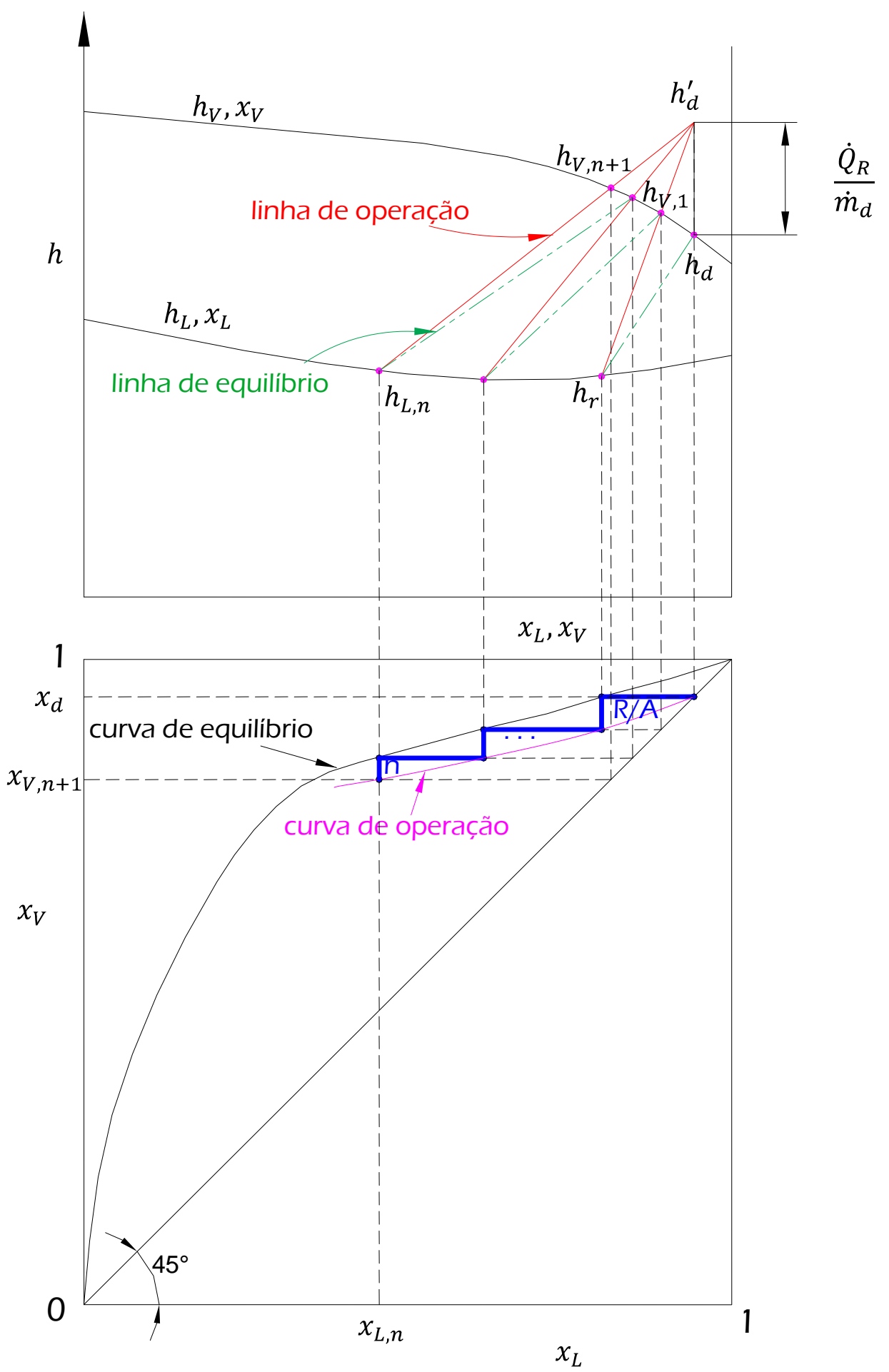

Figura 4.3 - Diagrama $h-x$ e $x_{L}-x_{V}$, para o balanço de massa e de energia na seção enriquecedora, retificador e acumulador. 
Define-se refluxo interno do prato " $n$ " a razão entre a massa do líquido saturado que sai do prato e o vapor saturado que ingressa nele prato, como mostrado na Eq. (4.13).

$$
r_{n}=\frac{\dot{m}_{L, n}}{\dot{m}_{V, n+1}}
$$

Fazendo um balanço de massa e de energia no volume de controle VC-4 da Fig. 4.2(a), obtém-se:

$$
\begin{gathered}
\dot{m}_{V, 1}=\dot{m}_{r}+\dot{m}_{d} \\
\dot{m}_{V, 1} h_{V, 1}=\dot{m}_{r} h_{r}+\dot{m}_{d} h_{d}+\dot{Q}_{R}
\end{gathered}
$$

Substituindo $\dot{m}_{V, 1}$ da Eq. (4.14) na Eq. (4.15) e $h_{d}{ }_{d}$ da Eq. (4.9) na Eq. (4.15), chega-se a:

$$
\dot{m}_{r}\left(h_{V, 1}-h_{r}\right)=\dot{m}_{d}\left(h_{d}^{\prime}-h_{V, 1}\right)
$$

Uma expressão para a razão de refluxo pode ser obtida substituindo a Eq. (4.16) na Eq. (4.1):

$$
R=\frac{\dot{m}_{r}}{\dot{m}_{d}}=\frac{h_{d}^{\prime}-h_{V, 1}}{h_{V, 1}-h_{r}}
$$

Na continuação será analisada a segunda parte dos balanços de massa e de energia, a qual corresponde à seção de esgotamento e gerador. As variáveis que intervêm no balanço de massa e de energia são apresentadas no volume de controle VC-5, da Fig. 4.4(a). A Fig. 4.4(b) mostra as linhas de operação e a curva de operação nos eixos $x-h$ e $x_{L}-x_{V}$ respectivamente. São indicadas na sequência, as equações de conservação da massa total, da massa de amônia e da energia, respectivamente, segundo a Fig. 4.4(a): 


$$
\begin{gathered}
\dot{m}_{L, m}-\dot{m}_{V, m+1}=\dot{m}_{s} \\
\dot{m}_{L, m} x_{L, m}-\dot{m}_{V, m+1} x_{V, m+1}=\dot{m}_{s} x_{s} \\
\dot{m}_{L, m} h_{L, m}+\dot{Q}_{G}=\dot{m}_{V, m+1} h_{V, m+1}+\dot{m}_{s} h_{s}
\end{gathered}
$$

Da Eq. (4.20) obtém-se:

$$
\dot{m}_{L, m} h_{L, m}-\dot{m}_{V, m+1} h_{V, m+1}=\dot{m}_{s} h_{s}^{\prime}
$$

Onde:

$$
h_{s}^{\prime}=h_{s}-\frac{\dot{Q}_{G}}{\dot{m}_{s}}
$$

Substituindo $\dot{m}_{s}$ da Eq. (4.18) na Eq. (4.19):

$$
\dot{m}_{L, m}\left(x_{L, m}-x_{S}\right)=\dot{m}_{V, m+1}\left(x_{V, m+1}-x_{S}\right)
$$

Da mesma forma, substituindo $\dot{m}_{s}$ da Eq. (4.18) na Eq. (4.21):

$$
\dot{m}_{L, m}\left(h_{L, m}-h_{s}^{\prime}\right)=\dot{m}_{V, m+1}\left(h_{V, m+1}-h_{s}^{\prime}\right)
$$

Relacionando as Eqs. (4.23) e (4.24) consegue-se:

$$
\frac{\dot{m}_{L, m}}{\dot{m}_{V, m+1}}=\frac{x_{V, m+1}-x_{s}}{x_{L, m}-x_{s}}=\frac{h_{V, m+1}-h_{s}^{\prime}}{h_{L, m}-h_{s}^{\prime}}
$$

A relação entre frações mássicas e entalpia específica da Eq. (4.25) é a linha reta $\overline{h_{s}^{\prime}-h_{V, m+1}}$ que pode ser mostrada no diagrama $h-x$ da Fig. 4.4(b). O balanço de massa e de energia em todos os pratos da seção de esgotamento fornece as 
linhas de operação, as quais se intersectam no ponto $\left(x_{s}, h_{s}^{\prime}\right)$. As projeções dos pontos correspondentes às frações mássicas de saturação das linhas de equilíbrio do diagrama $h-x$ ao diagrama $x_{L}-x_{V}$ fornecem pontos da curva de operação, se esses pontos são conectados obtém-se a curva de operação correspondente à seção de esgotamento e gerador.

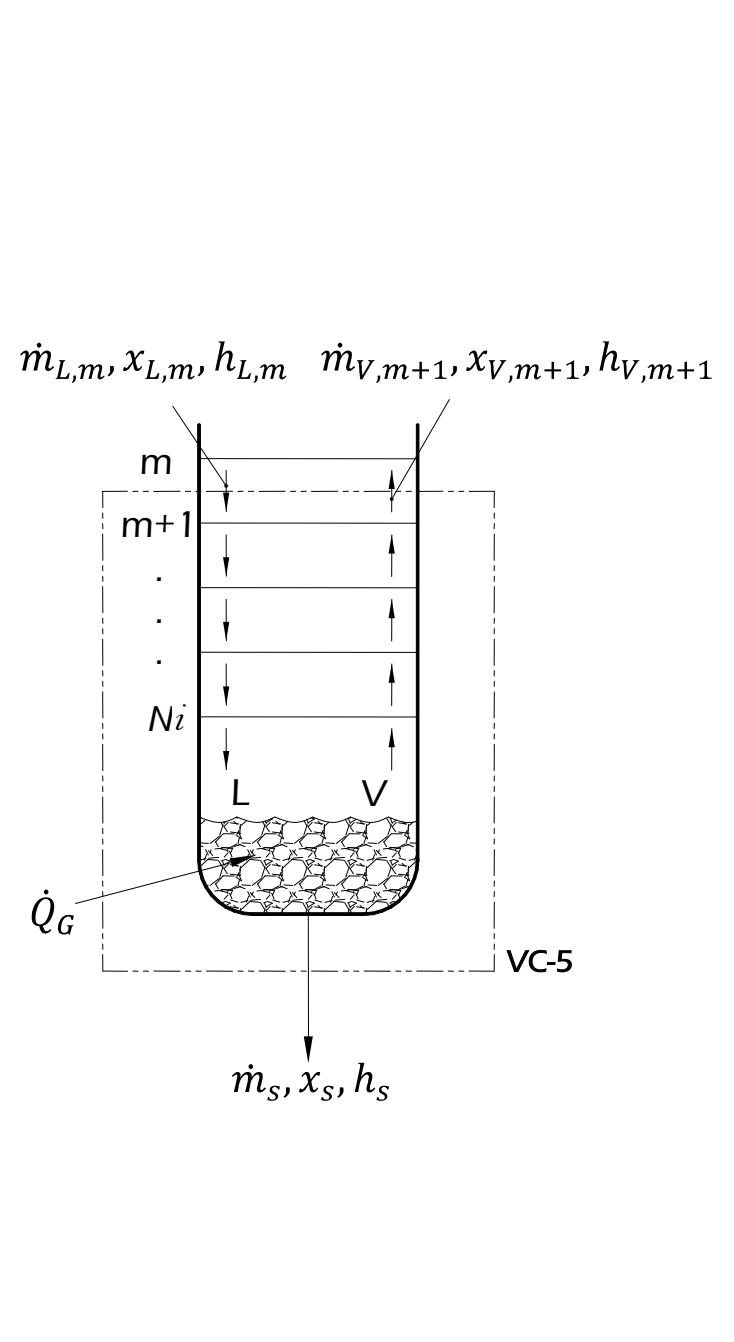

(a)

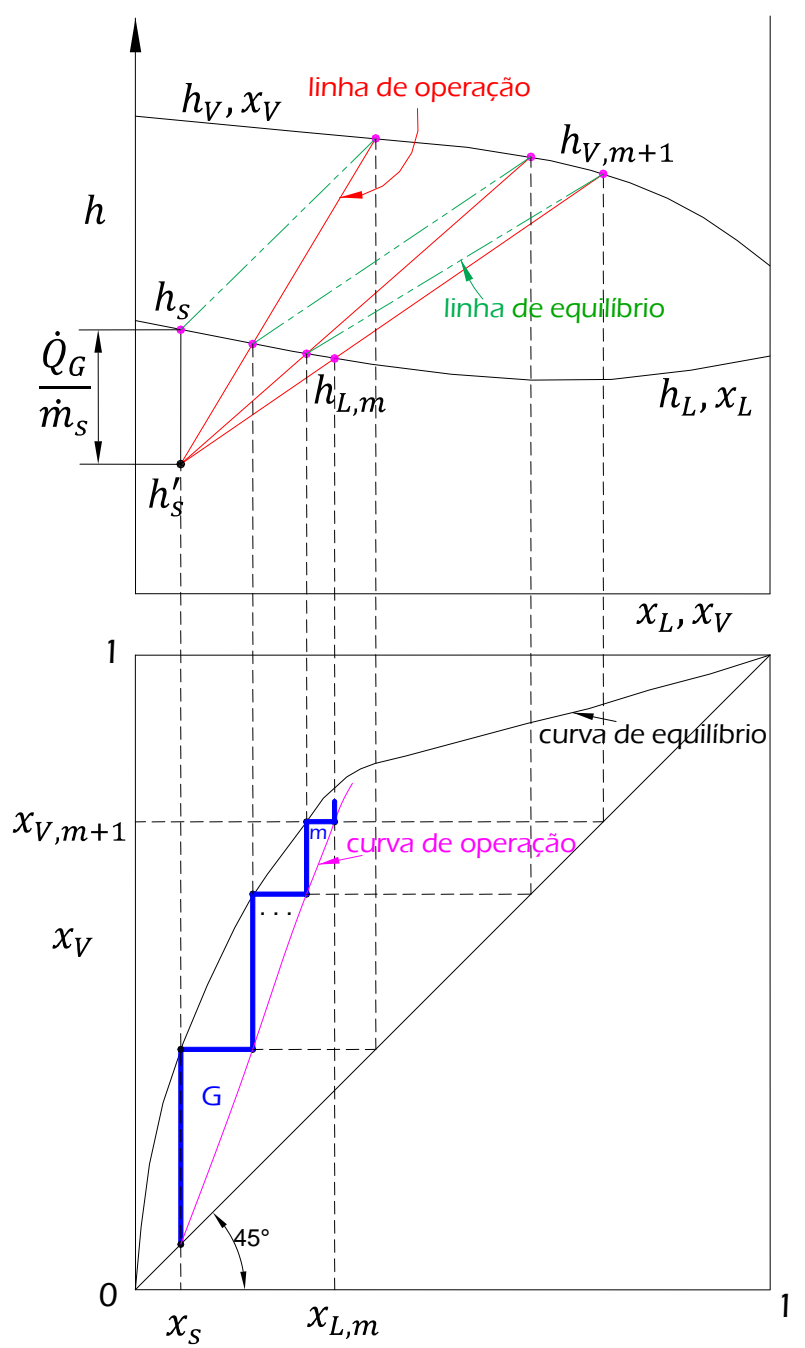

(b)

Figura 4.4 - Seção esgotamento e gerador (a) esquema para os balanços de massa e de energia, (b) diagrama $h-x$ e $x_{L}-x_{V}$.

Finalmente juntando a seção de esgotamento e gerador com a seção enriquecedora, retificador e acumulador obtêm-se a coluna de destilação completa. Fazendo o balanço geral de massa e de energia da coluna de destilação no volume de controle VC-1, mostrado na Fig. 4.1 chega-se a: 


$$
\begin{gathered}
\dot{m}_{e}=\dot{m}_{s}+\dot{m}_{d} \\
\dot{m}_{e} x_{e}=\dot{m}_{s} x_{s}+\dot{m}_{d} x_{d} \\
\dot{m}_{e} h_{e}+\dot{Q}_{G}=\dot{m}_{s} h_{s}+\dot{m}_{d} h_{d}+\dot{Q}_{R}
\end{gathered}
$$

Substituindo as Eqs. (4.9) e (4.22) na Eq. (4.28) obtém-se:

$$
\dot{m}_{e} h_{e}=\dot{m}_{s} h_{s}^{\prime}+\dot{m}_{d} h_{d}^{\prime}
$$

Também, substituindo a Eq. (4.26) nas Eqs. (4.27) e (4.29) obtém-se respectivamente:

$$
\begin{gathered}
\dot{m}_{s}\left(x_{e}-x_{s}\right)=\dot{m}_{d}\left(x_{d}-x_{e}\right) \\
\dot{m}_{s}\left(h_{e}-h_{s}^{\prime}\right)=\dot{m}_{d}\left(h_{d}^{\prime}-h_{e}\right)
\end{gathered}
$$

Relacionando essas duas equações:

$$
\frac{\dot{m}_{d}}{\dot{m}_{s}}=\frac{x_{e}-x_{s}}{x_{d}-x_{e}}=\frac{h_{e}-h_{s}^{\prime}}{h_{d}^{\prime}-h_{e}}
$$

Quando relacionadas à fração mássica e a entalpia específica da Eq. (4.32) obtém-se a linha de operação principal $\overline{p I-p I I}$, mostrada na Fig. 4.5. Sendo que os pontos $p I$ e $p I I$ correspondem a $\left(x_{d}, h_{d}^{\prime}\right)$ e a $\left(x_{s}, h_{s}^{\prime}\right)$, respectivamente.

Note-se que as curvas de operação se interceptam no ponto $w$, sendo esse ponto o par ordenado $\left(x_{f}, x_{g}\right)$ do diagrama $x_{L}-x_{V}$ e corresponde à alimentação da coluna, como será explicado na seguinte seção.

Segundo os balanços de massa e de energia feitos, o esquema da Fig. 4.5 mostra que é preciso seis pratos teóricos para atingir a pureza $x_{d}$ no vapor. 


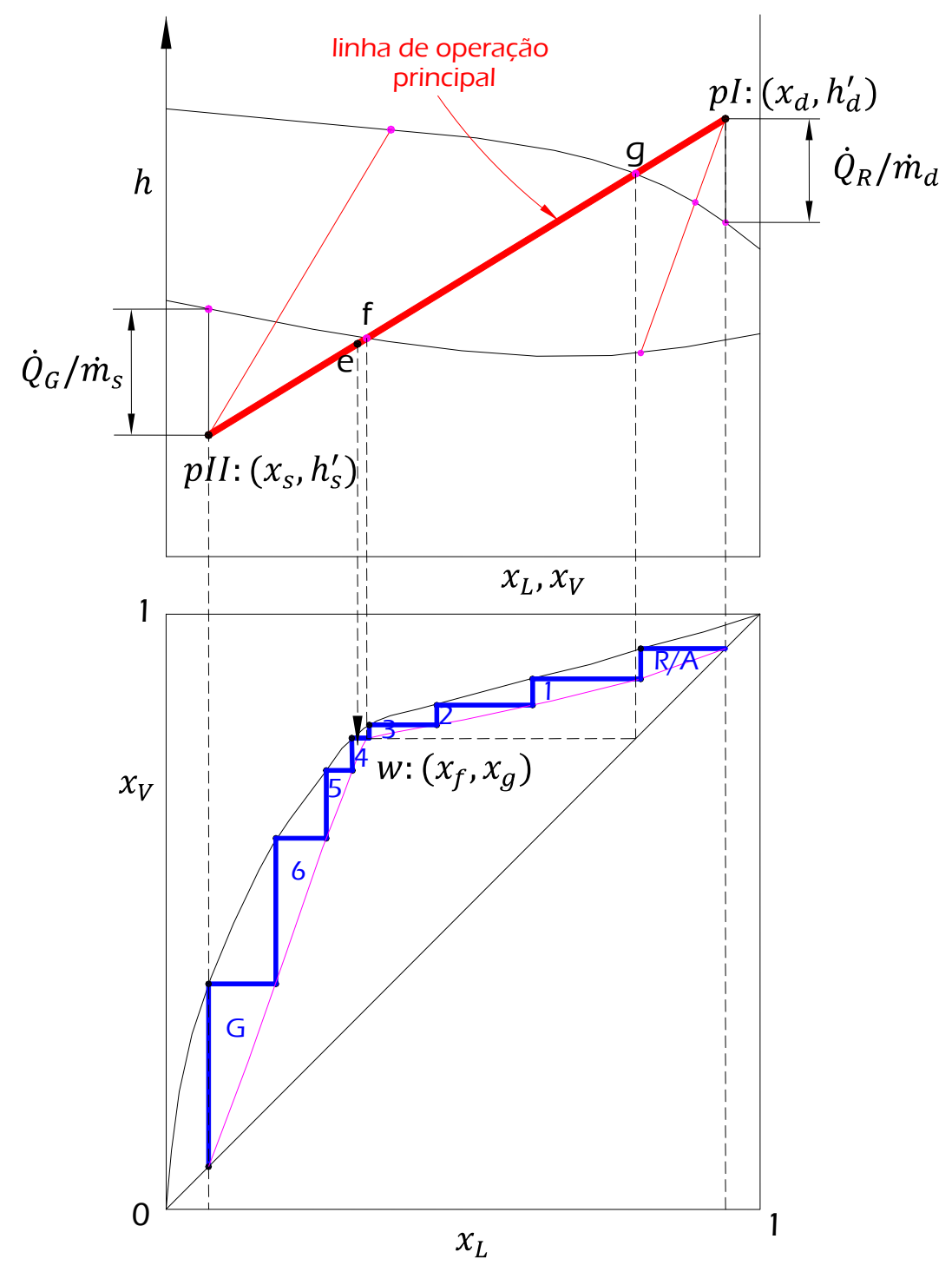

Figura 4.5 - Linha de operação principal.

\subsubsection{Análise dos parâmetros de operação da coluna de destilação}

(a) Entrada de solução forte na coluna de destilação

Depois de fazer os balanços de massa e de energia pode-se obter a curva de equilíbrio e os degraus que simbolizam os pratos na coluna. Como exemplo, se aceita que a coluna de destilação precisa de 4 pratos para conseguir uma concentração da solução fraca $x_{s}$ e concentração do vapor destilado $x_{d}$. A solução de alimentação à coluna tem concentração $x_{e}$ e indica que se deve posicionar no segundo prato, a qual corresponde à interseção das curvas de equilíbrio das seções de esgotamento e de retificação $(w)$, como mostrado na Fig. 4.6(a). Se a 
alimentação à coluna estiver no quarto prato, como aponta a Fig. 4.6(b), os balanços de massa e de energia do terceiro e do quarto prato corresponderiam ainda à seção de enriquecimento, e seria preciso de mais um prato na seção de esgotamento para conseguir a concentração da solução fraca, fazendo um total de 5 pratos na coluna de destilação. Mais pratos serão também necessários se a alimentação à coluna estiver acima do terceiro prato (começando a contagem de abaixo). Por tanto o segundo prato se mostra como ótimo para a alimentação da coluna, já que a coluna necessitaria do menor número de pratos para as concentrações de saída desejadas.

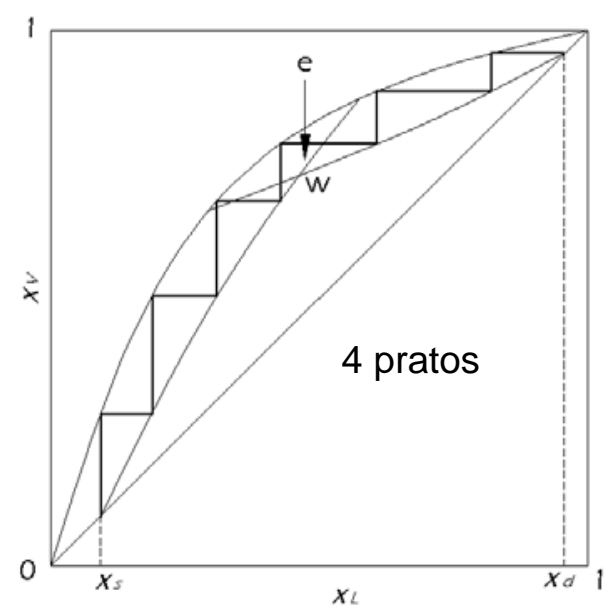

(a)

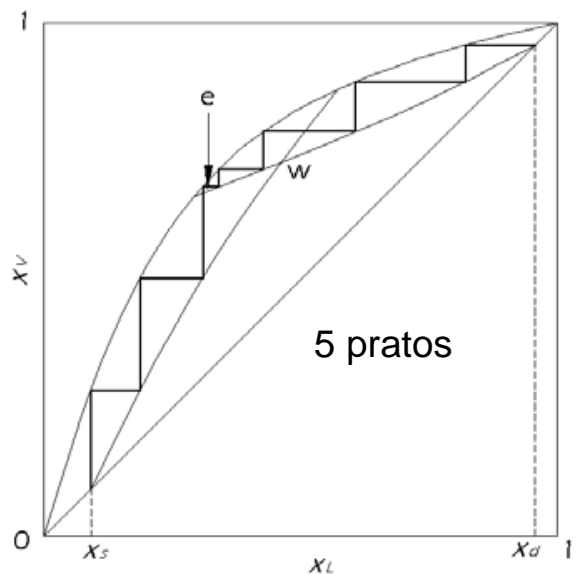

(b)

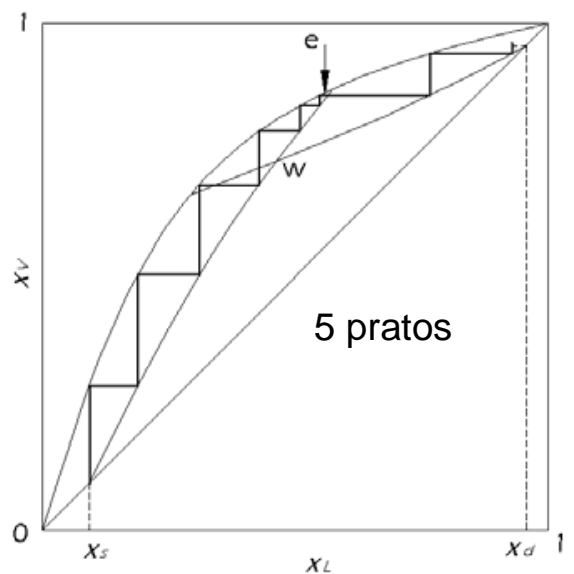

(c)

Figura 4.6 - Prato de alimentação à coluna destilação (a) ótima (b) muito abaixo (c) muito acima.

Pode-se perceber também nestes diagramas $x_{L}-x_{V}$ que quanto mais próximas estão as curvas de operação e de equilíbrio o número de pratos na coluna de destilação aumenta. 


\section{(b) Refluxo total}

Chega-se a essa condição quando:

- todo o vapor que sai do primeiro prato (parte superior da seção de enriquecimento) é condensado e todo este líquido volta à coluna,

- a alimentação à coluna é cessada e

- a saída da solução fraca interrompida (parte inferior da coluna).

Nestas condições, a razão de refluxo e o termo $h_{d}^{\prime}(p I)$ têm tendência ao infinito segundo a Eq. (4.17). No mesmo sentido, o termo $h_{s}^{\prime}(p I I)$ também tem tendência ao infinito (negativo), ver Fig. 4.5. Quando isso acontece, as linhas de operação são verticais, como expostas na Fig. 4.7 conseguindo-se assim, o menor número de pratos na coluna de destilação. Pode-se notar que o fluxo de calor fornecido ao gerador e o fluxo de calor retirado do retificador tendem também ao infinito, fazendo com que as vazões do líquido e do vapor aumentem, com isso o diâmetro da coluna de destilação será maior.

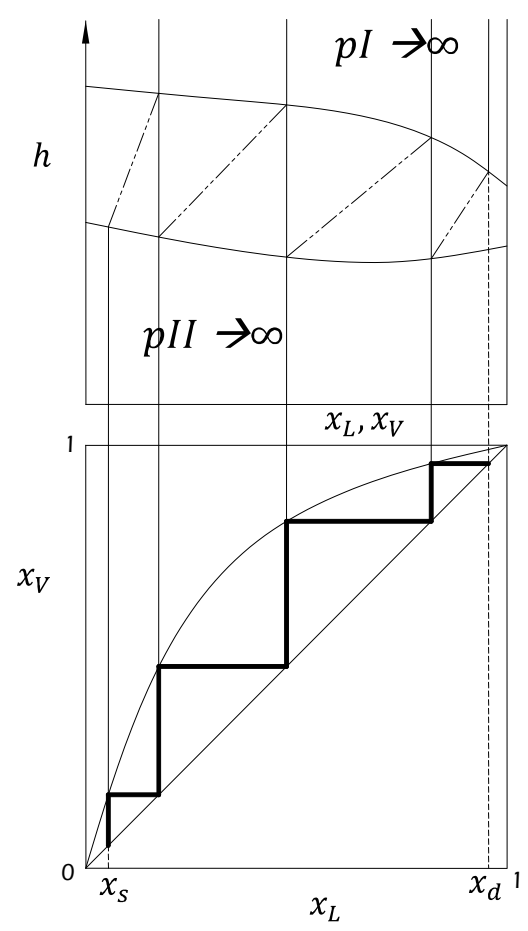

Figura 4.7 - Refluxo total - número de pratos mínimo. 


\section{(c) Refluxo mínimo}

Outra condição limite corresponde à razão de refluxo mínimo. Esta condição é atingida quando o número de pratos necessários para a destilação desejada é muito grande. Chega-se a isso quando a linha de operação principal coincide com a linha de equilíbrio num diagrama $h-x$. A Fig. 4.8 assinala com linha cheia a linha de operação principal trabalhando em condições normais e com a pontilhada a linha de operação coincidente com a linha de equilíbrio. Tomando como referência a linha de operação principal igual à linha de equilíbrio, um número de pratos muito grande será necessário perto dessa linha para conseguir purificar a amônia. Quando a razão de refluxo é igual à razão de refluxo mínimo $\left(R_{\min }\right)$, pela Eq. (4.17), o fluxo de calor fornecido ao gerador diminui. No mesmo sentido, o fluxo de calor retirado do retificador, também diminui.

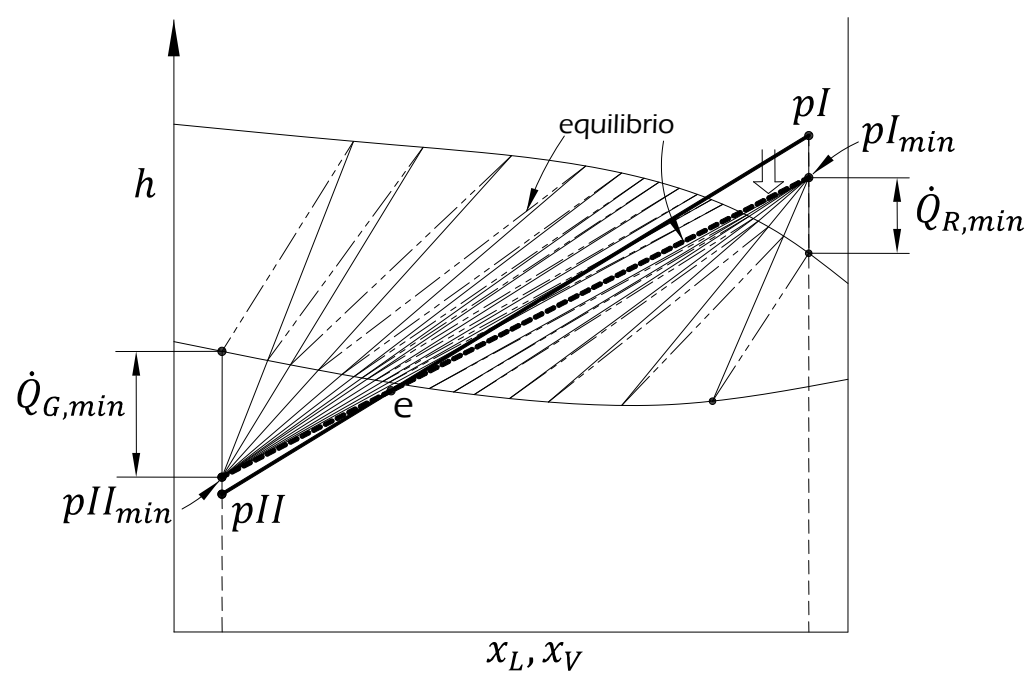

Figura 4.8 - Refluxo mínimo - número de pratos infinito.

Pode-se concluir destas duas condições extremas que uma razão de refluxo mínimo implica um custo maior da coluna de destilação por ter um número muito grande de pratos. De forma contrária, uma razão de refluxo total implica em um grande fluxo de calor a ser fornecido e a ser retirado do gerador e do retificador, respectivamente.

Define-se fator de refluxo $\left(f_{R}\right)$ a razão de refluxo de projeto dividido pela razão de refluxo mínimo. Kister (1992) indica o uso de fatores de refluxos entre 1,05 a 1,3. 


$$
f_{R}=\frac{R}{R_{\min }}
$$

\subsection{PROJETO HIDRÁULICO E GEOMETRIA INTERNA DA COLUNA DE DESTILAÇÃO}

Esta seção considera o dimensionamento da geometria interna da coluna de destilação. Para isso serão usadas correlações encontradas em aplicações na indústria de petróleo, petroquímica e gás natural, como as de Caldas et al. (2007), e correlações gerais para processos de destilação, fornecidas por Perry e Green (1997), Treybal (1981), Bennett e Myers (1978), entre outros.

Fisicamente, uma coluna de destilação para uma solução amônia/água é constituída por um conjunto de trocadores de calor e de massa, que podem ser cilindros de aço carbono ou aço inoxidável. O enchimento das seções de esgotamento e enriquecimento considerado neste trabalho são pratos perfurados, como já informado na Seção 2.2.1. De maneira global, pode-se considerar que os escoamentos de líquido e vapor na coluna de destilação estão em contracorrente, embora eles estejam em fluxo cruzado em cada prato, como indica a Fig. 4.9.

Os furos do prato permitem a passagem do vapor através deles. Quando a velocidade do vapor que atravessa o furo é pequena, formará bolhas grandes e a área interfacial de contato líquido-vapor por unidade de volume será pequena; além disso, grande parte do líquido passará no prato sem ter contato com o vapor. De maneira contrária, quando a velocidade do vapor é grande, o vapor será disperso no líquido de maneira intensa, formando espuma. Esta condição proporciona uma grande área de contato interfacial líquido-vapor por unidade de volume e uma alta eficiência de prato é conseguida. No entanto, se a formação de espuma é muito grande, causa uma baixa eficiência no prato. Serão explicados na sequência os problemas de funcionamento presentes na coluna de destilação. 


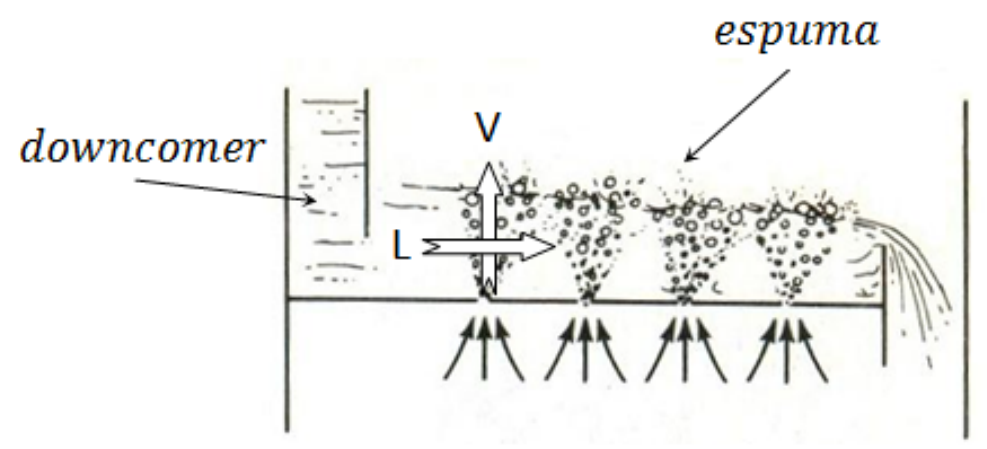

Figura 4.9 - Passagem de vapor pelos furos do prato, em fluxo cruzado com o escoamento líquido (adaptado de Kister, 1992).

Pode-se apresentar problemas de mau funcionamento da coluna quando a vazão de líquido é muito baixa, não sendo suficiente para cobrir a abertura do downcomer (canal de admissão de líquido, Fig. 4.9); e se a vazão de vapor (o gás) é alta, ele tende a passar por essa abertura, causando arraste excessivo do líquido acima do prato e no downcomer, este fenômeno é chamado de blowing e suas vazões características são mostradas na Fig. 4.10.

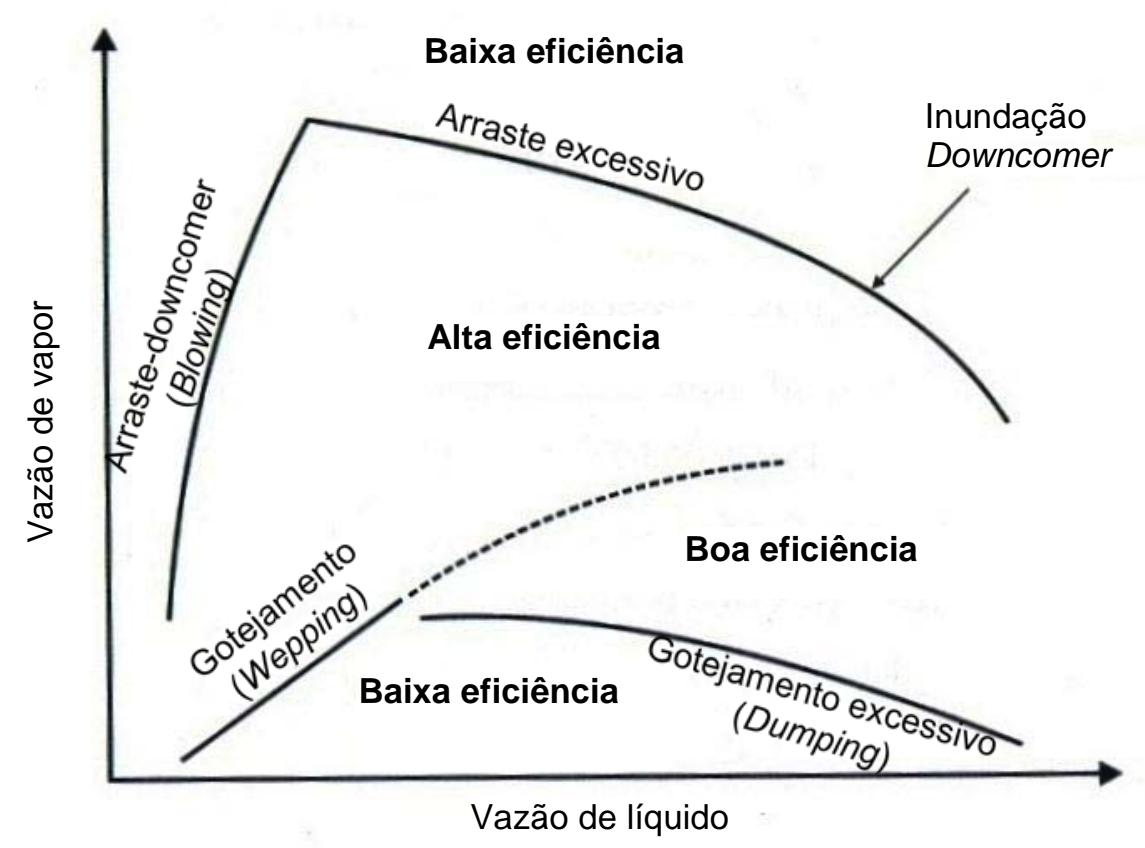

Figura 4.10 - Regimes de operação da coluna de destilação (adaptado de Caldas, 2007). 
Outro comportamento de mal funcionamento pode ser causado quando ocorre inundação (flooding). Existem duas formas de causar inundação na coluna, a primeira é quando uma vazão de líquido muito grande causa o sobrecarregamento do downcomer, resultando na elevação do inventário do líquido e uma alta queda de pressão no prato; o limite deste comportamento é quando a coluna fica inundada. $\mathrm{O}$ fenômeno descrito é conhecido como inundação do downcomer.

A outra forma de inundação acontece quando para uma vazão fixa de líquido a vazão de vapor aumenta, causando um arraste (entrainment) excessivo de líquido. O limite deste fenômeno é quando o líquido de alimentação na coluna é carregado pelo vapor, não o deixando entrar, este comportamento é chamado de inundação por arraste excessivo (priming).

Quando a vazão de vapor é muito baixa o líquido tende a gotejar pelos furos do prato; a este fato se denomina weeping. Se a vazão de líquido aumenta muito, o líquido todo passa pelos furos, e o fenômeno é chamado de dumping.

A velocidade de inundação $V_{F}$ é definida como a velocidade de vapor que manteria uma gota de líquido suspensa sobre o prato. Esta velocidade de inundação pode ser calculada a partir da correlação desenvolvida em 1934, por Souders e Brown (Caldas et al., 2007), a qual é expressada na seguinte equação.

$$
V_{F}=C_{F}\left(\frac{\rho_{L}-\rho_{G}}{\rho_{G}}\right)^{1 / 2}
$$

Esta velocidade deve ser corrigida por um fator que considera a formação de espuma $\left(F_{e}\right)$, que depende dos fluidos e configurações de cada sistema; Treybal (1981) indica valores típicos de 0,80-0,85. Essa velocidade também é corrigida por um fator que considera o afastamento do limite de inundação $\left(F_{i}\right)$; Locket (1986) recomenda um valor típico de 0,8, enquanto Caldas (2007), que segue a recomendação da Koch-Glitch, sugere um fator de 0,82. Desta maneira, a velocidade do vapor de projeto é definida como:

$$
V_{V}=F_{e} F_{i} V_{F}
$$


$\mathrm{Na}$ Eq. (4.34), $C_{F}$ é a constante empírica de inundação, que depende da distância entre pratos $\left(L_{1}\right)$, da tensão superficial do líquido $(\sigma)$ e das massas específicas $(\rho)$ e fluxos mássicos $\left(\dot{m}^{\prime \prime}\right)$ do vapor e do líquido, como mostrado abaixo, Treybal (1981).

$$
C_{F}=\left[\beta_{1} \log \left(\frac{1}{\left(\dot{m}_{L}^{\prime \prime} / \dot{m}_{V}^{\prime \prime}\right)\left(\rho_{V} / \rho_{L}\right)^{0,5}}+\beta_{2}\right)\right]\left(\frac{\sigma}{0,020}\right)^{0,2}
$$

O parâmetro de fluxo (Eq. (4.37)) será designado neste trabalho por $i_{2}$ :

$$
i_{2}=\frac{\dot{m}_{L}^{\prime \prime}}{\dot{m}_{V}^{\prime \prime}}\left(\frac{\rho_{V}}{\rho_{L}}\right)^{0,5}
$$

Quando se tem diâmetros de furos menores que $6 \mathrm{~mm}$, as seguintes relações podem ser usadas para calcular a Eq. (4.36):

$$
\begin{gathered}
i_{2} \geq 0,1 \Rightarrow\left\{\begin{array}{c}
\text { usar } i_{2}=0,1 \\
\beta_{1}=0,0744 L_{1}+0,01173 \\
\beta_{2}=0,0304 L_{1}+0,0150
\end{array}\right. \\
i_{2}<0,1 \Rightarrow\left\{\begin{array}{c}
\text { usar } i_{2} \text { calculado } \\
\beta_{1}=\left(5 i_{1}+0,5\right)\left(0,0744 L_{1}+0,01173\right) \\
\beta_{2}=\left(5 i_{1}+0,5\right)\left(0,0304 L_{1}+0,0150\right)
\end{array}\right.
\end{gathered}
$$

Onde $i_{1}$ (Eq. (4.40)) é a razão entre a área total de todos os furos $\left(A_{0}\right)$ e a área ativa do prato $\left(A_{a}\right)$, também conhecida como área de borbulhamento, as quais podem ser vistas na Fig. 4.11. A área ativa inclui ainda a área dos furos do prato. Nesta figura aparece também a área transversal do downcomer $\left(A_{d}\right)$.

$$
i_{1}=\frac{A_{0}}{A_{a}}
$$




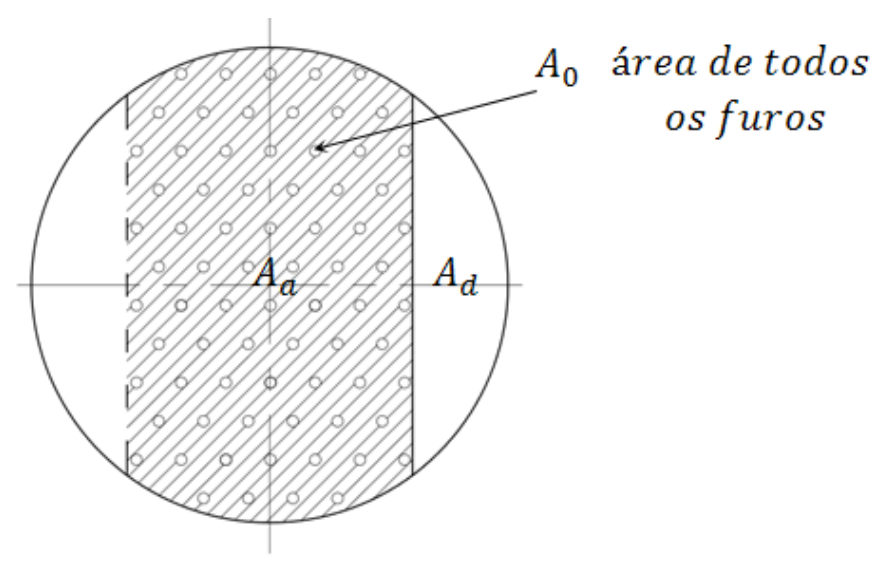

Figura 4.11 - Geometria do prato.

Para uma distância entre os centros dos furos $(b)$, de 2,5 a 5 vezes o diâmetro do furo $d_{0}$, e um arranjo entre eles em forma de triângulo equilátero (Fig. 4.12) a razão de áreas da Eq. (4.40) pode ser expressa como:

$$
i_{1}=\frac{A_{0}}{A_{a}}=0,907\left(\frac{d_{0}}{b}\right)
$$

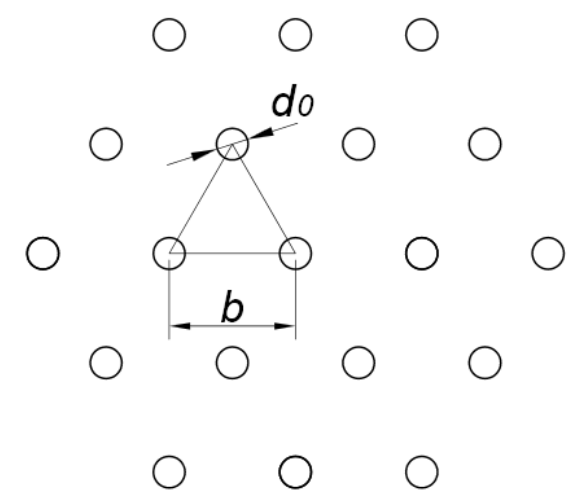

Figura 4.12 - Distribuição dos furos em forma de triangulo equilátero.

O número total de furos no prato pode ser obtido com a seguinte relação:

$$
N_{f}=\frac{A_{0}}{\pi\left(\frac{d_{0}^{2}}{4}\right)}
$$


E a velocidade do vapor ao passar pelo furo:

$$
V_{0}=\frac{\dot{Q}_{V}}{A_{0}}
$$

Onde $\dot{Q}_{V}$ é a vazão volumétrica do vapor, definida como:

$$
\dot{Q}_{V}=\frac{\dot{m}_{V}}{\rho_{V}}
$$

Os pratos geralmente são feitos de chapas de aço com espessura $(e)$ de 2 $\mathrm{mm}(\sim$ bitola 14$)$ para aços inoxidáveis e de $4,5 \mathrm{~mm}$ ( bitola 7$)$ para aço carbono (Treybal, 1981). Os diâmetros dos furos no prato (Fig. 4.13) variam de $1 \mathrm{~mm}$ até 25 $\mathrm{mm}(0,04$ " a 1 "), sendo mais usados os de $3 \mathrm{~mm}$ até $13 \mathrm{~mm}(1 / 8$ " a $1 / 2$ ") (Perry e Green, 1997).

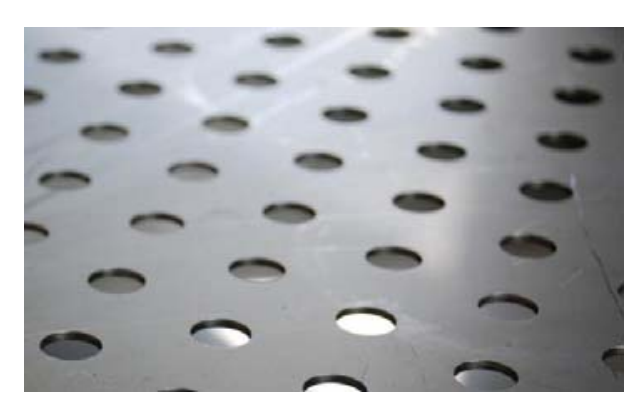

Figura 4.13 - Furos no prato.

A área de passagem do vapor pela coluna (antes ou depois do prato, ver Fig. 4.14), designada por $A_{n}$ é igual à vazão volumétrica do vapor dividida pela velocidade dele (Eq. 4.45). Na Fig. 4.14, vê-se também a altura do vertedor $L_{v}$ e a altura acima do vertedor $L_{0 v}$. Caldas (2007) recomenda alturas do vertedor na faixa de $7 \mathrm{~mm}$ (mínimo) até $100 \mathrm{~mm}$ (máximo).

$$
A_{n}=\frac{\dot{Q}_{V}}{V_{V}}
$$




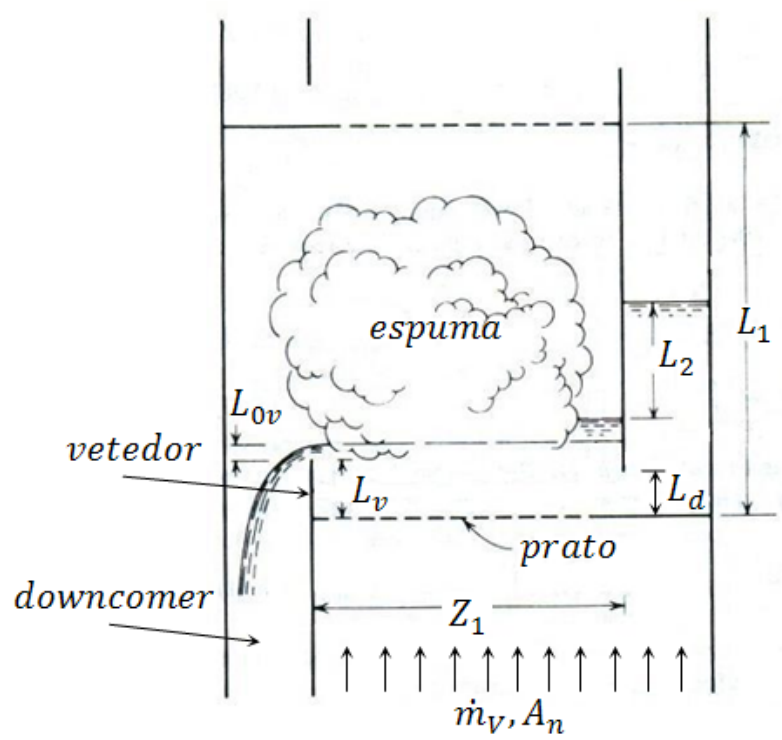

Figura 4.14 - Configuração dos escoamentos líquido e vapor e algumas dimensões no prato (adaptado de Treybal, 1981).

A vista de planta da Fig. 4.14 é mostrado na Fig. 4.15, a qual indica também, algumas outras dimensões no prato.
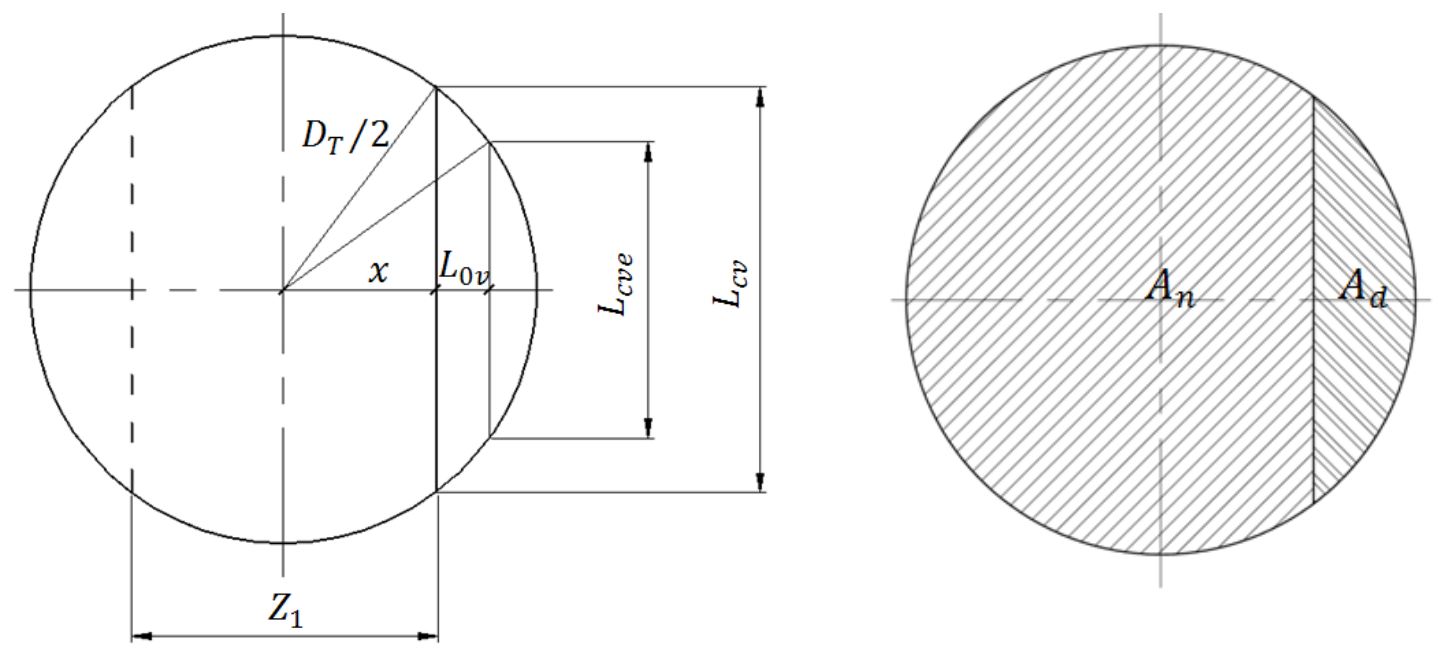

Figura 4.15 - Dimensões no prato.

Define-se como fator vertedor-diâmetro da coluna $\left(F_{v}\right)$ a razão entre 0 comprimento de corda do vertedor e o diâmetro da coluna, como apontado na Eq. (4.46), Treybal (1981) recomenda valores de 0,6 até 0,8, enquanto Caldas (2007) assinala como típico, 0,85. 


$$
F_{v}=\frac{L_{c v}}{D_{T}}
$$

Da Fig. 4.15, obtêm-se as seguintes relações usando $F_{v}$ :

$$
\begin{gathered}
j_{1}=\frac{x}{D_{T}}=\frac{Z_{1}}{2 D_{T}}=\sqrt{\frac{1}{4}-\frac{F_{v}^{2}}{4}} \\
j_{2}=\frac{A_{d}}{A_{T}}=\frac{8}{\pi}\left[\frac{\operatorname{arcsen}\left(F_{v}\right)}{8}-\left(\frac{1}{4}-\frac{F_{v}^{2}}{4}\right)^{0,5}\left(\frac{F_{v}}{4}\right)\right]
\end{gathered}
$$

Se $F_{v}$ varia de 0,6 até 0,8, a área do downcomer será de 5,2\% até 14,2\% à área transversal da coluna.

Da Fig. 4.15 tem-se:

$$
A_{T}=A_{n}+A_{d}
$$

Assim, das Eqs. (4.48) e (4.49):

$$
A_{T}=\frac{A_{n}}{1-j_{2}}
$$

Também:

$$
D_{T}=\sqrt{\frac{4 A_{T}}{\pi}}
$$

Da Fig. 4.11:

$$
A_{a}=A_{T}-2 A_{d}
$$


E a velocidade do vapor na área de borbulhamento é definida como:

$$
V_{a}=\frac{\dot{Q}_{V}}{A_{a}}
$$

$\mathrm{Na}$ Fig. 4.15, $L_{c v}$ é o comprimento de corda do vertedor. A altura acima do vertedor $L_{0 v}$ e a vazão volumétrica do líquido $\left(\dot{Q}_{L}\right)$ estão relacionadas pela equação de Francis (Treybal, 1981), a qual adquire a forma da Eq. (4.54) para o vertedor segmentado mostrado na Fig. 4.14. Nessa equação, utiliza-se o comprimento efetivo de corda do vertedor $\left(L_{c v e}\right)$, que corrige o efeito de curvatura da parede da coluna.

$$
\frac{\dot{Q}_{L}}{L_{c v e}}=1,839 L_{0 v}^{3 / 2}
$$

Onde $\dot{Q}_{L}$ é a vazão volumétrica do líquido, definida como:

$$
\dot{Q}_{L}=\frac{\dot{m}_{L}}{\rho_{L}}
$$

Da Fig. 4.15 consegue-se:

$$
\begin{gathered}
\left(\frac{D_{T}}{2}\right)^{2}=\left(\frac{L_{c v}}{2}\right)^{2}+x^{2} \\
\left(\frac{D_{T}}{2}\right)^{2}=\left(\frac{L_{c v e}}{2}\right)^{2}+\left(x+L_{0 v}\right)^{2}
\end{gathered}
$$

Substituindo $x$ da Eq. (4.56) na Eq. (4.57)

$$
\left(\frac{L_{c v e}}{2}\right)^{2}=\left(\frac{D_{T}}{2}\right)^{2}-\left\{\left[\left(\frac{D_{T}}{2}\right)^{2}-\left(\frac{L_{c v e}}{2}\right)^{2}\right]^{0,5}+L_{0 v}\right\}^{2}
$$

Multiplicando a Eq. (4.58) por $\left(4 / L_{c v}^{2}\right)$, chega-se a: 


$$
\left(\frac{L_{c v e}}{L_{c v}}\right)^{2}=\left(\frac{D_{T}}{L_{c v}}\right)^{2}-\left\{\left[\left(\frac{D_{T}}{L_{c v}}\right)^{2}-1\right]^{0,5}+2 \frac{L_{0 v}}{D_{T}} \frac{D_{T}}{L_{c v}}\right\}^{2}
$$

As equações (4.54) e (4.59) resolvem-se simultaneamente para obter $L_{c v e} \mathrm{e}$ $L_{0 v}$.

Algumas dimensões do prato foram estudadas. Na sequência serão consideradas as quedas de pressão do vapor no prato. Nele, podem ser identificados três tipos de quedas de pressão: quando o vapor atravessa a espessura do prato, quando o vapor atravessa o líquido e outra, produto do desprendimento da bolha de vapor do prato, chamada queda de pressão residual (Treybal, 1981).

A queda de pressão do vapor ao passar pelo prato pode ser entendida como se ele passasse por uma placa de orifício (seco) e depende das configurações geométricas do prato, do coeficiente de descarga $\left(C_{0}\right)$ e do fator de atrito de Fanny $(f)$, como relacionado abaixo:

$$
\Delta P_{P}=C_{0}\left[0,40\left(1,25-\frac{A_{0}}{A_{n}}\right)+4 \frac{e f}{d_{0}}+\left(1-\frac{A_{0}}{A_{n}}\right)^{2}\right] \frac{V_{0}^{2}}{2} \rho_{V}
$$

Onde os três termos do lado direito desta equação representam as quedas de pressão quando o vapor entra, passa e sai do prato, respectivamente. Para valores de $\left(e / d_{0}\right)$ de 0,2 até 2,0 o coeficiente de descarga é definido como:

$$
C_{0}=1,09\left(\frac{d_{0}}{e}\right)^{0,25}
$$

A queda de pressão do vapor, ao passar pelo líquido no prato, é calculada para um líquido sem presença de espuma. A altura do líquido sem espuma é menor do que $\left(L_{v}+L_{0 v}\right)$. Essa queda de pressão pode ser calculada pela seguinte correlação: 


$$
\Delta P_{L}=\rho_{L} g\left[6,10 \times 10^{-3}+0,725 L_{v}-0,238 L_{v} V_{a} \sqrt{\rho_{V}}+1,225\left(\frac{\dot{Q}_{L}}{z}\right)\right]
$$

Onde $g$ é a aceleração da gravidade e $z$ é uma medida da largura onde passa o líquido no prato, podendo ser calculada como:

$$
z=\frac{D_{T}+L_{c v}}{2}
$$

A altura equivalente de líquido para a perda de pressão $\Delta P_{L}$ é igual a:

$$
L_{L}=\frac{\Delta P_{L}}{\rho_{L} g}
$$

A queda de pressão residual é uma medida da diferença da queda de pressão medida experimentalmente e a calculada. Esta diferença varia com a tensão superficial quando é calculada a partir do desprendimento da bolha de vapor do prato:

$$
\Delta P_{R}=\frac{6 \sigma}{d_{0}}
$$

Assim, a queda de pressão total do vapor será:

$$
\Delta P_{V}=\Delta P_{p}+\Delta P_{R}+\Delta P_{L}
$$

Outra queda de pressão importante é a da água quando passa sob o downcomer. Se o atrito é desprezível, essa queda de pressão pode ser expressa como: 


$$
\Delta P_{d}=\rho_{L} \frac{3}{2}\left(\frac{\dot{Q}_{L}}{A_{d a}}\right)^{2}
$$

Onde $A_{d a}$ é a área menor entre a área transversal do downcomer $\left(A_{d}\right)$ e a área por onde passa o líquido sob o downcomer (ver Fig. 4.14). A última definida como:

$$
A_{x}=L_{c v} \times L_{d}
$$

A altura do líquido no downcomer $\left(L_{2}\right)$, mostrada na Fig. 4.14 pode ser calculada como a soma das alturas equivalentes às perdas de pressão do vapor e do líquido, segundo a seguinte equação:

$$
L_{2}=\frac{\Delta P_{V}}{\rho_{L} \times g}+\frac{\Delta P_{d}}{\rho_{L} \times g}
$$

Como já comentado no início dessa seção, um mal funcionamento da coluna acontece quando as gotas de líquido são carregadas pelo vapor (arraste); esse fato faz com que as pequenas gotas se misturem com o líquido do prato superior, diminuindo sua eficiência. Treybal (1981) recomenda que para evitar esse problema, pode ser usada a seguinte condição:

$$
L_{1}>2\left(L_{2}+L_{v}+L_{0 v}\right)
$$

Esta condição será um parâmetro importante considerado neste trabalho.

Como já discutido, outra condição que causa problemas no funcionamento adequado da coluna é quando a velocidade do vapor não é o suficientemente grande e, como consequência o líquido vaza pelos furos do prato (weeping). Para garantir que isso não aconteça, Treybal (1981) aconselha que a velocidade do vapor deva ser maior que uma mínima, definida como:

$$
V_{0 w}=0,0229\left(\frac{\sigma}{\mu_{V}}\right)\left(\frac{\mu_{V}^{2}}{\sigma \rho_{V} d_{0}} \frac{\rho_{L}}{\rho_{V}}\right)^{0,379}\left(\frac{e}{d_{0}}\right)^{0,293}\left(\frac{2 A_{a} A_{0}}{\sqrt{3} b^{3}}\right)^{\frac{2,8}{\left(\frac{Z_{1}}{d_{0}}\right)^{0,724}}}
$$




\subsection{EFICIÊNCIA DA COLUNA DE DESTILAÇÃO E NÚMERO DE PRATOS REAIS}

$\mathrm{Na}$ Seção 4.1 foi calculado o número de pratos ideais que a coluna de destilação deve ter para atingir teoricamente a pureza desejada do vapor de amônia. $\mathrm{Na}$ condição de pratos ideais, o tempo de mistura entre o líquido e o vapor que entram no prato é o suficientemente longo para que eles saiam do mesmo em condições de equilíbrio. Assim, não é mais possível haver maior mudança em concentrações dos efluentes do que aqueles quando atingem o equilíbrio, mas na prática essas condições ideais de equilíbrio não acontecem.

Esta seção considera o cálculo do número de pratos reais em função da eficiência global da coluna e o número de pratos ideais.

A eficiência global da coluna é definida como:

$$
\eta_{c}=\frac{N_{i}}{N_{r}}
$$

Onde $N_{i}$ representa o número de pratos ideias da coluna e $N_{r}$, o número de pratos reais. O primeiro pode ser calculado pelo método de Ponchon-Savarit, como informado na Seção 4.1. O número de pratos reais pode ser calculado se a eficiência global da coluna é determinada.

Para avaliar essa eficiência, considera-se primeiramente a transferência de massa no elemento mostrado na Fig. 4.16(a). Nas fases líquida e vapor desse elemento, existe um gradiente de concentração, ocasionando que os elementos que o conformam se movimentem da porção de maior concentração à de menor concentração. Se os escoamentos permanecem imóveis, os elementos de diferentes gradientes se difundirão a uma velocidade lenta. Já se os escoamentos estão em turbulência, os elementos se movimentarão rápido, fazendo com que a troca de massa seja intensificada.

Cada faixa transversal horizontal do elemento da Fig. 4.16(a) terá concentrações de vapor e líquidos diferentes, variando debaixo para cima em um 
diferencial de fração molar $d \bar{x}$. Essa faixa pode ser representada na Fig. 4.16(b), onde se podem ver as frações molares no seio do vapor $\left(\bar{x}_{V}\right)$ e do líquido $\left(\bar{x}_{L}\right)$, assim como as frações molares na interface, para o vapor $\left(\bar{x}_{V, i}\right)$ e para o líquido $\left(\bar{x}_{L, i}\right)$, as quais encontram-se em equilíbrio.

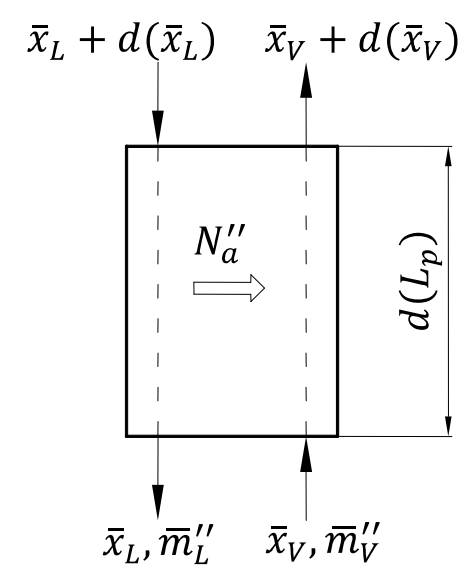

(a)

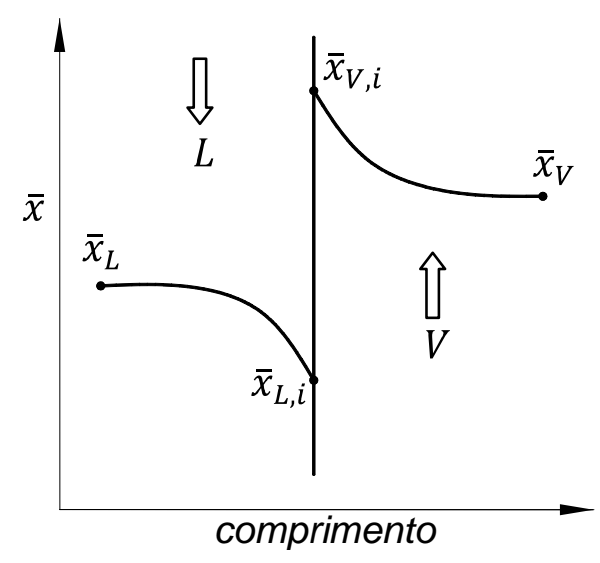

(b)

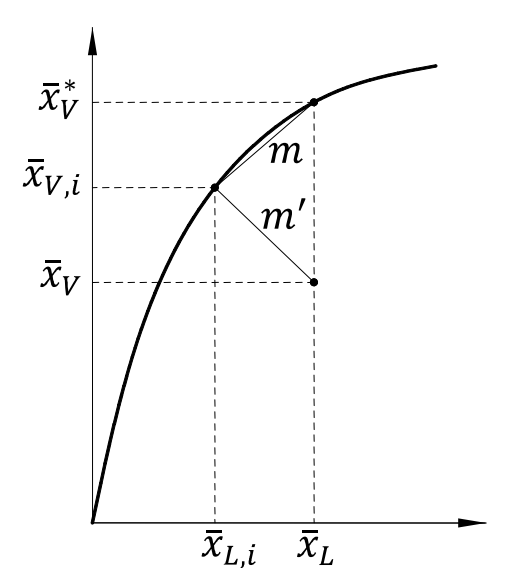

(c)

Figura 4.16 - (a) transferência de massa num elemento, (b) representação das frações molares na interface (c) representação das frações molares na curva de equilíbrio.

As frações molares da faixa do elemento também podem ser representadas na curva de equilíbrio, como exposto na Fig. 4.16(c).

Lewis e Whitman, em 1924 (Caldas, 2007), propuseram a teoria das duas resistências, supondo-se que na interface líquido-vapor a resistência à difusão é 
nula ou desprezível. Assim, o fluxo que passa da fase líquida à fase vapor não terá variação. Em concordância com a expressão para o fluxo de calor, o fluxo molar na fase líquida pode ser representado da seguinte forma:

$$
N_{a}^{\prime \prime}=k_{x}\left(\bar{x}_{L}-\bar{x}_{L, i}\right)
$$

Da mesma maneira, o fluxo molar na fase vapor:

$$
N_{a}^{\prime \prime}=k_{y}\left(\bar{x}_{V, i}-\bar{x}_{V}\right)
$$

Onde $k_{x}$ e $k_{x}$ são os coeficientes de transferência de massa para o líquido e para o vapor, respectivamente. As Eqs. (4.73) e (4.74) não são práticas se se quer calcular o fluxo molar, já que deve-se conhecer as concentrações molares na interface e qualquer instrumento colocado nela perturbaria o equilíbrio. Para evitar essas dificuldades se adota a seguinte equação:

$$
N_{a}^{\prime \prime}=K_{Y}\left(\bar{x}_{V}^{*}-\bar{x}_{V}\right)
$$

Onde $K_{Y}$ é chamado de coeficiente global de transferência de massa baseado na fase vapor e $\bar{x}_{V}^{*}$ representa uma fração molar de vapor fictícia, que está em equilíbrio com $\bar{x}_{L}$, ver Fig. 4.16(c). Da mesma figura pode-se obter:

$$
\begin{gathered}
m=\frac{\bar{x}_{V}^{*}-\bar{x}_{V, i}}{\bar{x}_{L}-\bar{x}_{L, i}} \\
\bar{x}_{V}^{*}-\bar{x}_{V}=\left(\bar{x}_{V, i}-\bar{x}_{V}\right)+\left(\bar{x}_{V}^{*}-\bar{x}_{V, i}\right)
\end{gathered}
$$

Substituindo as Eqs. (4.73) a (4.76) na Eq. (4.77), chega-se a:

$$
\frac{1}{K_{Y}}=\frac{1}{k_{y}}+\frac{m}{k_{x}}
$$

Nota-se que $1 / K_{Y}$ tem em conta as resistências da fase líquida e da fase vapor, assim, representa a resistência global da transferência de massa. 
À continuação analisar-se-á a transferência de massa na interface assim como a mudança em massa no eixo vertical do elemento da Fig. 4.16(a). A quantidade de moles por unidade de tempo que atravessa a superfície interfacial $d S_{i}$ é $N_{a}^{\prime \prime} d S_{i}$. Da mesma forma, a variação em moles de " $a$ " por unidade de tempo no comprimento vertical $d\left(L_{p}\right)$ é $A d\left(\bar{m}_{V}^{\prime \prime} \bar{x}_{V}\right)$. Igualando estes dois termos:

$$
N_{a}^{\prime \prime} d S_{i}=A d\left(\bar{m}_{V}^{\prime \prime} \bar{x}_{V}\right)
$$

Onde $A$ é a área transversal do elemento e $\bar{m}_{V}^{\prime \prime}$ é o fluxo molar de vapor no sentido vertical, o qual se admite como constante, assim temos:

$$
N_{a}^{\prime \prime} d S_{i}=A \bar{m}_{V}^{\prime \prime} d \bar{x}_{V}
$$

Define-se $a_{i}$ como a área interfacial por unidade de volume:

$$
a_{i}=\frac{d S_{i}}{d V}=\frac{d S_{i}}{A d L_{p}}
$$

Substituindo-o na Eq. (4.80)

$$
N_{a}^{\prime \prime} a_{i} d L_{p}=\bar{m}_{V}^{\prime \prime} d \bar{x}_{V}
$$

Se a Eq. (4.74) é substituída em (4.82), tem-se:

$$
k_{y}\left(\bar{x}_{V, i}-\bar{x}_{V}\right) a_{i} d L_{p}=\bar{m}_{V}^{\prime \prime} d \bar{x}_{V}
$$

E daí:

$$
\int_{\bar{x}_{V, n+1}}^{\bar{x}_{V, n}} \frac{d \bar{x}_{V}}{\bar{x}_{V, i}-\bar{x}_{V}}=\int_{0}^{L_{L}} \frac{k_{y} a_{i} d L_{p}}{\bar{m}_{V}^{\prime \prime}}
$$

$\mathrm{Na}$ equação anterior, considera-se o produto $k_{y} a_{i}$ como constante. $\mathrm{O}$ elemento da esquerda é definido como número de unidades de transferência da fase vapor, assim essa equação fica como: 


$$
N_{t V}=\frac{k_{y} a_{i} L_{L}}{\bar{m}_{V}^{\prime \prime}}
$$

Seguindo o mesmo procedimento para o fluxo molar na fase líquida e para o fluxo molar em função do coeficiente de transferência de massa global, obtém-se:

$$
\begin{gathered}
N_{t L}=\frac{k_{x} a_{i} L_{L}}{\bar{m}_{L}^{\prime \prime}} \\
N_{\text {toV }}=\frac{K_{Y} a_{i} L_{L}}{\bar{m}_{V}^{\prime \prime}}
\end{gathered}
$$

Se as Eqs. (4.85) a (4.87) se substituem na Eq. (4.78), consegue-se:

$$
\frac{1}{N_{t o V}}=\frac{1}{N_{t V}}+m \frac{\bar{m}_{V}^{\prime \prime}}{\bar{m}_{L}^{\prime \prime}} \frac{1}{N_{t L}}
$$

Da Fig. 4.16(c) a inclinação $m^{\prime}$ pode ser calculada como:

$$
m^{\prime}=\frac{\bar{x}_{V, i}-\bar{x}_{V}}{\bar{x}_{L, i}-\bar{x}_{L}}
$$

Substituindo as Eqs. (4.73), (4.74), (4.85) e (4.86) na Eq. (4.89) obtém-se:

$$
m^{\prime}=-\frac{k_{x}}{k_{y}}=-\frac{\bar{m}_{L}^{\prime \prime}}{\bar{m}_{V}^{\prime \prime}} \frac{N_{t L}}{N_{t V}}
$$

Define-se agora a eficiência de ponto referente ao vapor (Eq. (4.91)) como a razão da mudança em fração molar do vapor de um ponto ao passar num estágio, dividido pela mudança em fração molar, que aconteceria no mesmo ponto em um estágio teórico. De acordo com a Fig. 4.17: 


$$
\eta_{P V}=\left[\frac{\bar{x}_{V, n}-\bar{x}_{V, n+1}}{\bar{x}_{V, n}^{*}-\bar{x}_{V, n+1}}\right]_{\text {local }}
$$

Onde $\bar{x}_{V, n, l o c a l}^{*}$ está em equilíbrio com $\bar{x}_{L, n, l o c a l}$, a qual, na definição de eficiência de ponto, é considerada constante na direção vertical, portanto $\bar{x}_{V, n, l o c a l}^{*}$ também será constante.

Das Eq. (4.75) e (4.82) e considerando a Fig. 4.17, obtém-se:

$$
\int_{\bar{x}_{V, n+1, l o c a l}}^{\bar{x}_{V, n, l o c a l}} \frac{d \bar{x}_{V}}{\bar{x}_{V, n, l o c a l}^{*}-\bar{x}_{V}}=\int_{0}^{L_{L}} \frac{K_{Y} a_{i} d L_{p}}{\bar{m}_{V}^{\prime \prime}}
$$

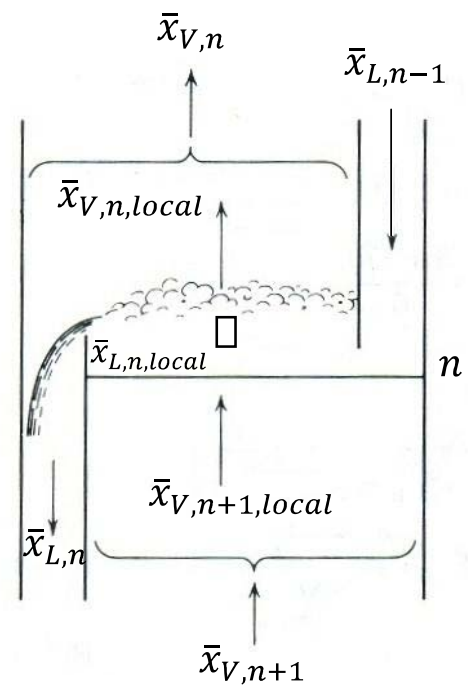

Figura 4.17 - Esquema para o cálculo da eficiência de ponto, e do prato.

$$
-\ln \left(\frac{\bar{x}_{V, n}^{*}-\bar{x}_{V, n}}{\bar{x}_{V, n}^{*}-\bar{x}_{V, n+1}}\right)_{\text {local }}=\frac{K_{Y} a_{i} L_{L}}{\bar{m}_{V}^{\prime \prime}}
$$

Substituindo termos da Eq. (4.87) e (4.91) na Eq. (4.93) obtém-se:

$$
\eta_{P V}=1-e^{-N_{t o V}}
$$


A eficiência do ponto leva em conta uma faixa vertical do estágio. Agora, será definida a eficiência de Murphree (Locket, 1986), que é análoga à do ponto, porém neste caso se considera todo o prato. Tendo como referência o vapor, a eficiência de Murphree é a razão entre a mudança da fração molar de vapor num prato real e a que teria em um prato teórico. Esta eficiência em concordância com a Fig. 4.17 é definida como:

$$
\eta_{M V}=\frac{\bar{x}_{V, n}-\bar{x}_{V, n+1}}{\bar{x}_{V, n}^{*}-\bar{x}_{V, n+1}}
$$

A eficiência do prato está relacionada com a do ponto mediante o número de Peclet, que considera o grau de mistura da solução bifásica, definida neste caso como:

$$
P e=\frac{Z_{1}^{2}}{D_{E} \theta_{L}}
$$

Onde $Z_{1}$ é o percurso do líquido no prato, $D_{E}$ é a difusividade turbilhonar e $\theta_{L}$ é tempo de residência da fase líquida no prato, sendo que o tempo de residência mínimo para permitir que as bolhas de vapor se separem do líquido é de 5 segundos (com muita espuma) e 4 segundos com espuma moderada (Caldas, 2007).

A razão entre a eficiência de Murphree e do ponto podem ser calculadas pela equação desenvolvida por Gester et al. em 1958 (Caldas, 2007), que é dada por:

$$
\frac{\eta_{M V}}{\eta_{P V}}=\frac{1-e^{-(\xi+P e)}}{(\xi+P e)\left[1+\frac{(\xi+P e)}{\xi}\right]}+\frac{e^{\xi}-1}{\xi\left[1+\frac{\xi}{(\xi+P e)}\right]}
$$

Onde:

$$
\xi=\frac{P e}{2}\left(\sqrt{1+4 m \frac{\bar{m}_{V}^{\prime \prime}}{\bar{m}_{L}^{\prime \prime}} \frac{\eta_{P V}}{P e}}-1\right)
$$


Treybal (1981) indica as seguintes equações empíricas para o caso de pratos perfurados:

$$
\begin{gathered}
N_{t V}=\frac{0,776+4,57 L_{v}-0,238 V_{a} \sqrt{\rho_{V}}+104,6 \frac{\dot{Q}_{L}}{z_{1}}}{\sqrt{S c_{V}}} \\
N_{t L}=40000 \sqrt{D_{L}}\left(0,213 V_{a} \sqrt{\rho_{V}}+0,15\right) \theta_{L} \\
D_{E}=\left(3,93 \times 10^{-3}+0,017 V_{a}+3,67 \frac{\dot{Q}_{L}}{Z_{1}}+0,18 L_{v}\right)^{2} \\
\theta_{L}=\frac{L_{L} z Z_{1}}{\dot{Q}_{L}}
\end{gathered}
$$

O arraste de líquido pelo vapor (entrainment) é um problema muitas vezes inevitável, por causa de diversos fatores, como por exemplo, a variação das vazões do líquido e do vapor. O arraste faz com que a eficiência do prato diminua. Assim, a eficiência de Murphree pode ser corrigida, considerando o arraste, pela expressão de Colburn (Perry e Green, 1997):

$$
\frac{\eta_{M V E}}{\eta_{M V}}=\frac{1}{1+\eta_{M V}\left(\frac{\psi}{1-\psi}\right)}
$$

Onde $\psi$ é o arraste fracionário definido por Fair (1961) como:

$$
\psi=\frac{\bar{m}_{e}}{\bar{m}_{L}+\bar{m}_{e}}
$$

$\bar{m}_{e}$ é a vazão molar de arraste entrando no prato superior. Fair (1961) fez trabalhos experimentais com o arraste e inundação e obteve um gráfico, relacionando o arraste fracionário, o parâmetro fluxo e o de inundação. Economopoulos, em 1978 (Anand e Erickson, 1999), conseguiu equacionar o arraste fracionário, coincidindo com o gráfico obtido experimentalmente por Fair (1961). Segue a equação mencionada acima: 


$$
\psi=e^{\left[-\left(6,692+1,956 F_{i}\right) i_{2}^{\left(-0,132+0,654 F_{i}\right)}\right]}
$$

A eficiência global da coluna se relaciona com a eficiência de Murphree, corrigida pelo arraste, mediante equação de Lewis (Perry e Green, 1997).

$$
\eta_{c}=\frac{\log \left[1+\eta_{M V E}\left(m \frac{\bar{m}_{V}^{\prime \prime}}{\bar{m}_{L}^{\prime \prime}}-1\right)\right]}{\log \left(m \frac{\bar{m}_{V}^{\prime \prime}}{\bar{m}_{L}^{\prime \prime}}\right)}
$$

\subsection{VARIÁVEIS DE ENTRADA E SAÍDA E PARÂMETROS DE SIMULAÇÃO}

Nos itens anteriores, foram revisados conceitos de equilíbrio líquido-vapor em misturas bifásicas, balanço de massa e de energia na coluna de destilação, assim como considerações hidráulicas do sistema, geometria interna da coluna e finalmente a eficiência desta. As equações desenvolvidas a partir desses conceitos, juntamente com as propriedades termodinâmicas e de transporte, assim como, condições de equilíbrio da mistura, formam um sistema não linear de equações as quais serão implementadas num modelo computacional.

O software utilizado para resolver esse sistema de equações é o EES (Engineering Equation Solver), o qual já tem como sub-rotina condições de equilíbrio e propriedades termodinâmicas para a mistura amônia/água que serão acopladas ao sistema de equações.

As variáveis de entrada para a simulação da coluna de destilação analisada pelo método de Ponchon-Savarit são mostradas esquematicamente na Fig. 4.18(a), as quais são: escoamentos de entrada e saída da coluna, pressão do sistema e fator de refluxo. A partir dessas variáveis é possível conhecer o estado e as propriedades termodinâmicas dos escoamentos que saem e que ingressam em cada prato, tanto para o líquido quanto para o vapor; assim como outras variáveis, indicadas na Fig. 4.18(b). Uma vez implementadas as equações no EES, é possível avaliar a sensibilidade de cada variável. 


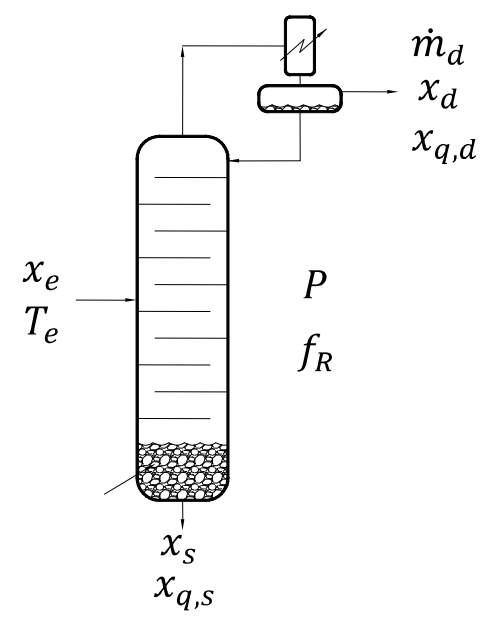

(a)
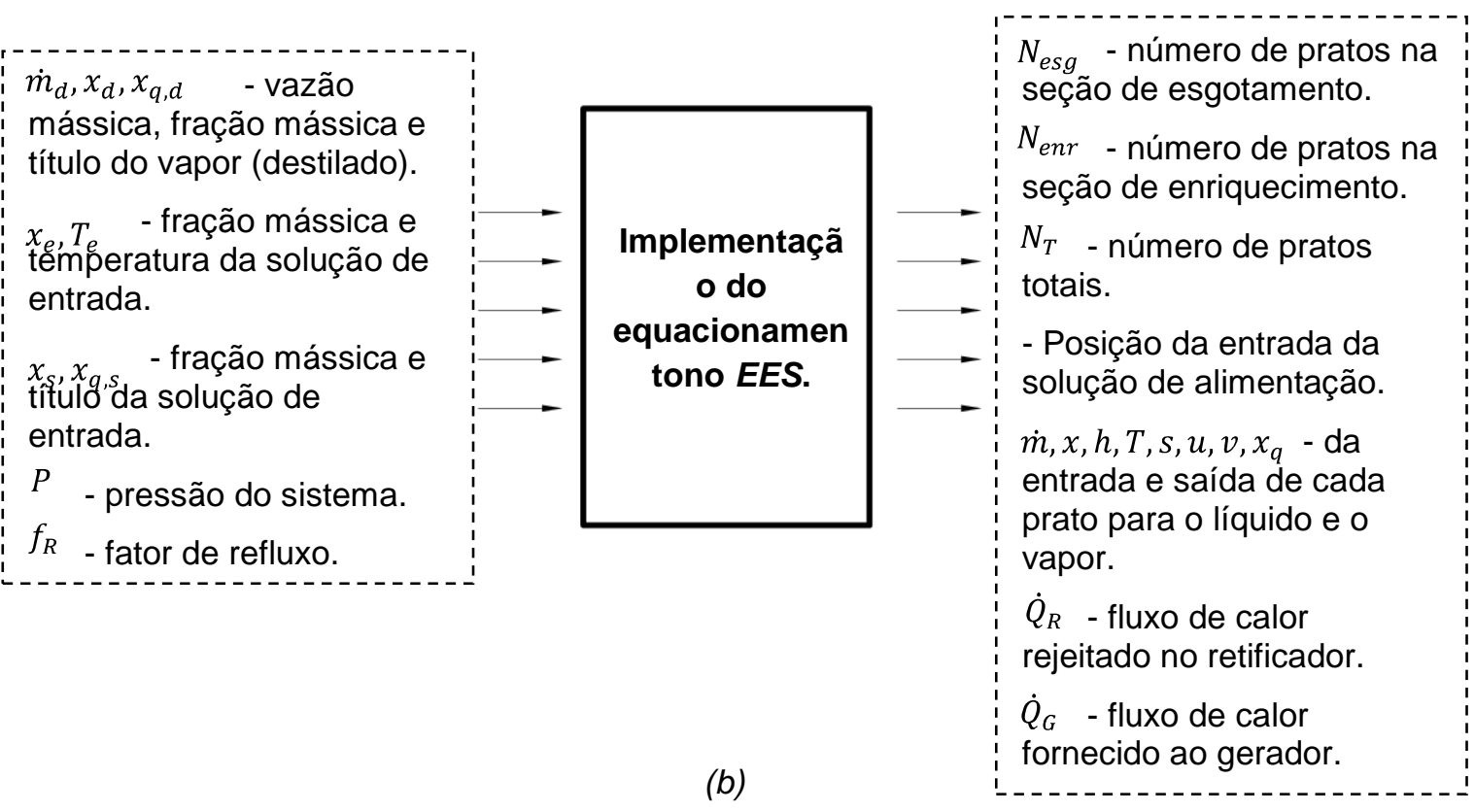

Figura 4.18 - (a) variáveis de entrada (b) variáveis de entrada e saída para a o balanço da coluna de destilação segundo o método de Ponchon-Savarit.

As variáveis $\dot{m}_{d}, x_{d}, x_{q, d}, x_{e}, T_{e}, x_{s}, x_{q, s}, P$ foram obtidas de Ortigosa (2008). Quanto ao fator de refluxo $f_{R}$, Kister (1992) recomenda valores de 1,05 a 1,3. Esse fator é importante na hora de calcular o número de pratos da coluna e os fluxos de calor envolvidos no gerador e no retificador; portanto sua sensibilidade será avaliada. 
É apresentado na Fig. 4.19 um esquema das variáveis de entrada e as de saída para o cálculo da geometria e eficiência da coluna. Na sequência, serão analisadas as variáveis de entrada envolvidas no cálculo.

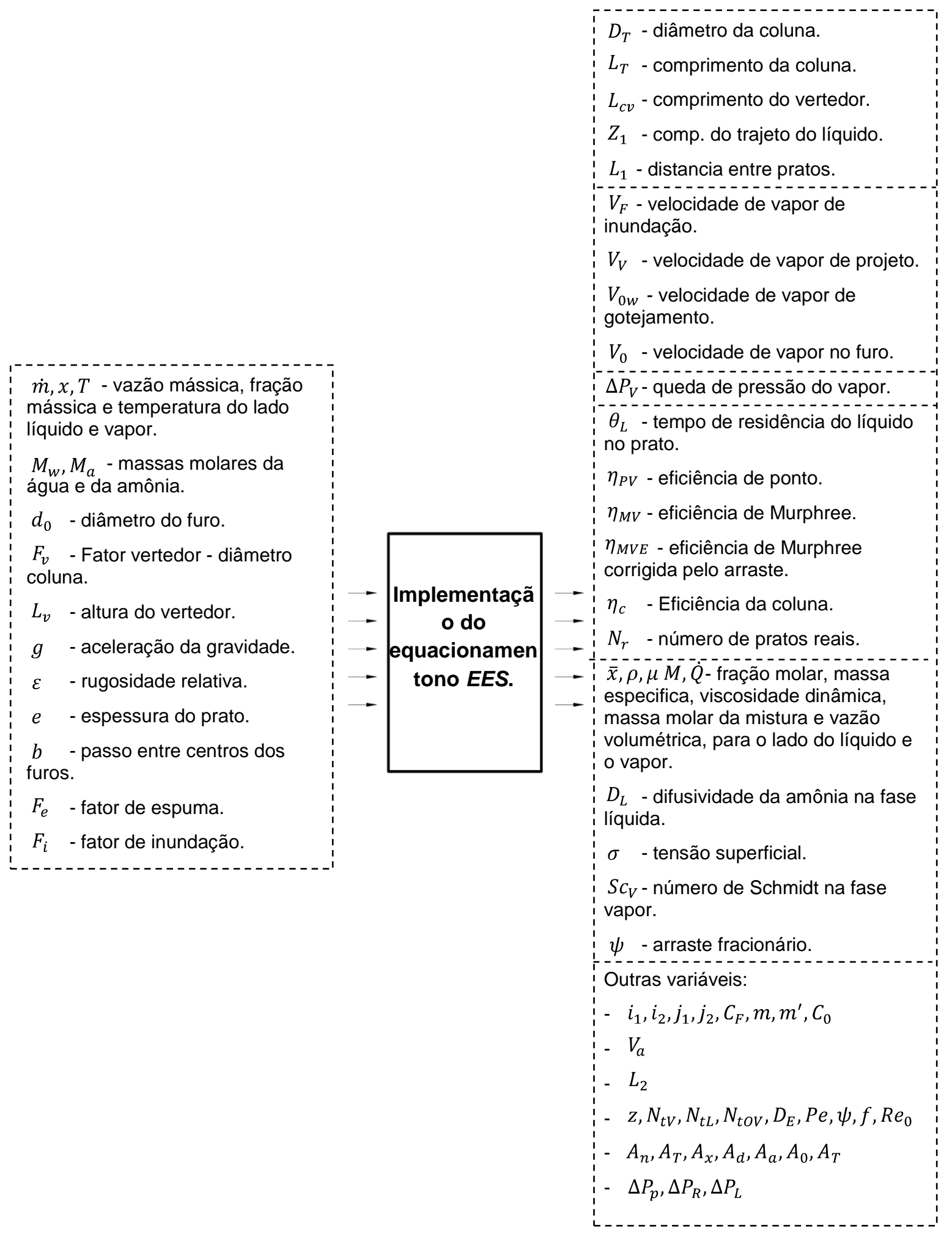

Figura 4.19 - Variáveis de entrada e saída para o cálculo da geometria da coluna, 
A vazão mássica, fração mássica e temperatura $(\dot{m}, x, T)$ dos escoamentos do líquido e do vapor são obtidas a partir do balanço feito na coluna mediante o método de Ponchon-Savarit, as massas molares da amônia e da água são apresentadas na Tabela 4.2.

Tabela 4.2 - Massa molar da amônia e da água.

\begin{tabular}{ccc}
\cline { 2 - 3 } & Unidade & Massa Molar \\
\hline Amônia & $\mathrm{kg} / \mathrm{kmol}$ & 17 \\
Água & $\mathrm{kJ} / \mathrm{kmol}$ & 18 \\
\hline
\end{tabular}

A espessura do prato é estabelecida por fatores de resistência. Tomando isso em consideração, são usadas bitolas padrão US de 10 a 14 (de 4 mm a 2 mm aproximadamente), da mesma forma, pela dureza do metal e considerações de usinagem, o diâmetro do furo, segundo Perry e Green (1997), é limitado pela seguinte relação:

$$
0,4<\frac{e}{d_{0}}<0,7
$$

Desta relação pode-se inferir que o diâmetro do furo varia segundo a seguinte relação:

$$
\frac{e}{0,7}<d_{0}<\frac{e}{0,4}
$$

Treybal (1981) recomenda uma espessura de chapa para o aço inoxidável de 2 mm, então, segundo a Eq. (4.108), o diâmetro de furo varia de 2,86 mm até $5 \mathrm{~mm}$. Adotar-se-á neste trabalho um diâmetro de furo de $3 \mathrm{~mm}$.

O arranjo dos furos no prato usualmente é de forma de triângulo equilátero com distância entre furos (b) de 2,5 a 4 vezes seu diâmetro, já que, segundo Perry e Green (1997), distâncias menores que essa, podem acarretar gotejamento do líquido 
pelos furos e, distâncias maiores causam maiores quedas de pressão e altos valores de arraste. Neste trabalho, se considera uma distância entre furos de 3,75 vezes seu diâmetro.

Para a razão de corda do vertedor seguir-se-á a recomendação de Caldas (2007) em um valor de 0,85. Para o fator de espuma se adotará um valor de 0,83 (Treybal, 1981) e o fator de inundação usar-se-á um valor típico de 0,80 (Locket, 1986).

A rugosidade relativa é considerada desprezível dada a espessura muito pequena do prato, assim, a queda de pressão no furo referente ao atrito é pequena. Para a aceleração da gravidade adotar-se-á o valor padrão de 9,81 $\mathrm{m} / \mathrm{s}^{2}$.

A altura do vertedor é um parâmetro de projeto que será variado para reduzir a geometria da coluna. 


\section{RESULTADOS E DISCUSSÃO}

$\mathrm{Na}$ Seção 4.1, foram apresentados os balanços de massa e de energia pelo método de Ponchon-Savarit na coluna de destilação, dando ênfase à análise de posicionamento de entrada da solução forte, número de pratos teóricos e razão de refluxo.

Nas Seções 4.2 e 4.3 foram estudados os principais inconvenientes de um incorreto funcionamento da coluna de destilação e foram apresentadas as correlações necessárias para o cálculo da geometria interna da coluna, assim como, das quedas de pressão. Finalmente, apresentou-se um estudo de transferência de massa, com o qual se obteve a eficiência da coluna, e assim corrigiu-se o número de pratos ideais considerados. Nessa ordem também serão abordadas os resultados da simulação.

Neste capítulo apresentam-se os resultados das simulações executadas na plataforma EES. Os resultados e discussões iniciam-se com a eleição da vazão mássica e composição do vapor destilado, composição e temperatura da solução forte e a composição do líquido saturado que sai da coluna. Estas variáveis serão calculadas a partir do trabalho de Ortigosa (2008) para um ciclo tipo GAX, como apresentado na Fig. 2.5, tomando como referência um ciclo de refrigeração por absorção de amônia/água com capacidade de $5 T R$, temperatura de evaporação de $-2{ }^{\circ} \mathrm{C}$ e condensação de $40{ }^{\circ} \mathrm{C}$. Os resultados de Ortigosa (2008) mostram que, para essas condições de trabalho do ciclo de refrigeração, a coluna de destilação deve ter as variáveis de entrada mostradas na Tabela 5.1.

Tabela 5.1 - Variáveis de entrada para o balanço de massa e de energia na coluna de destilação.

\begin{tabular}{|c|c|c|c|c|c|}
\hline & $\begin{array}{c}\text { Vazão } \\
\text { mássica } \\
(k g / s)\end{array}$ & $\begin{array}{c}\text { Fração } \\
\text { mássica } \\
(-)\end{array}$ & Temperatura & $\begin{array}{c}\text { Pressão } \\
\text { (bar) }\end{array}$ & $\begin{array}{c}\text { Título } \\
(-)\end{array}$ \\
\hline Vapor destilado $(d)$ & 0,015 & 0,999 & - & 15,56 & 1 \\
\hline Solução forte $(e)$ & - & 0,4517 & 98,14 & 15,56 & - \\
\hline Solução fraca $(s)$ & - & 0,152 & - & 15,56 & 0 \\
\hline
\end{tabular}


A pressão do sistema é considerada constante e o fator de refluxo, seguindo a recomendação de Kister (1992), será suposto como 1,1. O fator de refluxo será avaliado posteriormente para mostrar sua sensibilidade no sistema. As variáveis de entrada são esquematizadas na Fig. 5.1.

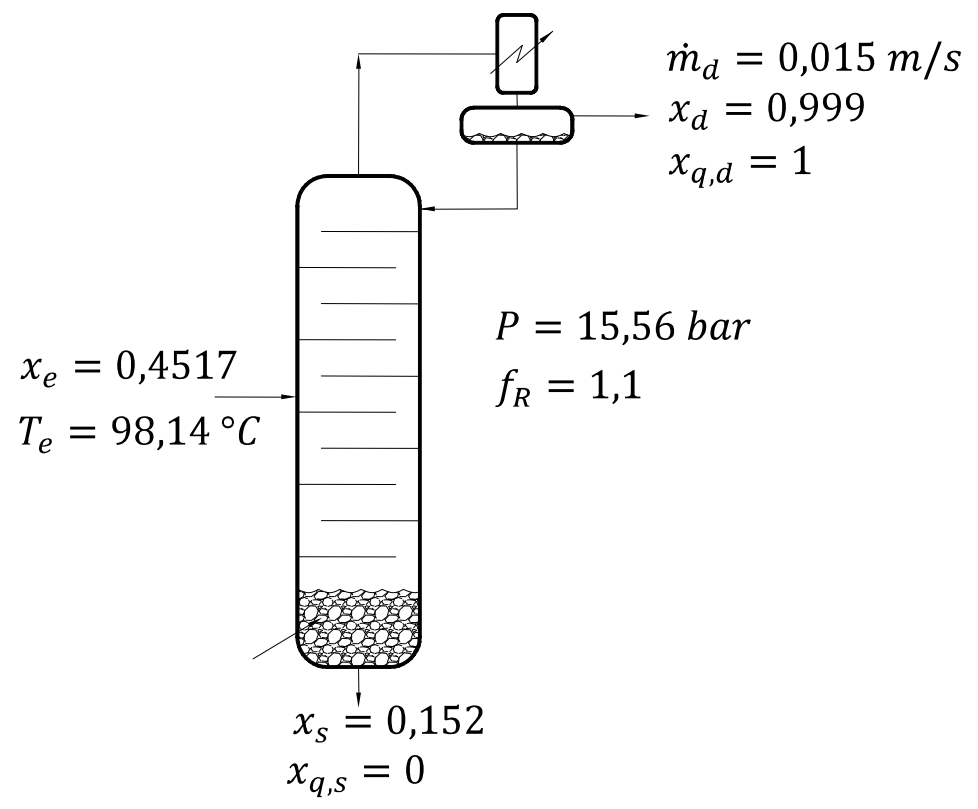

Figura 5.1 - Esquema das variáveis de entrada na coluna de destilação.

Com os valores de entrada proporcionados, o programa desenvolvido no EES fornece os valores de vazão mássica e propriedades termodinâmicas nas entradas e saídas de cada prato, assim como a localização da entrada de solução forte na coluna de destilação, a qual corresponde acima do prato 2, como mostra a Fig. 5.2. Nessa figura aparece a linha de entrada abaixo do prato dois, mas, essa posição é genérica no programa. O número de pratos ideais para conseguir a purificação de vapor de amônia de 99,9 \%, segundo a simulação, é de 4; já o fluxo de calor necessário para ser fornecido ao gerador é de 27,5 $\mathrm{kW}$, e sendo que a capacidade de refrigeração do ciclo é de $5 T R$, o coeficiente de eficácia para esse ciclo corresponde a 0,64 , o qual é um valor típico em ciclos de refrigeração por absorção tipo GAX. O fluxo de calor que tem que ser retirado do retificador corresponde a 4,404 kW e ele pode ser retirado pela linha que vem da bomba, a qual apresenta uma temperatura aproximada de $42{ }^{\circ} \mathrm{C}$ e resulta adequada neste caso, já que a temperatura do vapor que entra ao retificador é de aproximadamente $90{ }^{\circ} \mathrm{C}$ e o vapor destilado sai a $50,65^{\circ} \mathrm{C}$. 


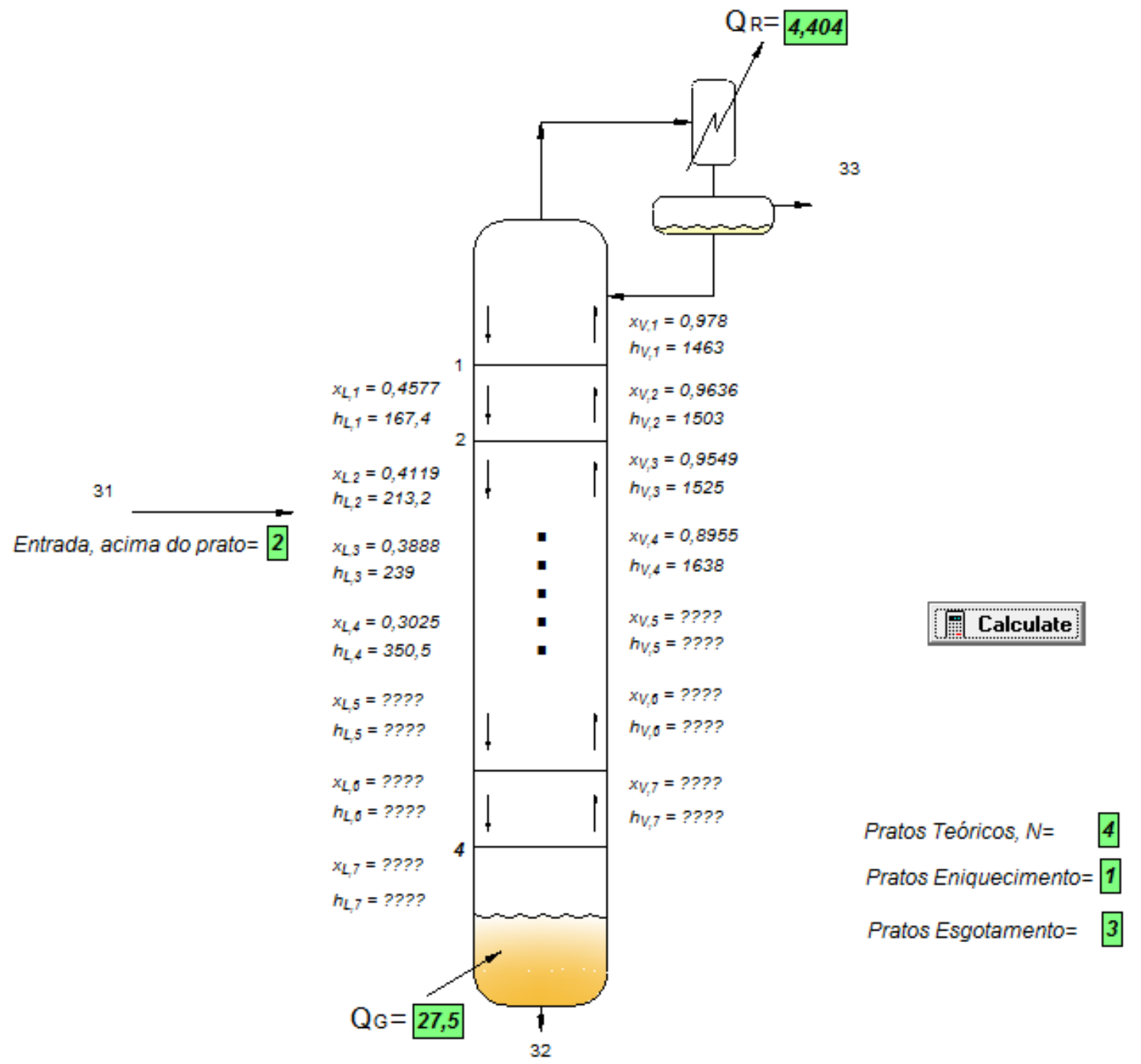

Figura 5.2 - Esquema mostrando alguns resultados da simulação.

O esquema da coluna de destilação mostrada na Fig. 5.2 é genérica, portanto a posição de entrada da solução na coluna não representa de forma exata a posição verdadeira. Nesta figura, por questões de espaço, somente a fração mássica e a entalpia específica dos escoamentos de cada prato aparecem. Outras propriedades termodinâmicas de interesse e vazões mássicas são apresentadas na Tabela 5.2. Nesta tabela, os valores são dados no mesmo formato da Fig. 5.2, isto é, a vazão mássica, temperatura, fração mássica e entalpia específica, se mostram na entrada e na saída de cada prato. 
Tabela 5.2 - Vazão mássica e principais propriedades termodinâmicas dos escoamentos da coluna.

\begin{tabular}{|c|c|c|c|c|c|c|c|c|}
\hline \multicolumn{4}{|c|}{ Líquido } & \multirow[b]{2}{*}{ Prato } & \multicolumn{4}{|c|}{ Vapor } \\
\hline $\begin{array}{c}\dot{m}_{L} \\
(k g / s)\end{array}$ & $\begin{array}{c}T_{L} \\
\left({ }^{\circ} \mathrm{C}\right)\end{array}$ & $\begin{array}{l}x_{L} \\
(-)\end{array}$ & $\begin{array}{c}h_{L} \\
(k J / k g)\end{array}$ & & $\begin{array}{c}m_{V} \\
(\mathrm{~kg} / \mathrm{s})\end{array}$ & $\begin{array}{c}T_{V} \\
\left({ }^{\circ} \mathrm{C}\right)\end{array}$ & $\begin{array}{l}x_{V} \\
(-)\end{array}$ & $\begin{array}{c}h_{V} \\
(k J / k g)\end{array}$ \\
\hline 0,0014 & 50,65 & 0,7599 & 74,05 & & 0,01644 & 89,65 & 0,9780 & 1463 \\
\hline 0,0011 & 89,65 & 0,4577 & 167,4 & - & 0,01605 & 99,05 & 0,9636 & 1503 \\
\hline 0,0405 & 99,05 & 0,4119 & 213,2 & & 0,01311 & 103,55 & 0,9549 & 1525 \\
\hline 0,0402 & 103,55 & 0,3888 & 239 & & 0,01280 & 122,75 & 0,8955 & 1638 \\
\hline 0,0400 & 122,75 & 0,3025 & 350,5 & & 0,01257 & 160,25 & 0,6306 & 2018 \\
\hline
\end{tabular}

Os resultados obtidos da simulação podem ser apresentados também em diagramas de equilíbrio $h-x$ e $x_{V}-x_{L}$, como mostrado na Fig. 5.3. No diagrama entalpia específica - fração mássica pode-se observar as linhas de operação, a linha de operação principal e as linhas de equilíbrio entre o vapor e o líquido que saem de cada prato. Já no diagrama $x_{V}-x_{L}$ pode-se apreciar a posição de entrada de solução forte e o número de pratos ideais. 

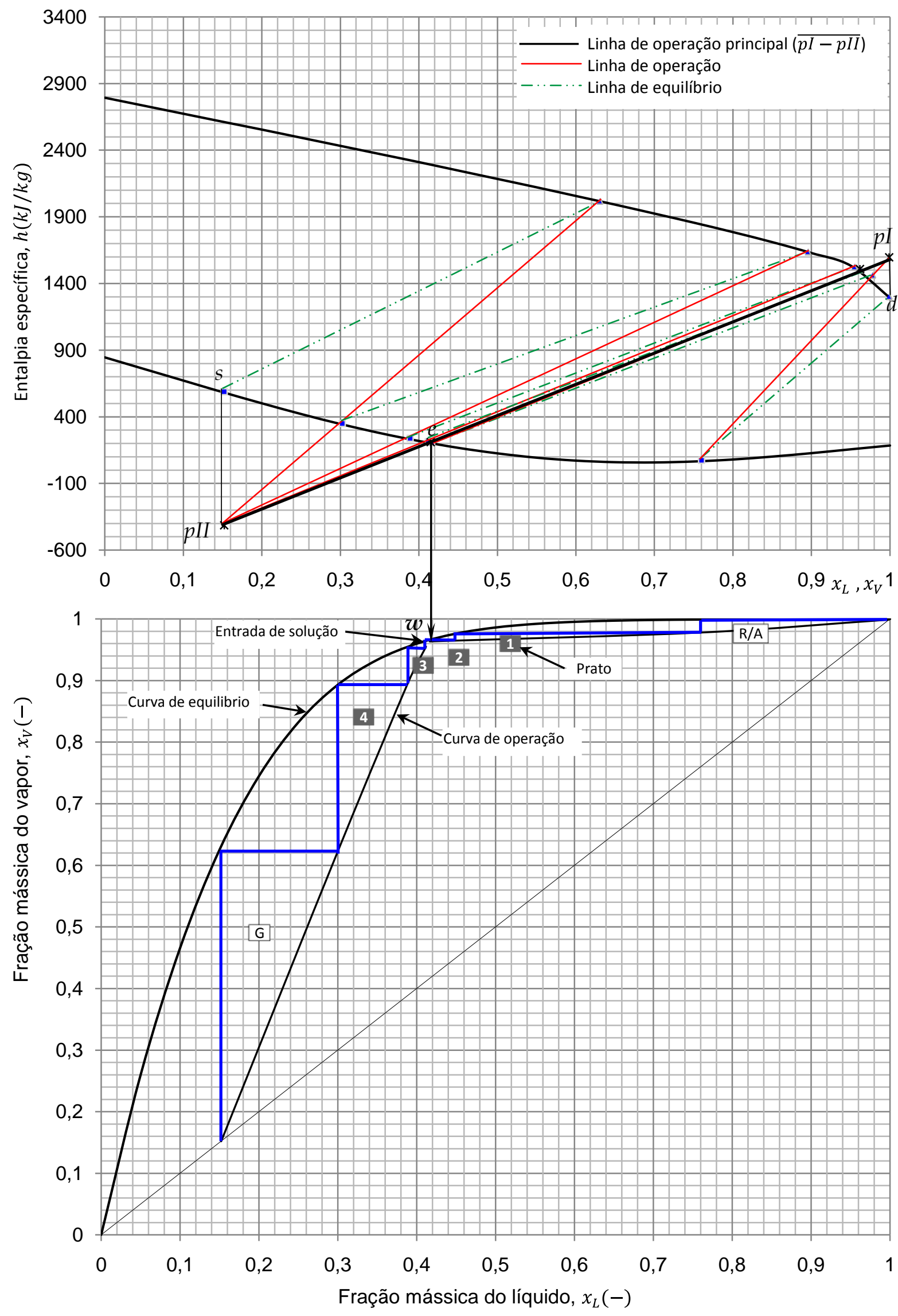

Figura 5.3 - Linhas de operação e equilíbrio e número de pratos teóricos nos eixos $h-x$ e $x_{V}-x_{L}$. 
São mostradas a seguir as mudanças de algumas variáveis de interesse, ao longo do comprimento da coluna de destilação. A Fig. 5.4 mostra o aumento da fração mássica do vapor quando sobe ao longo da coluna, nela pode-se observar que a variação da fração mássica aumenta mais na seção de esgotamento (51 \%), fazendo com que esta parte da coluna seja de grande importância pela grande variação de aumento da composição do vapor. Já na seção de enriquecimento (variação de 1,5 \%) e no retificador (variação de 2,1 \%), a purificação será menor, porém, nessas partes conseguem-se um aumento mais refinado da pureza.

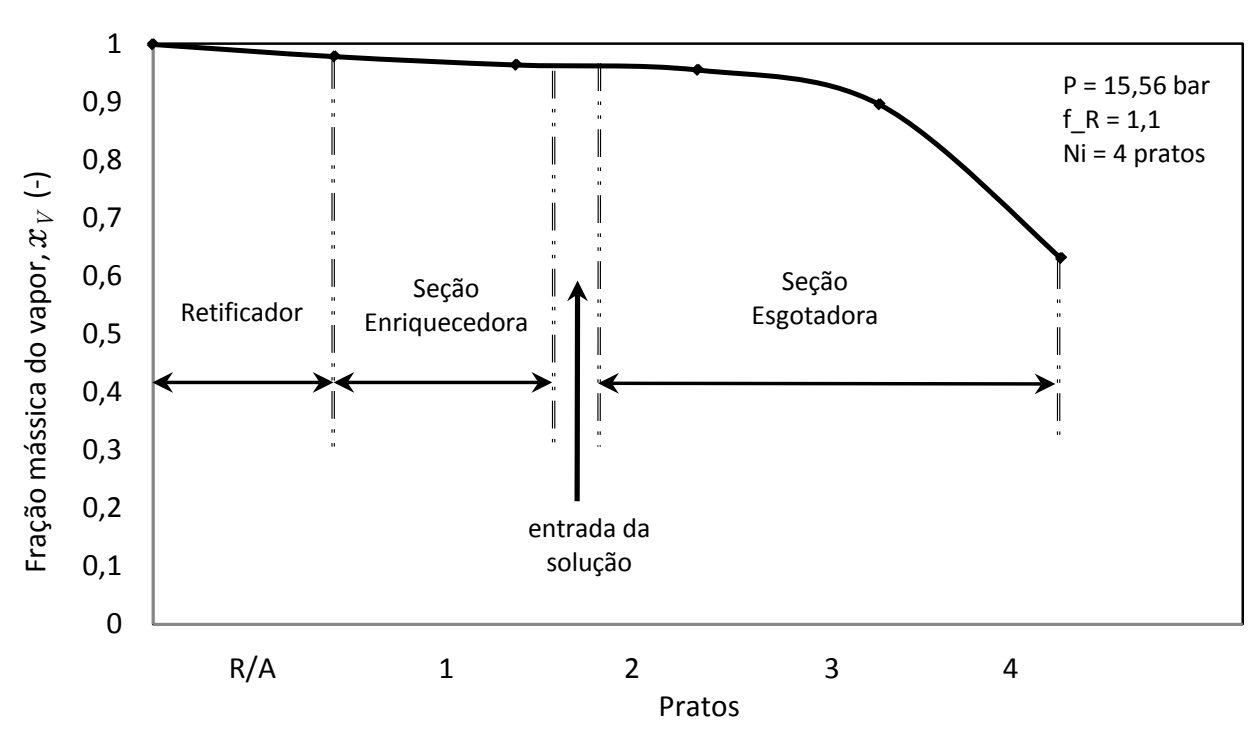

Figura 5.4 - Variação da fração mássica do vapor na coluna.

A Fig. 5.5 indica a variação da fração mássica do líquido ao longo da coluna. Nela, pode-se ver que, mesmo que a seção de enriquecimento esteja composta somente por um prato, a fração mássica diminui muito no sentido descendente. $\mathrm{Na}$ seção de esgotamento, a fração mássica do líquido diminui de maneira quase constante e, no gerador, a variação é mais acentuada.

Já a Fig. 5.6 mostra a variação da vazão mássica do vapor na coluna, onde pode-se observar que aumenta de maneira quase constante no sentido ascendente ao longo da coluna, salvo no ponto de alimentação, lugar que faz com que a vazão mássica de vapor aumente aceleradamente por causa do grande aporte de amônia. 


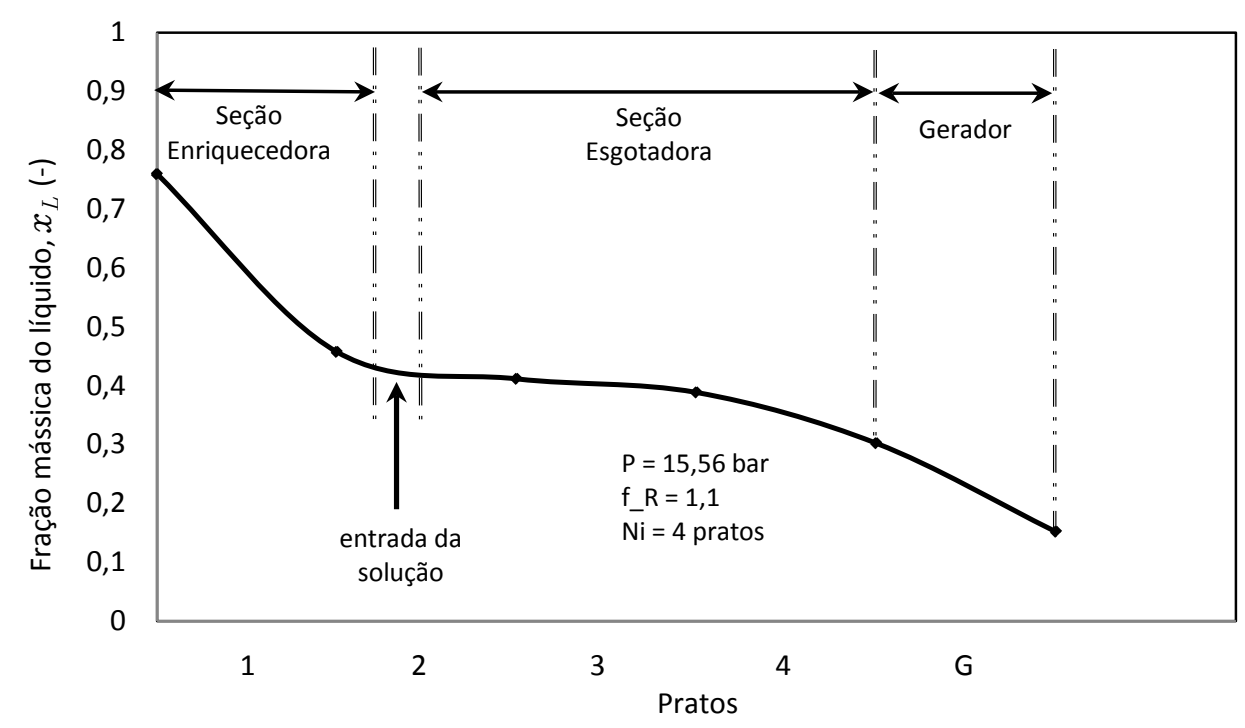

Figura 5.5 - Variação da fração mássica do líquido na coluna.

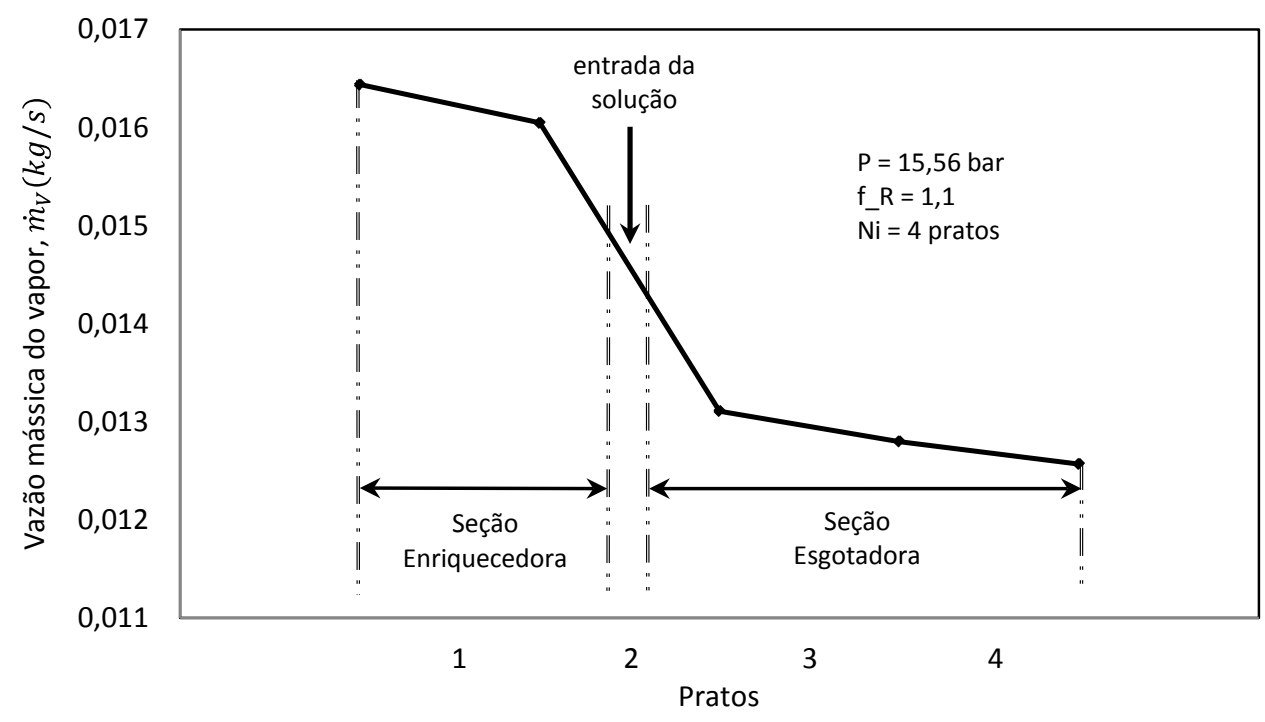

Figura 5.6 - Variação da vazão mássica do vapor na coluna.

A variação da vazão mássica do líquido pode ser vista na Fig. 5.7 e percebese que ela aumenta muito no segundo prato por causa da alimentação da coluna; já nos outros pratos, sua vazão diminui ligeiramente no sentido descendente. 


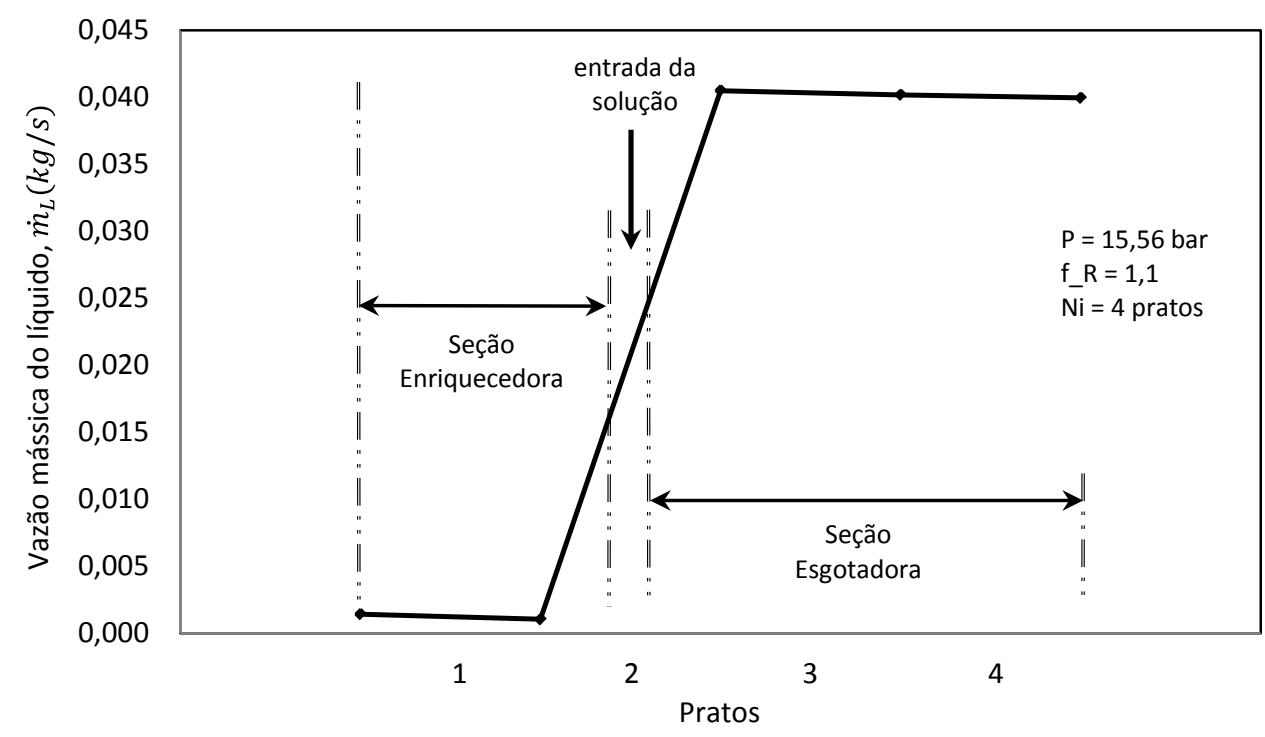

Figura 5.7 - Variação da vazão mássica do líquido na coluna.

$\mathrm{Na}$ Fig. 5.8, pode-se notar a variação da temperatura dos escoamentos ao longo da coluna de destilação, o vapor aumenta sua temperatura enquanto sobe pela coluna e o líquido diminui sua temperatura enquanto desce. Este comportamento é típico de escoamentos em contracorrente. A entrada da solução forte na coluna não influencia muito na transferência de calor, uma vez que sua temperatura e a dos escoamentos do líquido e do vapor são muito próximas.

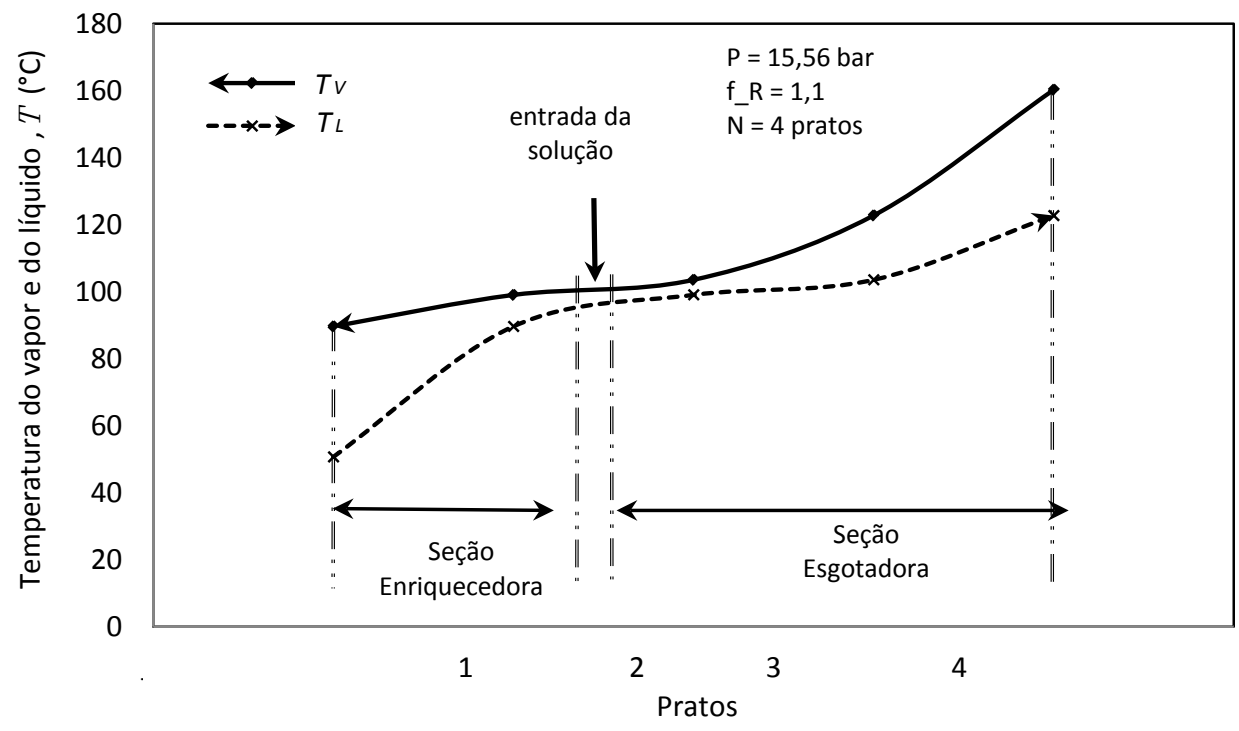

Figura 5.8 - Variação da temperatura dos escoamentos na coluna. 
A solução de amônia/água que sai da coluna de destilação retorna ao absorvedor com uma concentração de 0,152 em massa e com uma temperatura de $160,25^{\circ} \mathrm{C}$. Esse escoamento, devido à sua alta temperatura, é geralmente reaproveitado dentro do ciclo para aquecer a algum ramo frio, se necessário.

Na sequência, serão analisadas a influencia do fator de refluxo nas variáveis da coluna de destilação. Nesta análise, somente será alterado o fator de refluxo. Como mencionado, o fator de refluxo é o quociente entre a razão de refluxo de projeto e a razão de refluxo mínimo. Sendo que, quando se tem razão de refluxo mínimo, o número de pratos para atender a purificação desejada é o maior possível. Este fato pode ser visto na Fig. 5.9, a qual mostra que para um fator de refluxo igual a 1, isto é, uma razão de refluxo de projeto igual à razão de refluxo mínimo, o número de pratos é 8 e corresponde ao maior possível. Pode-se também perceber que o número de pratos é muito sensível a valores do fator de refluxo que estão entre 1 e 1,06. Para valores maiores do fator de refluxo, o número de pratos se mostra pouco sensível. O número de pratos da seção de esgotamento sempre será maior a de enriquecimento. Para valores maiores de 1,9 os pratos na seção de enriquecimento não são mais necessários.

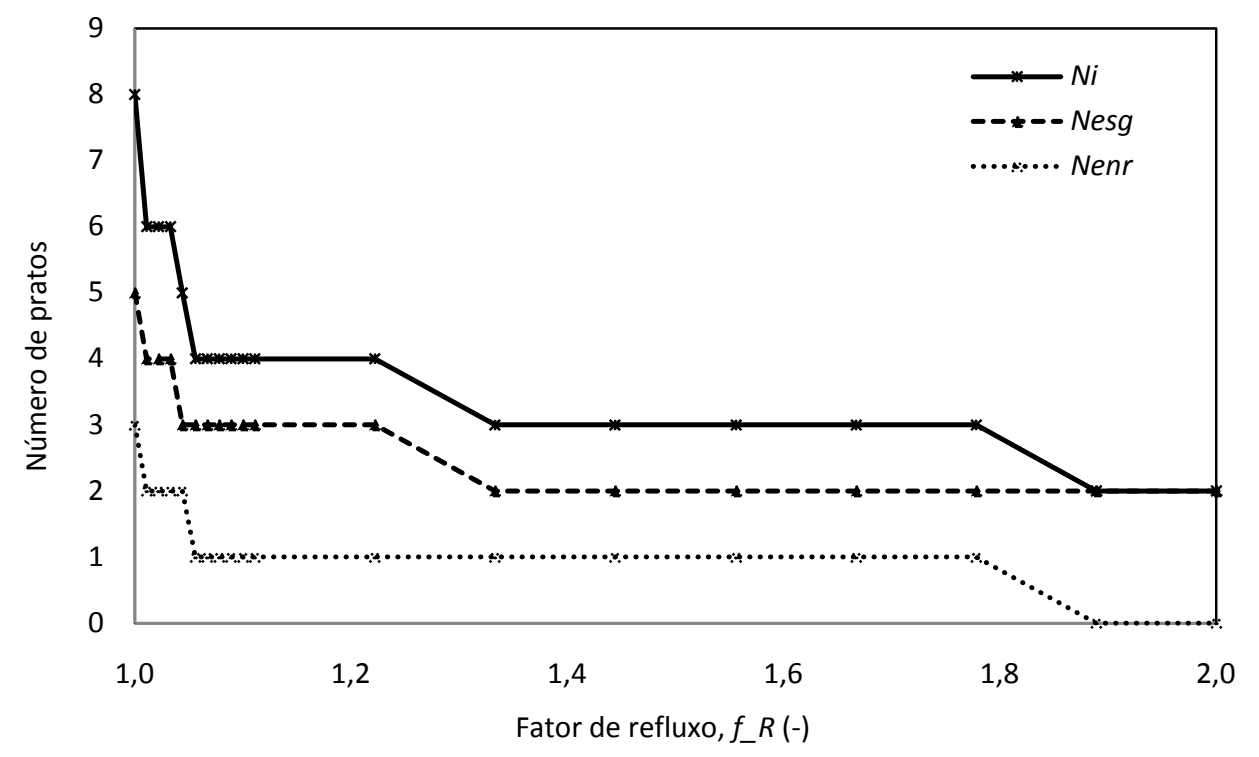

Figura 5.9 - Variação do número de pratos com o fator de refluxo.

O fluxo de calor que deve ser fornecido ao gerador será maior para valores do fator de refluxo maiores, isto acontece, porque mais líquido retorna à coluna de 
destilação a partir do acumulador. Desta maneira, o fluxo de calor necessário para evaporar a solução será também maior, como notada na Fig. 5.10.

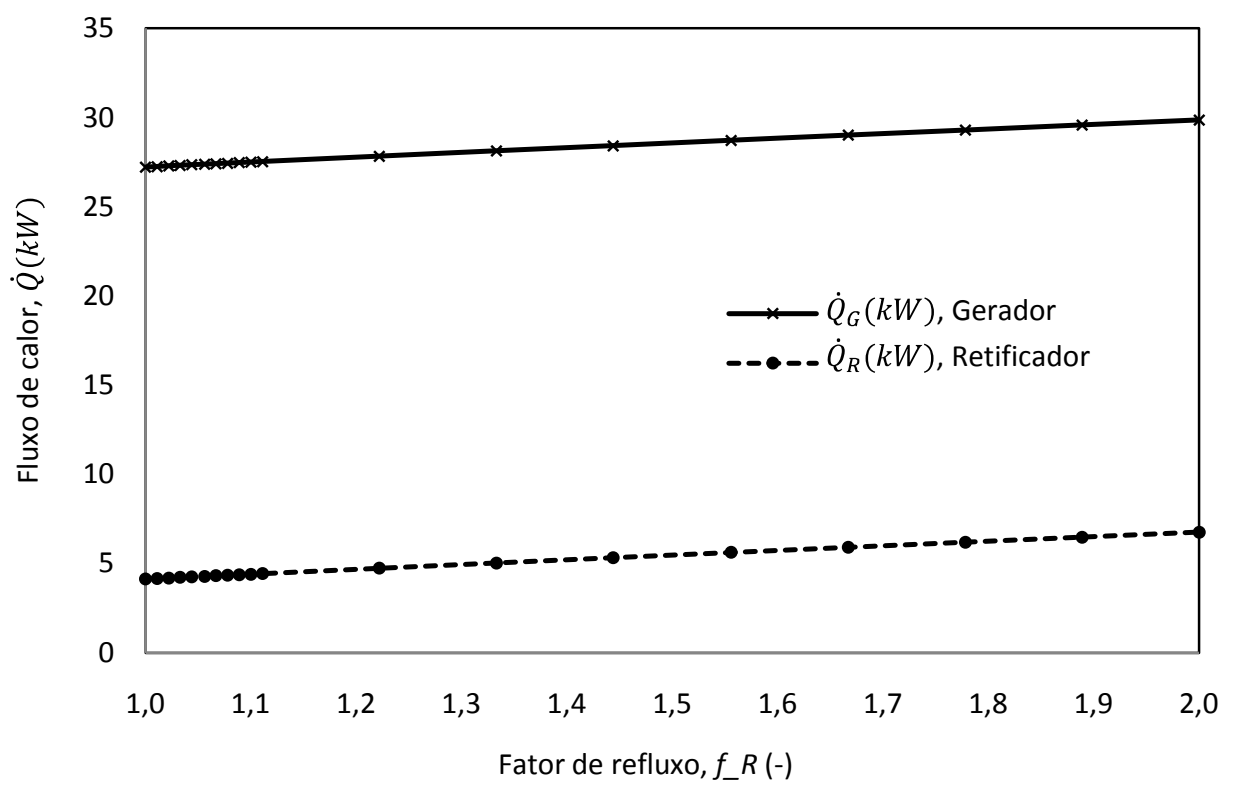

Figura 5.10 - Variação do fluxo de calor no gerador e no retificador com o fator de refluxo.

Um fator de refluxo baixo implica em um número de pratos maior e com isso um gasto de dinheiro maior no projeto inicial do equipamento, já que não somente serão necessários mais pratos, mas também o tamanho da coluna de destilação será maior, porém, o gasto de fornecimento de fluxo de calor no gerador será o menor possível. Já com um fator de refluxo maior, o número de pratos diminui, mas o fluxo de calor fornecido ao gerador aumenta e o COP diminui, como pode ser visto na Fig. 5.11. Sendo necessária, então, uma decisão econômica no projeto. 


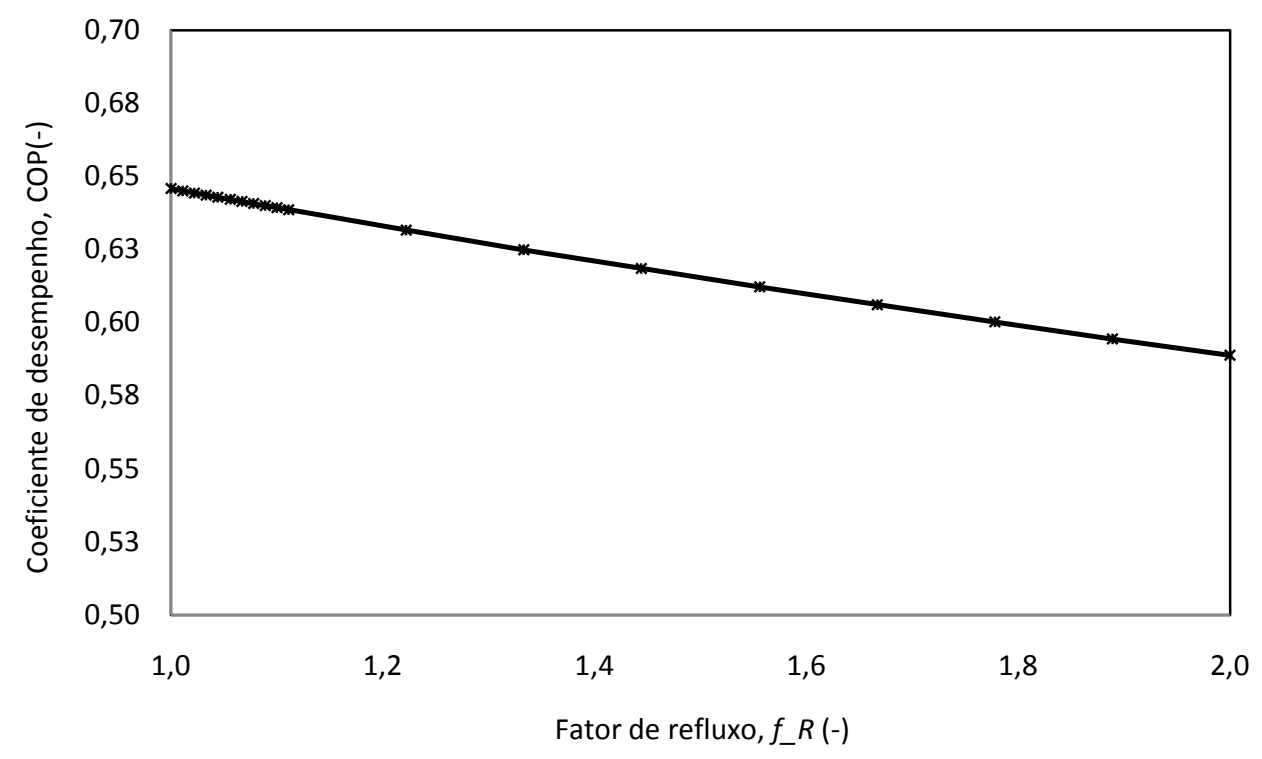

Figura 5.11 - Variação do COP com o fator de refluxo.

Uma vez que o número de pratos ideais foi calculado, será necessário projetar a geometria da coluna e o número de pratos reais. Na sequência são apresentados os valores das variáveis de entrada na Tabela 5.3. Os cálculos foram feitos para o prato inferior da coluna, os valores de vazão mássica, fração mássica, temperatura e número de pratos ideais, foram obtidos do balanço de massa e de energia da coluna. Os valores das outras variáveis representam valores típicos usados em colunas de destilação, segundo explicado na Seção 4.4. 
Tabela 5.3 - Variáveis de entrada para o cálculo da geometria da coluna.

\begin{tabular}{lccc}
\hline \multicolumn{1}{c}{ Grandeza } & Unidade & \multicolumn{2}{c}{ Valor } \\
\hline Vazão mássica & & Vapor & Líquido \\
\cline { 2 - 4 } Fração mássica & $\mathrm{kg} / \mathrm{s}$ & 0,0126 & 0,04 \\
Temperatura & - & 0,6306 & 0,3025 \\
\hline Fator de espuma & ${ }^{\circ} \mathrm{C}$ & 160,25 & 122,75 \\
\hline Fator de inundação & - & 0,83 \\
Fator vertedor - diâmetro da coluna & - & 0,80 \\
Diâmetro do furo & $m$ & 0,85 \\
Espessura da chapa & $m$ & 0,003 \\
Altura do vertedor & $m$ & 0,002 \\
Rugosidade relativa & - & 0,01 \\
Aceleração da gravidade & $m / s^{2}$ & 0 \\
Número de pratos ideais & - & \multicolumn{2}{c}{4} \\
\hline
\end{tabular}

Em seguida, são mostrados os resultados obtidos da simulação, os quais estão resumidos na Tabela 5.4.

Tabela 5.4 - Resultados da simulação para a geometria da coluna.

\begin{tabular}{lcc}
\hline \multicolumn{1}{c}{ Grandeza } & Unidade & Valor \\
\hline Diâmetro da coluna & $m$ & 0,1226 \\
\hline Distância entre pratos & $m$ & 0,1 \\
\hline Altura total da coluna & $m$ & 0,8 \\
\hline Número de pratos reais & - & 8 \\
\hline Comprimento do vertedor & $m$ & 0,1042 \\
\hline Comprimento do trajeto do líquido & $m$ & 0,0646 \\
Número de furos & - & 61 \\
\hline Distância entre furos & $m$ & 0,012 \\
\hline Eficiência da coluna & - & 0,5 \\
\hline Velocidade do vapor a jusante ao prato & $m / s$ & 0,16 \\
\hline Velocidade do vapor no furo & $m / s$ & 3,63 \\
Velocidade do vapor de gotejamento & $m / s$ & 2,22 \\
\hline Queda de pressão do vapor no prato & $P a$ & 265,3 \\
\hline
\end{tabular}


A geometria do prato é mostrada na Fig. 5.12 e da coluna na Fig. 5.13.

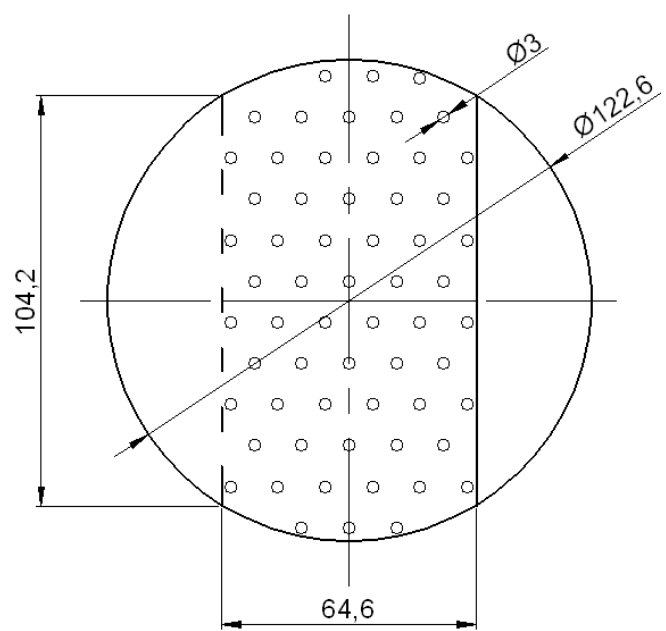

Figura 5.12 - Geometria dos pratos da coluna de destilação.

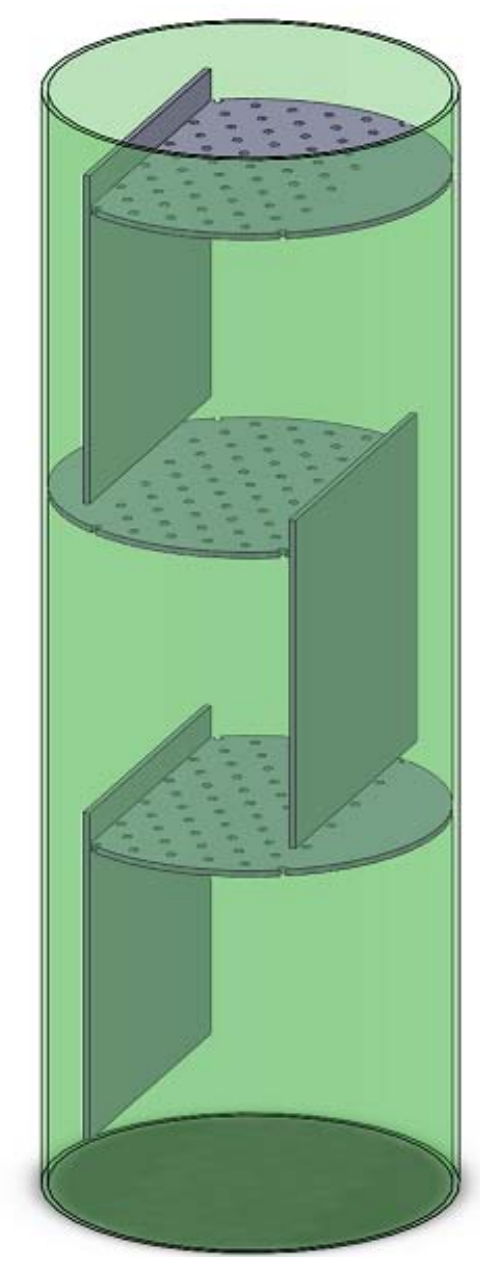

Figura 5.13 - Geometria da coluna de destilação. 
O mesmo cálculo foi feito para o primeiro prato mudando somente as vazões mássicas, frações mássicas e temperaturas para os escoamentos líquido e vapor; e considerando as outras variáveis iguais, segundo a Tabela 5.3. Obteve-se um diâmetro da coluna de 0,1204 m, isto representa uma diferença de 1,8 \% comparado com o mesmo cálculo feito com o último prato. Kister (1992) recomenda que para diferenças maiores que 20 \% dever-se-ia usar diâmetros diferentes.

A distância entre pratos é um parâmetro importante no projeto da coluna de destilação, já que com menores espaçamentos conseguem-se alturas de coluna menores, o que é desejável em ciclos de refrigeração por absorção de pequeno porte. Por tanto se considerou neste trabalho que a distancia entre pratos é um fator de compactibilidade do projeto. Entretanto, distâncias pequenas podem acarretar problemas de arraste. Como citado acima, Treybal (1981) recomenda que a distância entre pratos seja no mínimo o dobro do nível do líquido no downcomer. Uma variável que influencia muito esta condição é a altura do vertedor, e quando ela mudou notou-se que muitas das variáveis da coluna também se modificaram. Na sequência, este fato é mostrado.

Na Fig. 5.14 pode-se ver que o diâmetro da coluna atinge valores máximos para alturas de vertedor da ordem de $6 \mathrm{~mm}$, para valores maiores que esta altura, 0 diâmetro da coluna sempre diminui. Como a longitude de corda do vertedor é 0,85 vezes o diâmetro da coluna, esta variará com a mesma tendência.

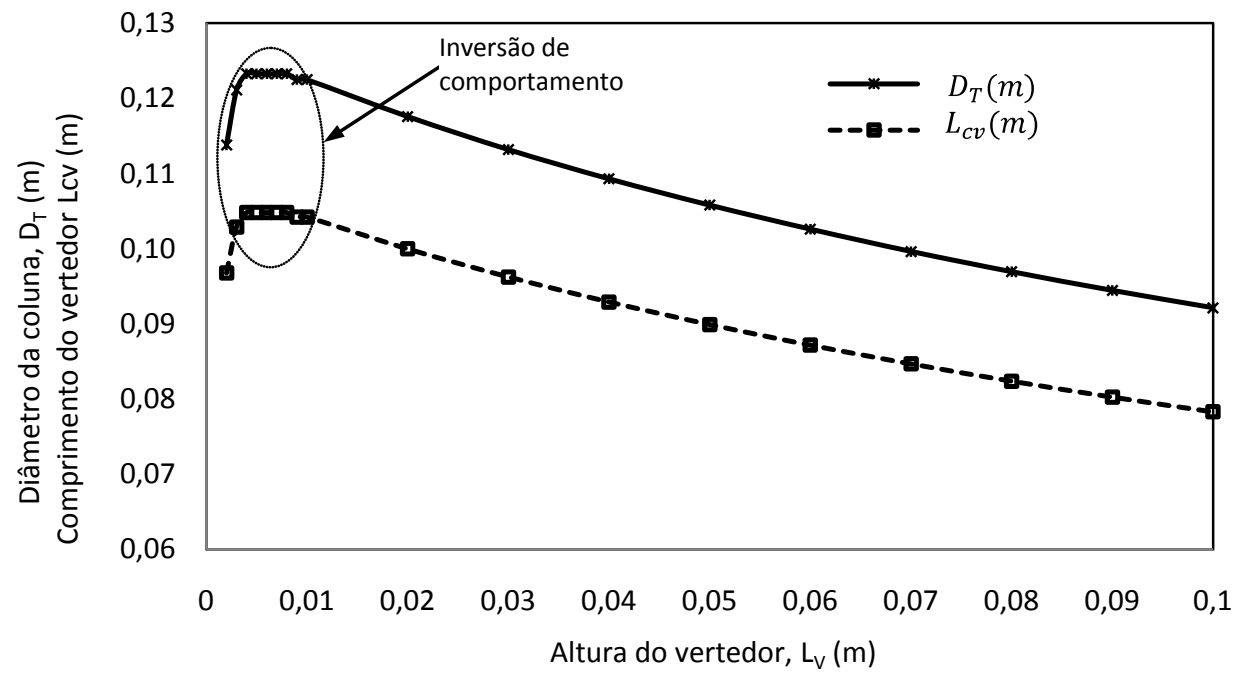

Figura 5.14 - Variação do diâmetro da coluna e o comprimento do vertedor com a altura do vertedor. 
Já na Fig. 5.15 nota-se a variação da distância entre os pratos, assumindo valores mínimos para uma altura do vertedor entre $4 \mathrm{~mm}$ e $8 \mathrm{~mm}$. Para valores maiores, a distância entre pratos sempre aumenta, de acordo com a altura de líquido no downcomer, a qual depende da soma das quedas de pressão do líquido e do vapor (Fig. 5.18). A velocidade de inundação tem o mesmo comportamento que a distância entre pratos, logo, para manter uma mesma vazão volumétrica de vapor, o diâmetro varia de forma inversa à velocidade do vapor (proporcional à velocidade de inundação). A altura da coluna tem o mesmo comportamento que a distância entre pratos, como pode ser visto na Fig. 5.16.

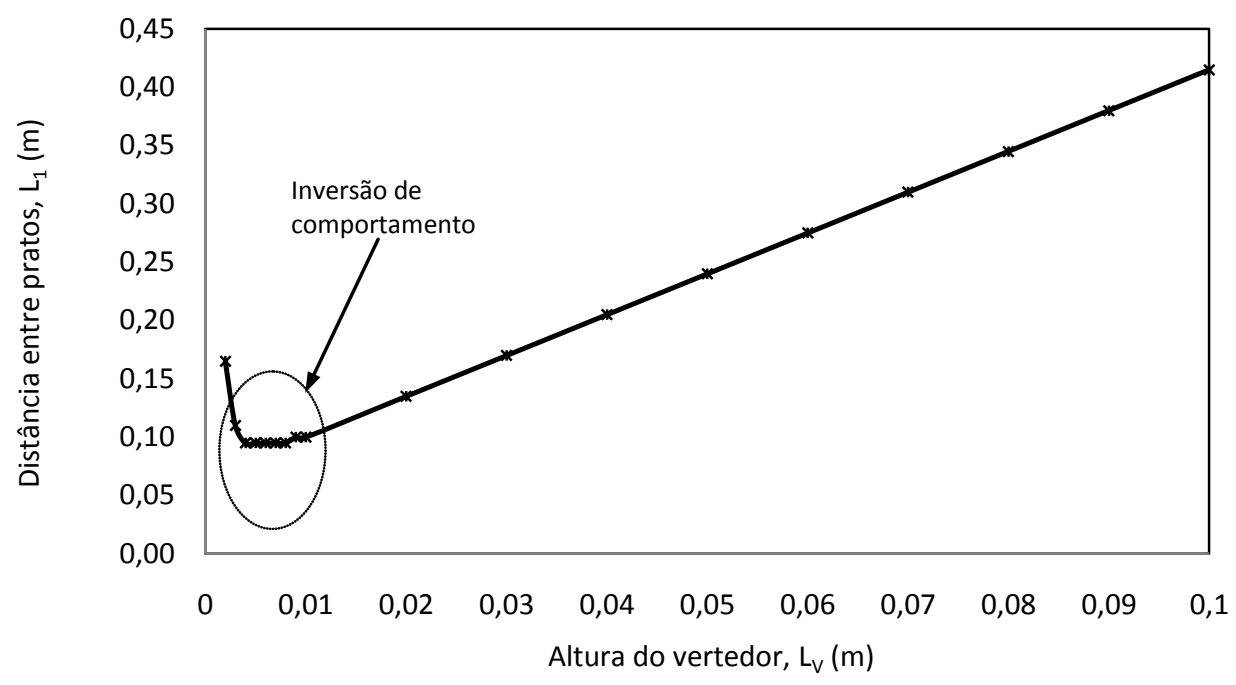

Figura 5.15 - Variação da distância entre pratos com a altura do vertedor.

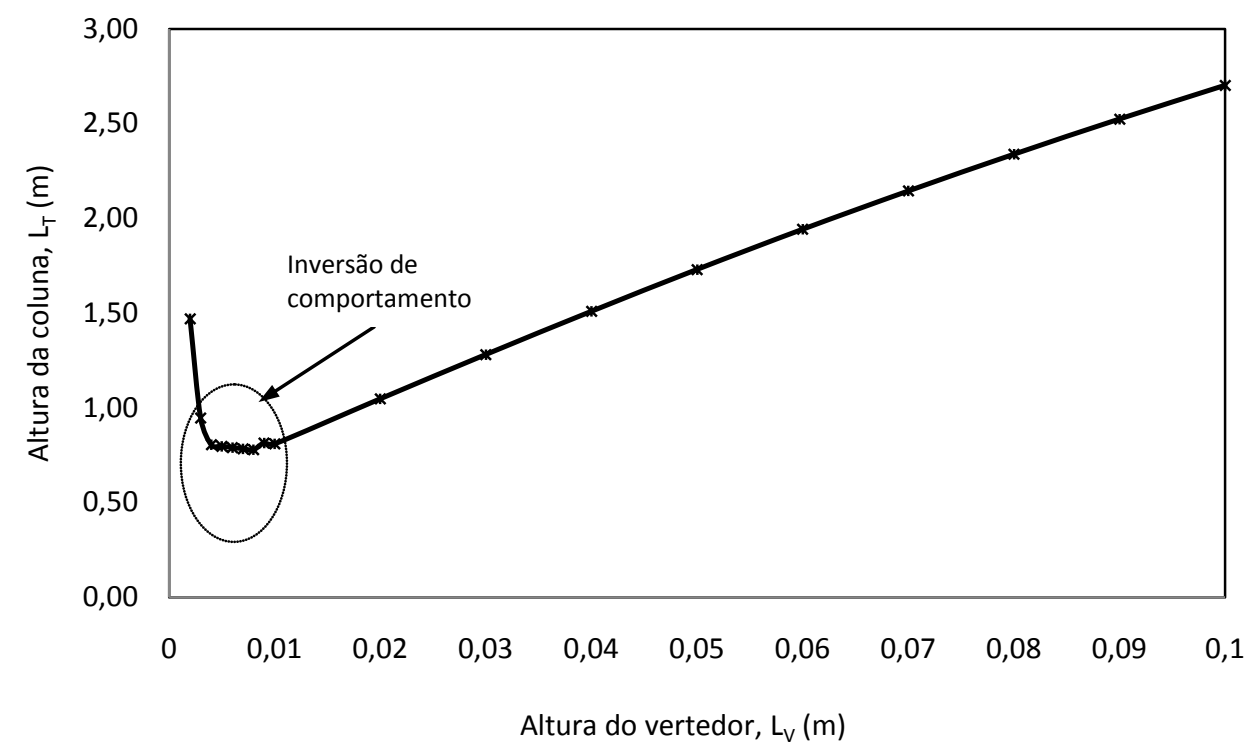

Figura 5.16 - Variação da altura da coluna com a altura do vertedor. 
A Fig. 5.17 apresenta a variação da eficiência de ponto, de Murphree (prato), de Murphree corrigida pelo arraste e da coluna. A eficiência de ponto resulta menor do que a eficiência do prato. É possível notar que o arraste não influi de maneira apreciável à eficiência do prato. A eficiência da coluna resulta muito menor do que a eficiência de Murphree corrigida pelo arraste, isto se deve ao fato de que a eficiência da coluna está fortemente ligada ao escoamento líquido e quando este é alto, comparativamente ao escoamento do vapor, a eficiência da coluna diminui.

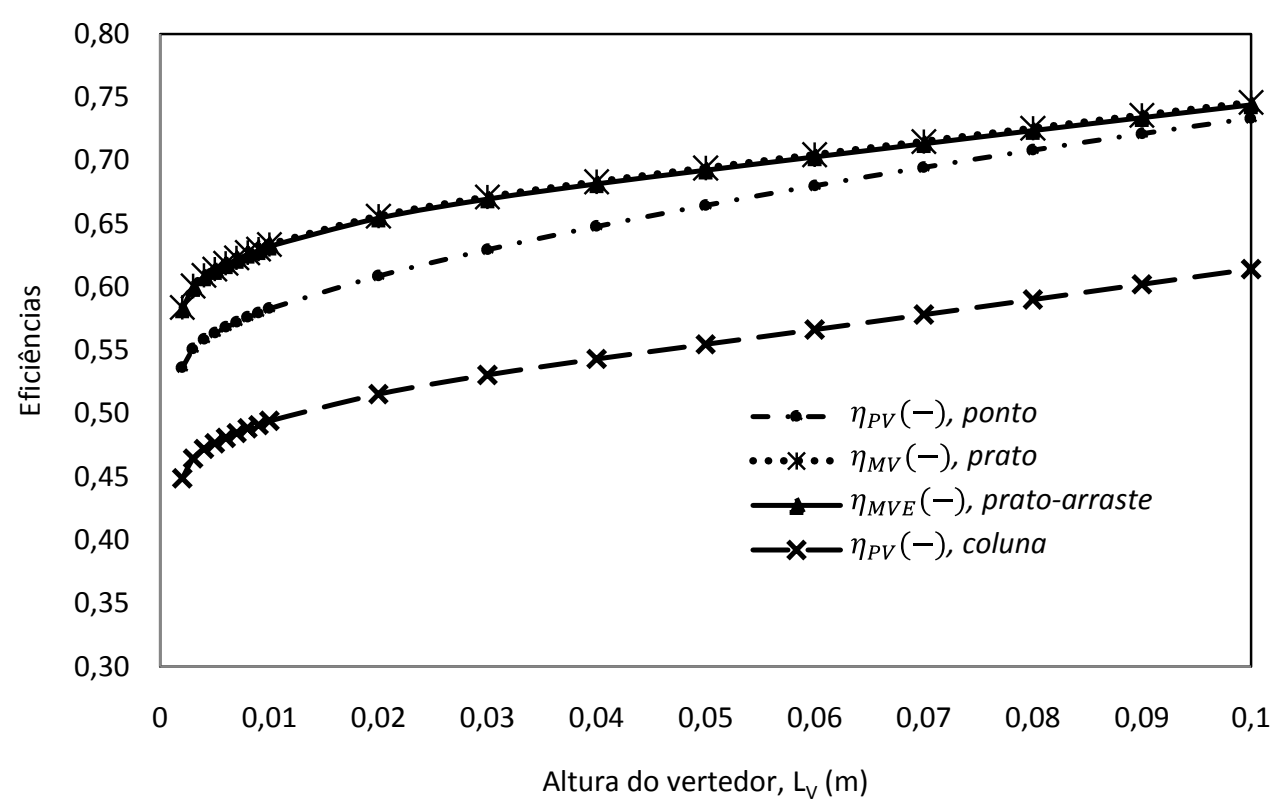

Figura 5.17 - Variação das eficiências com a altura do vertedor.

A eficiência aumenta com a altura do vertedor já que o tempo de residência do líquido no prato aumenta também, propiciando uma maior troca de massa. Os gráficos apontam que uma geometria compacta pode ser atingida quando a altura do vertedor está entre $4 \mathrm{~mm}$ e $8 \mathrm{~mm}$. Deve-se levar em conta que a variação da geometria da coluna com a altura do vertedor, está fortemente ligada à velocidade de inundação, e esta corresponde à correlação de Treybal (1981), a partir do diagrama de Fair (1961), a qual foi testada em colunas de destilação de grande porte, portanto para uma maior confiabilidade deve-se considerar os resultados após a inversão de comportamento, isto é, para alturas de vertedor maiores que $8 \mathrm{~mm}$. 
A queda de pressão do vapor aumenta com a altura do vertedor, como pode ser visto na Fig. 5.18, já que a velocidade do vapor e a altura do líquido no prato aumentam. Quando a altura do vertedor é pequena, a área de passagem do líquido sob o downcomer é também pequena, aumentando a velocidade do líquido e, como resultado, aumenta sua perda de carga. No entanto, quando a altura do vertedor é maior, a perda de carga diminui.

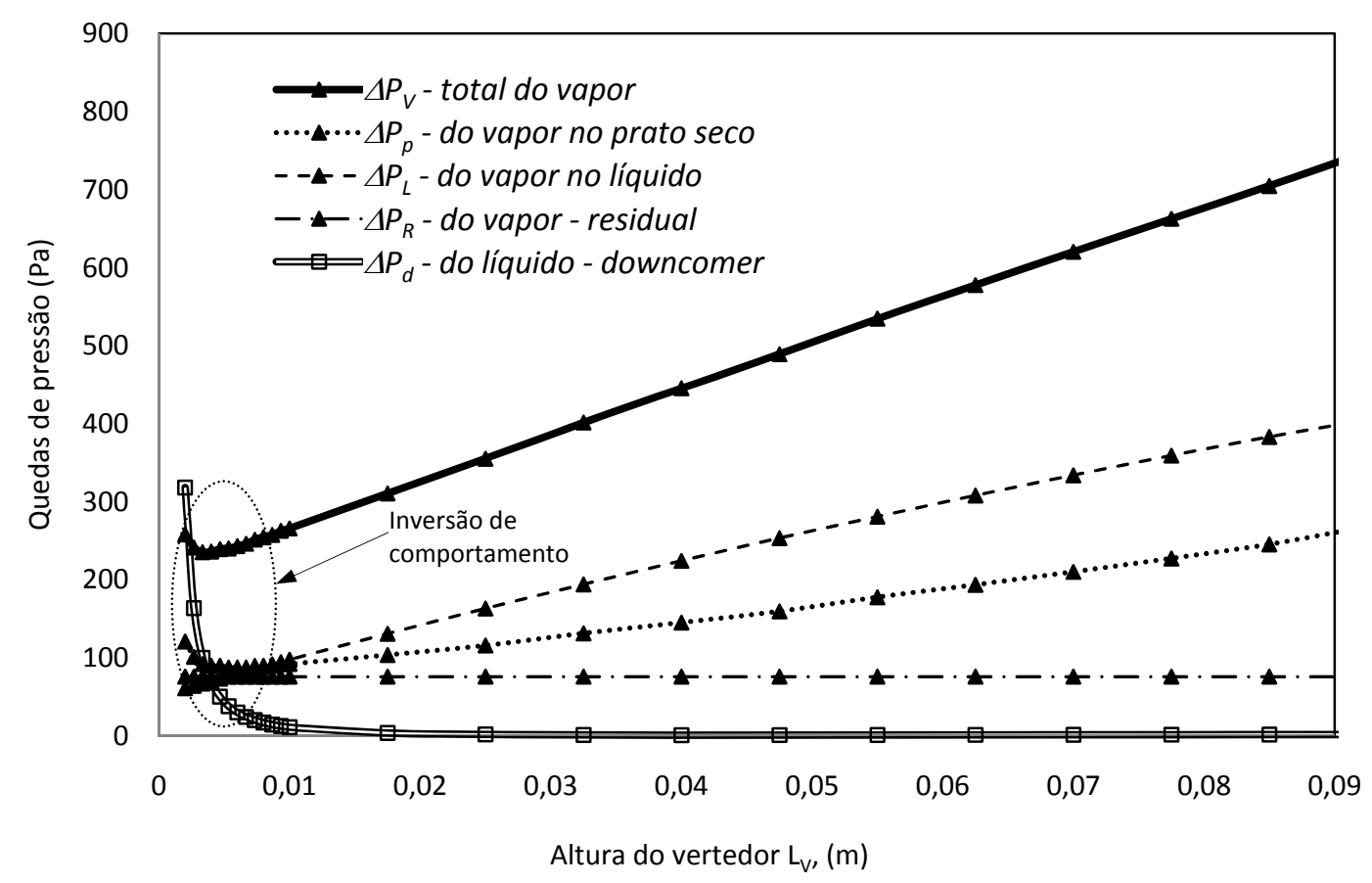

Figura 5.18 - Quedas de pressão no prato.

O diâmetro do furo resulta não ter influência significativa no diâmetro da coluna (o comprimento do vertedor e o comprimento do trajeto do líquido sobre o prato são proporcionais ao diâmetro da coluna) como mostra a Fig. 5.19, já que a velocidade do vapor não varia significativamente antes ou depois do prato. Por outro lado, a distância entre pratos se torna sensível para diâmetros de furo compreendidos entre $1 \mathrm{~mm}$ e $4 \mathrm{~mm}$, sendo que para diâmetros maiores a distância entre pratos não varia. Essa sensibilidade se deve ao fato de que a distância entre pratos está ligada à soma da queda de pressão do líquido e do vapor. A queda de pressão residual aumenta para diâmetros de furo pequeno, como mostrada na Fig. 5.20 . 


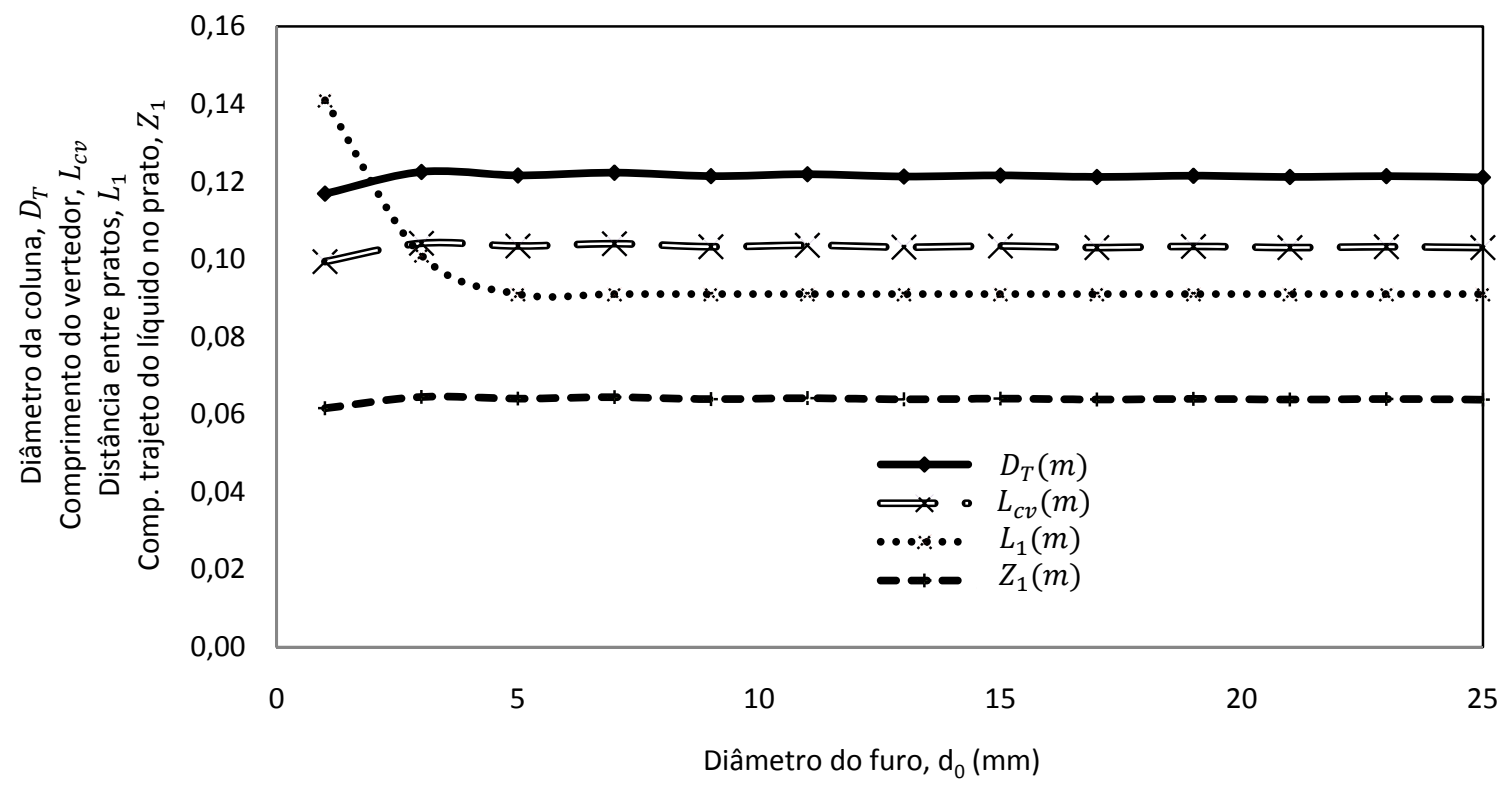

Figura 5.19 - Variação da geometria da coluna com o diâmetro do furo.

A queda de pressão residual é mais significativa para diâmetros de furo menores que $4 \mathrm{~mm}$, como mostrado a Fig. 5.20. Por tanto é recomendável usar diâmetros de furo maiores que $4 \mathrm{~mm}$ para atingir perdas de carga menores. Deve-se ter em consideração que a perda de carga do vapor no prato para um diâmetro de furo de $1 \mathrm{~mm}$ é de $411 \mathrm{~Pa}(0,00411$ bar) a qual é um valor relativamente baixo.

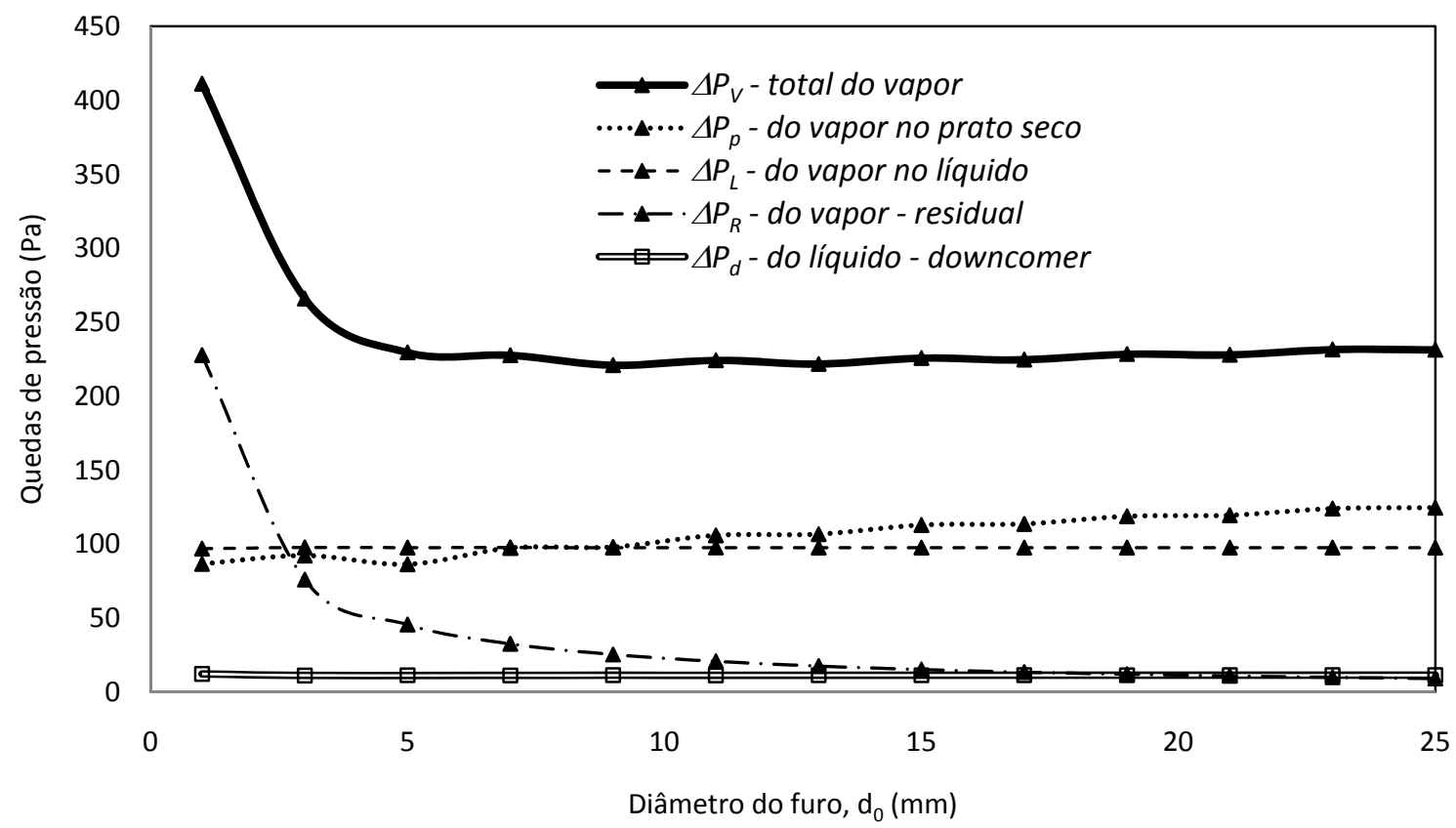

Figura 5.20 - Variação das quedas de pressão com o diâmetro do furo. 
Considerando as variáveis de entrada da Tabela 5.3 e variando somente a vazão do vapor pode-se ver sua influência na geometria da coluna, como observada na Fig. 5.21. Produto do aumento da vazão volumétrica do vapor, o diâmetro da coluna tende a aumentar.

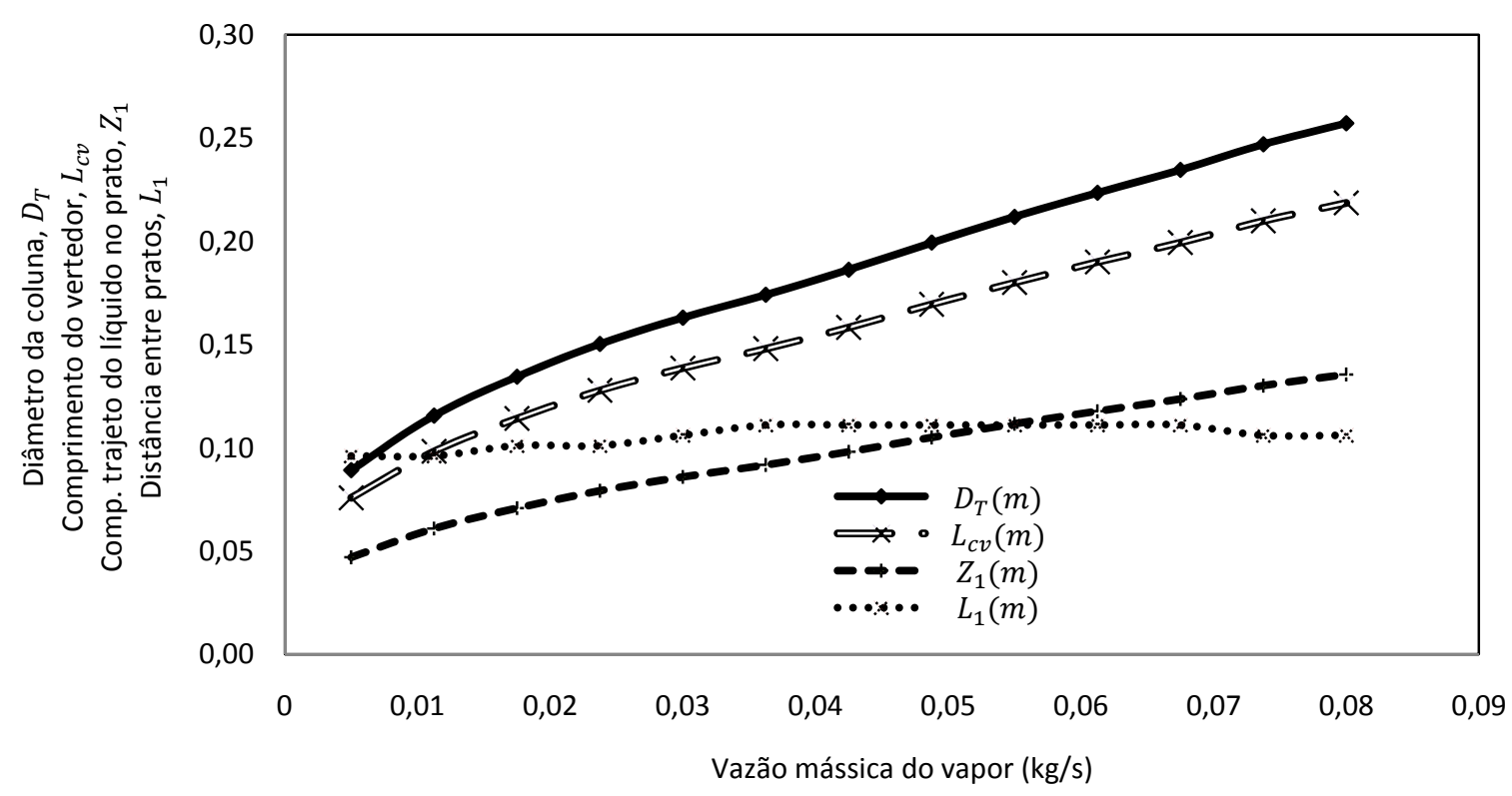

Figura 5.21 - Variação da geometria da coluna com a vazão de vapor.

A distância entre pratos não varia significativamente já que a altura do vertedor é constante e a soma das quedas de pressão do líquido e do vapor se mantém quase constante, como pode ser visto na Fig. 5.22.

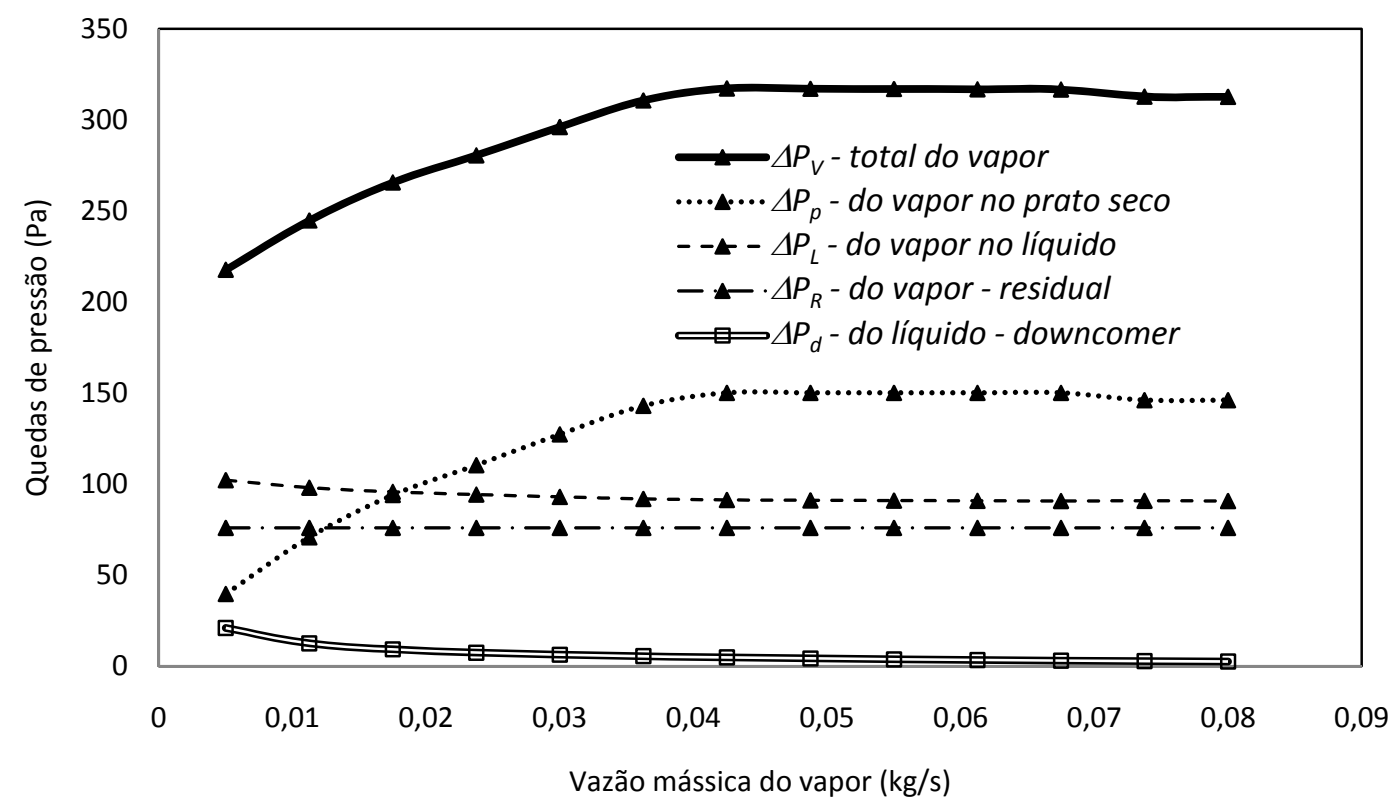

Figura $\mathbf{5 . 2 2}$ - Variação das quedas de pressão com a vazão mássica do vapor. 
Como a velocidade do vapor aumenta, sua queda de pressão ao passar pelo prato seco também aumenta. A altura do vertedor é constante, portanto a queda de pressão do vapor ao passar pelo líquido se mantém quase constante. A queda de pressão do líquido sob o downcomer é ligeiramente maior para vazões de vapor menores uma vez que o diâmetro da coluna é menor, assim como, a área de passagem do líquido sob o downcomer.

A eficiência da coluna aumenta para maiores vazões de vapor, como pode ser visto na Fig. 5.23, já que a velocidade de vapor aumenta, aumentando também sua turbulência e sua capacidade de mistura com o líquido.

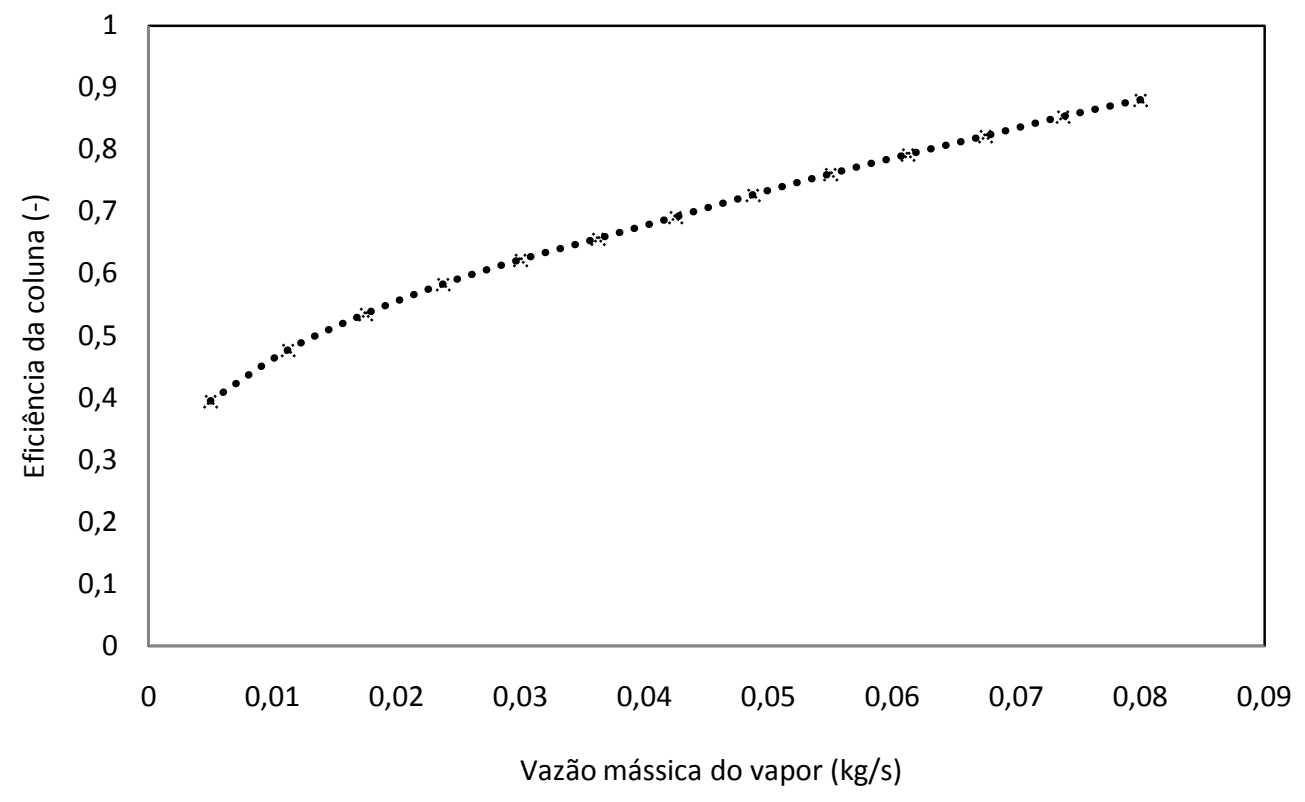

Figura 5.23 - Variação da eficiência da coluna com a vazão mássica do vapor.

Quando a vazão do líquido na coluna é maior, pode-se perceber que o diâmetro da coluna aumenta, como mostrado na Fig. 5.24. Isto se deve ao fato de que o parâmetro de fluxo aumenta e a velocidade de inundação diminui com o aumento da vazão do líquido, e para manter uma mesma vazão volumétrica do vapor, o diâmetro da coluna tem que aumentar.

Uma vez que a altura do vertedor é constante, a distância entre pratos depende somente da altura do líquido no downcomer, que está ligada a soma das quedas de pressão, a qual se mantém quase constante (Fig. 5.25). 


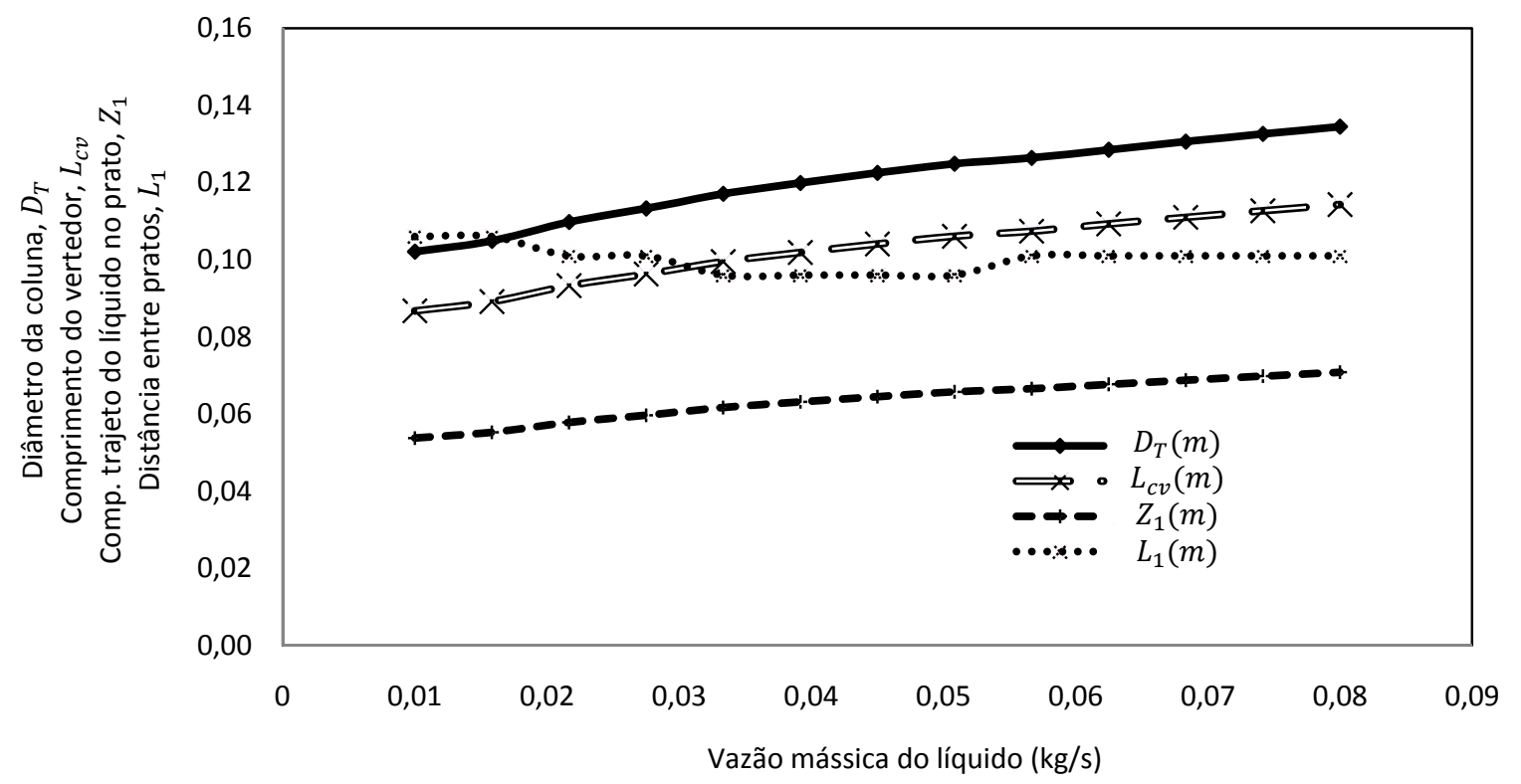

Figura 5.24 - Variação da geometria da coluna com a vazão mássica do líquido.

Já que a velocidade do vapor diminui, a queda de pressão do vapor ao passar pelo prato seco diminui também. A queda de pressão do líquido sob o downcomer aumenta por causa do aumento da vazão mássica do líquido, como pode ser visto na Fig. 5.25

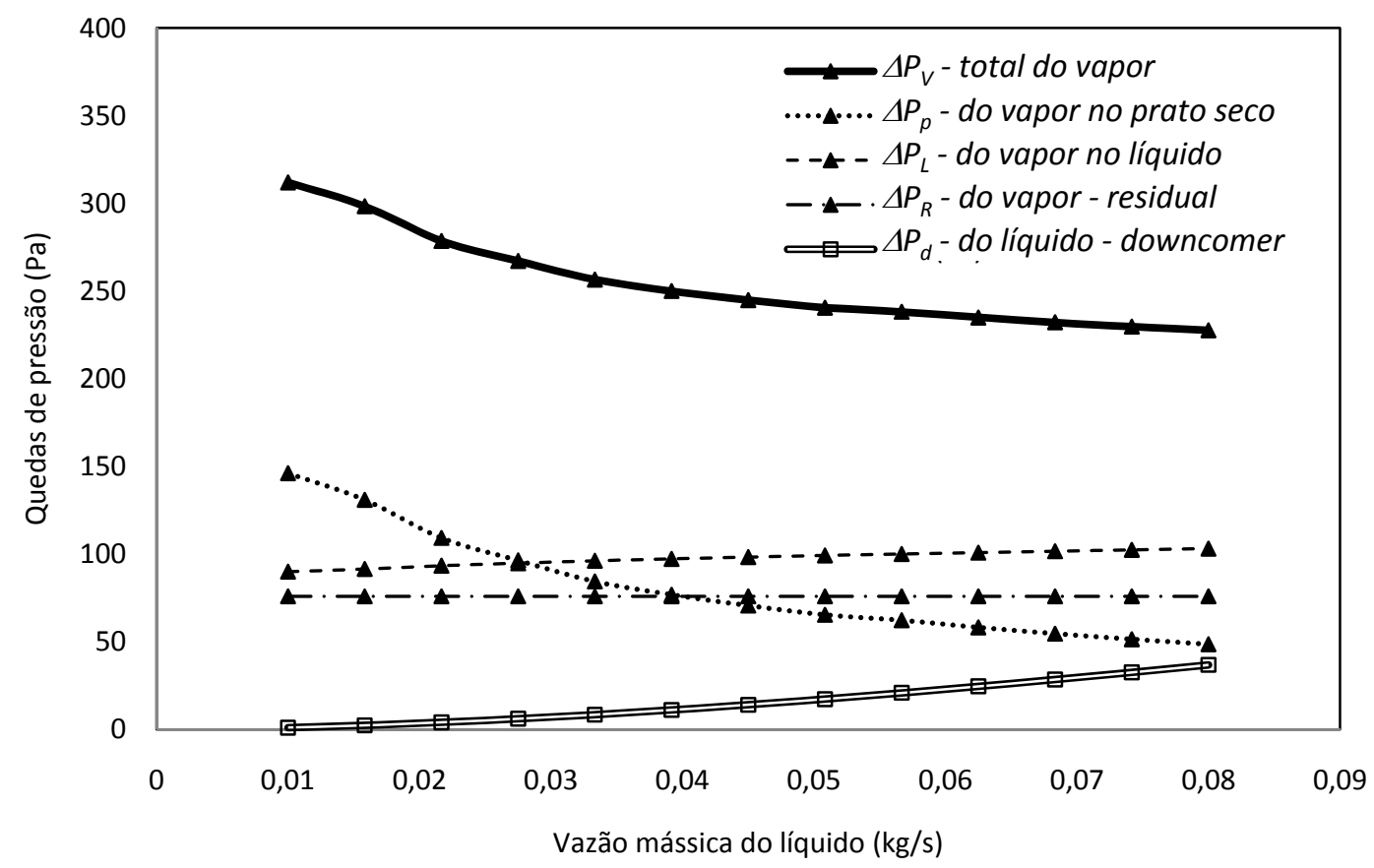

Figura 5.25 - Variação das quedas de pressão com a vazão mássica do líquido. 
A eficiência da coluna diminui com o aumento da vazão do líquido, como mostrada na Fig. 5.26, pois o tempo de residência do líquido no prato diminui.

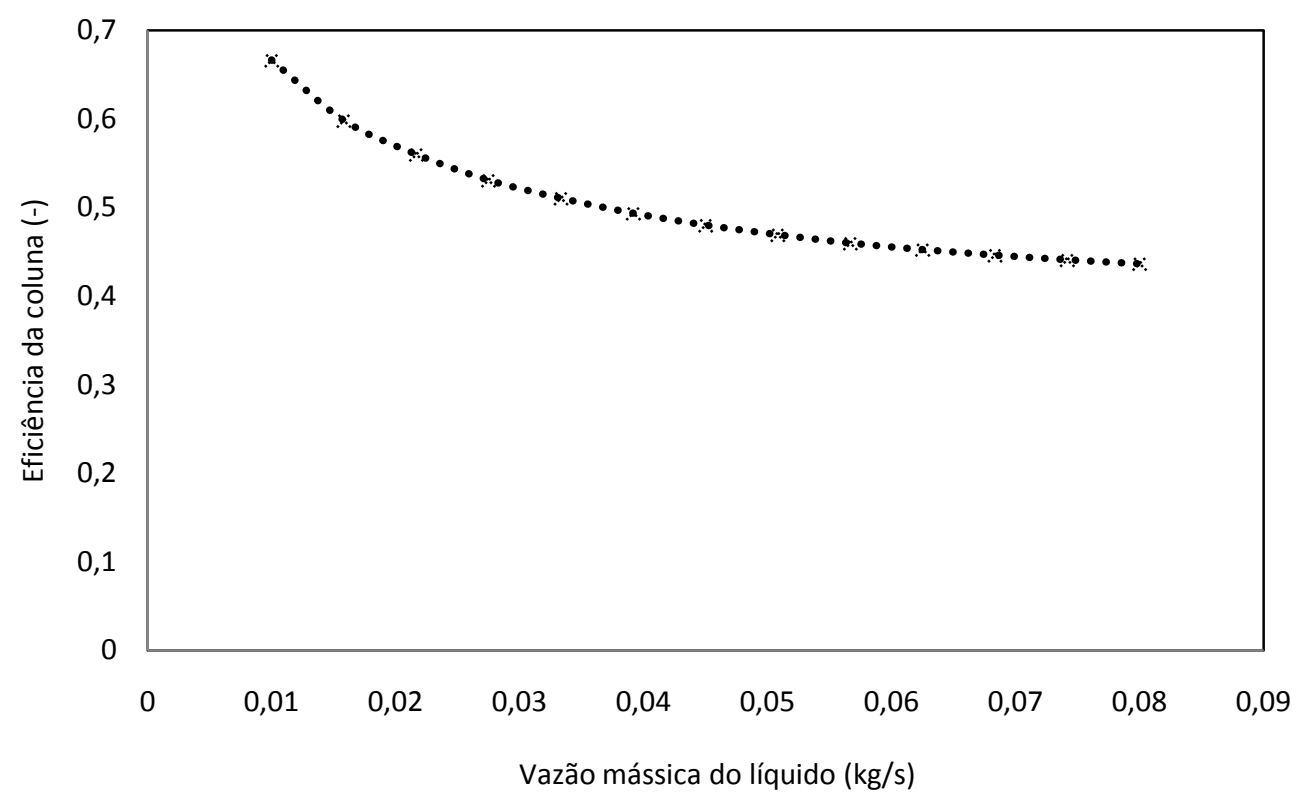

Figura 5.26 - Variação da eficiência da coluna com a vazão mássica do líquido. 


\section{CONCLUSÕES E SUGESTÕES DE FUTUROS TRABALHOS}

Neste trabalho, apresentou-se a análise de uma coluna de destilação de um ciclo de refrigeração por absorção de amônia/água de $5 T R$. As simulações feitas através dos modelos matemáticos foram implementadas no programa EES (Engineering Equation Solver). A análise dos resultados obtidos conduziu às seguintes conclusões relevantes:

O método de Ponchon-Savarit, usado para fazer os balanços de massa e de energia na coluna de destilação, resulta apropriado, pois fornece resultados precisos.

A partir da análise dos balanços de massa e de energia notou-se a importância da seção de esgotamento, já que fornece um aumento considerável na concentração vapor (51 \%). Já a seção de enriquecimento provê um aumento em concentração de vapor de 1,5\% e o retificador de 2,2 \%. Os dois últimos fazem um trabalho mais refinado no processo de purificação e não devem ser ignorados, uma vez que se o ciclo de refrigeração trabalhasse com uma concentração de vapor igual à concentração da saída da seção de esgotamento $(0,9549)$ ou a da saída da seção de enriquecimento $(0,9780)$ ele entraria em colapso por causa do acúmulo da água no evaporador.

O fator de refluxo é um parâmetro importante no projeto da coluna de destilação, porque o número de pratos na coluna e os fluxos de calor envolvidos no gerador e no retificador estão sensivelmente ligados a ele, muito mais para valores perto de 1. Para o caso de refluxo mínimo (fator de refluxo igual a 1) o número de pratos necessários atinge o valor máximo de 8 , mas o fluxo de calor necessário fornecido ao gerador atinge o valor mínimo $(27,22 \mathrm{~kW})$. Já para valores do fator de refluxo superiores a 1,9 o número de pratos chega a 2 , no entanto, o fluxo de calor necessário de se fornecer ao gerador chega a 29,6 kW. Isto leva a decisões econômicas de: maiores custos iniciais na construção da coluna de destilação $\left(f_{R} \sim 1\right)$ ou maiores custos no funcionamento do ciclo, se por exemplo, o fluxo de calor fornecido ao gerador for por queima de $G N$.

O diâmetro da coluna se mostra sensível ao aumento da vazão do vapor. Ou seja, para um aumento do dobro da vazão de vapor o diâmetro da coluna aumenta 
em 26 \%. Já para um aumento da vazão do líquido do dobro o diâmetro aumenta em 12 \%. Para diâmetros de furo maiores que $4 \mathrm{~mm}$, a geometria da coluna se mostra insensível, inclusive para a queda de pressão.

Quando se fez o modelo matemático para o cálculo da geometria do prato e da coluna, a condição de que a altura do líquido no downcomer teria que ser no máximo a metade da distância entre os pratos (já que se fosse maior acarretaria problemas de arraste excessivo) fez descobrir que, a altura do vertedor influía muito na distância entre pratos. A altura da coluna depende diretamente da distância entre pratos, resultando esta ser uma medida de compactibilidade da coluna. Como analisado, a altura do vertedor influi diretamente no diâmetro da coluna, comprimento de corda do vertedor, eficiência da coluna, entre outros; a coluna resulta mais compacta para valores de altura do vertedor entre $4 \mathrm{~mm}$ e $8 \mathrm{~mm}$, embora seja recomendável usar alturas maiores que $8 \mathrm{~mm}$ por serem valores mais confiáveis.

O programa de simulação desenvolvido no EES tem as seguintes limitações:

- Pratos perfurados com vertedor segmentado.

- Arranjo dos furos em triangulo equilátero.

- Distância entre furos de 2,5 até 5 vezes o diâmetro do furo (recomendado de 2,5 até 4 vezes o diâmetro do furo).

- $e / d_{0}$ de 0,2 até 2,0 (recomendado de 0,4 até 0,7).

- O coeficiente de inundação corresponde à correlação de Treybal.

São apresentadas as seguintes sugestões para trabalhos futuros:

- Fazer simulações com outros tipos de vertedores, por exemplo, os de tipo circular e posteriormente compará-los com os de recheio.

- Integração da modelagem da coluna de destilação ao ciclo de refrigeração por absorção.

- Montagem experimental de uma coluna de destilação de pratos perfurados.

- Estudo do balanço térmico ao redor do gerador envolvendo energia solar, rejeito de produtos de combustão de biomassa e bicombustível. 


\section{REFERÊNCIAS}

Ahachad, M.; Charia, M. e Bernatchou, A. Study of an improved $\mathrm{NH}_{3}-\mathrm{H}_{2} \mathrm{O}$ solar absorption refrigerating machine in Rabat (Morocco). Sol. Energy Mater. Sol. Cells, v. 28, n. 1, p. 71-79, 1992.

Almeida, G. S. Metodologia para Avaliação Econômica de Unidades Resfriadoras de Líquidos por Ciclos de Compressão e Absorção. Mestrado, Universidade de Brasilia, Brasilia, 2006.

Anand, G. e Erickson, D. C. Compact Sieve-Tray Distillation Column for Ammonia-Water Absorption Heat Pump: Part I-Design Methodology. ASHRAE Trans., v. 105, n. 1, 1999.

Bardelin, C. Os Efeitos do Racionamento de Energia Elétrica ocorrido em 2001 e 2002 com ênfase no Consumo de Energia Elétrica. Mestrado, Universidade de São Paulo, Brasil, 2004.

Bennett, C. O. e Myers, J. E. Fenômenos de Transporte, quantidade de movimento, calor e massa. São Paulo, McGraw-Hill, 1978, 812p.

Bogart, M. J. P. Pitfalls in ammonia absorption refrigeration. Int. J. Refrig., v. 5, n. 4, 1982.

Caldas, J. N.; Lacerda A. I.; Veloso E. e Paschoal, L. C. M. Internos de Torres: Pratos e Recheios, $2^{\text {da }}$ ed., Ed. Interciência Ltda., Rio de Janeiro, 2007, 510p.

Calm, J. The next generation of refrigerants - Historical review, Considerations, and Outlook. Int. J. Refrig., v. 31, n. 7, p. 1123-1133, 2008.

Cheung, K.; Hwang, Y.; Judge, J. F.; Kolos, K.; Singh, A. e Radermacher, R. Performance assessment of multistage absorption cycles. Int. J. Refrig., v. 19, n. 7, p. 473-481, 1996.

Devault, R. C. e Marsala, J. Ammonia-water triple-effect absorption cycle. ASHRAE Trans, v. 96, n. 1, p. 676-682, 1990.

Einstein, A. e Szilard, L. Refrigeration. US PI 1781541, 11 Nov. 1930.

Electrolux. Revolucionary Products. Disponível em:<http://electrolux.com/revolutio nary_products.aspx>. Acesso em: 07 Mai. 2009.

Empresa de Pesquisa Energética. Balanço Energético Nacional, 2008, Disponível em: < https://www.ben.epe.gov.br>. Acesso em: 05 Fev. 2009.

Energy Information Administration. International Energy Outlook, 2008. 2008. Disponível em: <http://www.eia.doe.gov/oiaf/ieo/index.html>. Acesso em: 20 Jan. 2009.

Fair, J. R. How to Predict Sieve Tray Entrainment and Flooding. Petro/Chem Engineer. 1961. 
Felamingo, J. C. Produzindo frio através de calor de compressão e de gases de descarga de caldeira. Tecnologia em Metalurgia e Materiais, São Paulo, v.3, n.4, p. 36-39, 2007.

Fernández-Seara, J. e Sieres, J. Ammonia-water absorption refrigeration systems with flooded evaporators. Appl. Therm. Eng., v. 26, n. 17-18, p. 22362246, 2006a.

Fernández-Seara, J. e Sieres, J. The importance of the ammonia purification process in ammonia-water absorption systems. Energ. Convers. Manage., v. 47, n. $13-14$, p. $1975-1987,2006 b$.

Fernández-Seara, J.; Sieres, J. e Vázquez, M. Simultaneous Heat and Mass Transfer of a Packed Distillation Column for Ammonia-Water Absorption Refrigeration Systems. Int. J. Therm. Sci., v. 41, n. 10, p. 927-935, 2002.

Fernández-Seara, J.; Vales, A. e Vázquez, M. Heat recovery System to Power an Onboard $\mathrm{NH}_{3}-\mathrm{H}_{2} \mathrm{O}$ Absorption Refrigeration Plant in Trawler Chiller Fishing Vessels, Appl. Therm. Eng., v. 18, n. 12, p. 1189-1205, 1998.

Foley, G.; DeVault, R. e Sweetser, R. The Future of Absorption Technology in America. Advanced Building Systems-2000 Conference, 16 de Jun. 2000.

Foust, A. S.; Wenzel, L. A.; Clump, C. W.; Maus, L. e Andersen, L. B. Princípios das Operações Unitárias, Ed. Guanabara Dois S.A., Rio de Janeiro-RJ, 1982, 670p.

Herold, K. E.; Radermacher, R. e Klein, S. A. Absorption Chillers and Heat Pumps. New York, CRC Press, 1996, 329p.

Kister, H. Z. Distillation Design, McGraw-Hill, USA. 1992.

Kuehn, T. H.; Ramsey, J. W. e Threlkeld, J. L. Thermal Environmental Engineering, $3^{\text {rd }}$ ed. Prentice-Hall Upper Saddle River, New Jersey, EUA, 1998, 740 .

Liao, X. e Radermacher, R. Absorption chiller crystallization control strategies for integrated cooling heating and power systems. Int. J. Refrig., v. 30, n. 5, p. 904-911, 2007.

Locket, M. J. Distillation Tray Fundamentals, Cambridge University. UK, 1986.

Marques, A. S.; Santos, C. A. C.; Santos, C. M.; Torres, E. A. e Luciano, W. Análise Termoeconômica de um sistema de refrigeração automotivo por absorção. ENCIT 2006, Curitiba, Brasil, 2006.

Mejbri, Kh.; Ezzine, N. B.; Guizani, Y. e Bellagi, A. Discussion of the Feasibility of the Einstein Refrigeration Cycle. Int. J. Refrig., v. 29, n. 1, p. 60-70, 2006.

Mendes, G. A. Estudo de Sistemas de Refinação de Vapor numa Máquina de Absorção de Pequena Potência Alimentada por Energia Solar. Mestrado, Universidade Técnica de Lisboa, Lisboa, Portugal, 2008.

Nielsen, O. J.; Javadi, M. S.; Andersen, M. P. S.; Hurley, M. D.; Wallington, T. J. e Singh, R. Atmospheric chemistry of $\mathrm{CF}_{3} \mathrm{CF}=\mathrm{CH}_{2}$ : Kinetics and mechanisms of 
gas-phase reactions with $\mathrm{Cl}$ atoms, $\mathrm{OH}$ radicals, and $\mathrm{O}_{3}$. Chem. Phys. Lett., $\mathrm{v}$. 439, n. 1-3, p. 18-22, 2007.

Ortigosa, A. S. P. Modelagem, Simulação e Otimização de um Ciclo Comercial de Produção de Água Gelada por Absorção de Amônia. Trabalho de Formatura, Universidade de São Paulo, São Paulo, Brasil, 2007.

Ortigosa, A. S. P.; Preter, F. C.; Labozetto, R. L.; Zavaleta-Aguilar, E. W. e SimõesMoreira, J. R. Modeling, and Simulation of a Commercial Ammonia - Water Absorption Refrigeration Cycle for Production of Chilled Water. ENCIT-2008, Belo Horizonte-M.G., 8p. 2008.

Perry, R. H. e Green, D. H. Perry's Chemical Engineers' Handbook. $7^{\mathrm{a}}$ Ed. USA, McGraw-Hill, 1997, p 14-1 a 14-98.

Platen, B. C. e Munters, C. G. Refrigeration, US PI 1609334, 7 Dez. 1926.

Robur. Installation, use and Maintenance Manual: GA Line ACF 60-00 Model. Disponível em <www.robur.com>. Acesso em: 27 Maio 2009.

Santos, C. M. S.; Torres, E. A. e Santos, C. A. C. Estudo exergo-econômico de uma planta de cogeração com motor a gás natural e sistema de refrigeração por absorção água amônia. CONEM 2008, Salvador, Brasil, 2008.

Sieres, J e Fernández-Seara, J. Experimental investigation of mass transfer performance with some random packings for ammonia rectification in ammonia-water absorption refrigeration systems. Int. J. Therm. Sci., v. 46, n. 7, p. 699-706, 2007.

Sieres, J.; Fernández-Seara, J. e Uhía, F. Experimental analysis of ammoniawater rectification in absorption systems with the $10 \mathrm{~mm}$ metal Pall ring packing. Int. J. Refrig., v. 31, n. 2, p. 270-278, 2008.

Experimental characterization of the rectification process in ammoniawater absorption systems with a large-specific area corrugated sheet structured packing. Int. J. Refrig., v. 32, n. 6, p. 1230-1240, 2009.

Srikhirin,P. e Aphornratana, S. Investigation of a diffusion absorption refrigerator. Appl. Therm. Sci., v. 22, n. 11, p. 1181-1193, 2002.

Srikhirin P.; Aphornratana, S. e Chungpaibulpatana, S. A review of Absorption Refrigeration Technologies. Renew. Sust. Energ. Rev., v. 5, n 4, p. 343-372, 2001.

Stephan K. History of absorption heat pumps and working pair developments in Europe. Int. J. Refrig., v. 6, n. 3, p. 160-166, 1983.

Treybal, R. E. Mass-Transfer Operations, $3^{\text {rd }}$ ed., Singapore, McGraw-Hill Book Company, 1981, 784p.

Tuma. Dimensions BCT16. Disponível em <www.empresastuma.com.br>. Acesso em: 26 Abr. 2009.

United Nations Population Division. The World at six Billion, 1999. Disponível em: <http://www.un.org>. Acesso em: 02 Fev. 2009. 
. World Population Prospects, The 2008 Revision. Disponível em: <http://www.un.org>. Acesso em: 23 Fev. 2010.

Wang, S. Handbook of Air Conditioning and Refrigeration. $2^{\text {nd }}$ ed. New York, McGraw-Hill, 2001, p 9.1-9.16.

1994 ASHRAE Handbook: Refrigeration: Systems and Applications, Atlanta, 1994. 
APÊNDICE A - ROTINA DO PROGRAMA DE SIMULAÇÃO

REALIZADO NO EES 
Rotina para balanço de massa e de energia segundo Ponchon-Savarit

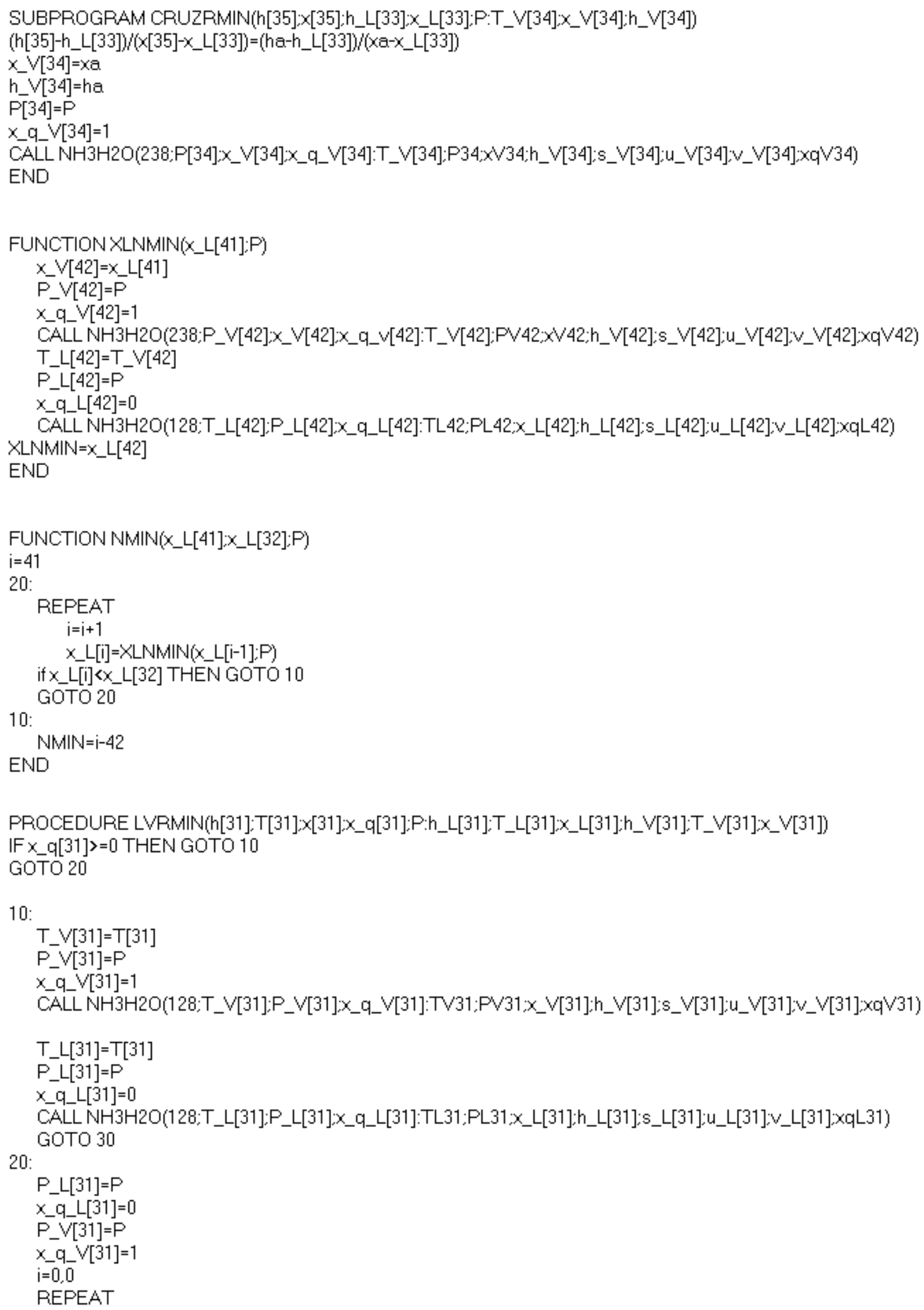




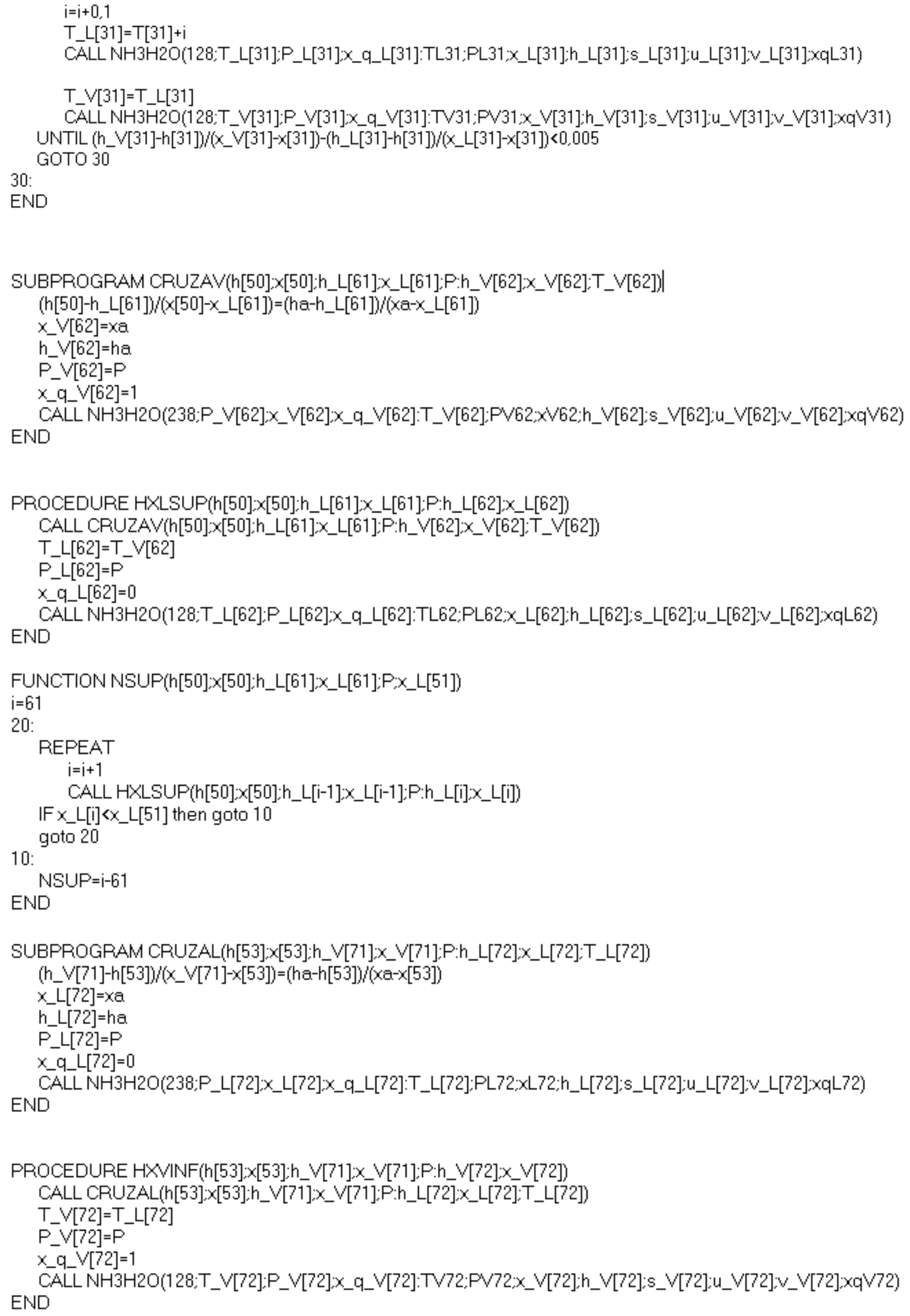




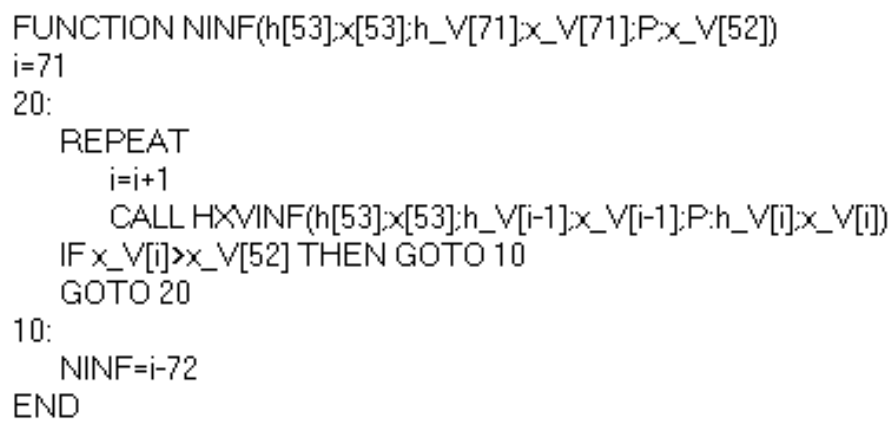

"Calcula as propriedades termodinámicas da solução de alimentação"

$P[31]=P$

CALL NH3H2O(123:T[31]:P[31]:x[31]:T31:P31:X31:h[31]:s[31]:u[31]:v[31]:X_q[31])

"Calcula as propriedades termodinámicas da solução fraca"

$P \_L[32]=P$

CALL NH3H2O(238:P_L[32]:X_L[32]:X_q_L[32]:T_L[32]:PL32:XL32:h_L[32]:s_L[32]:U_L[32]:V_L[32]:XqL32)

"Calcula as propriedades termodinámicas do vapor destilado"

$P \_$[33] $=P$

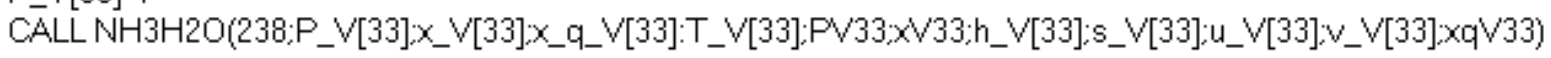

"Calcula as vazões mássicas da solução de alimentação e da solução fraca"

$m[31]=m_{-} L[32]+m_{-} V[33]$

$m[31]^{*} \times[31]=m_{-} L[32]^{*} \times\left[L[32]+m_{-} V[33]^{*} \times V_{-} V[33]\right.$

"Calcula a razão de refluxo mínimo"

call LVRMINN(h[31]:T[31]:X[31]:X_q[31]:P:h_L[31]:T_L[31]:X_L[31]:h_V[31]:T_V[31]:X_V[31])

$\left(h[35]-h_{-} L[31]\right) /\left(x[35]-x \_L[31]\right)=\left(h_{-} V[31]-h_{-} L[31]\right) /\left(x \_V[31]-x \_L[31]\right)$

$x[35]=x_{-} V[33]$

$\mathrm{P}[35]=\mathrm{P}$

CALL NH3H2O(234:P[35]:x[35]:h[35]:T[35]:P35; 35:h35;s[35]:u[35]:v[35]:q[35])

T_L[33]=T_V[33]

$P_{-} L[33]=P$

$x_{-}$Q_L $[33]=0$ 
CALL NH3H2O(128:T_L[33]:P_L[33]:X_q_L[33]:TL33:PL33:x_L[33]:h_L[33]:s_L[33]:U_L[33]:V_L[33]:XqL33)

CALL CRUZRMIIN(h[35]:x[35]:h_L[33]:X_L[33]:P:T_V[34]:X_V[34]:h_V[34])

$\operatorname{Rmin}=\left(h[35]-h_{2} V[34]\right) /\left(h_{-} V[34]-h_{-} L[33]\right)$

"Calcula o número de pratos mínimo"

$x_{-} L[41]=x_{-} L[33]$

$N \min =N M \mid N\left(x_{-} L[41] \times x_{-} L[32]: P\right)$

"Calcula o calor do Gerador, do Retificador e a Linha Principal de Operação"

$R=f \_R^{*}$ Rmin

$R=\left(h[50]-h \_V[54]\right) /\left(h \_V[54]-h \_L[33]\right)$

$\left(h[50]-h_{-} L[33]\right) /\left(\times[50]-x_{-} L[33]\right)=\left(h b-h \_L[33]\right) /\left(x b-x \_L[33]\right)$

$x[50]=x_{-} V[33]$

$x_{-} \vee[54]=x b$

$h_{-} V[54]=h b$

$P_{-} \vee[54]=P$

$x_{-} q_{-} \vee[54]=1$

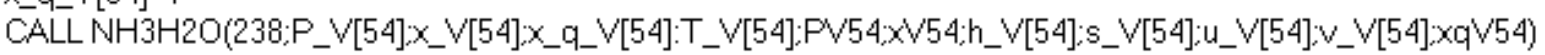

$\mathrm{P}[50]=\mathrm{P}$

CALL NH3H2O(234:P[50]:x[50]:h[50]:T[50]:P50:x50:h50:s[50]:u[50]:v[50]:q[50])

$m[31]^{* h}[31]=m_{-} V[33]^{*} h[50]+m_{-} L[32]^{*} h[53]$

$P[53]=P$

$\times[53]=\times[L[32]$

CALL NH3H2O(234;P[53]:x[53]:h[53]:T[53]:P53:×53:h53:s[53];u[53]:v[53]:q[53])

$h[50]=h \_V[33]+Q \_R / m_{-} V[33]$

$h[53]=h \_L[32]-Q \_G / m \_L[32]$

$\mathrm{COP}=\mathrm{Q}_{-} \mathrm{E} / \mathrm{Q} \mathrm{G}_{\mathrm{G}}$

"calcula a interseção da linha principal com a linha de saturação líquida"

$(h[50]-h[53]) /(\times[50]-\times[53])=(h c-h[53]) /(\times c-x[53])$

$\times \_L[51]=\times C$

$h_{-} L[51]=h c$

$P_{-} L[51]=P$

$X_{-}$_L $L[51]=0$

CALL NH3H2O(238:P_L[51]:X_L[51]:x_q_L[51]:T_L[51]:PL51:xL51:h_L[51]:s_L[51]:u_L[51]:v_L[51]:xqL51)

"calcula a interseção da linha principal com a linha de saturação de vapor"

$(h[50]-h[53]) /(\times[50]-\times[53])=(h d-h[53]) /(x d-x[53])$

$x-V[52]=x d$

h_V $\vee 52]=h d$

$P_{-} V[52]=P$

$\times$ _q_V[52] 1

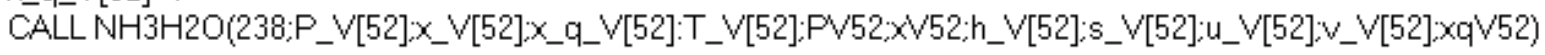

"calcula o número de pratos de enriquecimento"

h_L[61] $=h_{-} L[33]$

$x_{-} L[61]=x_{-} L[33]$

NSUP=NSUP(h[50]:x[50]:h_L[61]:X_L[61]:PX_L[51])

Nenr=NSUP-1 


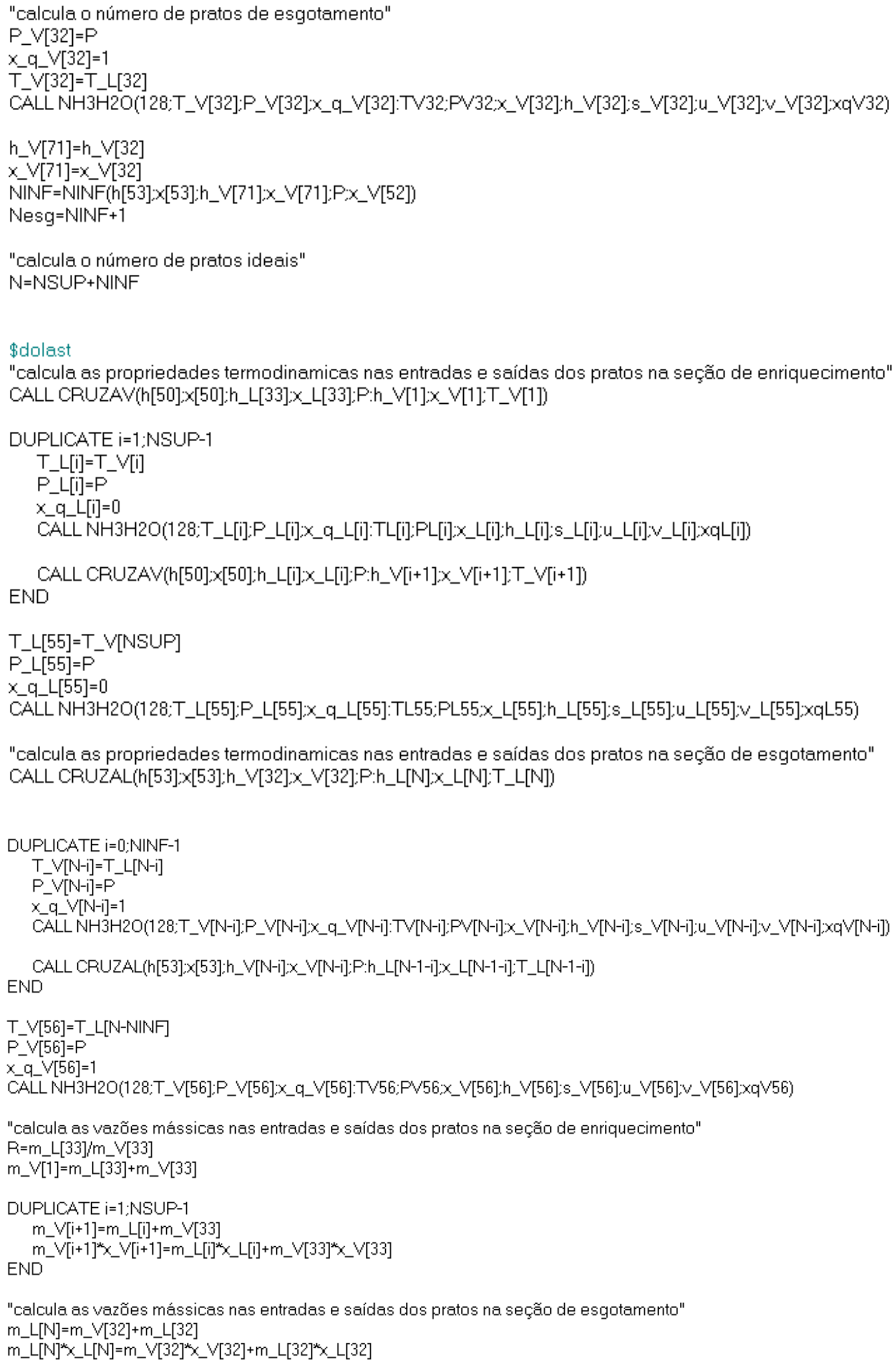




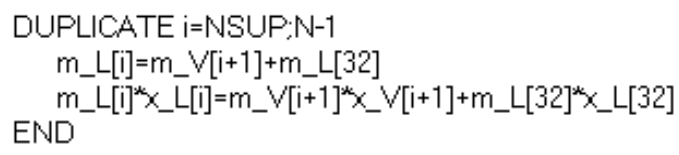

\$enddolast

\section{Rotina para a geometria e eficiência da coluna}

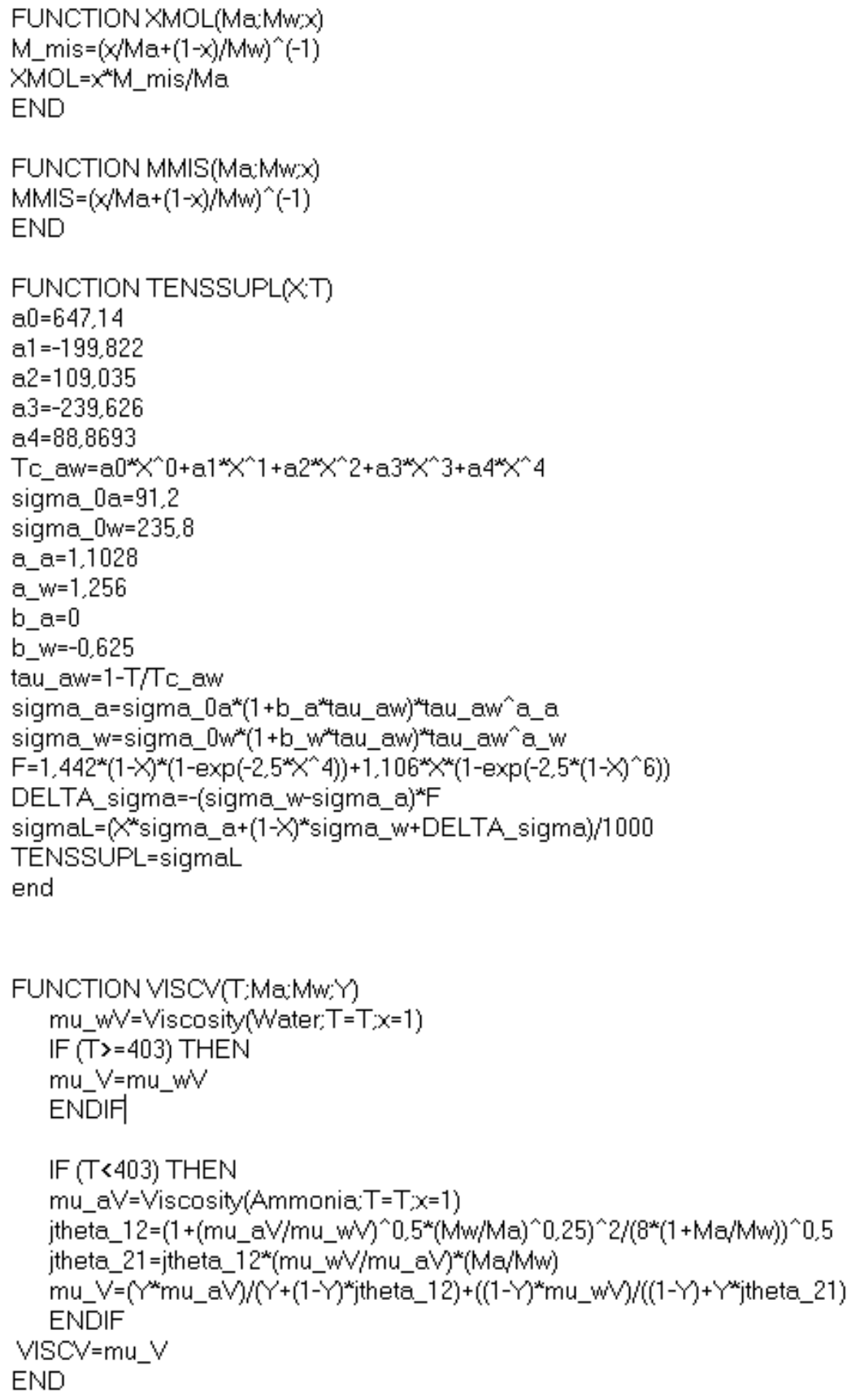




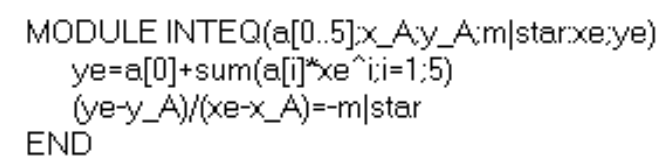

"cálculo de convergencia, para as principais geometrias na Coluna de Destilação"

PROCEDURE DESPTRAYYT_L:PX_L:T_V.X_V:Ma:Mw:d_0:m_L:m_V:f_vel;F_v:L_v:g:Atraysup;epsilon;e:

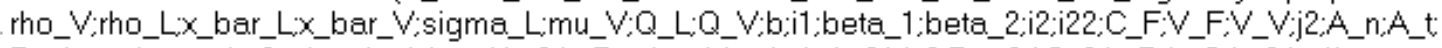
D_tL_cviL_cve:L_0v,A_x:A_d:A_ad:h_2:h_R:z;A_a:V_ah_L:A_0:V_0;Re_0t:C_0:h_D;h_G:h_3:L_1)

ts $=0,001$

10:

$\mathrm{ts}=\mathrm{ts}+0,005$

CALL VARDTH(ts:T_L:P:x_L:T_Vx_V:Ma:Mw:d_0:m_L:m_V;f_vel;F_v:0:0:L_v:g:Atraysup;epsilon;e:rho_V:

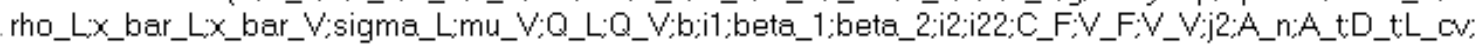

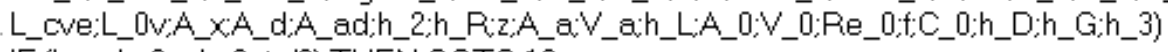

IF $\left(L_{-} v+L_{-} 0 v+h_{-} 3>\right.$ ts/2) THEN GOTO 10

$L \_1=t s$

END

SUBPROGRAM VARDTH(ts:T_L:P:_L:T_Vx_V:Ma:Mw;d_0:m_L:m_V;fvel:F_v:R1:R2:L_vig:Atraysup:

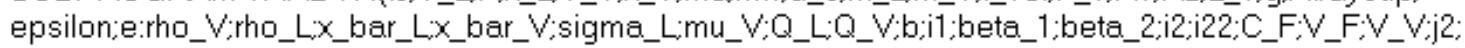

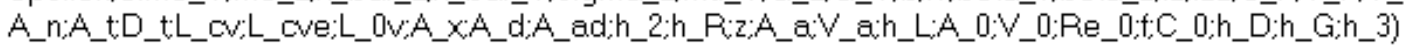

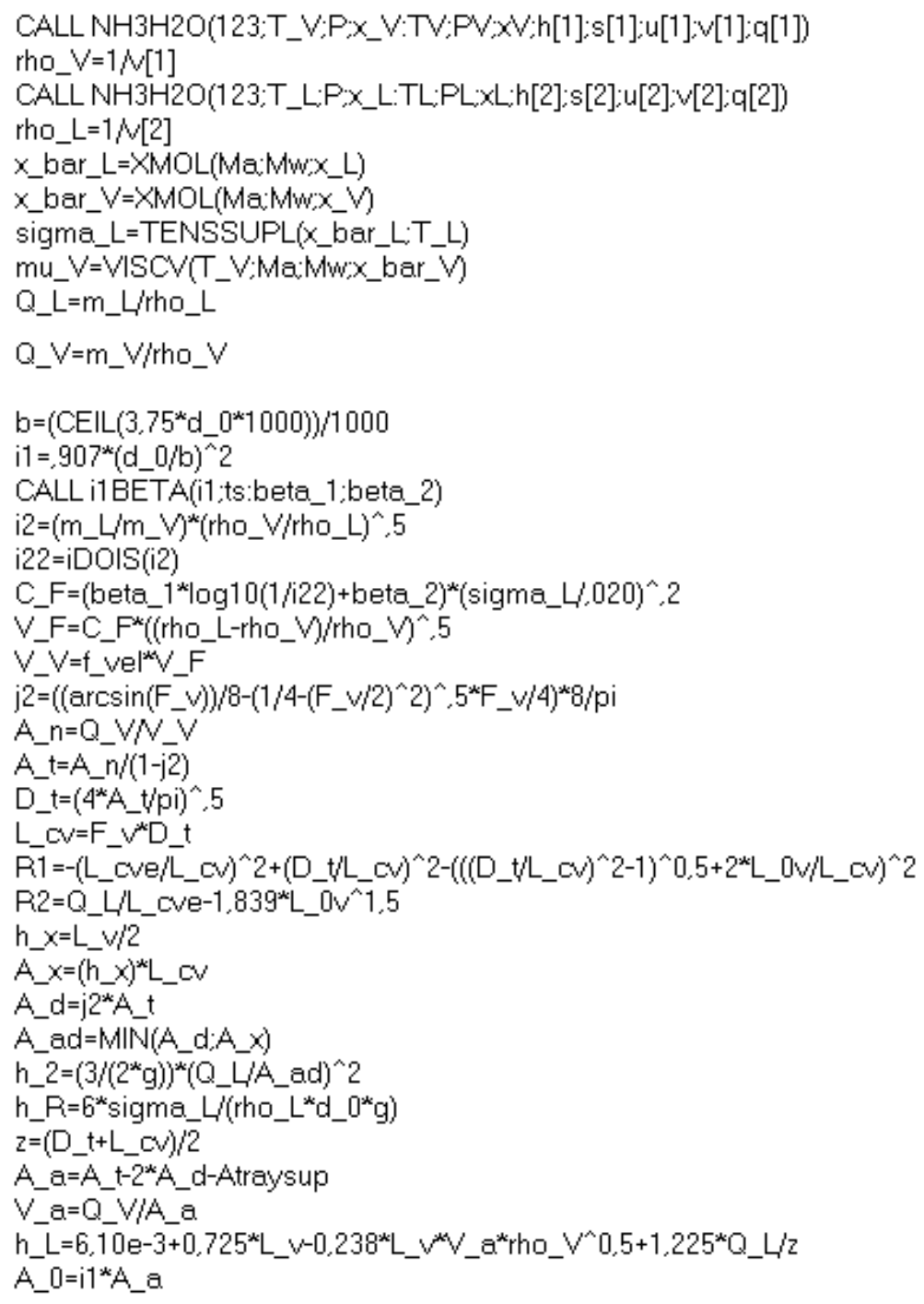


$V_{-} 0=Q_{-} V_{/ A}{ }_{-} 0$

$\mathrm{Re} \bar{e}_{-} 0=\mathrm{d}_{-} 0^{\mathrm{N}} \overline{\mathrm{V}} \mathrm{O}^{*} \mathrm{rho} \mathrm{V} / \mathrm{mu} \mathrm{V}$

$\mathrm{f}=$ (MoodyChart(Re_0;epsilon) $) / 4$

C_ $0=1,09^{*}\left(d_{-} 0 / e\right)^{\wedge} 0,25$

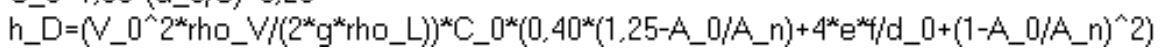

h_G $=h \_D+h \_L+h \_R$

END

h_3 $=h \_2+h \_G$

CALL DESPTRAY(T_L:PX_L:T_Vx_V:Ma:Mw;d_0:m_L:m_V;f_vel:F_V:L_v:g;Atraysup;epsilon;e:rho_V: rho_Lx_bar_L;x_bar_V;sigma_L:mu_V:Q_L:Q_V; b;i:beta_1:beta_2;i2;i22;C_F:V_F:V_V:j2:A_n;A_t:D_tL_CV,

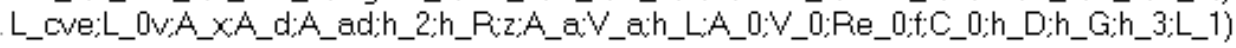

"PROGRAMA PRINCIPAL"

"

"DADOS DE ENTRADA"

$m_{-} \vee=0,0126$

$m_{-} L=0,04$

$x_{-} \vee=0,6306$

$x_{-} L=0,3025$

$T_{-} \cdot V=160,25+273,15$

T_L $=122,75+273,15$

$P=15,56$

"kg/s" "VAZÃOMÁSSICA DO VAPOR"

"kg/s" "VAZÃOMÁSSICADO LÍQUIDO"

"-" "FRACZ̃OMÁSSICA DO VAPOR"

"-" "FRAÇO MÁSSICA DO LIOUUIDO"

" $\mathrm{C} "$ "TEMPERATURA DO VAPOR"

" "C" "TEMPERATURA DO LÍQUIDO"

"bar" "PRESSÃO DO SISTEMA-PARAA CURVA DE EQUILIBRIO"

F_i $=0,80$

"-" "FATORDE INUNDACÃO"

$\mathrm{F} \cdot \mathrm{V}=.85$

d_ $0=3 / 1000$

"-" "FATORDE ESPUMA"

$M a=17$

"-"

"FATOR VERTEDOR-DIAMMETRO DA COLUNA"

"m" "DIAMETRO DO FURO"

$M w=18$

"kg/kmol" "MASSA MOLAR DAAMÔNIA"

$\mathrm{g}=9.81$

$\mathrm{e}=2 / 1000$

$L_{-} V=0,01$

"kg/kmol" "MASSA MOLAR DAÁGUA"

epsilon=0

"m/s^2"

"m"

"ACELERACÃO DA GRAVIDADE"

"m" "ALTURADO VERTEDOR"

"-" "RUGOSIDADE RELATIVA"

$\mathrm{Ni}=4$

"-" "NÚMERO DE PRATOS IDEAIS"

f_vel=F_i*F_e

Atraysup $=0$

i3 $=$ Q_L LL_CV

"calcula as quedas de pressão do vapor"

DELTA_P_V=rho_L*'g*h_G

DELTA_P_p=rho_L* $g^{*} h \_D$

DELTA_P_L=rho_L* $\mathrm{g}^{*} h \_L$

DELTA_P_R $=$ rho_L* $g^{*} h \_R$

"calcula a queda de pressão do líquido"

DELTA_P_e=rho_L*'g*h_2

"calcula o número de furos"

Nfur=A_0/(3,1416 $\left.6^{*} d \_0^{\wedge} 2 / 4\right)$

"calcula a relação geometrica do prato j1"

$\mathrm{j} 1=\left(5^{\wedge} 2-\left(F_{-} \vee / 2\right)^{\wedge} 2\right)^{\wedge}, 5$

"calcula a distancia percorrida do líuido no prato"

$Z 1=2^{*} i 1^{*} D_{-}{ }^{\dagger}$ 
"calcula a velocidade de gotejamento pelo furo"

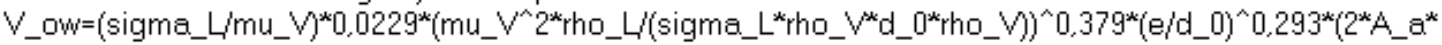

d_ $\left.0 /\left(3^{\wedge}(1 / 3)^{\wedge} b^{\wedge} 3\right)\right)^{\wedge}\left(2,8 /\left(\left(21 / d_{-} 0\right)^{\wedge} 0.724\right)\right)$

"calcula o número de Schmidt do vapor"

Sc_V=SCHMIDTV(T_V:P:Ma:Mw,rho_V:mu_V)

"calcula a difusividade de amônia na solução líquida"

mu_L=VISCL(T_L_x_bar_L)

D_L=DIFL(Mw; $\bar{T}_{-}$L; $\left.; \overline{m u}_{\mathbf{L}} \mathrm{L}\right)$

"calcula o número de unidades de transferência da fase vapor"

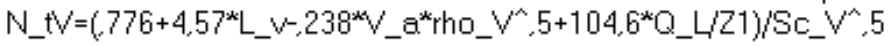

"calcula o tempo de residência do líquido no prato"

theta_L=h_L* $z^{*} Z 1 / Q_{-} L$

"calcula o número de unidades de transferência da fase líquida"

N_tL $=40000^{*} D_{-} L^{\wedge}, 5^{*}\left(213^{\star} V_{-} a^{*} \text { rho_ } V^{\wedge}, 5+15\right)^{*}$ theta_L

"calcula a difisuvidade turbilhonar"

D_E $=\left(3,93 e-3+, 0171^{\star} V_{-} a+3,67^{*} \mathrm{Q} \_L / 21+, 18^{*} L_{-} V\right)^{\wedge} 2$

"calcula a massa molar da fase vapor"

MM_V=MMIS(Ma:Mw×_V)

"calcula a massa molar da fase líquida"

MM_L=MMIS(Ma:Mwx_L)

"calcula a vazão molar da fase vapor"

m_bar_V=m_V/MM_V

"calcula a vazão molar da fase líquida"

m_bar_L=m_LlMM_L

"calcula a inclinação do das frações molares no seio do líquido até a curva de equilibrio"

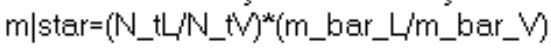

"calcula a inclinação da curva de equilibrio"

$N=21$

DUPLICATE $j=1,21$

$\times 0[j]=-0,05+0,05^{* j}$

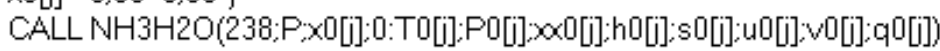

$T 1[i]=T 0[i]$

CALL NH3H2O(128:T1[i];:P:1:T11[i];:P2[]]:y1[i];h1[i];:1[]]:u1[i];:1[i];:1[])

$\left.M M \_L[]=(x 0[]] / M a+(1-x 0[i]) / M w\right) \wedge(-1)$

$M M_{-} V[i]=(y 1[i] / M a+(1-y 1[j]) / M W)^{\wedge}(-1)$

$x_{-}$bar_L[i] $=x 0[i]^{*} M M M_{-} L[] / M a$

end

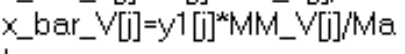

CALL curvefit1 d('poly5':x_bar_L[1..N]:x_bar_V[1..N]:a[0..5]:rms;bias;:R|2;a_err[0..5])

CALL INTEQ(a[0..5]:x_bar_LX_bar_V:m|star:x_bar_Lex_bar_Ve)

X_bar_LB=x_bar_L

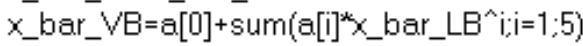

$\mathrm{m}=(\mathrm{x}$ bar_VB-x_bar_Ve $)(\overline{\text { x_bar_LB-x_bar_Le })}$ 


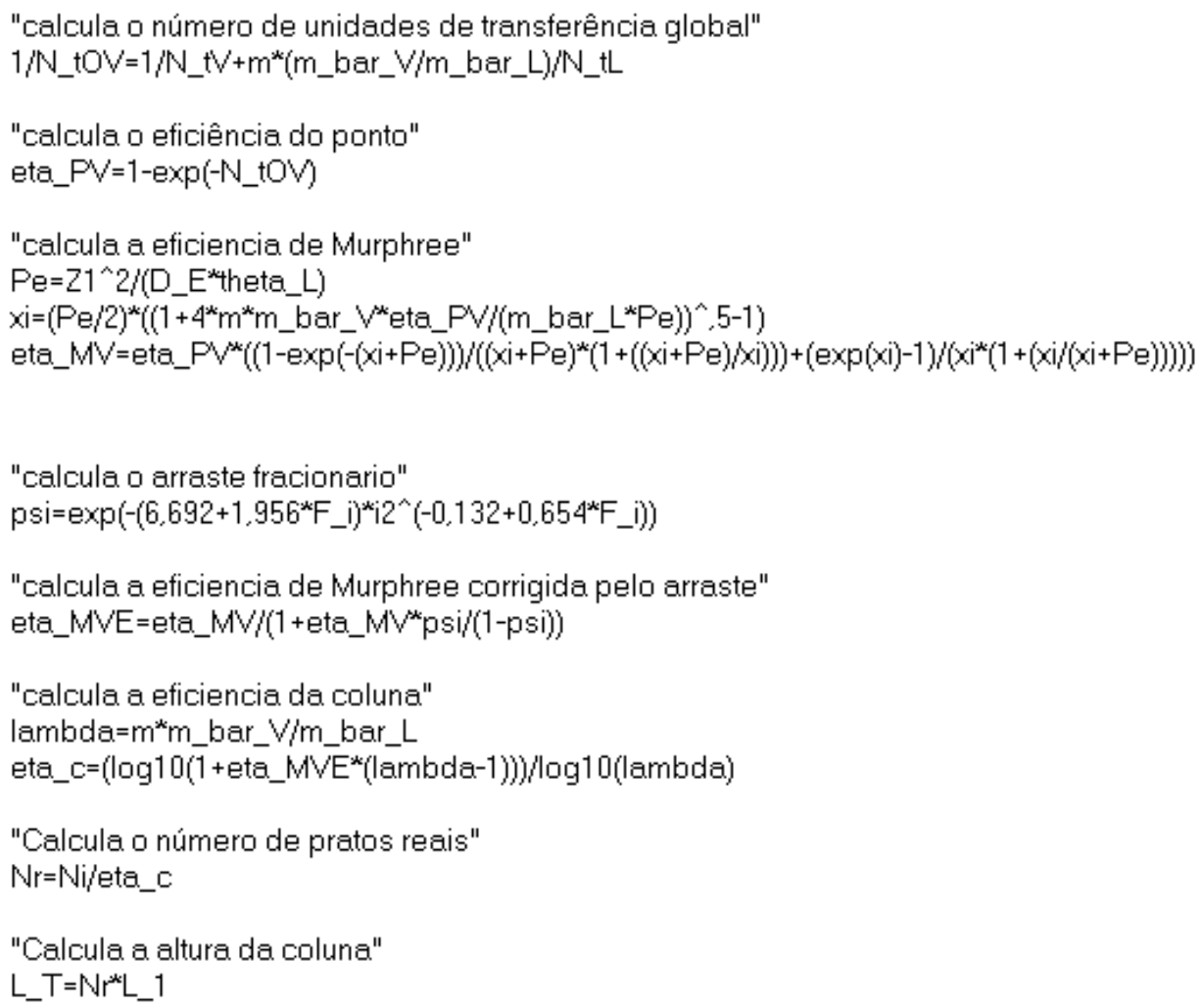

